Aus der Abteilung Nephrologie und Rheumatologie (Prof. Dr. med. G.A. Müller)

im Zentrum Innere Medizin

der Medizinischen Fakultät der Universität Göttingen

\title{
Bedeutung des löslichen CD14-Rezeptors in Plasma und Urin als immunologischer Parameter nach Nierentransplantation und sein Verhältnis zu den löslichen Rezeptoren IL2R, CD4 und CD8
}

\author{
INAUGURAL - DISSERTATION \\ zur Erlangung des Doktorgrades \\ der Medizinischen Fakultät \\ der Georg-August-Universität zu Göttingen
}

vorgelegt von

Oliver Müssig

aus

Celle

Göttingen 2010 
Dekan:

I. Berichterstatter: Prof. Dr. med. R. W. Grunewald

II. Berichterstatter/in: Prof. Dr. rer. nat. Walter

III. Berichterstatter/in: Prof. Dr. med. Dressel

Tag der mündlichen Prüfung: 24. Mai 2011 
Abkürzungsverzeichnis

$\begin{array}{ll}\text { 1. Einleitung } & 1\end{array}$

1.1 Aktueller Stand der Nierentransplantation in Deutschland $\quad 1$

1.2 Komplikationen nach Nierentransplantation: Die Transplantatdysfunktion 1

1.3 Immunologischer Mechanismus bei Transplantatabstoßung 4

1.3.1 Immunologische Zellen und Rezeptoren bei Abstoßungsreaktion 4

1.3.1.1 T-Lymphozyten (T-Zellen), lösliche Zellrezeptoren CD4 und CD8

1.3.1.2 B-Lymphozyten (B-Zellen) $\quad 8$

1.3.1.3 Monozyten/Makrophagen $\quad 8$

1.3.1.4 Membranständiger CD14 (mCD14) 9

1.3.1.5 Löslicher Zellrezeptor CD14 (sCD14) 10

1.3.1.6 Löslicher Zellrezeptor IL2R (sIL2R) 12

1.3.2 Immunantwort bei Transplantatabstoßung 15

$\begin{array}{lll}1.4 & \text { Nierenfunktion } & 18\end{array}$

$\begin{array}{llr}\text { 1.4.1 Glomeruläre Teilfunktion } & 18\end{array}$

$\begin{array}{lll}\text { 1.4.2 Tubuläre Teilfunktion } & 18\end{array}$

1.5 Medikamentöse Therapie 20

1.5.1 Wirkmechanismus der Immunsuppressiva 20

$\begin{array}{lll}\text { 1.5.1.1 } & \text { Glukokortikoide } & 20\end{array}$

$\begin{array}{ll}\text { 1.5.1.2 Azathioprin } & 21\end{array}$

1.5.1.3 Ciclosporin A (CsA) 22

1.5.1.4 Monoklonaler Antikörper OKT3 22

1.6 Zielsetzung der Promotion 25

$\begin{array}{ll}\text { 2. Patienten und Methoden } & 26\end{array}$

$2.1 \quad$ Patienten und Diagnosen 26

$\begin{array}{lll}2.1 .1 & \text { Patienten } & 26\end{array}$

$\begin{array}{lll}\text { 2.1.2 Diagnosen } & 26\end{array}$

$\begin{array}{lll}\text { 2.1.2.1 } & \text { Ursachen der terminalen Niereninsuffizienz }\end{array}$

$\begin{array}{lll}\text { 2.1.2.2 Nebendiagnosen } & 27\end{array}$ 
2.1.2.3 Virologischer Status vor Transplantation 28

2.1.2.4 Abstoßungsreaktionen nach Transplantation 29

2.1.2.5 Infektionen nach Transplantation 29

2.1.2.6 Entlassung der Patienten 30

2.1.3 Basisimmunsuppression 30

2.1.4 Therapie bei Transplantatabstoßung 31

2.1.5 Antibakterielle Therapie 32

2.1.6 Prophylaktische antivirale Therapie 32

2.1.7 Antihypertensive Therapie 32

2.2 Patientenüberwachung 33

2.3 Kriterien für akute Abstoßung, Infektion und stabile Transplantatfunktion 33

2.3.1 Stabile Transplantatfunktion 33

2.3.2 Abstoßungsreaktion $\quad 34$

2.3.3 Infektionen $\quad 34$

2.4 Methoden und Messtechnik 35

2.4.1 Kreatininbestimmung

2.4.2 Bestimmung der löslichen Rezeptoren 35

2.4.2.1 Lösliche CD14-Bestimmung 35

2.4.2.1.1 Testdurchführung 36

$\begin{array}{lll}\text { 2.4.2.1.2 Testauswertung } & 37\end{array}$

2.4.3 Lösliche CD8-Bestimmung 37

2.4.4 Lösliche CD4-Bestimmung 37

2.4.5 Lösliche IL2R-Bestimmung 37

2.4.6 Reproduzierbarkeit der verwendeten ELISA-Tests 37

$\begin{array}{lll}2.5 & \text { Statistik } & 38\end{array}$

$\begin{array}{ll}\text { 3. Ergebnisse } & 40\end{array}$

3.1. Repräsentative Verläufe $\quad 40$

3.1.1 Stabile Transplantatfunktion $\quad 40$

3.1.2 Abstoßungsreaktion 43

3.1.3 Infektion 46

$\begin{array}{lll}3.1 .4 & \text { Nierenfunktion } & 48\end{array}$ 
3.2 Varianzanalyse des Kreatinin im Serum 49

3.3 Verhältnis von glomerulärer Filtrationsrate (GFR) und Serumkreatinin 50

3.4 Löslicher Zellrezeptor CD14 (sCD14) 51

3.5 Zeitlicher Verlauf des löslichen CD14 vor Komplikation 56

3.6 Löslicher CD14 im Urin 59

3.7 Quotientenbildung von sCD14 und Kreatinin 61

3.8 Korrelation von Kreatinin im Serum und sCD14 im Plasma 63

3.9 Korrelation von Kreatinin im Serum und sCD14 im Urin 63

3.10 Korrelation der im Plasma und im Urin erhobenen Werte von sCD14 63

3.11 Das Verhältnis von sCD14 zu sIL2R

3.11.1 Plasmawerte des sIL2R $\quad 64$

$\begin{array}{lll}3.11 .2 & \text { Quotient aus sCD14 und sIL2R }\end{array}$

$\begin{array}{lll}\text { 3.11.3 Korrelation von sCD14 und sIL2R } & 74\end{array}$

3.12 Das Verhältnis von sCD14 zu sCD4 75

$\begin{array}{ll}3.12 .1 & \text { Plasmawerte des sCD4 }\end{array}$

3.12.2 Quotient aus sCD14 und sCD4 80

3.12.3 Korrelation von sCD14 und sCD4 81

3.13 Das Verhältnis von sCD14 zu sCD8 82

3.13.1 Plasmawerte des SCD8 82

3.13.2 Quotient aus sCD14 und sCD8 84

3.13.3 Korrelation von sCD14 und sCD8 85

$\begin{array}{lr}\text { 4. Diskussion } & 86\end{array}$

4.1 Probengewinnung, Aufbewahrung und Verarbeitung 86

4. 2 Datengewinnung und Statistik 88

$\begin{array}{lll}\text { 4.2.1 Erläuterungen zur Datengewinnung } & 88\end{array}$

4.2.2 Kritische Reflexion der angewandten biomathematischen Testverfahren 90

4.3 GFR und Serumkreatinin, Varianzanalyse der Patientengruppen 92

4.4 Löslicher CD14 im Plasma 93

4.5 Glomeruläre Teilfunktion und Konzentration des sCD14 im Plasma 97

4.6 Proximaler Tubulus: Einfluss auf sCD14 in Plasma und Urin 101

4.7 Erhöhung von sCD14 bereits vor Diagnose von Infektion und Abstoßung 106 
4.8 Verhältnis von löslichem CD14 und löslichem IL2R im Plasma 107

4.9 Verhältnis von löslichem CD14 und löslichem CD4 im Plasma 110

4.10 Verhältnis von löslichem CD14 und löslichem CD8 im Plasma 110

5. Zusammenfassung 112

$\begin{array}{ll}\text { 6. Literaturverzeichnis } & 113\end{array}$

$\begin{array}{ll}\text { 7. Anhang: Abbildungen } 7.1 \text { bis } 7.42 & 135\end{array}$ 


\section{Abkürzungsverzeichnis}

\begin{tabular}{|c|c|}
\hline APC & Antigen präsentierende Zelle \\
\hline AUC & Area under the curve \\
\hline CD & Cluster of Differentiation (Nomenklatur der Oberflächenantigene) \\
\hline $\mathrm{Cl}^{-}$ & Chlorid \\
\hline CMV & Zytomegalievirus \\
\hline CsA & Ciclosporin A \\
\hline dl & Deziliter \\
\hline EBV & Epstein-Barr-Virus \\
\hline ELISA & Enzyme linked immunosorbent assay \\
\hline GFR & Glomeruläre Filtrationsrate \\
\hline GN & Glomerulonephritis \\
\hline h & Stunde \\
\hline HSV & Herpes-simplex-Virus \\
\hline IFN & Interferon \\
\hline IgA & Immunglobulin A \\
\hline IgG & Immunglobulin G \\
\hline IgM & Immunglobulin M \\
\hline IL & Interleukin \\
\hline i.v. & intravenös \\
\hline $\mathrm{K}^{+}$ & Kalium \\
\hline $\mathrm{kD}$ & Kilodalton \\
\hline $\mathrm{kg}$ & Kilogramm \\
\hline KG & Körpergewicht \\
\hline LPS & Lipopolysaccharide \\
\hline mg & Milligramm \\
\hline MHC & Major Histocompatibility Complex \\
\hline $\mathrm{n}$ & Fallzahl \\
\hline $\mathrm{Na}^{+}$ & Natrium \\
\hline neg. & Negativ \\
\hline $\mathrm{ng} / \mathrm{ml}$ & Nanogramm/Milliliter \\
\hline pM & Pikomol \\
\hline
\end{tabular}


p.o.

per os

pos.

Positiv

sCD14 Löslicher CD14-Rezeptor

sCD4

Löslicher CD4-Rezeptor

sCD8

Löslicher CD8-Rezeptor

sIL2R

Löslicher Interleukin2-Rezeptor

Tx

Transplantat

$\mathrm{U} / \mathrm{ml}$

Units/Milliliter

VZV

Varizella-Zoster-Virus 


\section{EINLEITUNG}

\subsection{Aktueller Stand der Nierentransplantation in Deutschland}

Im Jahr 2007 erhielten insgesamt 2776 Patienten in Deutschland ein Nierentransplantat, mehr als je zuvor. Dennoch weist die Liste der Deutschen Stiftung Organtransplantation (DSO) noch immer 8473 wartende Patienten aus, zusätzlich 775 weitere, die aufgrund eines Transplantatversagens im Jahr 2007 wieder einer Dialysetherapie zugeführt werden mussten (Frei und SchoberHalstenberg 2008). Die Vorerkrankungen der Patienten und die Wirksamkeit der immunsuppressiven Therapie bestimmen die Überlebensrate des Transplantats (Ponticelli 2004). Eine sichere medikamentöse Therapie und eine schnelle und zuverlässige Detektion von Transplantatdysfunktionen haben deshalb die Prognose des Spenderorgans im letzten Jahrzehnt zwar entscheidend verbessert (Hariharan et al. 2000), doch besteht auch weiterhin angesichts knapper Spenderorgane die Notwendigkeit, das Auftreten von Komplikationen in noch größerem Maße zu verhindern.

\subsection{Komplikationen nach Nierentransplantation: Die Transplantatdysfunktion}

Betrug die Höhe der Abstoßungsreaktionen in den 80er Jahren des letzten Jahrhunderts noch 50 - 60\% (Cecka und Terasaki 1989), so konnte sie bis zur Mitte der 90er Jahre auf ca. 30\% gesenkt werden und wird heute im Mittel mit ca. 15\%, in manchen Zentren auch mit unter $10 \%$ der behandelten Patienten angegeben (Port et al. 2005).

Trotz großer Fortschritte der Operationstechniken und der immunsuppressiven Therapie stellt die Transplantatdysfunktion mit der Gefahr eines Transplantatversagens nach wie vor die häufigste Komplikation nach Nierentransplantation dar.

Ursächlich hierfür sind Abstoßungsreaktionen, Infektionen und organschädigende Nebenwirkungen der Immunsuppression (Ponticelli 2004). Eine unzureichende bzw. verzögerte Therapie der genannten Komplikationen stellt nicht nur eine akute Bedrohung des Patienten dar, sondern beeinträchtigt maßgeblich das Langzeitüberleben des transplantierten Organs (Daniel et al. 1995). So ist beispielsweise die 10-Jahres-Überlebensrate des Transplantates bei Patienten mit 
durchgemachter akuter Abstoßung zwischen 8-49\% niedriger als bei Patienten ohne vorausgegangene Abstoßungsreaktion. Besonders betroffen sind hier Patienten mit einer späten, also länger als drei Monate nach Transplantation diagnostizierten Abstoßungsreaktion sowie Patienten mit mehrfachen Abstoßungskomplikationen (Sijpkens et al. 2003, Dickenmann et al. 2002).

Eine wesentliche Voraussetzung für die Vermeidung einer Transplantatdysfunktion ist die optimale Einstellung der immunsuppressiven Therapie nach Transplantation. Sowohl Unter- als auch Überdosierungen der Immunsuppression können gravierende Komplikationen zur Folge haben. Eine Überdosierung führt zu einer Schwächung des Immunsystems mit der Gefahr schwerwiegender Infektionen und dem Risiko einer Tumorentstehung. Die Unterdosierung kann Abstoßungsrektionen mit Schädigung des Spenderorgans bis hin zum totalen Funktionsverlust zur Folge haben. Die individuelle Immunsuppression ist allerdings nicht nur von der Dosis bzw. dem Blutspiegel der Immunsuppressiva abhängig, sondern wird von einer Vielzahl verschiedener Faktoren (z. B. Infektionen, metabolische, endokrinologische und hämodynamische Veränderungen, operative Interventionen) bestimmt (Pascual et al. 2002).

Die für eine rasche und adäquate Behandlung notwendige diagnostische Ursachenklärung einer neu aufgetretenen Transplantatdysfunktion ist im klinischen Alltag häufig außerordentlich schwierig. Während die Funktionsstörung auf dem Boden einer Überdosierung von Immunsuppressiva (Ciclosporin A, Takrolimus) mit Hilfe des therapeutischen Drug Monitorings (TDM) schnell erfasst werden kann, stellt die klinische Differenzierung zwischen einer Abstoßungsreaktion und einer Infektion eine große Herausforderung für den behandelnden Arzt dar. Die meisten akuten Abstoßungen treten innerhalb der ersten sechs Monate nach Transplantation auf, so dass der Patient gerade in diesem Zeitintervall einer besonderen Beobachtung bedarf. An eine akute Abstoßung muss immer dann gedacht werden, wenn es zu einem nicht erklärbaren Anstieg des Serumkreatinin kommt. Als assoziierte klinische Symptome kann die Urinausscheidung abnehmen und der arterielle Blutdruck ansteigen. Fieber oder Schmerzen und Schwellungen im Bereich des Transplantates treten seit Einführung von Ciclosporin A nur noch selten auf. Aufgrund der außerordentlich unspezifischen Symptome müssen die Patienten in der Postransplantationsphase engmaschig labormedizinisch überwacht werden. 
Hierbei kommt dem Serumkreatinin eine besondere Bedeutung $z u$, da der Kreatininanstieg in der klinischen Praxis nach wie vor als labormedizinischer Marker für eine akute Abstoßung bzw. Transplantatdysfunktion angesehen wird. Das Serumkreatinin hängt jedoch nicht nur von der glomerulären Filtrationsrate (GFR) ab, sondern wird von einer Reihe von Faktoren (z.B. Alter, Muskelmasse) beeinflusst. So können Medikamente (z.B. Antibiotika, NSAR) die tubuläre Sekretion hemmen bzw. mit labormedizinischen Nachweismethoden (Jaffé-Methode) interferieren und auf diese Weise die Kreatininkonzentration im Serum erhöhen. Darüber hinaus beträgt die Eliminationshalbwertszeit von Kreatinin bei einer GFR von 50\% (eine vollfunktionsfähige Transplantatniere) ca. 5 Stunden. Im Falle einer akuten Funktionseinschränkung kommt es daher zu einem verzögerten Anstieg des Serumkreatinin. Darüber hinaus ist das Serumkreatinin ein sehr unspezifischer Laborparameter, der keine ätiologische Zuordnung der Transplantatdysfunktion erlaubt. Aufgrund des Fehlens ausreichend sensitiver und spezifischer Laborparameter gilt nach wie vor die Organbiopsie als diagnostischer Goldstandard bei einer Transplantatdysfunktion (Deng 1996).

Das bereits erwähnte therapeutische Drug Monitoring (TDM) ist seit einigen Jahren mit der Intention etabliert worden, eine individuelle Therapieanpassung vorzunehmen (Kuypers 2005).

Zur Erweiterung des diagnostischen Instrumentariums sind zunehmend auch immunologische Parameter wie z.B. lösliche Zellrezeptoren gerückt. Diese eignen sich möglicherweise für eine exaktere Therapieüberwachung und frühzeitigere Komplikationsdetektion und werden im Folgenden näher beschrieben. 


\subsection{Immunologischer Mechanismus bei Transplantatabstoßung}

\subsubsection{Immunologische Zellen und Rezeptoren bei Abstoßungsreaktion}

Am Abstoßungsprozess sind T-Lymphozyten, B-Lymphozyten und Monozyten/Makrophagen beteiligt, diese werden nachfolgend beschrieben.

\subsubsection{T-Lymphozyten (T-Zellen), Iösliche Zellrezeptoren CD4 und CD8}

T-Lymphozyten weisen spezifische, zur so genannten Ig-Superfamilie gehörende TZellrezeptoren in ihrer Oberfläche auf, die entsprechend ihrer heterodimeren Rezeptorketten in die zwei Hauptgruppen TCR-1 und TCR-2 eingeteilt werden. Die beiden Gruppen unterscheiden sich durch die aus Polypeptiden gebildeten Heterodimere. Beide Rezeptoren sind mit einem Polypeptidkomplex assoziiert, der als CD-3 bezeichnet wird und dessen Polypeptide das Signal über verschiedene Mechanismen in die Zelle übermitteln (Rubin B et al. 2007).

Eine T-Zelle exprimiert CD-3 und verfügt entweder über TCR-1 oder TCR-2. Im peripheren Blut haben ca. 95\% der T-Lymphozyten den TCR-2 ( $\alpha \beta$-Form)- und lediglich ca. 5\% den TCR-1 ( $\gamma \delta$-Form)-Rezeptor (Mosmann und Moore 1991). Die TCR-1-positiven Zellen lassen sich phänotypisch in CD4- und CD8- unterteilen. Sie erkennen und zerstören antigentragende Zellen in Abhängigkeit vom MHC-Molekül (Kappes und Tonewaga 1991). TCR-2-positive Zellen sind hingegen phänotypisch entweder CD4 ${ }^{+}$oder $\mathrm{CD}^{+}$(Spetz et al. 1991). Die CD4 ${ }^{+}$werden auch als THelferzellen bezeichnet und erkennen Antigene in Verbindung mit Klasse-2-MHCMolekülen (Gilliland et al. 1991, Gay et al. 1987). Aktivierte CD4-Zellen sezernieren Interleukin-4 (IL-4) und Interleukin-10 (IL-10) und sorgen über ein negatives Feedback dieser Rezeptoren für eine Limitation von Ausmaß und Dauer der Immunantwort (Di Julio et al. 1996). Im Zusammenspiel mit den Immunglobulinen $\operatorname{lgG} 1$, IgG2a und IgG2b sowie Iöslichen Antigenen kommt es darüber hinaus ebenfalls zu einer CD4 ${ }^{+}$-Zellaktivierung (Hjelm et al. 2006).

Die $\mathrm{CD}^{+}$werden Suppressorzellen oder zytotoxische Zellen genannt und reagieren auf Antigene in Verbindung mit Klasse-1-MHC-Molekülen (Lydyard und Grossi 1991), allerdings ebenso auch auf virusinfizierte Zellen und Tumorzellen 
(Rubin B et al. 2006). Strukturell handelt es sich bei dem CD4-Rezeptor um ein Glykoprotein mit vier extrazellulären Domänen auf einer Kette, während der CD8Rezeptor über zwei Ketten mit je einer extrazellulären Domäne verfügt (Röllinghoff und Wagner 1997).

Kommt es zum Kontakt zwischen einer T-Zelle und einer Antigen präsentierenden Zelle, die das Fremdantigen gemeinsam mit MHC-1 oder MHC-2 auf der Zelloberfläche aufweist, kann die T-Zelle über ihren Rezeptorkomplex TCR/CD3 und CD4 oder CD8 dieses Antigen erkennen (Kuhns and Davis 2007). Allerdings gibt es auch einen TCR/CD3-unabhängigen Weg der T-Zell-Aktivierung über eine gemeinsame, auf CD4- und CD8-positiven Zellen vorkommende so genannte Gamma-Kette, die über eine Stimulation durch Interleukin-2 (IL-2) und Interleukin-15 (IL-15) zu einer Ausschüttung führt (von Geldern et al. 2006).

Im Mäuseversuch konnte gezeigt werden, dass die Proteinkinase C (PKC) die durch den TCR/CD3-Komplex induzierte Exozytose von lytischen Enzymen bei CD8positiven Zellen reguliert (Ma et al. 2007), wohingegen bei CD4-positiven Zellen durch selbigen Vorgang eine Degranulation ohne Iytisch agierende Zytokine erfolgt (Shen et al. 2006). Weiterhin kommt es über den TCR/CD3-vermittelten Signalweg in CD8-positiven Zellen zu einer schnellen Sekretion des proinflammatorischen Chemokins RANTES, das aus intrazellulären Vesikeln freigesetzt wird (Catalfamo et al. 2004).

In der Transplantationsmedizin konnte weiterhin gezeigt werden, dass CD4-positive Zellen durch Stimulation wiederum CD8-positive Zellen aktivieren und diese im Transplantat mit Hilfe von Adhäsionsmolekülen und durch Ausschüttung des zytotoxischen Perforin ihre destruierende Wirkung entfalten (Trivedi 2007).

Wie und warum es im Weiteren zu einer Ablösung der membranständigen Rezeptoren kommt, und welche Rolle diese im Plasma messbaren Rezeptoren im Rahmen einer Immunaktivierung spielen, ist indes weitestgehend ungeklärt.

Klinisch finden sich für beide löslichen Rezeptoren deutlich erhöhte Plasmawerte bei entzündlichen und infektiösen Erkrankungen wie beispielsweise bei Enzephalitis (Vrbic et al. 2004), Borreliose (Zajkowska et al. 2004), akuter Pankreatitis (Uehara et al. 2004), hämorrhagischem Dengue-Fieber (Kurane et al. 1991), Sinusitis (Olszewski et al. 2003) oder Mononukleose (Yoneyama et al. 1995). 
In der Transplantationsmedizin konnten Grunewald et al. (2000b) zeigen, dass beide löslichen Zellrezeptoren, sCD4 und sCD8, bei akuten Abstoßungsreaktionen im Plasma signifikant höher auftraten als bei stabiler Transplantatfunktion.

Zudem war der lösliche CD8-Rezeptor bei Zytomegalie-Virusinfektionen signifikant höher als bei akuten Abstoßungsreaktionen, was eine Differenzierung unterschiedlicher auslösender Ursachen für eine Aktivierung des Immunsystems anhand der Rezeptor-Plasmakonzentration möglich zu machen scheint (Grunewald et al. 2000a). 
Abb. 1: Antigen-Rezeptor-Komplex:

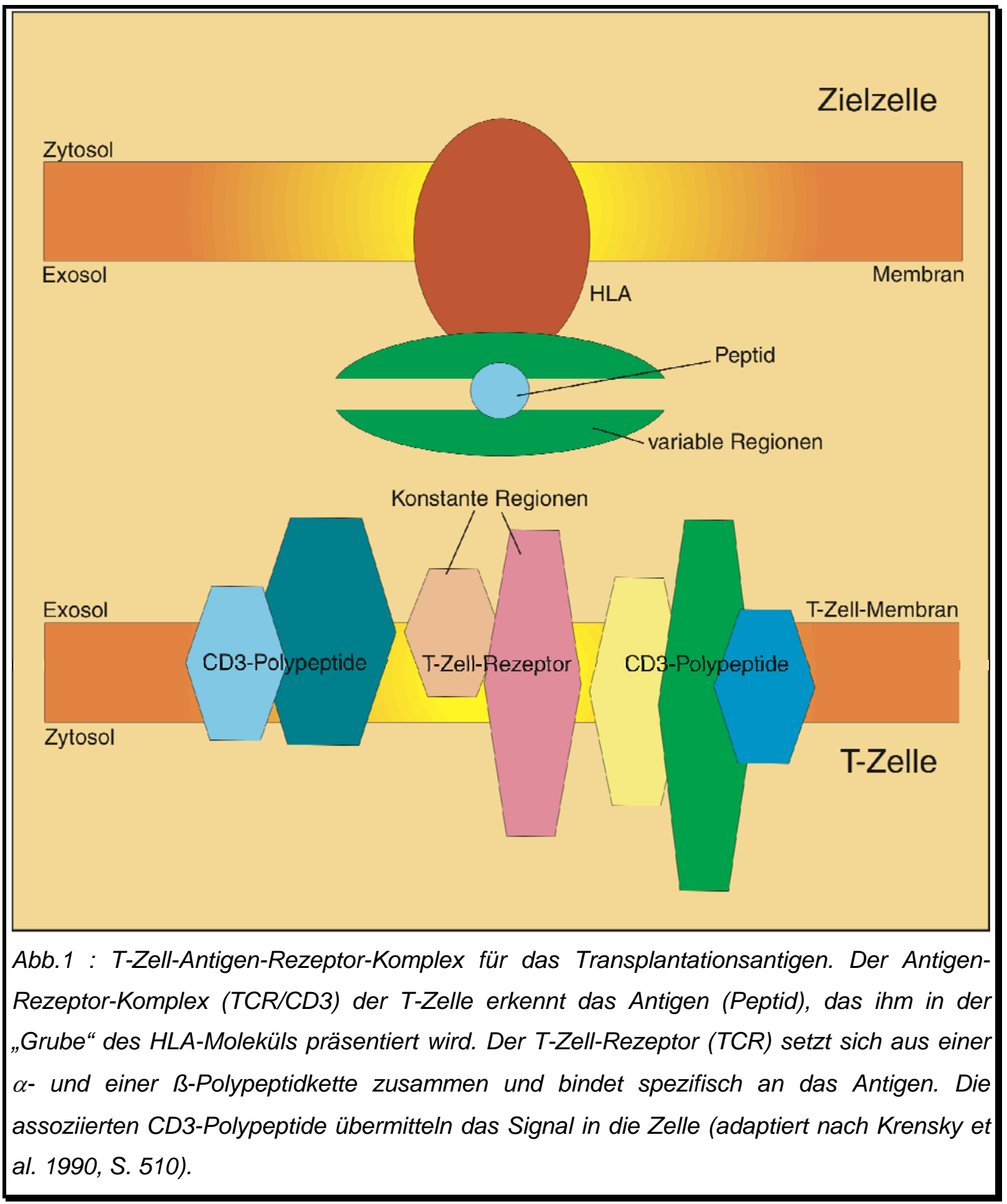




\subsubsection{B-Lymphozyten (B-Zellen)}

B-Lymphozyten repräsentieren nur etwa 5-15 \% der zirkulierenden lymphatischen Zellen und sind klassischerweise durch die Anwesenheit von endogen produzierten Immunglobulinen (Antikörper) definiert. Die Mehrzahl der B-Zellen trägt MHC-KlasseII-Antigene, die als HLA-DP-, DQ- und DR-Antigene bezeichnet werden und bei der Kooperation mit T-Lymphozyten eine wichtige Rolle spielen (Lydyard und Grossi 1991). Zur Aktivierung von B-Lymphozyten ist im Allgemeinen die Anwesenheit von T-Zellen erforderlich, wobei jedoch nach Kontakt mit T-Zell-unabhängigen Antigenen auch ohne Präsenz von T-Lymphozyten eine Aktivierung erfolgen kann. Trotzdem kann die volle Entwicklung und optimale Stimulation der B-Zellen nur in der Gegenwart von T-Zellen und ihren Produkten erfolgen. Das humorale Immunsystem hat die Fähigkeit, auf die verschiedenen Arten von Antigenen mit der Produktion von verschiedenen Klassen von Antikörpern zu reagieren (Abbas et al. 1996).

B-Lymphozyten reagieren genau wie T-Lymphozyten auf das von akzessorischen Zellen sezernierte Interleukin-1 (IL-1). Das erste, auf B-Zellen wirkende Produkt der T-Lymphozyten ist Interleukin-4 (IL-4). B-Zellen, die durch Antigen IL-1 und IL-4 stimuliert sind, vergrößern sich und treten in den Zellzyklus, bevor das ebenfalls von T-Zellen gebildete Interleukin-5 (IL-5) zum Wachstum der B-Lymphozyten und zur Produktion von Antikörpern beiträgt. Das nächste Molekül, das von T-Zellen gebildet wird und von den B-Lymphozyten zur Bildung einer hohen Immunglobulinproduktionsrate benötigt wird, ist das Interleukin-6 (IL-6). Die B-Zellen selber exprimieren vorübergehend einen Rezeptor für Interleukin-2 (IL-2), der auf die BZellen als potenter Wachstums- und Differenzierungsfaktor wirken kann (Feldmann und Male 1991).

\subsubsection{Monozyten/Makrophagen}

Monozyten/Makrophagen spielen ebenfalls eine besondere Rolle im Verlauf einer Abstoßungsreaktion und Infektion. Die aus der myeloischen Reihe hervorgehenden Zellen besitzen zwei wesentliche Funktionen: Zum einen sind sie in der Lage Antigene zu phagozytieren, zum anderen fungieren sie als Antigen präsentierende 
Zellen (APC) (Lydyard und Grossi 1991). Aus einer weiten, genetisch determinierten Variabilität der Expression verschiedener, funktionell wichtiger Oberflächenrezeptoren für Chemokine resultieren entsprechend unterschiedlich ausgeprägte Reaktionen und Wirkungen im Rahmen der Aktivierung des Immunsystems, wobei das Expressionsprofil der Oberflächenrezeptoren interindividuell stark variiert (Cravens et al. 2007). Neben der vornehmlich lokal im Gewebe stattfindenden Aktivierung der Monozyten im Rahmen einer Entzündungsreaktion (Lehtonen et al. 2007) können Monozyten/Makrophagen allerdings auch beispielsweise systemisch zirkulierende Immunkomplexe phagozytieren (Kavai and Szegedi 2007). Darüber hinaus sezernieren sie nach Aktivierung Interleukin-1, das die Proliferation von CD4+-T-Lymphozyten induziert und auf die Monozyten im Sinne eines positiven Feedbacks zurückwirkt (Halloran et al. 1989).

Einen ähnlichen Effekt hat auch das von tubulären Epithelzellen sezernierte Monocyte chemoattractant protein-1 (MCP-1) als spezifischer chemotaktischer und aktivierender Faktor auf Monozyten (Prodjosudjadi et al. 1996). Es wird bei Abstoßungsreaktionen nach Nierentransplantation in signifikant höheren Konzentrationen vorgefunden als bei stabiler Transplantatfunktion. Die Zahl der das Gewebe infiltrierenden Monozyten korreliert dabei mit der Ausschüttung dieses Peptids. MCP-1 scheint bei der Transplantatzerstörung durch Monozyten einen wichtigen modulierenden Einfluss zu haben (Grandaliano et al. 1997), insbesondere bezogen auf tubuläre Funktionsstörungen, Proteinurie und Grad der Niereninsuffizienz (Stasikowska und Wagrowska-Danilewicz 2007). Ebenso ist es positiv korreliert mit der monozytären Infiltration des Nierengewebes durch Monozyten nach renalen ischämischen Zuständen (Rice et al. 2002) und gilt als wichtiger Einflussfaktor bei chronisch fibrosierenden Nierenveränderungen (Wada et al. 2004).

\subsubsection{Membranständiger CD14 (mCD14)}

Monozyten besitzen wie die anderen immunologischen Zellen charakteristische Oberflächenmoleküle. Von besonderer Bedeutung ist hierbei der membranständige CD14. Dieser Rezeptor ist ein Glykoprotein und existiert in einer 53-kDa 
schweren membranständigen Form, vornehmlich auf Monozyten/Makrophagen (Ziegler-Heitbrock et al. 1988, Ball et al. 1984). Er ist über eine PhosphatidylinositolBrücke auf den Zellen verankert (Haziot et al. 1988). Der membranständige CD14 scheint eine Schlüsselrolle bei der Reaktion auf Lipopolysaccharide (LPS),

bakterielle Lipopolysaccharid-Komplexe und bakterielle Lipopolysaccharidgebundene Proteine gram-negativer Bakterien zu spielen. Die genannten Antigene stimulieren die Monozyten zur Synthese des Tumor-Nekrose-Faktors (TNF) (Wright et al. 1990). Entsprechend führt eine Stimulation mit dem LPS verschiedener gramnegativer Bakterien (z.B. Escherichia coli, Helicobacter pylori oder Porphyromonas gingivalis) zu einem signifikanten Anstieg von CD14-positiven Monozyten (CD14 ${ }^{+}$) (Cunningham et al. 1996). Nahezu identische Reaktionen lassen sich allerdings auch in Gegenwart von gram-positiven Bakterien wie Pneumokokken beobachten, obwohl diese keine Lipopolysaccharide in ihrer Zellwand aufweisen. Die antigenen Domänen sind in diesem Fall Strukturen aus Teichoic-Säuren (Moreillon und Majcherczyk 2003).

Eine herausragende Rolle spielen CD14+-Monozyten auch im Verlauf von Abstoßungsreaktionen nach Nierentransplantation. So konnten im Rahmen von Gewebeuntersuchungen von Transplantatnieren CD14 ${ }^{+}$-Monozyten nachgewiesen werden, deren Zahl mit der Wahrscheinlichkeit des Auftretens einer Abstoßungsreaktion korrelierte (Bogman et al. 1991, Dooper et al.1994).

Auch in Urinbefunden bei akuter sowie chronischer Abstoßungsreaktion zeigen sich die Konzentrationen von CD14-positiven Monozyten signifikant erhöht gegenüber denen bei einer stabilen Transplantatfunktion (Grunewald et al. 2000a, Roberti und Reisman 2001).

Zusammenfassend werden Monozyten durch bestimmte Antigene im Verlauf von Abstoßungsreaktionen nach Nierentransplantation aktiviert. Als Zeichen der Aktivierung wird CD14 an der Oberfläche der Zellen exprimiert.

\subsubsection{Löslicher Zellrezeptor CD14 (sCD14)}

Die lösliche Variante ( $S C D 14)$ des membranständigen Rezeptors existiert in zwei Isoformen, nämlich als 48-kDa- sowie als 55-kDa-Glykoprotein (Durieux et al. 1994). Diese wurden bereits um 1990 u.a. in CD14+-Zellkulturen (Bazil und Strominger 
1991) sowie im Plasma und Urin (Dozil et al. 1986, Krüger et al. 1991) nachgewiesen. Die Funktion im Detail ist bislang nicht geklärt, doch wird eine SCD14abhängige Ausschüttung von Interleukin-8 (IL-8) z.B. bei Patienten mit septischem Schock beobachtet, die mit der Konzentration von sCD14/LPS-Komplexen korreliert und in Abwesenheit von sCD14 nicht bzw. nur in äußerst geringem Ausmaß erfolgt (Landmann et al. 1996).

Weiterhin erscheint der SCD14 genau wie die CD14 ${ }^{+}$-Monozyten in deutlich höherer Konzentration bei vielen bakteriellen und viralen Infektionen im Blutplasma, so z.B. bei gram-negativen Erregern wie Enterobacter (Soler-Rodriguez at al. 2000, Wenisch et al. 1996, Burgmann et al. 1996), Escherichia coli, Listeria monocytogenes oder Streptococcus pneumoniae (Cauwels et al. 1999).

Für virale Erreger finden sich erhöhte Plasmawerte beispielsweise bei der chronischen Hepatitis B und $\mathrm{C}$, akzeleriert besonders bei Patienten mit bereits bestehender Lebercirrhose, signifikant geringer auch in chronischen Stadien ohne cirrhotischen Leberumbau (Steyaert et al. 2003). Erhöhte sCD14-Plasmaspiegel werden des Weiteren auch bei Infektionen mit dem Human Immunodeficiency Virus (HIV) beobachtet (Ryan et al. 2002).

Als prädiktiver Marker beschrieben wird der lösliche CD14-Rezeptor ebenfalls zur Erkennung des Bronchiolitis obliterans Syndroms als Komplikation im Sinne einer chronischen Abstoßungsreaktion nach Lungentransplantation, hier mit deutlich erhöhten Konzentrationen in Bronchiallavage und Plasma (Ward et al. 2002). Zudem wurden deutliche Erhöhungen der SCD14-Konzentration bei Patienten mit Malaria (Wenisch et al. 1996), proliferativer diabetischer Retinopathie (Hernandez et al. 2010), Systemischem Lupus erythematodes (Nockher et al. 1994), akutem Respiratorischem Distress Syndrom (ARDS) (Martin et al. 1997), Dialysetherapie (Nockher und Scherberich 1995, Raj et al. 2009), Kawasaki Syndrom (Takeshita et al. 2000), Periodontitis (Nicu et al. 2009), Status asthmaticus (Garty et al. 2000), Rauchern (Regueiro et al. 2009), bronchialen Allergien (Julius et al. 2010), chronischer Herzinsuffizienz (Rauchhaus et al. 2000), Sepsis (Kitchens und Thompson 2003) und Restenosierung nach coronarer Stentimplantation (Shimada et al. 2004) nachgewiesen. 
Dem lösliche CD14 werden verschiedene immunmodulierende Eigenschaften zugeschrieben, die sich sowohl auf die humorale als auch auf die zelluläre Immunantwort beziehen. So bindet SCD14 beispielsweise an tonsilläre BLymphozyten und induziert die Produktion von Immunglobulin G1 (IgG1), unterdrückt aber gleichzeitig die Sezernierung von Interleukin-6 (IL-6) bei bereits aktivierten BZellen und die Ausschüttung von Immunglobulin E (IgE). Über die vermehrte Produktion von CD40 nach Kontakt mit T-Lymphozyten werden auf diesem Wege BZellen zusätzlich aktiviert (Arias et al. 2000). Weiter kann der lösliche CD14-Rezeptor direkt an aktivierte T-Lymphozyten binden und aufgrund einer Inhibition der Interleukin-2-Sekretion dieser Zellen eine weitere Profileration von $\mathrm{CD}^{+}$- und $\mathrm{CD} 8^{+}$Lymphozyten unterbinden. Ein inhibierender Effekt durch exogenes Interleukin-2 (IL2) nach Bindung von SCD14 an T-Lymphozyten findet allerdings nicht statt. Des Weiteren wird durch SCD14 die Produktion von Interferon-gamma (IFN-gamma) und Interleukin-4 (IL-4) vermindert und eine Akkumulation des inhibitorischen Proteins kappaB-alpha induziert (Rey-Nores et al. 1999). Weiterhin gibt es Hinweise, dass der sCD14 das Wachstum von gram-positiven wie -negativen Bakterien inhibieren kann (Ohnishi et al. 2010).

Neben immunologisch aktivierenden Mechanismen lassen sich für den löslichen CD14 also auch inhibitorische Eigenschaften feststellen, ohne dass alle diese Effekte im Gesamtbild einer immunologischen Reaktion bezüglich ihrer Wirkpotenz und ihres Wirkspektrums genau geklärt sind.

\subsubsection{Löslicher Zellrezeptor IL2R (sIL2R)}

Der lösliche Interleukin-2-Rezeptor (sIL-2R) ist letztlich das Produkt aus dem Interleukin-2 (IL-2) und dem membranständigen Interleukin-2-Rezeptor (IL-2R), so dass der Weg zum löslichen Zellrezeptor zum besseren Verständnis hier ebenfalls aufgezeigt wird.

Das 14-16 kDa schwere Interleukin-2 wird von aktivierten T-Lymphozyten sezerniert, wobei sich die Proteine durch unterschiedliche Glykosylierung voneinander unterscheiden. Es bindet autokrin und parakrin, also im Sinne eines Feedbacks an dieselbe sezernierende Zelle wie auch an Zellen der Umgebung und gilt funktionell als T-Zell-Wachstumsfaktor. Es verstärkt die Proliferation von B-Lymphozyten und bindet weiterhin an Monozyten und NK-Zellen (Natürliche-Killerzellen). 
Der Interleukin-2 Rezeptor dient dabei als spezifische Bindungsstelle des Interleukin2 und ist ein membranständiger, multimerer Rezeptor-Komplex, der aufgrund von Veränderungen der transmembranösen Polypeptidstruktur in drei verschiedene Unterformen aufgeteilt werden kann (Flad und Gemsa 1997). Es handelt sich dabei um die unterschiedlich schweren Interleukin-2 Rezeptoren Alpha (55 kDa), Beta (75 kDa) und Gamma (64 kDa), die eine verschiedene Bindungsaffinität zum Interleukin2 besitzen. Während ruhende T-Lymphozyten eine sehr geringe Expression des IL-2Rezeptors mit ca. 500 pro Zelle aufweisen, schnellt diese im aktivierten Zustand auf 4000-12000 Oberflächenrezeptoren hoch (Röllinghoff und Wagner 1997).

Nicht alle IL-2-Rezeptoren weisen ein gleiches Verhalten auf. Beispielsweise findet sich lediglich IL-2Rgamma in geringer Zahl auf ruhenden T-Lymphozyten, bei einem Stimulus kommt es dann innerhalb von 48-72 h durch eine de novo Synthese zu einer maximalen Dichte der Oberflächenrezeptoren. Weniger ausgeprägt und zeitlich weiter verzögert ist hingegen die Expression von IL-2Rbeta auf T-Zellen gegenüber den Alpha- und Gammavarianten.

Andererseits werden auf Monozyten nach Stimulation sehr schnell Oberflächenrezeptoren des IL-2Rbeta Typs exprimiert. Insgesamt werden auf verschiedenen Zelltypen verschiedene Varianten des Interleukin-2-Rezeptors verschieden schnell und in unterschiedlicher Ausprägung exprimiert, was auf eine sehr differenzierte Regulation einer immunologischen Aktivierung hindeutet (Hodge et al. 2000). Erweiternd kommt hinzu, dass sich das Expressionsausmaß des Interleukin-2-Rezeptors, zumindest für Monozyten in vitro beschrieben, in peripheren Geweben von dem in lymphatischen Geweben deutlich unterscheidet (Lai et al. 1991).

Funktionell werden für den Interleukin-2-Rezeptorkomplex (aktivierter IL-2-Rezeptor) unterschiedliche Fähigkeiten und Wirkungen beschrieben. Als Regulator für Zellwachstum, Proliferation und Zelldifferenzierung fungiert er ebenso wie für die als gegenläufigen Effekt einzustufende Apoptose. Interpretiert wird dies zum einen im Rahmen einer Toleranzbildung gegenüber körpereigenen antigenen Strukturen sowie zur sinnvollen Limitation von T-Zell-Aktivitäten zur Vermeidung überschießender Immunantworten (Nelson 2002). 
Der lösliche Interleukin-2-Rezeptor (sIL2-R) selbst ist eine Mixtur aus dem Interleukin-2 und dem Interleukin-2-Rezeptorkomplex und stellt ein komplexes Glykoprotein dar, dass ca. 10 kDa leichter ist als die zellständige Vorstufe und auch „Ïsliches IL-2-Rezeptorprotein p55“ (55 kDa) genannt wird. Der genaue Mechanismus bzw. Signalweg zur Abspaltung von der Zellmembran ist nicht geklärt. Es tritt gegenüber Interleukin-2 im Plasma auf und ist entsprechend messbar (Flad und Gemsa 1997). Über die funktionelle Bedeutung ist indes wenig bekannt, zumindest markiert die Ablösung eindeutig eine Aktivierung der Zelle (Rubin LA et al. 1985) und kann durch eine Blockade von $(3 \mathrm{H})$ Thymidin, beispielsweise durch Cyclosporin A oder Prednisolon, inhibiert werden (Degiannis et al. 1991). Rubin beschreibt eine Bindung des löslichen Rezeptors an Interleukin-2 (Rubin LA et al. 1986), während Zorn keine Interaktion zwischen beiden Komponenten feststellen konnte, aber eine erneute Bindung an den membranständigen Rezeptorkomplex postuliert (Zorn et al. 1994). Beide interpretieren ihre Ergebnisse zumindest dahingehend, dass damit wahrscheinlich eine Inhibition der Aktivierung zum Schutz einer überschießenden Immunantwort erfolgen solle.

Im klinischen Bereich wird ein deutlich erhöhter Plasmaspiegel des löslichen Interleukin-2-Rezeptors (sIL-2R) bei vielen entzündlichen und malignen Erkrankungen wie beispielsweise Tuberkulose (Shitrit et al. 2006), Kawasaki-Arteriitis (Peng et al. 2006), allergischem Asthma (Can et al. 2006), akuter Pankreatitis (Pezzilli et al. 1994, Uehara et al. 2003), rheumatoider Arthritis (Dooley at al. 1993), Bronchialkarzinom (Orditura et al. 1998), Wegner Granulomatose, Autoimmunhepatitis und systemischem Lupus erythematodes (SLE) (Dejica 2001) beobachtet.

Im Bereich der Hämatoonkologie wird der sIL-2R neben dem Monitoring des Therapieerfolgs von akuten myeloischen und lymphatischen Leukämien (Moon et al. 2004) auch zur Detektion eines Rezidivs nach Therapie herangezogen (Liu et al. 2005) und als schlechter prognostischer Faktor bei Non-Hodgkin-Lymphomen angesehen (Niitsu et al. 2001, Kono et al. 2000, Shimomura et al. 1999).

In der Transplantationsmedizin, insbesondere bei Nierentransplantationen, zeigte sich eine signifikant erhöhte Plasmakonzentration des sIL-2R bei Infektionen sowie akuten Abstoßungsreaktionen gegenüber einer stabilen Transplantatfunktion 
(Metha et al. 2004, Zucchelli et al. 1990). Auch ein Therapieversuch mit einem Interleukin-2-Antikörper (Basiliximax) führte bei Komplikationen nach Nierentransplantation zu einem signifikanten Anstieg der Plasmawerte des SIL-2R, ein Effekt, der selbst nach Blockade des Rezeptors nicht verhindert werden konnte (Hamza et al. 2006).

Insgesamt ist das Auftauchen des löslichen Interleukin-2-Rezeptors im Plasma mit einer Stimulierung immunologischer Zellen gleich welcher Genese assoziiert, wobei über die genaue Funktion des sIL2-R wenig bekannt ist.

\subsubsection{Immunantwort bei Transplantatabstoßung}

Im Rahmen einer Nierentransplantation werden während des chirurgischen Eingriffs die Blutgefäße des Spenderorgans mit denen des Empfängers verbunden. Es kommt also unmittelbar nach der Transplantation zum Kontakt zwischen den Blutzellen des Empfängers mit dem Gewebe des implantierten Organs, wobei in den Gefäßen der transplantierten Niere zirkulierende naive T-Lymphozyten durch Anheftung an Oberflächenmoleküle von Endothelzellen und Makrophagen fixiert werden (Paul et al. 1992).

Verantwortlich für diese Interaktion zwischen T-Lymphozyten, Makrophagen und Endothelzellen sind so genannte akzessorische Moleküle (Taga und Kishimoto 1992). Diese Moleküle haben verschiedene Aufgaben bei der Adhäsion zwischen einzelnen Zellen, der Migration, der Signaltransduktion und dem Homing und werden je nach Funktion unterteilt in Adhärine, Integrine (CD-31, CD44, ICAM-2 und VLA und sein Ligand VCAM) und Selektine (L-, P- und E-Selektin). Bei der Verständigung immunkompetenter Zellen untereinander spielen diese Moleküle eine wichtige Rolle. Sie sind paarweise vorhanden, wobei sich das eine auf den Lymphozyten befindet und das andere auf den Monozyten/Makrophagen oder den Endothelzellen vorkommt. Durch diese akzessorischen Moleküle gelingt den Lymphozyten die Migration ins Gewebe der transplantierten Niere, wo es zum Kontakt mit den Antigen präsentierenden Zellen (APC) kommt (Shimizu et al 1992).

Die APC haben das Antigen bereits zuvor aufgenommen und durch sogenanntes Processing im Phagolysosomen mit proteolytischen Enzymen aufgespalten. 
Ein Teil des Materials wird wieder auf die Zelloberfläche zurückgebracht und zusammen mit MHC-Molekülen exprimiert (Steward 1991) und naiven T-Zellen mit deren T-Zell-Rezeptorkomplex neben anderen Molekülen zur weiteren Signalverarbeitung präsentiert (Hemmi und Akira 2005). Neben dem Antigen präsentieren die APC auch wichtige ko-stimulierende Moleküle wie CD80 und CD86, ohne die eine nachfolgende optimale T-Zell-Aktivierung nicht möglich ist (Wonigeit und Pichlmayr 1997). Eine Vielzahl anderer Mediatoren wie CD28/CTLA4, CD40, CD154 (Clarkson und Sayegh 2005), die ebenso eine Kommunikation zwischen APC und T-Zellen darstellen und mit dem so genannten T-Zell-Rezeptorkomplex assoziiert sind, spielen ebenso eine Schlüsselrolle für das Ausmaß der nachfolgenden Immunantwort. Entfällt dieser ko-stimulierende Signalweg, kommt es zu einer stark regulierten Einschränkung der Immunantwort (Rothstein und Sayegh 2003).

Nachfolgendes Schaubild (Abb.2) zeigt die Aktivierungskaskade nach Antigenerkennung mit den wichtigsten Zellen und Mediatoren: 
Abb.2: Antigenpräsentation und Immunantwort:

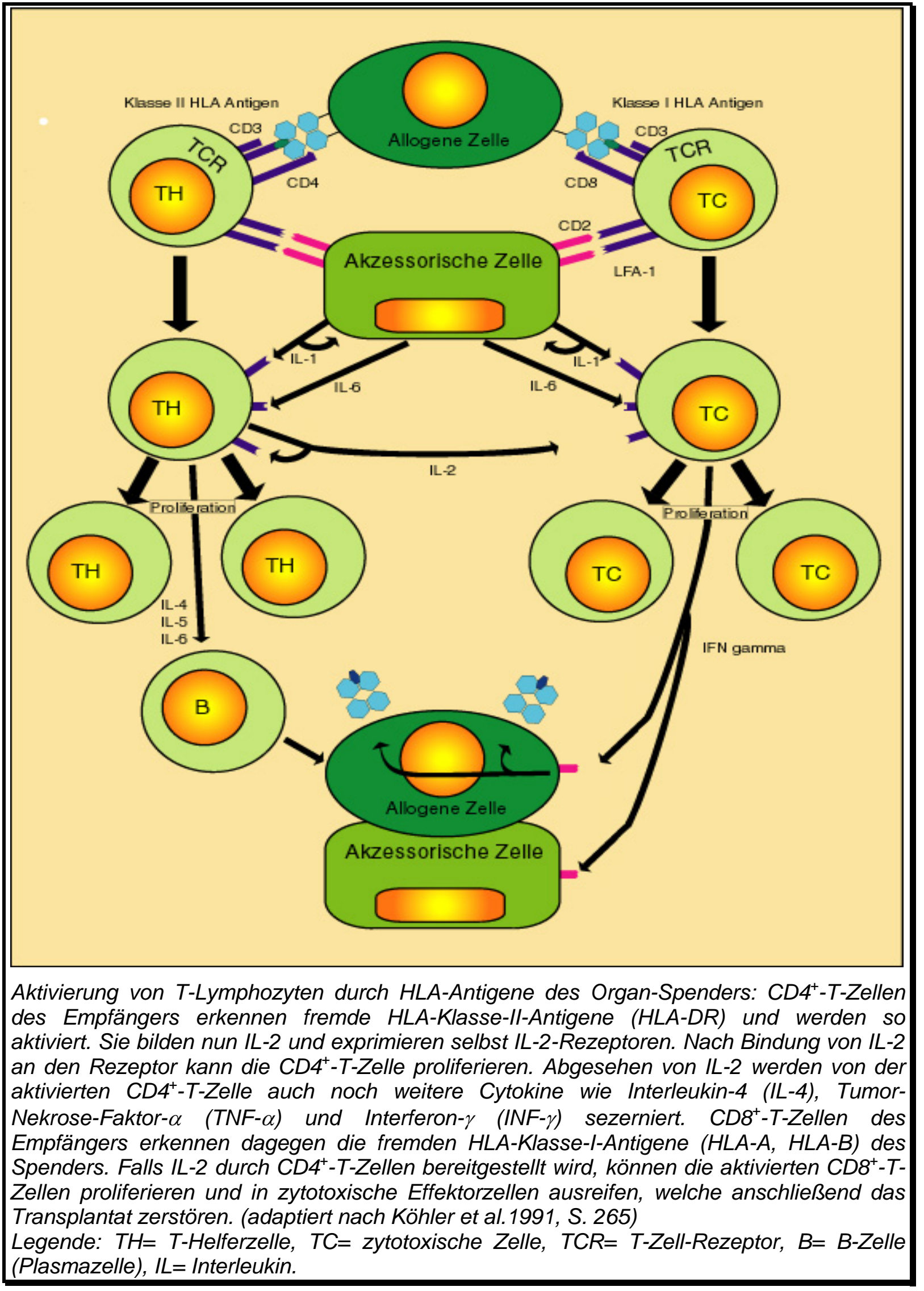




\subsection{Nierenfunktion}

\subsubsection{Glomeruläre Teilfunktion}

Zwei gesunde menschliche Nieren werden pro Minute ca. von $620 \mathrm{ml}$ Blutplasma durchflossen, dabei kommt es im Mittel zur Bildung von ca. 125 ml Primärharn (oder Ultrafiltrat), was insgesamt einer so genannten Filtrationsfraktion von etwa 0,2 entspricht. Zentraler funktioneller Organteil ist hier das Glomerulus, welches durch mehrere Untereinheiten als Filter wirkt und die meisten Plasmabestandteile im Normalfall nicht passieren lässt. Die glomeruläre Filtrationsrate (GFR) wird u.a. von der hydraulischen Leitfähigkeit, also der Wasserdurchlässigkeit, der Filterfläche und dem mittleren effektiven Filterdruck bestimmt. Änderungen dieser Parameter können entsprechend zu einer Verringerung der GFR führen.

Auf dem Weg zum Primärharn müssen gelöste Stoffe zunächst das Kapillarendothel des Glomerulus überwinden, welches mit Poren von einer Weite zwischen 50 und $100 \mathrm{~nm}$ ausgestattet ist. Die Weite der Poren wird u.a. durch eine Kommunikation zwischen Podozyten und Kapillarendothel über den Vascular-endothelial-growthfactor-A (VEGF-A) geregelt (Ballermann 2007).

Im Normalfall gelangen Moleküle bzw. Proteine bis zu einer Größe von ca. 70 kDa ungehindert in den Primärharn. Teilweise ist die Filtrierbarkeit aber nicht allein von der Größe, sondern auch von der Ladung der Stoffe abhängig (Silbernagl 2003).

Bezogen auf die vorliegende Arbeit kann abgeleitet werden, dass die hier untersuchten löslichen Rezeptoren allesamt frei filtriert werden, da sie das kritische Molekulargewicht sicher unterschreiten.

\subsubsection{Tubuläre Teilfunktion}

Der für diese Arbeit darzustellende Aspekt der tubulären Teilfunktion bezieht sich anatomisch wie funktionell auf den proximalen Teil des Tubulus, da hier Aminosäuren, Peptide, Polypeptide und Proteine resorbiert werden. Unter physiologischen Bedingungen werden Aminosäuren zu 98 bis 99,5\% über einen $\mathrm{Na}^{+}-$ Symportcarrier in die Tubuluszellen aufgenommen, ähnliche Prozentzahlen 
gelten auch für Peptide und Proteine. Peptide werden gespalten und ungespalten resorbiert, wobei eine Spaltung durch am luminalen Bürstensaum der Tubuluszellen verankerte Enzyme (z.B. Aminopeptidase, Endopeptidase, etc.) mit hoher katalytischer Aktivität und kurzer Kontaktzeit ermöglicht wird. Entstandene Aminosäuren werden dann an Ort und Stelle resorbiert. Für Di- und Tripeptide stehen zwei spezifische Peptid-H+'-Symportcarrier (PEPT1 und PEPT2) zur Verfügung.

Für größere Peptide bzw. Proteine wie die untersuchten löslichen Rezeptoren oder auch das Albumin geschieht die Resorption über eine rezeptorvermittelte und ATPabhängige Endozytose. Der Rezeptor, auch Megalin-Cubilin-Komplex genannt, sitzt an der Bürstensaummembran und endozytiert das Protein durch Abschnürung in ein Vesikel nach intrazellulär. Dieses Endosom genannte Vesikel verschmilzt anschließend mit einem Lysosom, dessen Inhalt aus Proteasen besteht. Dieses nimmt dann eine Aufspaltung des Proteins in Aminosäuren vor. Letztlich werden die Aminosäuren ins Zytoplasma und von dort in die Blutbahn entlassen, während die Vesikelmembran samt Rezeptor wieder in die luminale Zellmembran eingebaut wird (Silbernagl 2003).

Pathologische Zustände treten erst dann auf, wenn zu viel Protein ins Tubuluslumen gelangt. Am besten untersucht sind hier Zustände, die mit einer erhöhten Konzentration von Albumin einhergehen. Nach wie vor ist allerdings nicht exakt geklärt, wie viel Albumin die glomerulären Filter im physiologischen Fall passieren kann (zwischen $180 \mathrm{mg}$ und $9 \mathrm{~g}$ pro Tag werden diskutiert). Zumindest ist der schädigende Einfluss von erhöhten Albuminkonzentrationen auf die Tubuluszellen gut belegt (Birn und Christensen 2006), wobei eine niedrige Albuminbelastung hingegen protektive Einflüsse zu haben scheint (Caruso-Neves et al. 2006).

So induzieren hohe Albuminkonzentrationen an den Tubuluszellen die Ausschüttung von Monocyte-chemoattractant protein-1 (MCP-1) und lösen damit eine Kaskade tubulointestinaler proinflammatorischer Prozesse (Lai et al. 2007 / Eardley et al. 2006) wie die Sezernation von Interleukin-6 (IL-6) oder dem löslichen intrazellulären Adhäsionsmolekül-1 (sICAM-1) aus (Lai et al. 2007). Weiterhin hat eine erhöhte Konzentration von Albumin über einen mitochondrialen Signalweg einen apoptotischen Effekt auf proximale Tubuluszellen (Erkan et al. 2007). 
Eine hohe endozytische Resorptionsquote von Proteinen stört darüber hinaus die Kollagenhomöostase der Zelle und unterstützt den interstitiell-fibrosierenden Prozess (Wohlfahrth et al. 2003, Pollok und Poronnik 2007), ebenso wie eine variable, genetisch determinierte funktionelle Regulation Einfluss auf profibrotische oder tubulo-protektive Vorgänge zu haben scheint (Rudnicki et al. 2007).

Experimentelle Daten zeigen weiterhin, dass es bei einer artifiziell herbeigeführten Sepsis zu einer deutlichen tubulären Funktionsstörung kommt, diese sich aber vollständig regenerieren kann (Langenberg et al. 2007). Des Weiteren konnte im Tierversuch während einer milden und kurzen Ischämiezeit von 15 Minuten eine massive Proteinurie beobachtet werden, ohne dass jedoch eine Einschränkung der tubulären Funktion festgestellt wurde. Ebenso wenig fanden sich elektronenmikroskopisch morphologische Zellveränderungen (Andersson et al. 2007).

\subsection{Medikamentöse Therapie}

Für die posttransplantäre Therapie werden verschiedene Immunsuppressiva eingesetzt, deren Wirkmechanismus im folgenden beschrieben wird.

\subsubsection{Wirkmechanismus der Immunsuppressiva}

\subsubsection{Glukokortikoide}

Glukokortikoide sind ein wichtiger Bestandteil der medikamentösen Therapie in der Transplantationsmedizin und werden bei weit über $80 \%$ der Patienten als Basisimmunsuppression verwendet (Port et al. 2005). Zur Vermeidung von Steroidnebenwirkungen wie z.B. Osteoporose oder Diabetes mellitus wird die Dosis in der Dauertherapie unter der so genannten nebenwirkungsfreien Cushing-Schwelle gehalten. Darüber hinaus werden Glukokortikoide in hoher Dosis kurzfristig zur Behandlung von Abstoßungsreaktionen eingesetzt. Eines der gängigen Schemata ist hier die intravenöse Gabe von $500 \mathrm{mg}$ Prednisolon über 3 Tage als Stoßtherapie, mit der die meisten Abstoßungsreaktionen beherrscht werden können (Shinn et al. 1999). 
Glukokortikoide hemmen die Aktivierung von akzessorischen Zellen, indem sie die

Transkription des Interleukin-1 (IL-1) und des Interleukin-6 (IL-6) Gens blockieren (Köhler et al. 1991/Zanker et al. 1990). Glukokortikoide bewirken zudem eine deutliche Senkung der CD14+-Monozyten im Plasma nach Kortisonstoßtherapien, zum Teil mit einem Konzentrationsrückgang von bis zu 95\%, wobei hier der intrazelluläre Glukokorticoid-Rezeptor eine tragende Rolle zu spielen scheint (Dayyani et al. 2003). Allerdings ist für dendritische Zellen auch ein gegenläufiger Prozess beschrieben, bei dem es unter Dexamethason zu einer vermehrten Expression von CD14-Oberflächenrezeptoren kommt, ohne dass jedoch in der Folge die Auswirkungen und weiteren Mechanismen der Immunantwort genauer analysiert werden konnten (Duperrier et al. 2005).

\subsubsection{Azathioprin}

Zwei Mechanismen sind bei diesem Purinanaloga und seinem aktiven Metaboliten 6Mercaptopurin von Bedeutung. Zum einen hemmt es die de-novo Synthese von Purinnukleotiden, darüber hinaus wird es fälschlicherweise in die Zell-DNA eingebaut und verhindert als Antimetabolit die RNA- und Proteinsynthese und somit die Proliferation der T-Lymphozyten (Al-Safi und Maddocks 1983). Es wirkt im distalen Abschnitt der T-Zell-Aktivierungskaskade und kann deshalb die initiale GenAktivierung nicht verhindern. Der immunsupressive Effekt ist stärker bei den T- als bei den B-Lymphozyten ausgeprägt, so dass es bevorzugt die zelluläre Immunantwort blockiert. Auf die Antikörpersynthese hat Azathioprin keinen nachweisbaren Einfluß (Kaever und Resch 1995). Der klinisch erkennbare Wirkeintritt beginnt nicht unmittelbar sondern erst nach mehreren Wochen bis Monaten.

Beschrieben ist für das Azathioprin zudem eine deutliche Senkung von zirkulierendem Interleukin-6 (IL-6) (Barrera et al. 1996) sowie eine signifikante Suppression von CD8 ${ }^{+}$-Zellen im Rahmen von Untersuchungen zur Langzeitbehandlung mit diesem Medikament (Corsini et al. 2000). 


\subsubsection{Ciclosporin A (CsA)}

Dieses ringförmige, 11 Aminosäuren umfassende Polypeptid aus dem Pilz Trichoderma polysporum wirkt hochspezifisch auf Lymphozyten (Schreiber und Crabtree 1992). Durch Hemmung der Transkription und Produktion von Interleukin-2 (IL-2) in T-Helferzellen sowie durch Blockierung des Übergangs in die S-Phase des Zellzyklus verhindert es die Proliferation aktivierter T-Lymphozyten (Foxwell und Ruffel 1989). Ciclosporin A blockiert die Aktivierungskaskade der T-Zellen im Vergleich zu Glukokortikoiden auf einer distal gelegenen Stufe, so dass einige Elemente der T-Zell-Aktivierung unbeeinflußt bleiben. So kann z.B. die Aktivierung des IL-2 Rezeptor-Gens und damit die IL-2 Rezeptorexpression an der Oberfläche der antigen-stimulierten T-Lymphozyten nicht vollständig verhindert werden. Die Zellspezifität des am stärksten betroffenen Transkriptionsfaktors NFAT, der ausschließlich in T-Lymphozyten vorkommt, erklärt die weitgehende Selektivität dieses Immunsuppressivums. Neben der IL-2-Blockade wird auch die Synthese der Interleukine IL-1, IL-3 bis IL-6 und des Interferon-gamma unterbunden (Barrera et al. 1996). Ein Einfluss auf die Antikörperbildung besteht entsprechend nicht (Kaever und Resch 1995). Cyclosporin A verhindert weiterhin durch Inhibierung des unter anderem in aktivierten T-Lymphozyten gebildeten Makrophagen stimulierenden Faktors (M-CSF) eine entsprechende Aktivierung dieser Zellreihe (Fretier et al. 2002). Eine direkte Hemmung in der Ausbildung des Oberflächenrezeptors CD14 konnten allerdings nicht gefunden werden (Sindhi et al. 2001). Ciclosporin A hat als Basistherapeutikum nach Nierentransplantation in den letzten 20 Jahren zu einer signifikanten Verbesserung der Transplantatergebnisse geführt.

\subsubsection{Monoklonaler Antikörper OKT3}

Der monolonale Antikörper OKT3 bindet spezifisch an den konstanten Teil des TZell-Rezeptor-Komplexes (TCR/CD3) und blockiert die transmembranöse Signalübertragung. Der CD3-Komplex enthält zur Signalübermittlung an die Zelle neben den zwei zeta-Ketten (16 kDa) auch eine delta- (20 kDa), eine gamma- (25 kDa) sowie eine epsilon-Kette (20 kDa). OKT3 entfaltet seine Wirkung indem es spezifisch an die epsilon-Kette bindet und so nachfolgend die Funktion des 
CD3-Komplexes blockiert. Klinisch sind gute Ergebnisse auch in der so genannten First-line-Therapie einer akuten Abstoßungsreaktion belegt (Kamath et al. 1997).

Der monoklonale Antikörper findet als immunsupressive Möglichkeit der Vollständigkeit halber hier zwar Erwähnung, wurde aber bei den untersuchten Patienten nicht eingesetzt. Lediglich in einem Fall war die Indikation zur Anwendung gegeben, doch lehnte der Patient nach einem Aufklärungsgespräch die Therapie mit diesem Medikament ab. 
Abb. 3: Angriffspunkte der verwendeten immunsuppressiven Medikamente

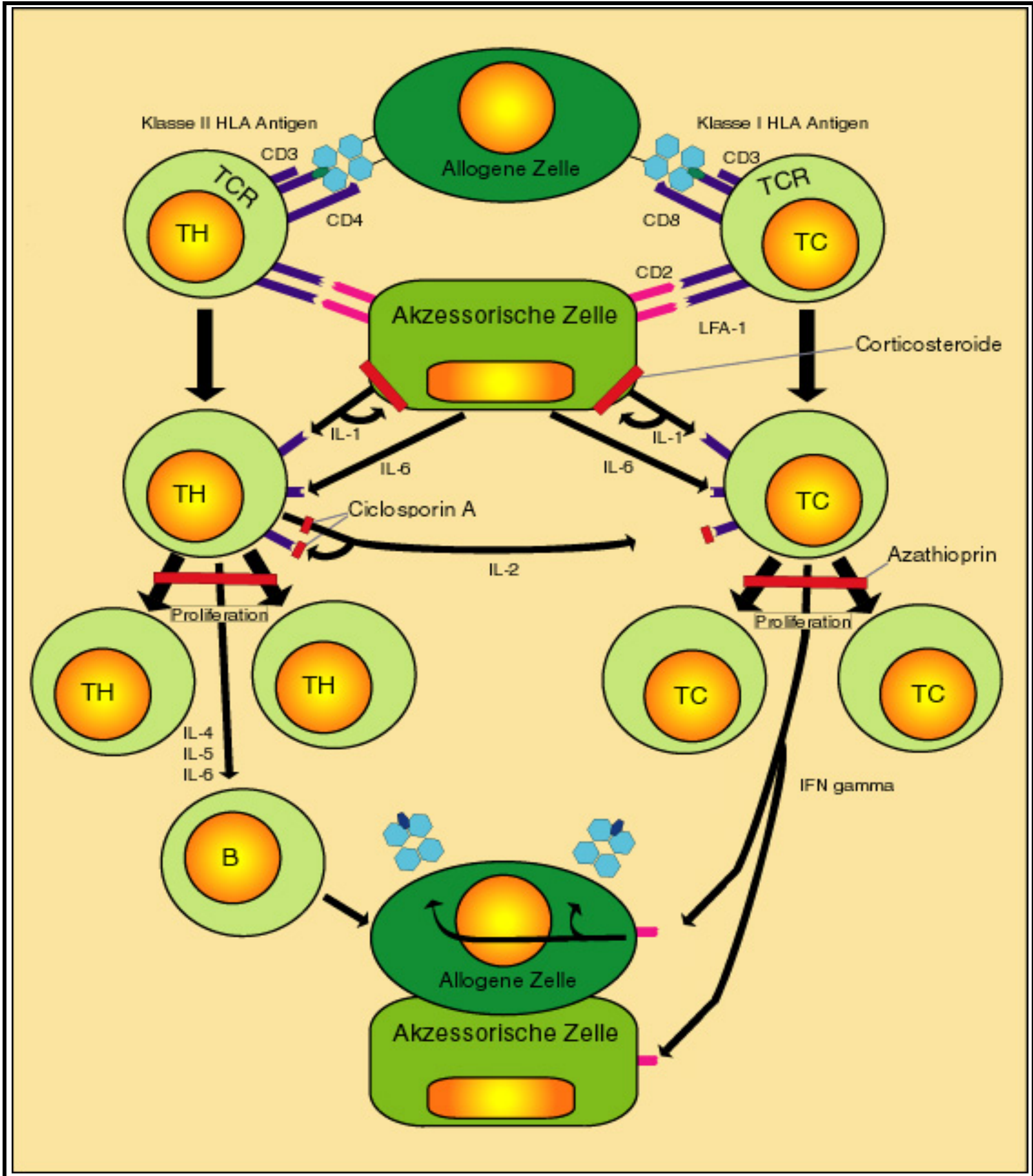

Abb. 3: Aktivierung von T-Lymphozyten durch HLA-Antigene des Organ-Spenders und die Angriffspunkte der angewandten Immunsuppressiva (Nach Köhler et al 1991).

Glukokortikoide hemmen die Aktivierung von akzessorischen Zellen, indem sie die Transkription des IL-1- und des IL-6-Gens blockieren. Ciclosporin A wirkt im Verlauf der T-Zell-Aktivierung weiter distal als die Glukokortikoide. Es hemmt vorwiegend die Produktion und Freisetzung von IL-2 und hemmt vor allem T-Helferzellen und zytotoxische Zellen, weniger die T-Suppressorzellen. Azathioprin hemmt als Antimetabolit die T-Zell-Aktivierung im Stadium der Proliferation, in der Aktivierungskaskade somit weiter distal als Glukokortikoide und Ciclosporin A. (Adaptiert nach Köhler et al.1991, S. 265) 


\subsection{Zielsetzung der Promotion}

Diese Arbeit beschäftigt sich in zentraler Position mit dem löslichen CD14 (sCD14) und seiner Bedeutung bei Patienten nach einer Nierentransplantation. Anhand der Bestimmung des Rezeptors im Plasma und im Urin in den zuvor definierten Transplantatsituationen „stabile Transplantatfunktion“, „Abstoßungsreaktion“ und „Infektion“ wird geprüft ob es möglich ist, über Konzentrationsunterschiede des sCD14 eine Differenzierung der beschriebenen Zustände zu erreichen.

Weiterhin wird betrachtet, ob die ermittelten Rezeptorkonzentrationen auch durch die Nierenfunktion selbst als Teil des Eliminationsweges beeinflusst werden.

Ferner wird der Blick auf die löslichen Rezeptoren IL2R, CD4 und CD8 gerichtet und untersucht, wie diese sich in gleichen Situationen gegenüber dem löslichen CD14 verhalten und ob über diese Muster weitere, den komplexen Mechanismus des Immunsystems erhellende Aussagen zum Rezeptorverhalten getroffen werden können. 


\section{Patienten und Methoden}

\subsection{Patienten und Diagnosen}

\subsubsection{Patienten}

Es wurden insgesamt 42 Patienten in die Untersuchung nach Nierentransplantation eingeschlossen. 40 Patienten wurden erstmalig transplantiert, zwei Patienten erhielten eine Zweittransplantation nach einem chronischen Transplantatversagen. Die Ergebnisse der Therapie und Diagnostik sind die Summe sowohl klinischer als auch laborchemischer und apparativer Befunde, die in der Zusammenschau zur genauen Definition verschiedener Transplantatzustände bzw. Komplikationen wie Abstoßungsreaktion und Infektion herangezogen wurden.

Das durchschnittliche Alter der Patientinnen und Patienten betrug 46,5 Jahre (24 61 Jahre) mit einer Geschlechterverteilung von 38 Männern und vier Frauen. Die durchschnittliche Dauer des Klinikaufenthaltes lag bei 47 Tage. Die Durchführung verschiedener Dialyseverfahren vor Transplantation erstreckte sich im Mittel über 26 Monate, wobei die Gruppe mit einer stabilen Transplantatfunktion eine durchschnittlich kürzere Wartezeit von 19 Monaten auf ein Spenderorgan gegenüber den Gruppen „Abstoßungsreaktion“ und „Infektion“ mit einer mittleren Wartezeit von 26 bzw. 29 Monaten aufwies. Die frühste Transplantation erfolgte bereits 6 Monate nach Dialysebeginn, am längsten musste ein Patient 86 Monate auf ein Spenderorgan warten.

Insgesamt wurden zwei Patienten im Verlauf der Beobachtung aufgrund eines Transplantatversagens zur Explantation des Spenderorgans verlegt. Es konnten demnach zwei Patienten $(4,7 \%$ der gesamten bzw. 6,3 \% der an Abstoßungsreaktionen bzw. Infekten erkrankten Patienten) nicht erfolgreich therapiert werden.

\subsubsection{Diagnosen}

\subsubsection{Ursachen der terminalen Niereninsuffizienz}

Die zur terminalen Niereninsuffizienz führenden Erkrankungen sind in der folgenden Tabelle aufgeführt. Unter den „Nephropathien unklarer Genese“ sind höchst- 
wahrscheinlich viele als Folge einer arteriellen Hypertonie zu werten, da diese bei nahezu allen Patienten als Nebendiagnose erhoben werden konnte, ohne dass durch anamnestische Angaben hier eine klare Trennung von einer primär gegenüber einer sekundär vorliegenden arteriellen Hypertonie gemacht werden kann.

Tab. 2:

\begin{tabular}{|c|c|}
\hline \multicolumn{2}{|l|}{ Ursachen der terminalen Niereninsuffizienz: } \\
\hline Nephropathien unklarer Genese & 29 \\
\hline \multicolumn{2}{|l|}{ Glomerulonephritiden: } \\
\hline membranöse GN & 2 \\
\hline sklerosierende GN & 2 \\
\hline IgA-Nephritis & 1 \\
\hline ohne histologische Angabe & 1 \\
\hline Zystennieren & 3 \\
\hline Refluxnephropathie & 1 \\
\hline Renale und retinale Dysplasie & 1 \\
\hline Alport-Syndrom & 2 \\
\hline
\end{tabular}

\subsubsection{Nebendiagnosen}

Als Nebendiagnosen imponiert darüber hinaus die nicht weiter differenzierte Anämie, welche in erster Linie als Folge der Niereninsuffizienz zu werten ist. Nahezu alle Patienten waren mit Erythropoetin substituiert. Weitere Nebendiagnosen finden sich in nachfolgender Tabelle.

Tab. 3:

\begin{tabular}{|l|c|}
\hline Nebendiagnosen: & $\mathbf{n}$ \\
\hline Arterieller Hypertonus & 34 \\
\hline Anämie & 33 \\
\hline Diabetes mellitus & 4 \\
\hline Koronare Herzkrankheit & 2 \\
\hline Nikotinabusus & 9 \\
\hline Hypothyreose & 2 \\
\hline Struma nodosa & 1 \\
\hline
\end{tabular}




\subsubsection{Virologischer Status vor Transplantation}

Ebenfalls ermittelt wurde ein virologischer Infektstatus vor Transplantation, der in Tabelle 4 dargestellt ist. Eine akute virale Infektion durch einen Zytomegalie-, Herpes-Simplex-, Epstein-Barr- oder Varizella-Zoster-Virus fand sich serologisch nicht.

Tab. 4:

\begin{tabular}{|c|c|c|}
\hline Gesamtgruppe & Pos. & Neg. \\
\hline \multicolumn{3}{|l|}{ Zytomegalie-Virus: } \\
\hline $\lg M$ & 0 & 42 \\
\hline $\lg G$ & 8 & 34 \\
\hline \multicolumn{3}{|l|}{ Epstein-Barr-Virus: } \\
\hline $\operatorname{lgM}$ & 0 & 42 \\
\hline $\lg G$ & 30 & 12 \\
\hline \multicolumn{3}{|l|}{ Herpes-simplex-Virus: } \\
\hline $\operatorname{lgM}$ & 0 & 42 \\
\hline $\lg G$ & 23 & 19 \\
\hline \multicolumn{3}{|l|}{ Varizella-Zoster-Virus: } \\
\hline $\lg M$ & 0 & 42 \\
\hline $\lg G$ & 25 & 17 \\
\hline
\end{tabular}

Tab. 5:

\begin{tabular}{|c|c|c|c|c|c|c|}
\hline \multirow[t]{2}{*}{ Untergruppen: } & \multicolumn{2}{|c|}{ Tx-stabil } & \multicolumn{2}{|c|}{ Infektion } & \multicolumn{2}{|c|}{ Abstoßung } \\
\hline & Pos. & Neg. & Pos. & Neg. & Pos. & Neg. \\
\hline \multicolumn{7}{|l|}{ Zytomegalie-Virus: } \\
\hline $\lg \mathrm{M}$ & 0 & 10 & 0 & 13 & 0 & 19 \\
\hline $\lg G$ & 1 & 9 & 1 & 12 & 6 & 13 \\
\hline \multicolumn{7}{|l|}{ Epstein-Barr-Virus: } \\
\hline $\operatorname{lgM}$ & 0 & 10 & 0 & 13 & 0 & 19 \\
\hline $\lg G$ & 4 & 6 & 10 & 3 & 16 & 3 \\
\hline \multicolumn{7}{|c|}{ Herpes-simplex-Virus: } \\
\hline $\lg \mathrm{M}$ & 0 & 10 & 0 & 13 & 0 & 19 \\
\hline $\lg G$ & 4 & 6 & 7 & 6 & 12 & 7 \\
\hline \multicolumn{7}{|c|}{ Varizella-Zoster-Virus: } \\
\hline $\lg M$ & 0 & 10 & 0 & 13 & 0 & 19 \\
\hline $\lg G$ & 5 & 5 & 7 & 6 & 12 & 7 \\
\hline
\end{tabular}




\subsubsection{Abstoßungsreaktionen nach Transplantation}

Erfüllten die Patienten die beschriebenen Kriterien für eine akute Abstoßungsreaktion, wurde eine Transplantatfeinnadelbiopsie mittels Biopty $Q$ unter sonographischer Kontrolle durchgeführt.

Von den in die Auswertung aufgenommenen Patienten wurden bis auf zwei Fälle alle akuten Abstoßungsreaktionen histologisch gesichert. In den zwei nicht biopsierten Fällen wurde die Diagnose aufgrund rasch steigender Serum Kreatininwerte, einem rapiden Diureserückgang, dem Sonographiebefund sowie aufgrund des Fehlens weiterer plausibler Transplantatversagensgründe gestellt. Eine weitere Unterteilung der biopsierten Patienten in Subgruppen nach Schweregrad der Abstoßung wurde nicht vorgenommen.

\subsubsection{Infektionen nach Transplantation}

Bei 13 Patienten wurde nach Transplantation eine Infektion wie in nachfolgender Tabelle angegeben diagnostiziert.

Tab. 6:

\begin{tabular}{|l|c|}
\hline Infektionen & n \\
\hline -septischer Harnwegsinfekt') & 1 \\
\hline -Kathetersepsis $^{2}$ ) & 2 \\
\hline -Pneumonien $^{3}$ ) & 4 \\
\hline -Zytomegalie-Virus $^{\prime}$ & 4 \\
\hline -Varizella-Zoster-Virus & 2 \\
\hline
\end{tabular}

1) Diagnose per Urinkultur: Staph. Epidermidis 2) Diagnosen per Blutkultur: Enterobacter cloacae und Acinetobacter ${ }^{3}$ ) Diagnosen auskultatorisch und radiologisch gestellt. 


\subsubsection{Entlassung der Patienten}

Alle Patienten wurden mit einer stabilen Transplantatfunktion in die ambulante Weiterbehandlung entlassen. Neben konstanten Gewichtsverhältnissen ohne Zeichen der Wasserretention zeigte sich das Serumkreatinin für die Gesamtgruppe im Mittel bei 1,69 mg/dl (Minimum = 0,71 mg/dl, Maximum = 3,05 mg/dl). Einen etwas niedrigeren Kreatininwert mit durchschnittlich $1,4 \mathrm{mg} / \mathrm{dl}$ hatte bei Entlassung die Gruppe mit der stabilen Transplantatfunktion gegenüber den Patienten mit einer erlittenen Abstoßungsreaktion $(1,81 \mathrm{mg} / \mathrm{dl})$ sowie gegenüber denen mit einer durchgemachten Infektion (1,72 mg/dl).

Die immunsupressive orale Therapie bestand aus Ciclosporin $A$ in einer mittleren täglichen Dosierung von 330 mg, durchschnittlich 7,5 mg Methylprednisolon und bei 20 Patienten zusätzlich mit 100 mg Azathioprin.

\subsubsection{Basisimmunsuppression}

Als Basisimmunsupression erhielten alle Patienten eine Kombination aus Ciclosporin A und Methylprednisolon. Der postoperative Ciclosporin-A-Talspiegel wurde im therapeutischen Bereich von 200-600 ng/ml gehalten. Die Dosis von Methylprednisolon wurde bei stabiler Transplantatfunktion wenn möglich in den ersten 10 Tagen von $100 \mathrm{mg} / \mathrm{d}$ auf $8 \mathrm{mg} / \mathrm{d}$ schrittweise reduziert.

Bei instabiler Transplantatfunktion, nach Abstoßungsbehandlung und bei bereits vorausgegangener Nierentransplantation wurde zusätzlich Azathioprin in einer Dosis von $100 \mathrm{mg} / \mathrm{d}$ oral appliziert. 


\section{Therapieschemata:}

1. Metyhlprednisolon:

Tab. 7:

\section{Methylprednisolon:}

\begin{tabular}{|l|c|}
\hline intraoperativ & $100 \mathrm{mg}$ i.v. \\
\hline 1.+2. Tag & $50 \mathrm{mg}$ p.o. \\
\hline 3.+4. Tag & $40 \mathrm{mg}$ p.o. \\
\hline 5.+6. Tag & $32 \mathrm{mg} \mathrm{p.o.}$ \\
\hline 7.+8. Tag & $24 \mathrm{mg}$ p.o. \\
\hline 9.+10.Tag & $16 \mathrm{mg}$ p.o. \\
\hline anschließend & $8 \mathrm{mg}$ p.o. \\
\hline Weitere Reduktion eventuell nach 8 Wochen. &
\end{tabular}

\section{Ciclosporin A:}

Tab. 8:

\section{Ciclosporin A (CsA):}

\begin{tabular}{|l|l|}
\hline $0-12 \mathrm{~h}$ & $\begin{array}{l}\text { Präoperativ Beginn mit } 3 \mathrm{mg} / \mathrm{kg} \mathrm{KG} \mathrm{CsA} \mathrm{i.v.} \mathrm{in} 250 \\
\mathrm{ml} \text { Glucose } 5 \% .\end{array}$ \\
\hline $12-24 \mathrm{~h}$ & $2,5 \mathrm{mg} / \mathrm{kg} \mathrm{KG}$ i.v. in $250 \mathrm{ml}$ Glucose $5 \%$. \\
\hline anschließend: & $\begin{array}{l}\text { Dosisanpassung nach Talspiegel. Therapeutischer } \\
\text { Bereich } 200-600 \mathrm{ng} / \mathrm{ml} \mathrm{im} \text { Vollblut. }\end{array}$
\end{tabular}

\subsubsection{Therapie bei Transplantatabstoßung}

Erfüllten Patienten die beschriebenen Kriterien einer akuten Abstoßungsreaktion, erhielten sie über drei Tage eine Kortison-Stoßtherapie mit jeweils 500 mg/d Methylprednisolon i.v. in $250 \mathrm{ml}$ Glucose 5\%. Bis auf zwei Patienten, die trotz wiederholter Therapieversuche ein progredientes Transplantatversagen aufwiesen, fand sich bei allen anderen Patienten in der Folge ein Rückgang der laborchemischen Entzündungsmarker, ein Abfall des Serumkreatinin sowie eine vermehrte bzw. wieder einsetzende Diurese. 


\subsubsection{Antibakterielle Therapie}

Die prophylaktische perioperative, antibakterielle Behandlung der Patienten wurde folgendermaßen durchgeführt:

Tab. 9:

\section{Operationsassoziierte antibakterielle Therapie:}

\begin{tabular}{|l|l|}
\hline Perioperativ über $48 \mathrm{~h}:$ & $3 \times 4 \mathrm{~g}$ Mezlocillin + 2x 500mg Metronidazol i.v. \\
\hline Anschließend prophylaktisch: & 2x 200mg Ofloxacin über 5 Tage i.v.
\end{tabular}

Patienten mit unklarem Fieber wurden mit Piperacillin und einem Aminoglykosid intravenös behandelt. Bei klinisch eindeutig lokalisierter oder kulturell gesicherter Infektion wurde eine spezifische antibakterielle Therapie nach bekanntem Erregerspektrum bzw. vermutetem Erreger eingeleitet. Diese konnte vom Schema bei unklarer Infektlokalisation abweichen und wurde nach individuellen klinischen/kulturellen Befunden angesetzt.

\subsubsection{Prophylaktische antivirale Therapie}

Bei der Konstellation Spender CMV-positiv/Empfänger CMV-negativ und ausreichender Nierenfunktion mit Kreatininwerten von $<2,8 \mathrm{mg} / \mathrm{dl}$ wurden die entsprechenden Patienten prophylaktisch mit 4x 200 mg Aciclovir behandelt.

\subsubsection{Antihypertensive Therapie}

Tab. 10:

\begin{tabular}{|l|l|}
\hline \multicolumn{2}{|l|}{ Perioperative antihypertensive Therapie: } \\
\hline intraoperativ: & Bolus: 0,28 mg/kg KG Diltiazem i.v. \\
\hline bis $48 \mathrm{~h}$ postoperativ: & Infusomat in $\mathrm{NaCl} \mathrm{0,9 \% :} \mathrm{3,1} \mathrm{mg/kg} \mathrm{KG/24h.}$ \\
\hline anschließend: & $2 \times 60 \mathrm{mg} / \mathrm{d}$ oral. \\
\hline
\end{tabular}

Je nach Schweregrad und Behandlungswürdigkeit der Hypertonie sowie individueller Verträglichkeit wurden als weitere Substanzgruppen im Verlauf ACE-Hemmer, $\beta$ Blocker, Diuretika, Kalzium-Antagonisten, Minoxidil sowie Clonidin eingesetzt. 


\subsection{Patientenüberwachung}

Bei den transplantierten Patienten wurden folgende Parameter in verschiedenen Zeitabständen routinemäßig überprüft:

Tab. 11:

\section{Täglich überprüfte Patientenparameter:}

\begin{tabular}{|l|}
\hline Ciclosporin A-Talspiegel (vor Einnahme der nächsten Dosis) \\
\hline $\mathrm{Na}^{+}, \mathrm{K}^{+}, \mathrm{Cl}$, Kreatinin , Harnstoff, Blutbild \\
\hline Urinstatus \\
\hline Körpergewicht \\
\hline Ein-/Ausfuhr (Flüssigkeitsbilanz/Diurese) \\
\hline Blutdruck und Temperatur \\
\hline
\end{tabular}

Tab. 12:

\section{Zweimal wöchentlich überprüfte Patientenparameter:}

GOT/GPT, AP, g-GT, Bilirubin, Quick, PTT (Leberfunktion)

Harnsäure, Gesamteiweiß, Plasma-Elektrophorese,

Blutzucker.

Transplantatsonographie mit Dopplersonographie der Nierengefäße.

Tab. 13:

\section{Wöchentlich überprüfte Patientenparameter:}

Virus-Serologie (CMV, EBV, VZV, HSV)

\subsection{Kriterien für akute Abstoßung, Infektion und stabile Transplantatfunktion}

\subsubsection{Stabile Transplantatfunktion}

Es wurde von einer stabilen Transplantatfunktion ausgegangen, wenn die Serumkonzentration von Kreatinin $\delta 1,7 \mathrm{mg} / \mathrm{dl}$ lag bzw. bei pathologisch erhöhten Werten eine deutlich fallende Tendenz von > 0,2 mg/dl pro Tag vorlag. Zudem sollte die Urinausscheidung bei gleichbleibend konstanter Flüssigkeitszufuhr und konstantem Körpergewicht $>$ 1,8 I/Tag betragen. Darüber hinaus durften keine 
Hinweise für eine Infektion vorliegen und der Sonographiebefund des Transplantates durfte keine pathologischen Veränderungen im Sinne verwaschener Parenchymgrenzen aufweisen. In der dopplersonographischen Untersuchung musste eine gute Perfusion mit einem Resistance-Index von unter 0,7 nachweisbar sein.

\subsubsection{Abstoßungsreaktion}

Bei 19 Patienten kam es im Verlauf nach Transplantation im Mittel nach 16 Tagen (5. - 28. Tag) zu einer akuten Transplantatabstoßung. In 17 Fällen konnte die Diagnose durch eine Biospie gesichert werden. Bei zwei Patienten erfolgte die klinische Diagnose u.a. aufgrund einer rasch progredienten Nierenfunktionseinschränkung mit einem täglichen Anstieg der Serumkreatininkonzentration um mehr als $0,2 \mathrm{mg} / \mathrm{dl}$ und gleichzeitig fehlenden Hinweisen für eine Ciclosporinintoxikation oder Infektion.

Darüber hinaus wurden folgende sonographische Befunde im Sinne einer akuten Transplantatabstoßung interpretiert:

Verwaschene Parenchym-Pyelon-Grenzen und echoarme Pyramiden sowie Pulsindices (Dopplersonographie) von über 0,8 mit tendentiellem Anstieg von 0,1$0,2 /$ Tag.

\subsubsection{Infektionen}

Bei Temperaturen über $38,5^{\circ} \mathrm{C}$ wurden aufgrund eines vermuteten bakteriellen bzw. viralen Infektes Blut- und Urinkulturen sowie virusspezifische serologische Marker bestimmt. Gekoppelt daran war durchweg auch ein Anstieg laborchemischer Entzündungsparameter wie beispielsweise das C-reaktive-Protein (CRP) zu beobachten. Bei 13 Patienten kam es im posttransplantären Verlauf zu einer bakteriellen bzw. viralen Infektion.

Vier Pneumonien wurden auskultatorisch, röntgenologisch und aufgrund steigender CRP-Werte diagnostiziert. In zwei Fällen gelang die Diagnose einer Varizella-ZosterInfektion über einen Titeranstieg von virusspezifischem IgM. 
Bei der CMV-Diagnostik (vier Patienten) konnte neben der IgM-Serologie zusätzlich der positive Nachweis über das virale Strukturantigen pp65 erbracht werden.

Ein septischer Harnwegsinfekt und zwei Fälle mit einer Kathetersepsis konnten als solche klinisch identifiziert und über eine Urin- bzw. Blutkultur diagnostiziert werden.

\subsection{Methoden und Messtechnik}

\subsubsection{Kreatininbestimmung}

Für die Kreatininbestimmung wurde die Methode nach Jaffé verwandt. Eine $25 \mu \mathrm{l}$ Probe wurde per Küvette und modifizierter Jaffélösung in einen Beckmann KreatininAnalysator-2 gegeben. Gemessen wurde die Absorptionszunahme durch Bildung des Pikrat-Kreatinin-Komplexes bei $520 \mathrm{~nm}$ Wellenlänge. Das Ergebnis wurde in mg/dl angezeigt. Die Umrechnung erfolgte in Stoffmengenkonzentration: $\mu \mathrm{mol} / \mathrm{l}: 88,4=$ $\mathrm{mg} / \mathrm{dl}$ (Thomas 2008).

\subsubsection{Bestimmung der löslichen Rezeptoren}

Das Testverfahren für alle hier bestimmten löslichen Rezeptoren unterlag dem Prinzip des ELISA-Tests. Nachfolgend wird dieses Verfahren einmal anhand der Bestimmung des löslichen CD14-Rezeptors (sCD14) dargestellt. Für die anderen löslichen Rezeptoren wurde auf eine erneute detaillierte Darstellung der Testdurchführung verzichtet.

\subsubsection{Lösliche CD14-Bestimmung}

Die Bestimmung des löslichen CD14 (sCD14) erfolgte mit einem kommerziellen TestKit der Firma IBL Hamburg. Es handelte sich um einen SandwichEnzymimmunoassay mit einem oligoklonalen und einem monoklonalen Antikörper zur quantitativen Bestimmung von löslichem CD14 in Serum, Plasma, Liquor, Urin, Synovialflüssigkeit und Zellkulturüberständen. Das Bestimmungsverfahren gestaltet sich wie folgt: 
Das in der Probe enthaltene SCD14 wird spezifisch an die Antikörper gebunden, die an der Mikrotiterplatte immobilisiert sind. Im gleichen Schritt bindet der zweite mit Biotin konjugierte monoklonale Antikörper an ein weiteres Epitop des CD14Moleküls. Nach einem Auswaschvorgang bindet sich das Streptavidin-PeroxidaseKonjugat an den Komplex. Nach einem weiteren Auswaschvorgang und Zugabe einer Tetramethylbenzidin-Substratlösung (Chromogen) entsteht eine Färbung, die der Konzentration an sCD14 proportional ist. Die Farbreaktion wird durch Zugabe einer Stopplösung beendet und die optische Dichte bei $450 \mathrm{~nm}$ gemessen.

\subsection{Testdurchführung}

Die entnommenen Plasmaproben zur Bestimmung des löslichen Zellrepeztors wurden in Heparinmonovetten abgenommen und innerhalb von ca. $60 \mathrm{~min}$. bearbeitet. Vor dem Einfrieren bei $-20{ }^{\circ} \mathrm{C}$ zum Konservieren für die später durchgeführte Messung erfolgte ein zehnminütiges Zentrifugieren bei $3000 \mathrm{U} / \mathrm{min}$.

Vor Testdurchführung wurden die Proben entsprechend aufgetaut und bei Raumtemperatur wie folgt weiterverarbeitet:

a) Pipettierung von $50 \mu \mathrm{l}$ der 1:101 vorverdünnten Proben in die Vertiefungen der Mikrotiterstreifen. Nachfolgende Zugabe von $50 \mu \mathrm{l}$ Anti-sCD14-Lösung.

b) Versiegelung der Platte mit Haftklebefolie und Inkubation bei Raumtemperatur in einem Orbitalschüttler.

c) Dreimaliges Auswaschen der Proben mit einem gebrauchfertigen Waschpuffer und Ausklopfen der Flüssigkeitsreste auf einer saugfähigen Unterlage.

d) Zugabe von je $150 \mu \mathrm{l}$ Enzymkonjugat in die Mikrotiterstreifen und Versiegelung mit Haftklebefolie. Erneutes, diesmal einstündiges Inkubieren bei Raumtemperatur in einem Orbitalschüttler.

e) Abermaliges dreifaches Auswaschen mit dem Waschpuffer.

f) Einbringen von $200 \mu \mathrm{l}$ gebrauchsfertiger TMB-Substratlösung in jede Probenkammer und erneutes Inkubieren für 10-20 min.

g) Pipettierung von je $100 \mu \mathrm{l}$ TMB-Stopplösung zum Beenden der Substratreaktion.

h) Kurzes Schütteln der Mikrotiterplatte und anschließende Messung der optischen Dichte bei $450 \mathrm{~nm}$. 


\subsection{Testauswertung}

Es wurden die Mittelwerte der optischen Dichte jeder Probe berechnet und auf semilogarithmischem Papier die mittlere optische Dichte der Standards auf der YAchse (linear) gegen die entsprechende Konzentration der Standards auf der XAchse (logarithmisch) aufgetragen. Es folgte die Ablesung der Konzentration der Patientenproben über deren mittlere optische Dichte aus der Standardkurve und die Multiplikation mit dem entsprechenden Verdünnungsfaktor.

\subsubsection{Lösliche CD8-Bestimmung}

Die Bestimmung des löslichen CD8 Zellrezeptors erfolgte mit einem kommerziellen Cellfree-T-8 Test-Kit der Fa. T-Cell Science Inc. (USA), der ebenfalls auf dem Prinzip des ELISA-Tests (Enzyme Linked Immunoabsorbant Assay) beruht.

\subsubsection{Lösliche CD4-Bestimmung}

Wie zur Bestimmung der SCD4 Konzentrationen wurde hier ein analoges Test-Kit der Firma T-Cell Sciences Inc., USA verwandt. Auch hier dem ELISA-Test-Prinzip folgend.

\subsubsection{Lösliche IL2R-Bestimmung}

Für die Konzentrationsbestimmung des löslichen IL2-Zellrezeptors diente ein kommerzielles Test-Kit der Firma Immunotech (Frankreich), das nach Anleitung des Herstellers (ELISA-Prinzip) eingesetzt und bedient wurde.

\subsubsection{Reproduzierbarkeit der verwendeten ELISA-Tests}

Die Präzision der verwandten ELISA-Mess-Kits lässt sich durch die intra-Assaysowie inter-Assay-Variation beschreiben und wurde nach den Angaben der Hersteller übernommen. Die beschriebenen Werte weisen die verwandten Tests als 
in hohem Maße reproduzierbar aus. Die entsprechenden Abweichungen sind der folgenden Tabelle zu entnehmen.

Tab. 14:

\begin{tabular}{|l|c|}
\hline \multicolumn{2}{|l|}{ Intra-Assay Reproduzierbarkeit: } \\
\hline & Variation in \% \\
\hline Löslicher CD14 & 4,7 \\
\hline Löslicher IL2R & 6,6 \\
\hline Löslicher CD4 & 4,1 \\
\hline Löslicher CD8 & 6,2 \\
\hline
\end{tabular}

Tab. 15:

\begin{tabular}{|l|c|}
\hline \multicolumn{2}{|l|}{ Inter-Assay Reproduzierbarkeit: } \\
\hline & Variation in \% \\
\hline Löslicher CD14 & 6,6 \\
\hline Löslicher IL2R & 11,4 \\
\hline Löslicher CD4 & 4,7 \\
\hline Löslicher CD8 & 10,1 \\
\hline
\end{tabular}

\subsection{Statistik}

In die statistische Auswertung eingeflossene Laborparameter wurden nur dann verwendet, wenn zuvor aus der Durchsicht des klinischen Verlaufs und in Zusammenhang mit entsprechenden anderen Parametern eine eindeutige Zuordnung zu den definierten Zuständen stabile Transplantatfunktion, Abstoßung oder Infektion erfolgen konnte.

Da es bei der Rekrutierung der erhobenen Werte nicht immer ein lückenlos chronologischen Monitoring gab, sondern ebenso punktuelle, wenn auch engmaschige Messungen des jeweiligen Transplantatzustandes stattfanden kann nicht davon ausgegangen werden, dass es sich bei den erhobenen Werten um den jeweils möglichen Maximalwert der einzelnen Episoden handelt. Wird zudem berücksichtigt, dass ein immunologisches Geschehen ein auch im kurzen Zeitverlauf 
sehr dynamischer Prozeß sein kann und es sich nicht um so genannte "On-Off"Situationen handelt , so wird zuvor beschriebener Sachverhalt noch deutlicher.

Bei der statistischen Auswertung wurde in dieser Arbeit neben der Berechnung von Mittelwert, Median, Standardabweichung und den 5\%- und 95\%-Quantile auch der zweiseitige Wilcoxon-Mann-Whitney-Test zur Ermittlung des Signifikanzniveaus für kleine Stichproben herangezogen. Dieser eignet sich vor allem deshalb, weil bei den erhobenen Werten nicht von einer Normalverteilung ausgegangen werden kann, so dass ein so genanntes finites Testmodell gewählt werden musste.

Weiterhin wurde innerhalb der Gruppen die Sensitivität und Spezifität für bestimmte Transplantatzustände ermittelt, immer mit dem konkreten Verweis auf den Gültigkeitsbereich dieser Werte unter den Bedingungen einer retrospektiven Analyse. Zudem wurden Korrelationen ausgewählter Wertepaare und -reihen durchgeführt, um gleich- bzw. gegenläufiges Verhalten von Rezeptor- bzw. Kreatininkonzentrationen untereinander darstellen zu können. Eine signifikante Korrelation wurde für $\geq \pm 0,7$ angenommen. 


\section{Ergebnisse}

\subsection{Repräsentative Verläufe}

Nachfolgend werden zunächst einige typische klinische Verläufe der einzelnen untersuchten Gruppen bzw. Patienten exemplarisch dargestellt, um die erhobenen Daten besonders im Hinblick auf den laborchemischen Verlauf anschaulicher darzustellen. Die ausgesuchten Fallbeispiele sind entsprechend dieser Zielsetzung kommentiert.

\subsubsection{Stabile Transplantatfunktion}

Die Abbildungen 3.1 bis 3.5 stellen den unauffälligen Verlauf eines 40-jährigen Patienten nach Nierentransplantation dar. Die Konzentrationen der gemessenen Zytokine und des Kreatinin fallen nach Transplantation rasch auf ein niedrignormales, stabiles Niveau ab.

Abb. 3.1: Exemplarischer Verlauf des Serumkreatinin bei einer stabilen Transplantatfunktion

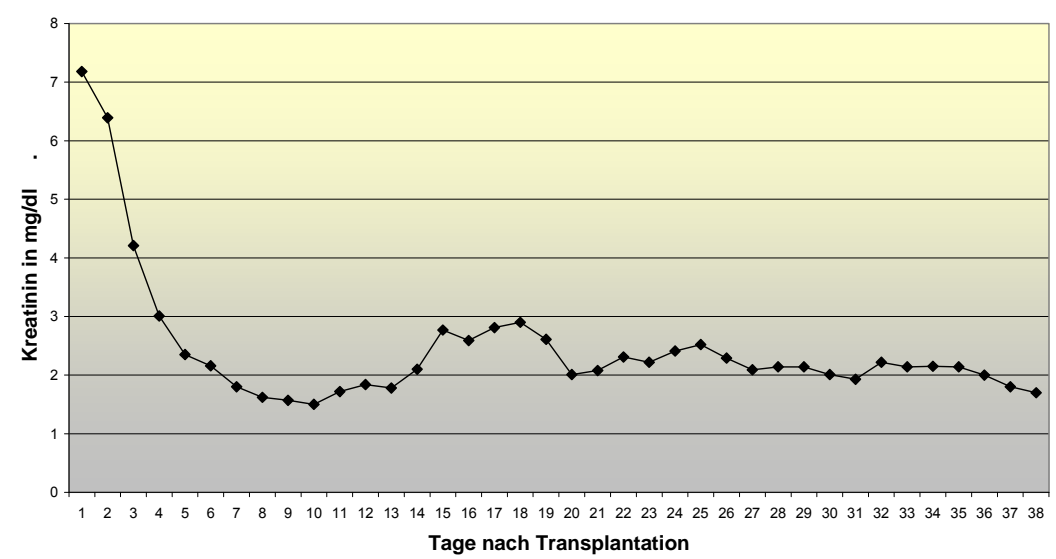

Abb. 3.1: Es wird der Kreatininverlauf im Serum bei einer stabilen Transplantatfunktion dargestellt. Die Werte bewegen sich bis auf die ersten postoperativen Tage durchweg in einem stabilen, niedrignormalen Niveau. 
Abb. 3.2: Exemplarischer Verlauf der Plasmawerte von SCD14 bei einer stabilen Transplantatfunktion:

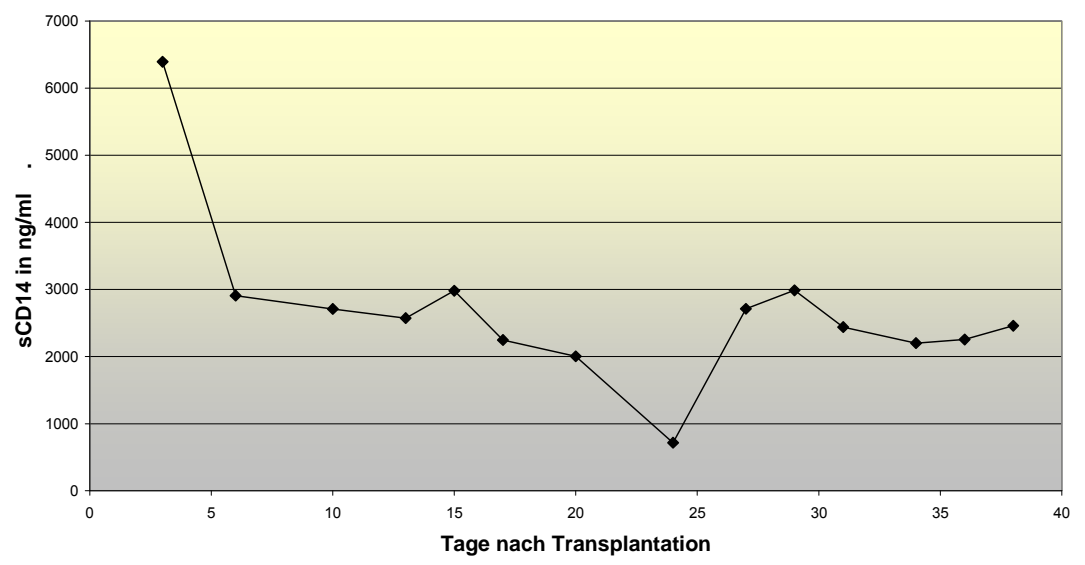

Abb. 3.2: Dargestellt ist der lösliche CD14-Rezeptor im Plasma bei einer stabilen Transplantatfunktion. Die Werte erreichen postoperativ schnell ein niedriges, konstantes Niveau.

Ab. 3.3: Exemplarischer Verlauf der Plasmawerte von sIL2R bei einer stabilen Transplantatfunktion:

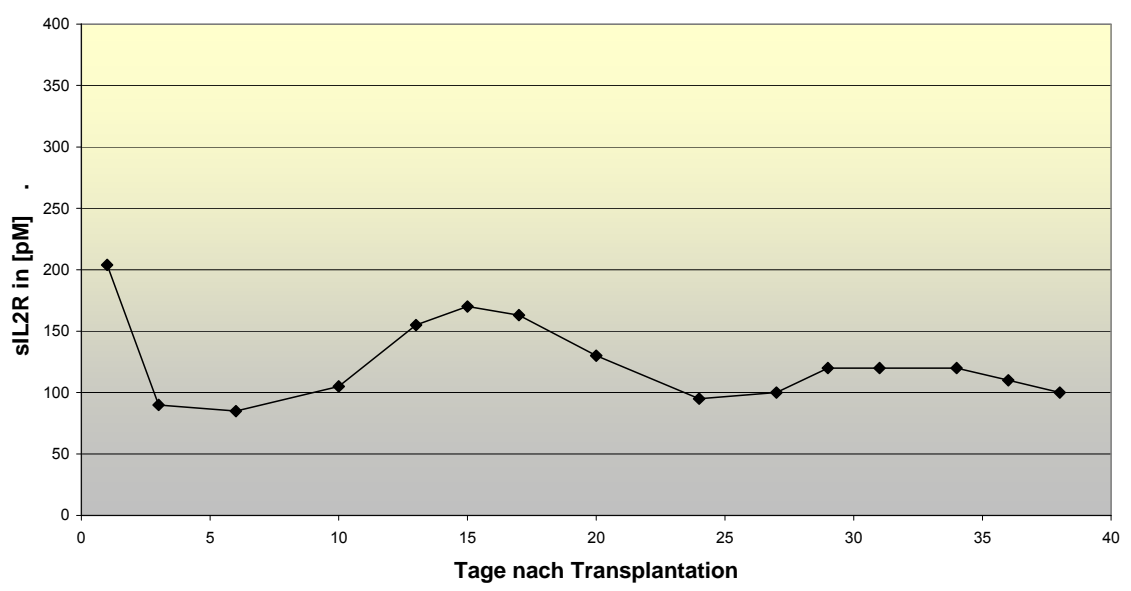

Abb. 3.3: Dargestellt ist der zeitliche Verlauf des sIL2R im Plasma bei einer stabilen Transplantatfunktion, welcher in einem engen, niedrignormalen Korridor unduliert. 
Abb. 3.4: Exemplarischer Verlauf der Plasmawerte von sCD4 bei einer stabilen Transplantatfunktion

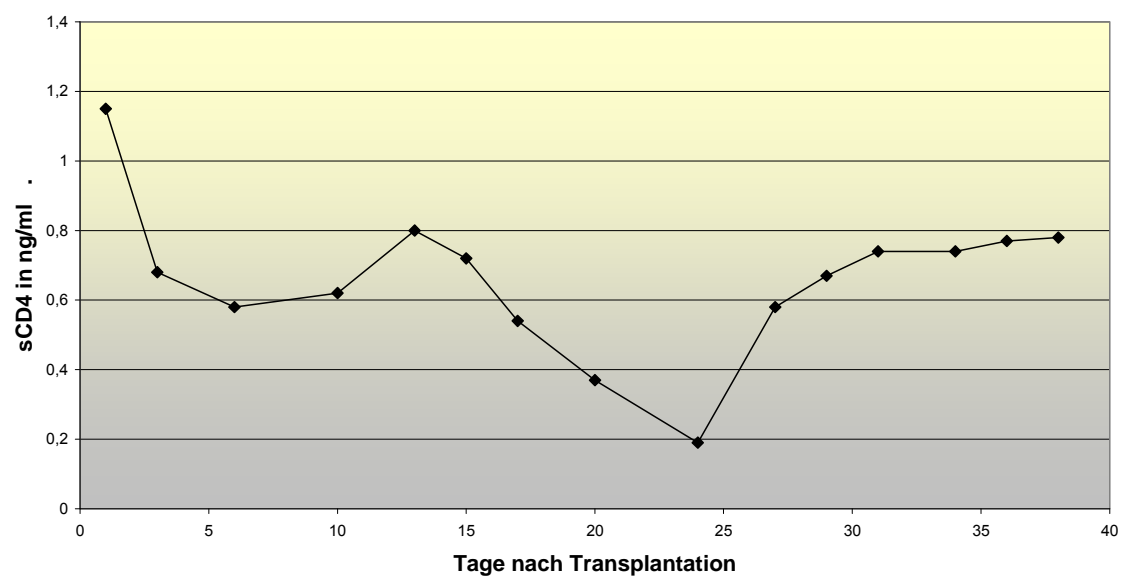

Abb. 3.4: Dargestellt ist hier der Verlauf der plasmatischen CD4-Konzentration bei einer stabilen Transplantatfuntkion. Die erhobenen Werte sind in einem niedrignormalen Bereich angesiedelt.

Abb. 3.5: Exemplarischer Verlauf der Plasmawerte von SCD8 bei einer stabilen Transplantatfunktion:

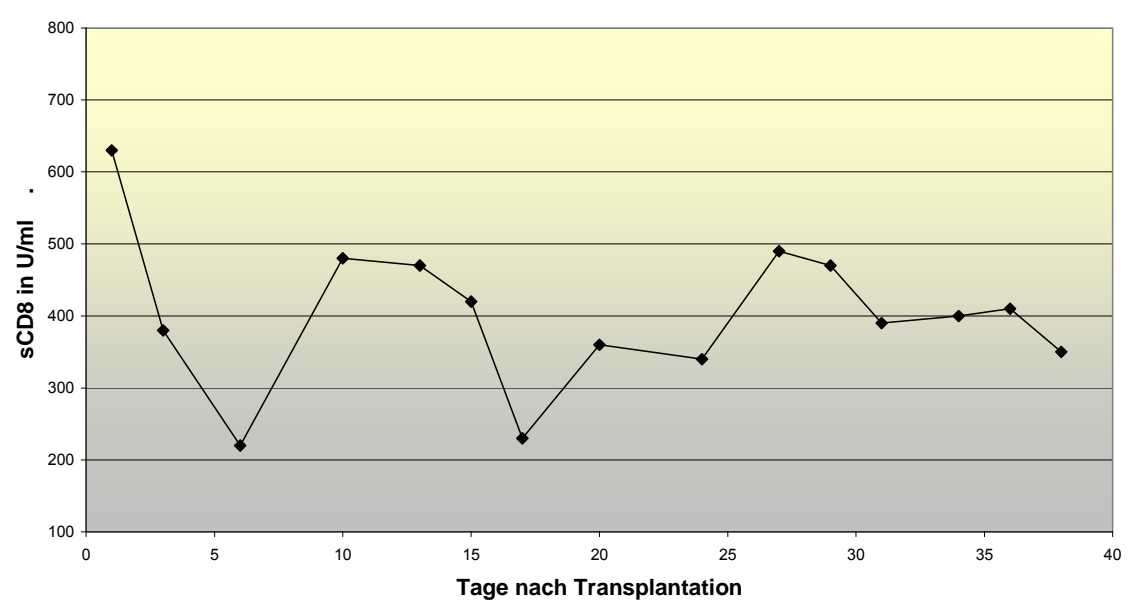

Abb. 3.5: Die chronologisch aufgetragenen Plasmakonzentrationen des löslichen CD8 zeigen bei der stabilen Transplantatfunktion einen Bereich innerhalb nahezu normaler Parameter. 


\subsubsection{Abstoßungsreaktion}

Die Abbildungen 3.6 bis 3.10 stellen den Verlauf eines 61-jährigen Patienten mit zunächst posttransplantär stabiler Nierenfunktion dar. Ab dem 18. Tag kam es zu einem progredienten Kreatininanstieg sowie nachfolgendem Fieber von $39,0^{\circ} \mathrm{C}$, so dass am 20. Tag eine Nierenbiopsie durchgeführt wurde. Es zeigte sich histologisch eine mittelgradige, floride interstitielle Abstoßungsreaktion. Es wurde unmittelbar eine Kortisonstoßtherapie mit je 500 mg Prednisolon in $250 \mathrm{ml}$ Glucose 5\% intravenös über drei Tage durchgeführt. Nach weiteren 10 Tagen fiel das Kreatinin auf Werte um $1,3 \mathrm{mg} / \mathrm{dl}$ ab und blieb im weiteren Verlauf stabil. Die weiteren Zytokine zeigten einen ebenfalls deutlichen Anstieg im Rahmen dieser Abstoßungsreaktion, bewegten sich nach suffizienter Therapie dann wieder in einen Bereich zurück, der dem einer stabilen Transplantatfunktion entspricht.

Abb. 3.6: Exemplarischer Verlauf der Serumwerte von Kreatinin bei einer Abstoßungsreaktion:

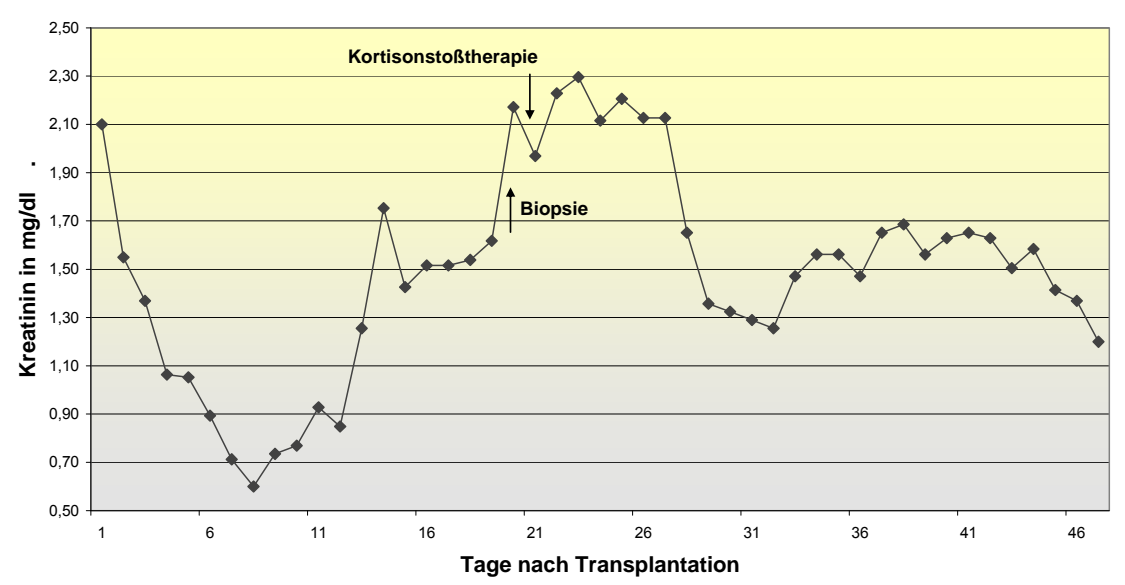

Abb. 3.6: Die Serumkonzentrationen des Kreatinin zeigen bei diesem Patienten einen Anstieg bis zur Diagnose einer akuten Abstoßungsreaktion und sinken nach erfolgreicher Behandlung mit einer Kortisonstoßtherapie wieder auf ein niedrignormales Ausgangsniveau zurück. 
Abb. 3.7: Exemplarischer Verlauf der Plasmawerte von SCD14 bei einer Abstoßungsreaktion:

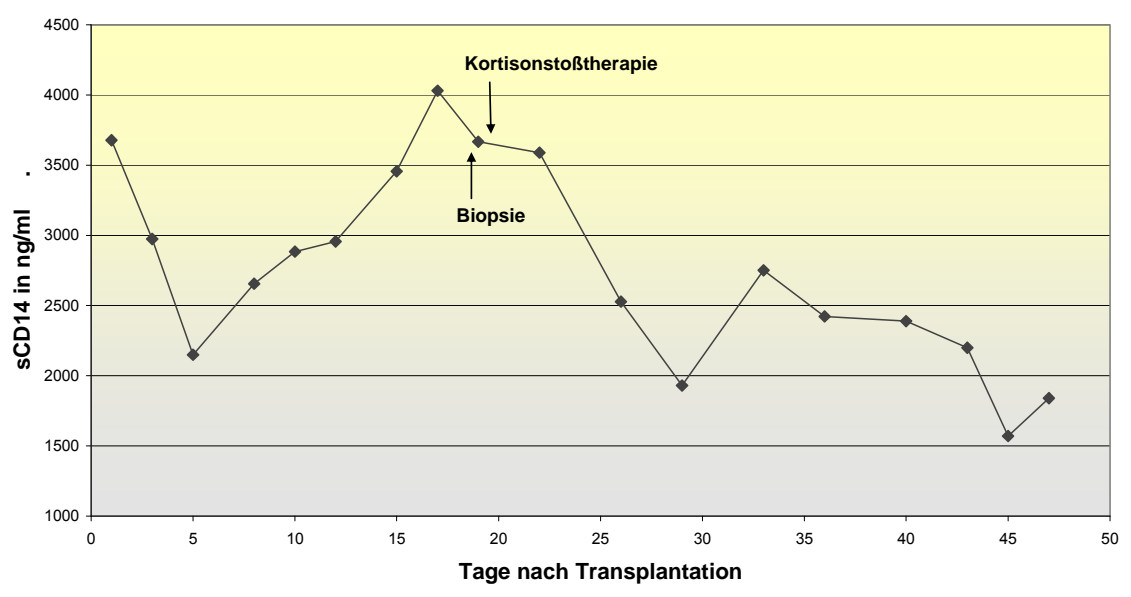

Abb. 3.7: Der Anstieg der Plasmakonzentration des SCD14 ist bis zur Diagnose einer akuten Abstoßungsreaktion retrospektiv verfolgbar. Die sCD14 Konzentration sinkt nach erfolgreicher Behandlung wieder auf das Niveau einer stabilen Transplantatfunktion.

Abb. 3.8: Exemplarischer Verlauf der Plasmawerte von sIL2R bei einer Abstoßungsreaktion

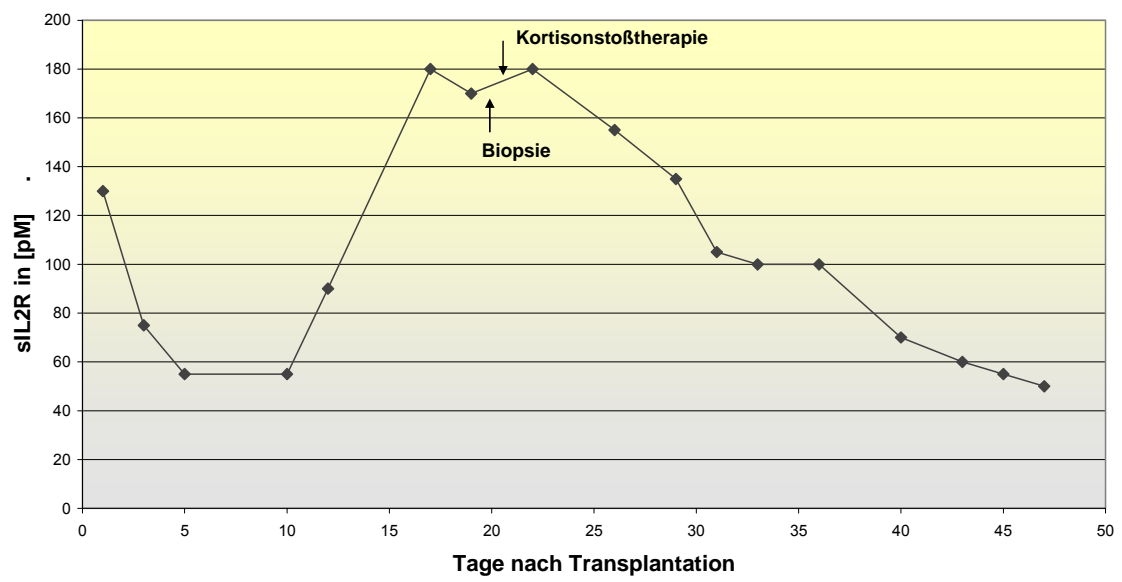

Abb. 3.8: Vor der akuten Abstoßungsreaktion zeigt sich ein deutlicher Anstieg des sIL2R im Plasma. Dieser lösliche Rezeptor erreicht nach der erfolgreichen Behandlung wieder ein Konzentrationsniveau wie bei einer stabilen Transplantatfunktion. 
Abb. 3.9: Exemplarischer Verlauf der Plasmawerte von SCD4 bei einer Abstoßungsreaktion:

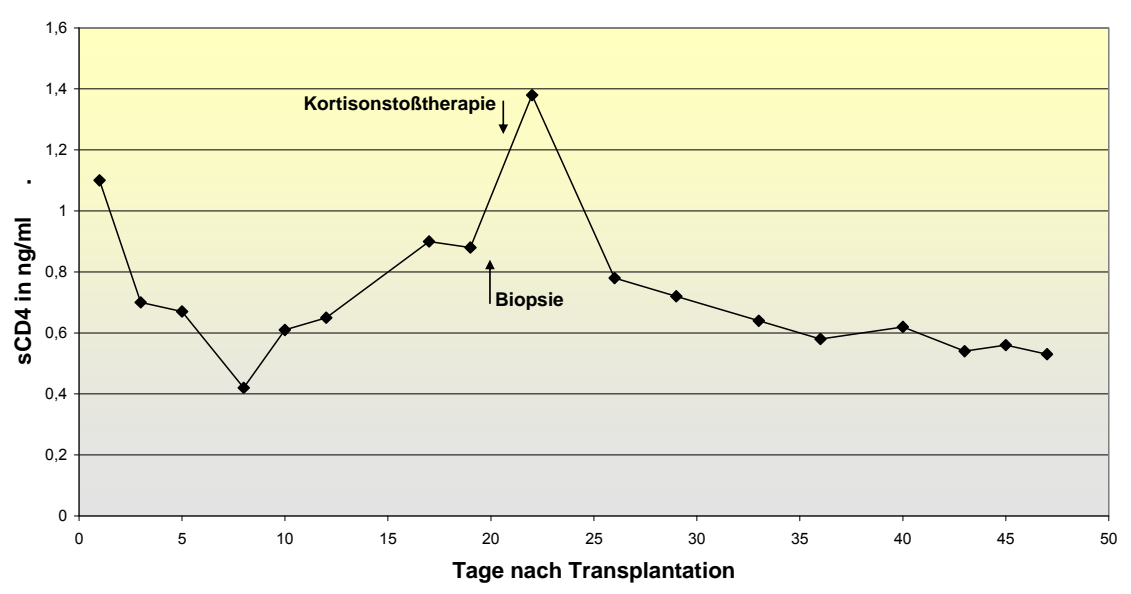

Abb. 3.9: Der lösliche CD4-Rezeptor zeigt einen deutlichen Anstieg der Plasmakonzentration im Rahmen einer akuten Abstoßungsreaktion. Nach Behandlung finden sich wieder Plasmakonzentrationen wie bei einer stabilen Transplantatfunktion.

Abb. 3.10: Exemplarischer Verlauf der Plasmawerte von SCD8 bei einer Abstoßungsreaktion:

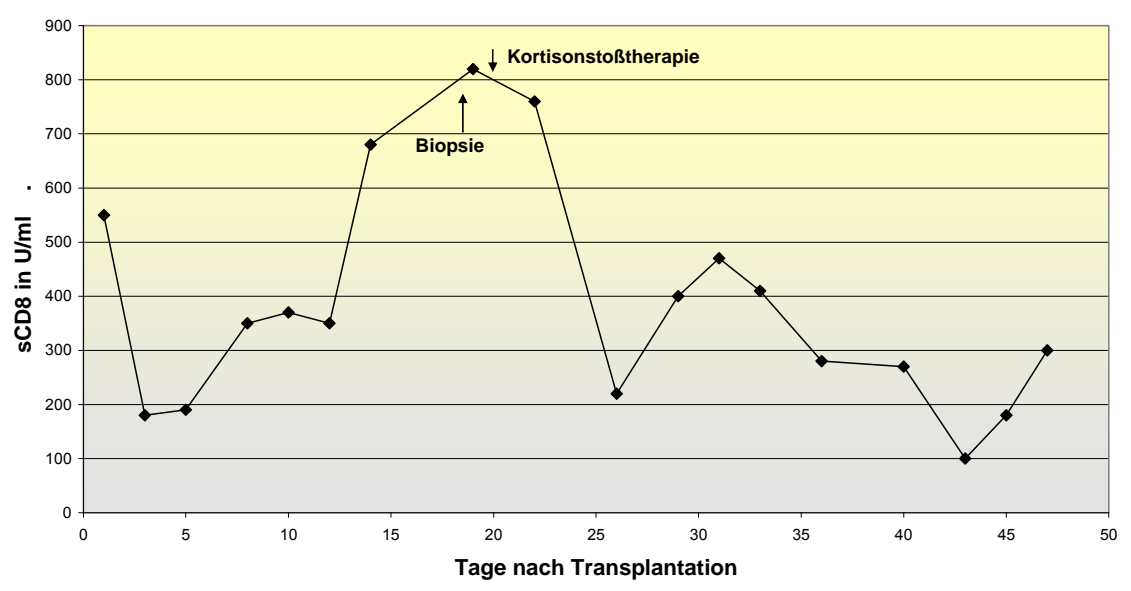

Abb. 3.10: In retrospektiver Sicht zeigt sich ein deutlicher Anstieg der Plasmakonzentration des löslichen CD8 vor einer akuten Abstoßungsreaktion. Nach erfolgreicher Behandlung sinkt diese Plasmakonzentration des löslichen CD8 wieder auf ein niedrignormales Niveau ab. 


\subsubsection{Infektion}

Die nachfolgenden Kurvenverläufe stammen von einem 53-jährigen Patienten, der zunächst posttransplantär eine stabile Transplantatfunktion aufwies und im weiteren Verlauf am 32./33. Tag septische Temperaturen bis $41^{\circ} \mathrm{C}$ und Schüttelfrost entwickelte. Diagnostisch fand sich in gewonnenen Blutkulturen eine Infektion durch Acinetobacter baumanii, am ehesten im Sinne einer Kathetersepsis. Nach Katheterwechsel und intravenöser Antibiotikatherapie mit Ofloxacin entfieberte der Patient rasch und war in der Folgezeit beschwerdefrei. Das Serumkreatinin zeigt sich hier im Normbereich, die Transplantatfunktion ist von der Infektion nicht bedeutend beeinträchtigt. Die gemessenen Zytokine hingegen reagieren im Sinne einer deutlichen Aktivierung des Immunsystems.

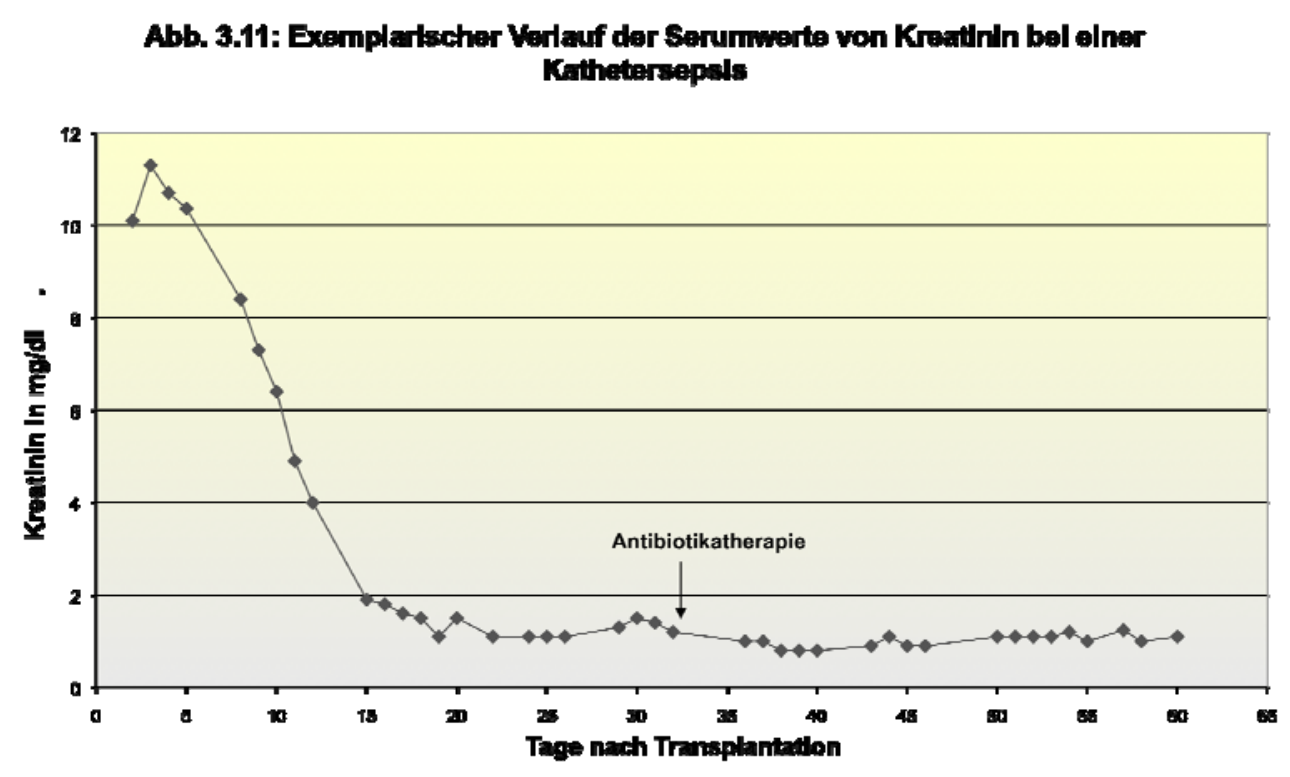

Abb. 3.11: Trotz eines zwischenzeitlich durchgemachten Infektes um den 30. Tag posttransplantär bleiben die Kreatininwerte auf einem niedrignormalen Niveau, da es keine Beteiligung des Organs während dieser Infektion gab. 


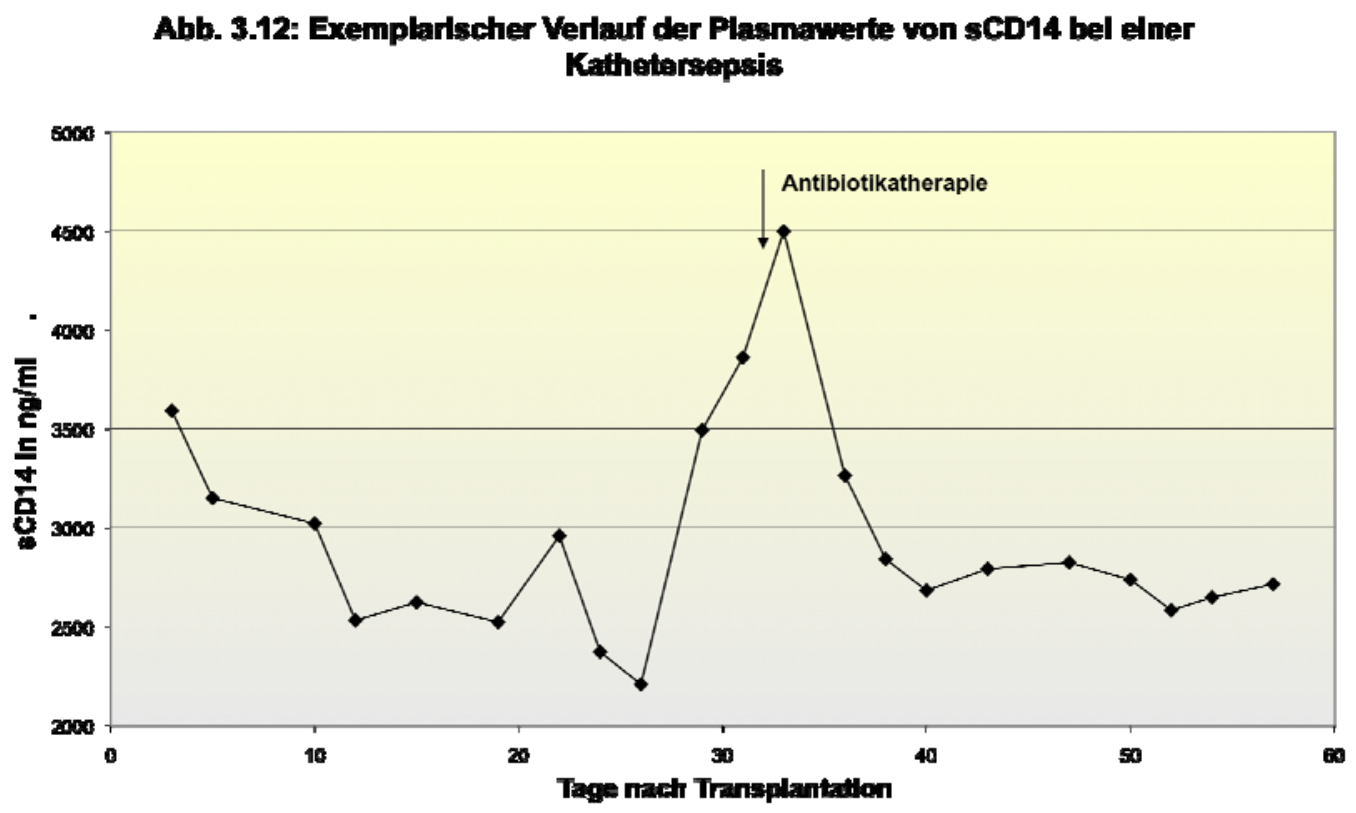

Abb. 3.12: Der steile Anstieg im Rahmen einer akuten Infektion (Kathetersepsis) beginnt beim löslichen CD14 im Plasma einige Tage vor der klinischen Diagnose. Nach erfolgreicher Therapie fallen die Werte zurück in den Ausgangsbereich.

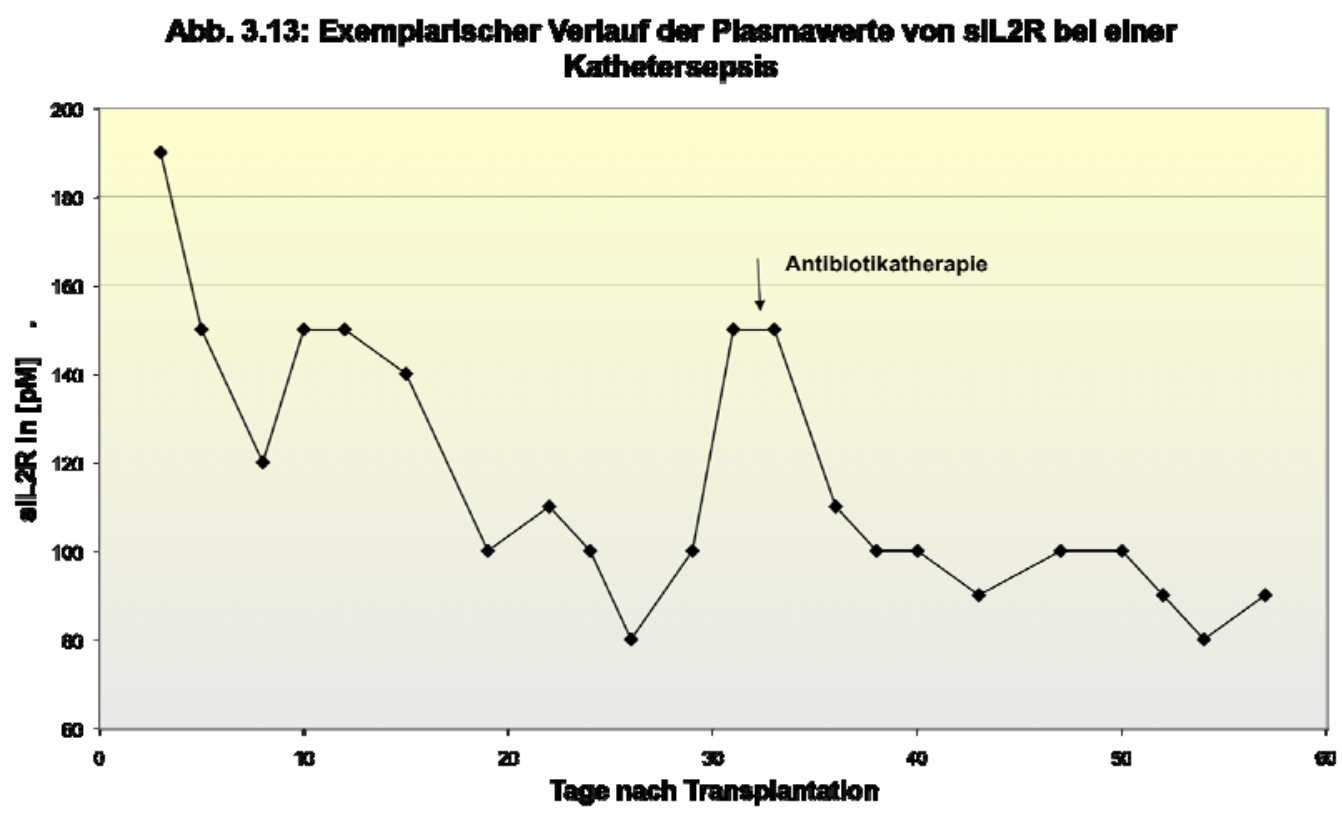

Abb. 3.13: Die Abbildung zeigt die hohe Plasmakonzentration des löslichen IL2R während einer akuten Infektion und den Rückgang in den Ausgangsbereich nach erfolgreicher Infektsanierung. 


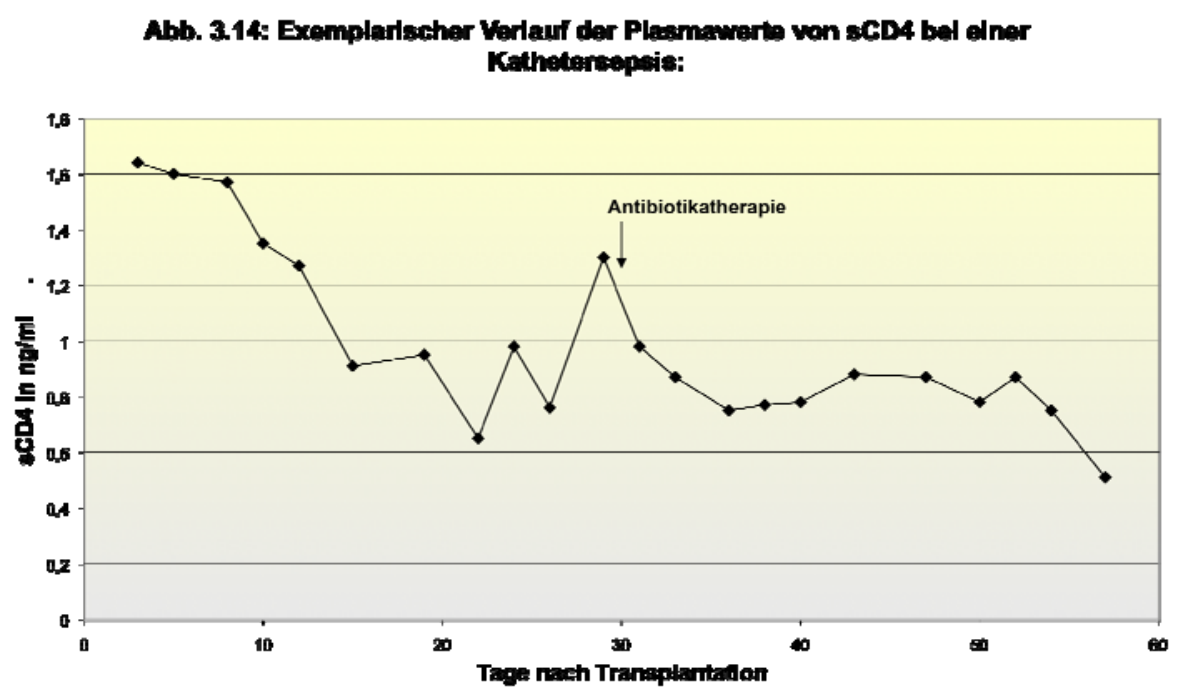

Abb. 3.14: nach der antibiotischen Behandlung der akuten Infektion fallen die Plasmakonzentrationen des löslichen CD4 langsam in den Bereich der ursprünglichen Konzentration zurück.

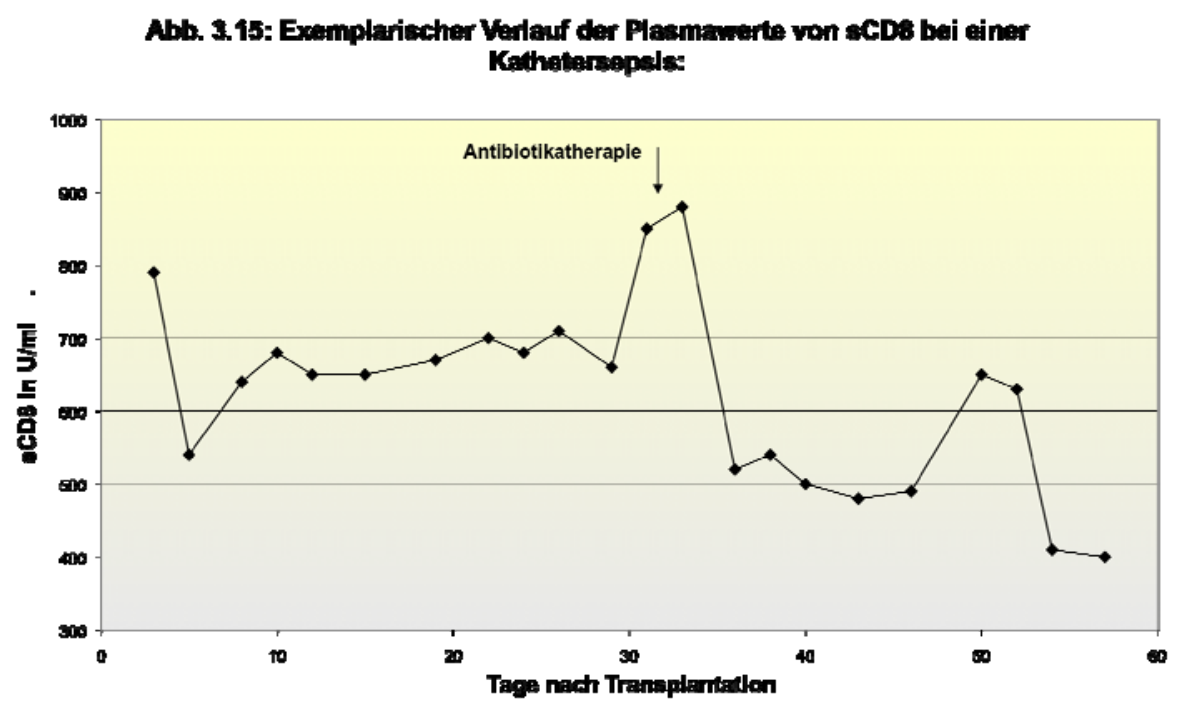

Abb. 3.15: Der lösliche CD8-Rezeptor erreicht sein höchstes Niveau bei Diagnose der akuten Infektion und fällt nach der erfolgreichen Behandlung auf ein niedriges, dem einer stabilen Transplantatfunktion entsprechendes Niveau zurück.

\subsubsection{Nierenfunktion:}

Die in den exemplarischen Verläufen höheren Spiegel von Kreatinin und löslichen Rezeptoren gerade zu Beginn nach Transplantation lassen vermuten, dass die Nierenfunktion die Rezeptorplasmaspiegel beinflusst. 


\subsection{Varianzanalyse des Kreatinin im Serum}

Um im weiteren die Bedeutung der Nierenfunktion und ihren möglichen Einfluss auf die Plasma- bzw. Urinkonzentrationen der untersuchten Zytokine genauer eingrenzen oder beschreiben zu können wurden die Kreatininwerte im Serum in den einzelnen Gruppen miteinander verglichen und graphisch dargestellt.

Tab. 3.1: Kreatinin Serumwerte im Gruppenvergleich:

\begin{tabular}{|l|c|c|c|}
\hline Werte in mg/dl & Gruppe Infekte & Gruppe Tx stabil & Gruppe Abstoßung \\
\hline $\mathrm{n}:$ & 13 & 10 & 19 \\
\hline Mittelwert: & 3,37 & 1,22 & 6,65 \\
\hline Median: & 2,18 & 1,23 & 3,71 \\
\hline Standard-Abweichung: & 1,68 & 0,21 & 3,66 \\
\hline Quantile: & & & 11,6 \\
\hline \multicolumn{1}{|c|}{$95 \%$} & 9,85 & 1,59 & 2,23 \\
\hline & 1,13 & 0,89 & 2,18 \\
\hline Minimum: & 1,02 & 0,8 & 13,2 \\
\hline Maximum: & 10,5 & 1,67 & \\
\hline
\end{tabular}

Anschließend wurden die verschiedenen Gruppen nach dem exakten, zweiseitigen Wilcoxon-Mann-Whitney-Test auf ihre Irrtumswahrscheinlichkeit (Signifikanz angenommen für $p<0,05$ ) hin geprüft:

Tab 3.2: Irrtumswahrscheinlichkeit des Serumkreatinin im Gruppenvergleich:

\begin{tabular}{|l|c|}
\hline Tx stabil vs. Abstoßung & $\mathbf{p}=\mathbf{0}$ (Gruppen disjunkt) \\
\hline Tx stabil vs. Infektion & $\mathbf{p}=\mathbf{0 , 0 0 2}$ \\
\hline Infekte vs. Abstoßung & $\mathbf{p}=\mathbf{0 , 0 0 4}$ \\
\hline
\end{tabular}

Die jeweiligen Gruppen zeigen untereinander eine Irrtumswahrscheinlichkeit von $<0,05$, wobei sich die Gruppen „stabile Transplantatfunktion“ und „Abstoßung“ disjunkt zueinander verhalten, sich also gar nicht überschneiden. 
Abb. 3.16: Kreatinin Serumwerte im Gruppenvergleich

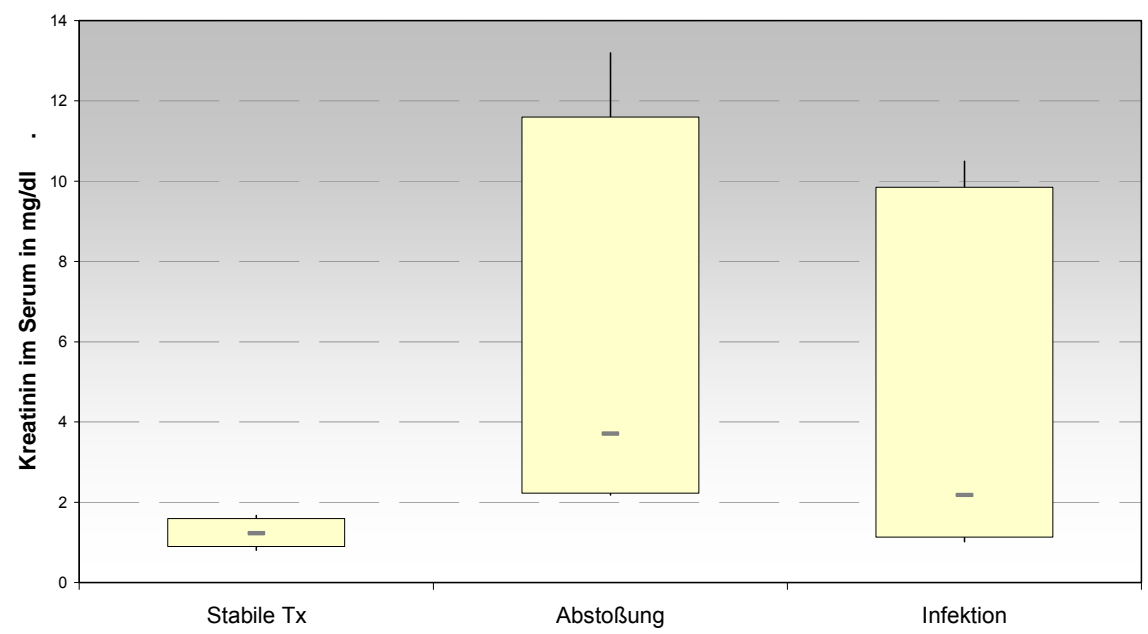

Abb. 3.16: Die Kreatininwerte der stabilen Transplantatfunktion befinden sich auf einem normalen Niveau und zeigen einen sehr engen Korridor. Hingegen sind die Werte bei akuter Abstoßung und Infektion im Mittel wesentlich höher und auch deutlich weiter gestreut.

\subsection{Verhältnis von glomerulärer Filtrationsrate (GFR) und Serumkreatinin}

Zur Beschreibung der Transplantatfunktion wurde die glomeruläre Filtrationsrate (GFR) aus der so genannten Kreatinin-Clearance per 24-h-Sammelurin ermittelt und mit dem entsprechenden Serumkreatinin korreliert. Eine signifikante Korrelation lässt es zu, den Kreatininwert aus dem Serum als Parameter zur Beschreibung der Transplantatfunktion zu benutzen.

Abb. 3.17: Korrelation von GFR und Serumkreatinin

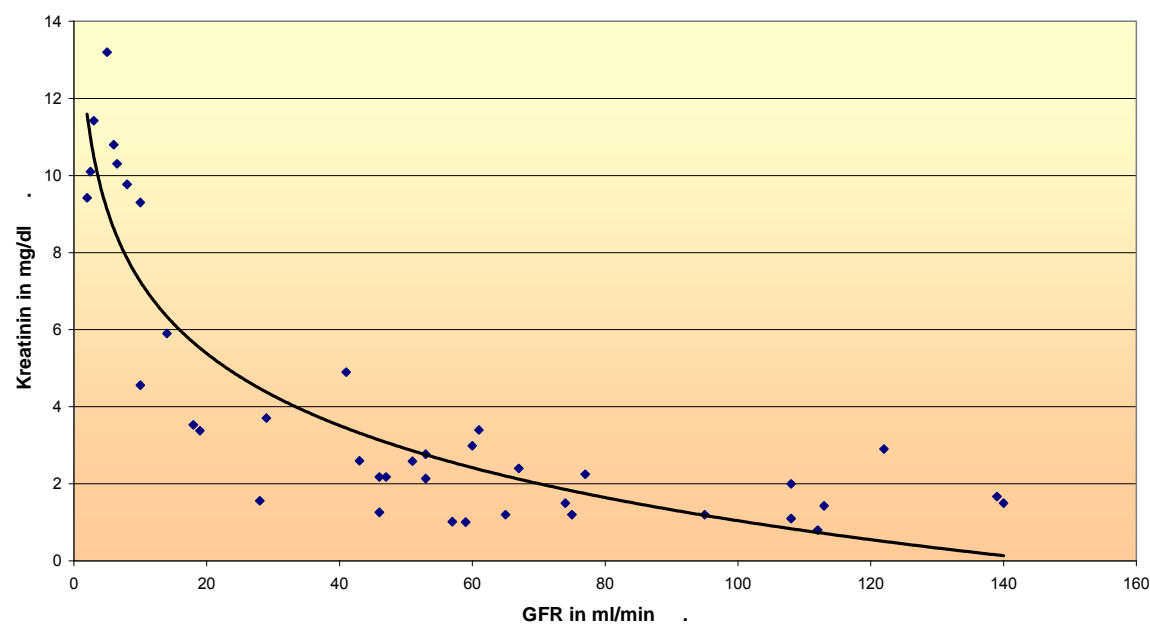

Abb. 3.17: Die Korrelation von GFR (glomerulärer Filtrationsrate) und Kreatinin im Plasma ist mit einem Korrelationskoeffizient von $r=-0,87$ (Regression mit Exponentialfunktion) signifikant. 


\subsection{Löslicher Zellrezeptor CD14 (sCD14)}

Bei 42 Patienten wurde der lösliche Zellrezeptor CD14 (sCD14) im posttransplantären Verlauf in regelmäßigen Abständen aus Plasmaproben bestimmt und ausgewertet. Die Tabellen 3.3 und 3.4 stellen die Ergebnisse dieser Gruppen separat und im Vergleich dar.

Tab. 3.3: Lösliche CD14-Plasmawerte im Gruppenvergleich:

\begin{tabular}{|l|c|c|c|}
\hline Werte in ng/ml & Gruppe Infekte & Gruppe Tx stabil & Gruppe Abstoßung \\
\hline n: & 13 & 10 & 19 \\
\hline Mittelwert: & 3847 & 2260 & 3114 \\
\hline Median: & 4096 & 2183 & 2980 \\
\hline Standard-Abweichung: & 685 & 328 & 674 \\
\hline Quantile: & & & 4416 \\
\hline \multicolumn{1}{|c|}{$5 \% \%$} & 4842 & 2762 & 2240 \\
\hline & 3058 & 1849 & 2113 \\
\hline Minimum: & 2987 & 1840 & 4434 \\
\hline Maximum: & 5359 & 2806 & \\
\hline
\end{tabular}

Anschließend wurden die verschiedenen Gruppen nach dem exakten, zweiseitigen Wilcoxon-Mann-Whitney-Test auf ihre Irrtumswahrscheinlichkeit (Signifikanz angenommen für $p<0,05)$ hin geprüft:

Tab 3.4: Irrtumswahrscheinlichkeit des sCD14 im Gruppenvergleich:

\begin{tabular}{|l|c|}
\hline Tx stabil vs. Abstoßung & $\mathbf{p}=\mathbf{0 , 0 0 3 8}$ \\
\hline Tx stabil vs. Infektion & $\mathbf{p}=\mathbf{0}$ (Gruppen disjunkt) \\
\hline Infekte vs. Abstoßung & $\mathbf{p}=\mathbf{0 , 0 0 4 6}$ \\
\hline
\end{tabular}

Die jeweiligen Gruppen zeigen untereinander eine Irrtumswahrscheinlichkeit von $<0,05$, wobei sich die Ergebnisse der Gruppen „stabile Transplantatfunktion“ und „Infektion“ disjunkt zueinander verhalten und sich gar nicht überschneiden. 


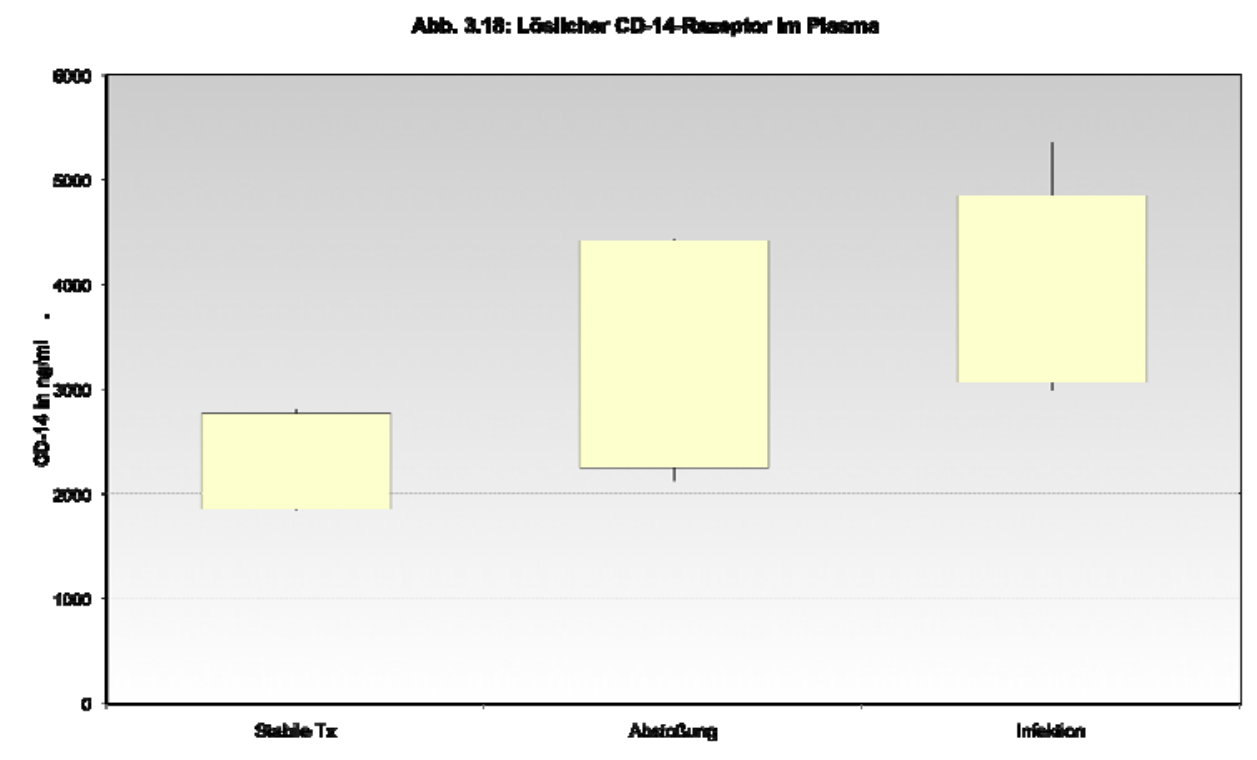

Abb. 3.18: Die Plasmakonzentrationen des löslichen CD14 zeigen sich in der Gruppe der stabilen Transplantatfunktion am niedrigsten, überschneiden sich mit denen bei Infektion gar nicht. In den Komplikationsformen sind die Werte erhöht, aber gegenüber der stabilen Funktion auch weiter gestreut.

Es erfolgte die Berechnung von Spezifität und Sensitivität unter Angabe des Trennwertes sowie die Darstellung als ROC-Kurven:

Abb. 3.19: Löslicher CD14 im Plasma: Tx stabil vs. Abstoßung:

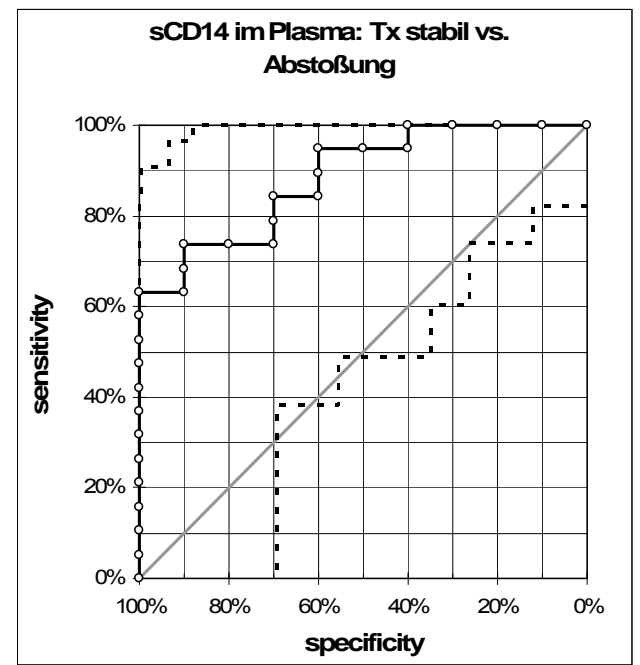


Abb. 3.19: In der ROC-Kurven-Analyse läßt sich die stabile Transplantatfunktion von der Abstoßungsreaktion bei einem angenommenen Cut-Off-Wert von $2435 \mathrm{ng} / \mathrm{ml}$ mit einer Sensitivität von $84 \%$ und einer Spezifität von $70 \%$ abgrenzen.

Abb. 3.20: Löslicher CD14 im Plasma: Tx stabil vs. Infektion:

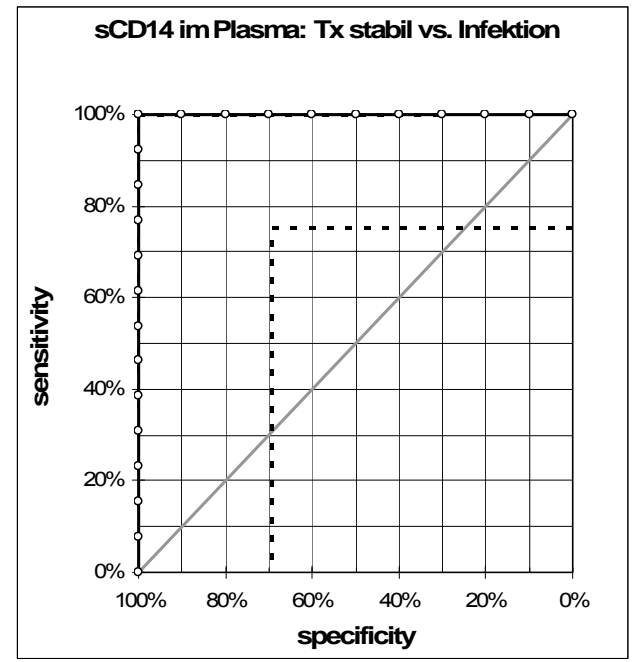

Abb. 3.20: In der ROC-Kurven-Analyse läßt sich die stabile Transplantatfunktion von der Infektion bei einem angenommenen Cut-Off-Wert von $2987 \mathrm{ng} / \mathrm{ml}$ mit einer Sensitivität von 100\% und einer Spezifität von 100\% abgrenzen. Die Trennschärfe mit einer AUC von 1,0 ist maximal.

\section{Abb. 3.21: Löslicher CD14 im Plasma: Infektion vs. Abstoßung:}

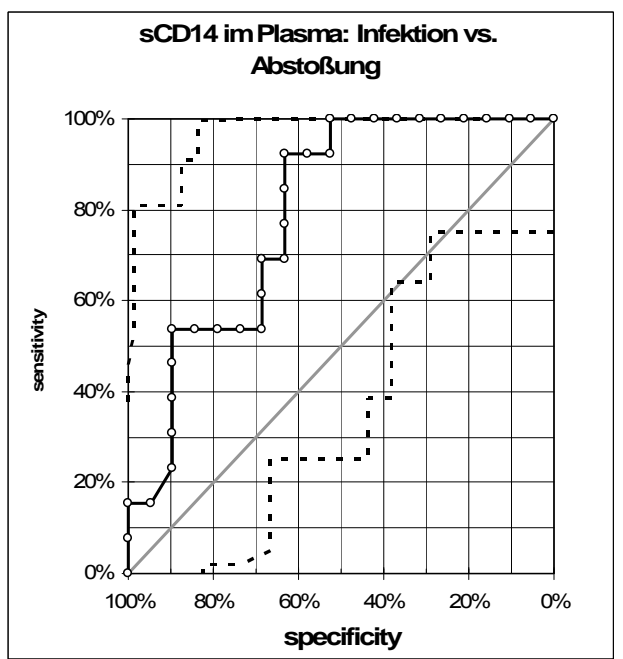

Abb. 3.21: In der ROC-Kurven-Analyse läßt sich die Infektion von der Abstoßungsreaktion bei einem angenommenen Cut-Off-Wert von $3105 \mathrm{ng} / \mathrm{ml}$ mit einer Sensitivität von 92\% und einer Spezifität von $63 \%$ abgrenzen $(A \cup C=0,79)$. 
Abb. 3.22: Löslicher CD14 im Plasma: Infektion vs. Abstoßung und Tx stabil:

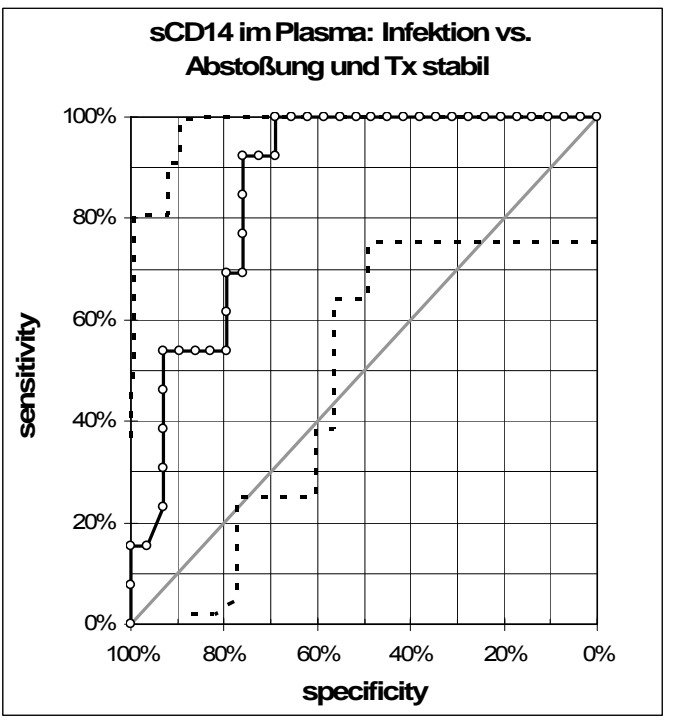

Abb. 3.22: In der ROC-Kurven-Analyse läßt sich die Infektion von der Abstoßungsreaktion sowie der stabilen Transplantatfunktion bei einem angenommenen Cut-Off-Wert von $2987 \mathrm{ng} / \mathrm{ml}$ mit einer Sensitivität von 100\% und einer Spezifität von 69\% abgrenzen (AUC = 0,86).

Abb. 3.23: Löslicher CD14 im Plasma: Abstoßung vs. Infektion und Tx stabil:

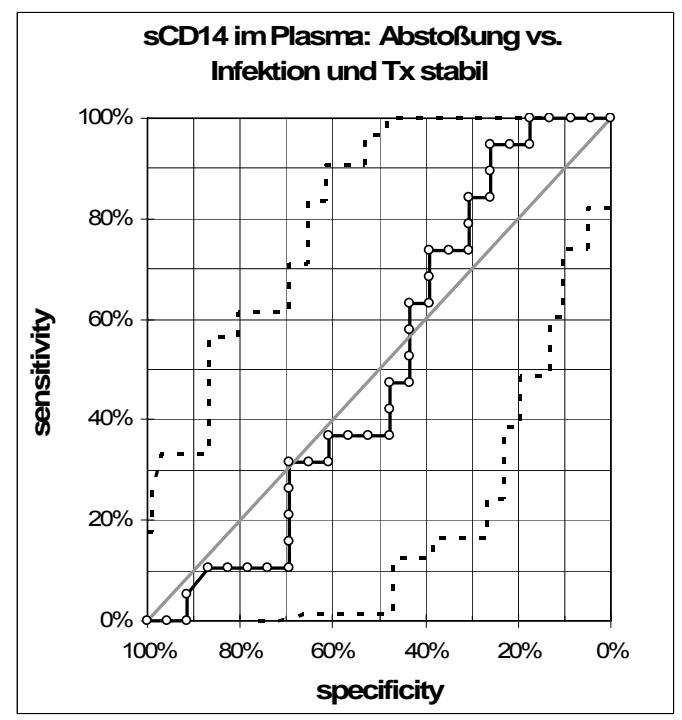

Abb. 3.23: In der ROC-Kurven-Analyse läßt sich die Abstoßungsreaktion von der Infektion sowie der stabilen Transplantatfunktion bei einem angenommenen Cut-Off-Wert von $2254 \mathrm{ng} / \mathrm{ml}$ mit einer Sensitivität von $95 \%$ und einer Spezifität von $26 \%$ abgrenzen $(A \cup C=0,5)$. 
Abb. 3.24: Löslicher CD14 im Plasma: Tx stabil vs. Abstoßung und Infektion:

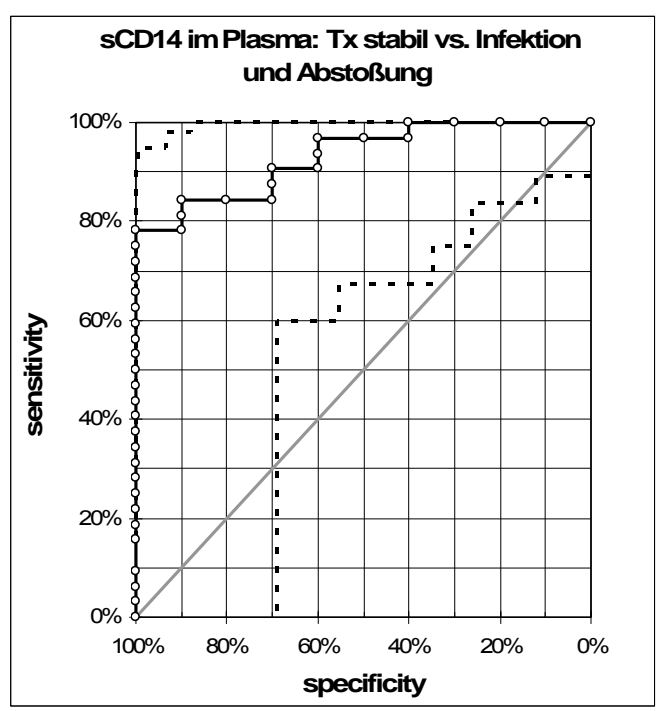

Abb. 3.24: In der ROC-Kurven-Analyse läßt sich die stabile Transplantatfunktion von der Infektion sowie der Abstoßungsreaktion bei einem angenommenen Cut-Off-Wert von $2879 \mathrm{ng} / \mathrm{ml}$ mit einer Sensitivität von 78\% und einer Spezifität von 100\% abgrenzen $(A \cup C=0,93)$.

Fazit: Die sCD14-Plasmawerte sind bei Abstoßung und Infektion gegenüber der stabilen Transplantatfunktion signifikant erhöht und zeigen in der ROC-Analyse mit AUC $=0,93$ einen hohen Grad an Trennschärfe. Sie erlauben aber untereinander keine genügende Abgrenzung, da bei den vorliegenden Werten eine große Streubreite vorliegt. Trotz eines $p=0,0046$ ist die Spezifität und Sensitivität in der ROC-Analyse zwischen Infektions- und Abstoßungsgruppe nicht überzeugend (AUC $=0,79)$ 


\subsection{Zeitlicher Verlauf des Iöslichen CD14 vor Komplikation}

Bei genauer retrospektiver Betrachtung der zeitlichen Verläufe des löslichen CD14 fiel auf, dass die Werte im Plasma bereits einige Tage vor dem klinisch apparent werdenden Komplikationsereignis gegenüber denen bei einer stabilen Transplantatfunktion deutlich erhöht waren. Hier sind die Medianwerte bei Abstoßungsreaktion und Infektion zusammen mit denen einer stabilen Transplantatfunktion im zeitlichen Verlauf aufgeführt.

Abb. 3.25: Löslicher CD14: Medianwerte im Verlauf vor klinischer Diagnosestellung

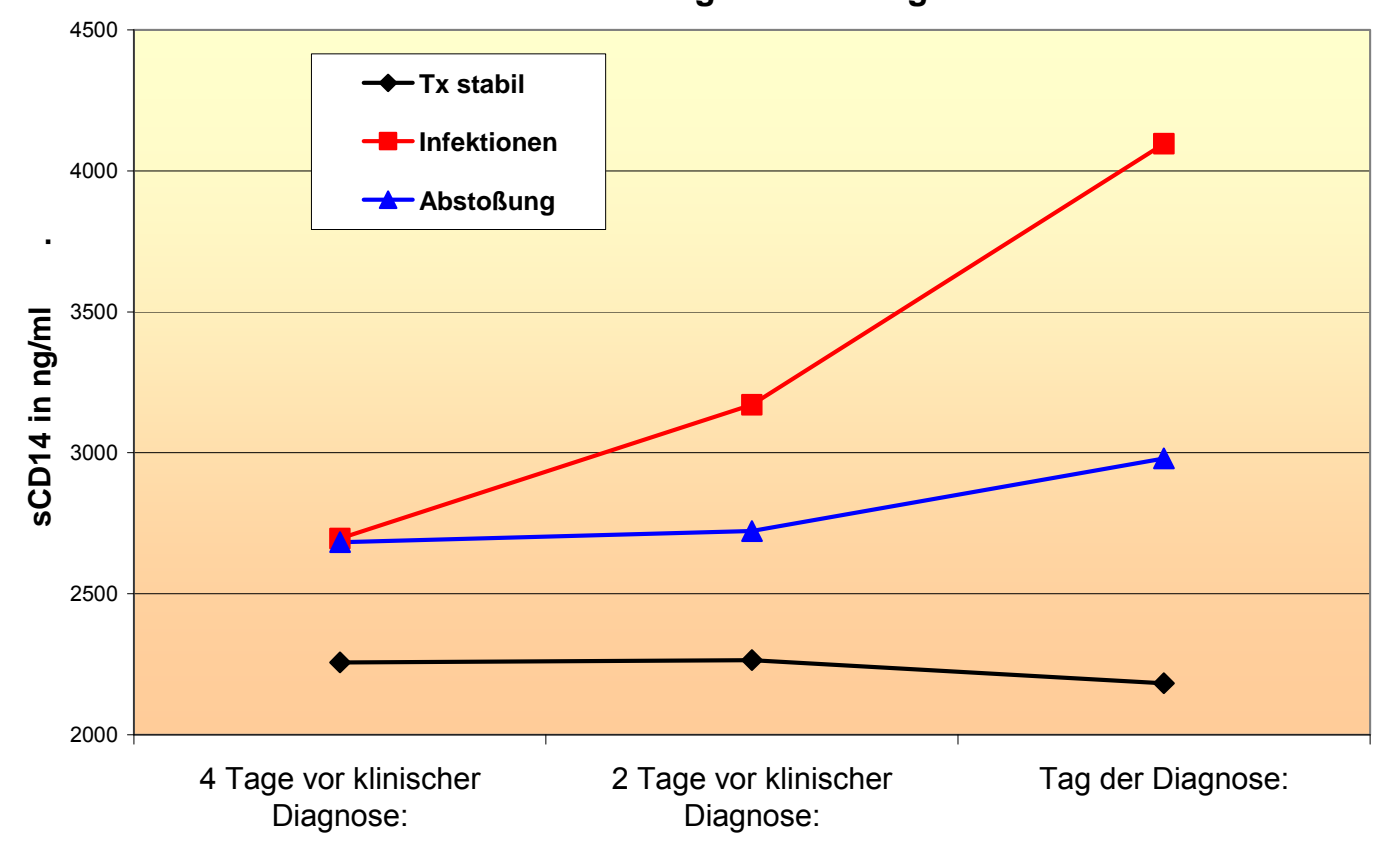

Abb. 3.25: Es ist der zeitliche Verlauf der Plasmakonzentrationen des löslichen CD14 aufgetragen. Bereits zwei Tage vor der retrospektiv gestellten Diagnose unterscheiden sich die Niveaus der Komplikationsformen „Abstoßung“ und „Infektion“ von dem der stabilen Transplantatfunktion deutlich. 
Tab. 3.5: sCD14 zwei Tage vor gesicherter Diagnose im Gruppenvergleich:

\begin{tabular}{|l|c|c|c|}
\hline Werte in ng/ml & Gruppe Infekte & Gruppe Tx stabil & Gruppe Abstoßung \\
\hline n: & 11 & 8 & 13 \\
\hline Mittelwert: & 3254 & 2338 & 2942 \\
\hline Median: & 3170 & 2265 & 2723 \\
\hline Standard-Abweichung: & 868 & 481 & 703 \\
\hline Quantile: & & & 3977 \\
\hline \multicolumn{1}{|c|}{$95 \%$} & 4715 & 3046 & 2051 \\
\hline Minimum: & 2196 & 1720 & 2049 \\
\hline Maximum: & 1920 & 1571 & 4135 \\
\hline
\end{tabular}

Anschließend wurden die verschiedenen Gruppen nach dem exakten, zweiseitigen Wilcoxon-Mann-Whitney-Test auf ihre Irrtumswahrscheinlichkeit (Signifikanz angenommen für $p<0,05)$ hin geprüft:

Tab 3.6: Irrtumswahrscheinlichkeit des SCD14 im Gruppenvergleich:

\begin{tabular}{|l|c|}
\hline Tx stabil vs. Abstoßung & $\mathbf{p}=\mathbf{0 , 0 6}$ \\
\hline Tx stabil vs. Infektion & $\mathbf{p}=\mathbf{0 , 0 2 7}$ \\
\hline Infekte vs. Abstoßung & $\mathbf{p}=\mathbf{0 , 4 8}$ \\
\hline
\end{tabular}


Abb. 3.26: Löslicher CD14 im Plasma zwei Tage vor Diagnosestellung

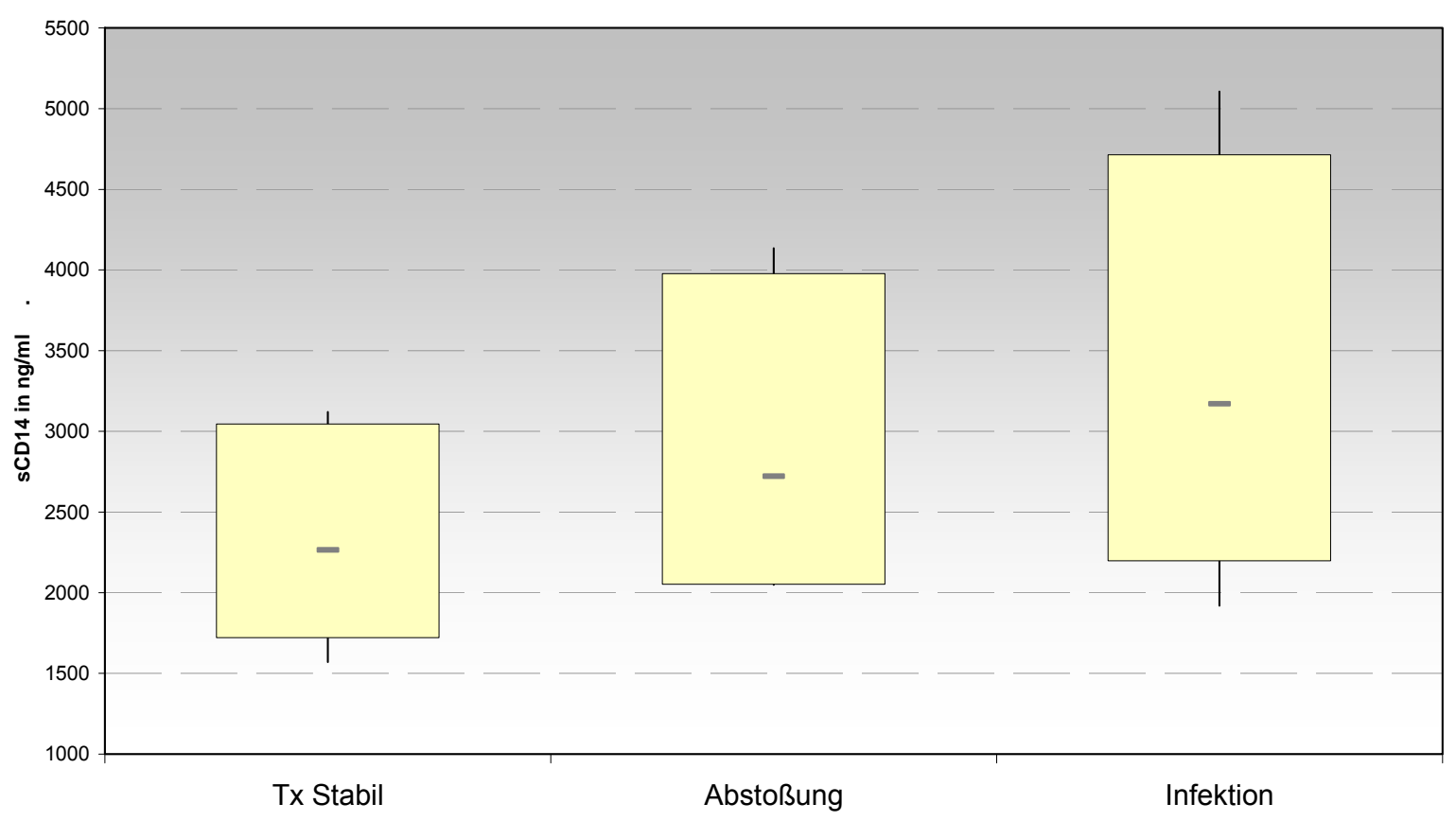

Abb. 3.26: Bereits zwei Tage vor der eigentlichen (retrospektiven) Diagnosestellung unterscheiden sich die Plasmakonzentrationen der einzelnen Transplantatzustände deutlich. Besonders zeigt sich dies zwischen einer stabilen Transplantatfunktion und einer Infektion.

Fazit: Vier Tage vor gesicherter Diagnose liegen die Plasmawerte des SCD14 in allen drei Gruppen kaum unterscheidbar zusammen. Bereits 2 Tage vor der Diagnosesicherung gibt es bereits signifikante Unterschiede zwischen stabiler Transplantatfunktion und Infektion. Nahezu signifikante Unterschiede finden sich dann auch zwischen der stabilen Transplantatfunktion gegenüber der Abstoßungsreaktion. 


\subsection{Löslicher CD14 im Urin}

Bei 32 Patienten wurde der lösliche Zellrezeptor CD14 (sCD14) im posttransplantären Verlauf in regelmäßigen Abständen aus Urinproben bestimmt und ausgewertet. Die Tabellen 3.7 und 3.8 stellen die Ergebnisse dieser Gruppen in sich und im Vergleich dar.

Tab. 3.7: Löslicher CD14 im Urin im Gruppenvergleich

\begin{tabular}{|l|c|c|c|}
\hline Werte in ng/ml & Gruppe Infekte & Gruppe Tx stabil & Gruppe Abstoßung \\
\hline n: & 11 & 8 & 13 \\
\hline Mittelwert: & 897 & 879 & 855 \\
\hline Median: & 868 & 794 & 942 \\
\hline Standard-Abweichung: & 235 & 157 & 228 \\
\hline Quantile: & & & 1180 \\
\hline \multicolumn{1}{c|}{$95 \%$} & 1227 & 1114 & 527 \\
\hline & 527 & 711 & 505 \\
\hline Minimum: & 445 & 710 & 1235 \\
\hline Maximum: & 1241 & 1150 & \\
\hline
\end{tabular}

Anschließend wurden die verschiedenen Gruppen nach dem exakten, zweiseitigen Wilcoxon-Mann-Whitney-Test auf ihre Irrtumswahrscheinlichkeit (Signifikanz angenommen für $p<0,05)$ hin geprüft:

Tab 3.8: Irrtumswahrscheinlichkeit des sCD14 im Urin im Gruppenvergleich:

\begin{tabular}{|l|c|}
\hline Tx stabil vs. Abstoßung & $\mathbf{p}=\mathbf{0 , 9 7}$ \\
\hline Tx stabil vs. Infektion & $\mathbf{p}=\mathbf{0 , 7 8}$ \\
\hline Infekte vs. Abstoßung & $\mathbf{p}=\mathbf{0 , 8 6}$ \\
\hline
\end{tabular}


Abb. 3.27: Löslicher CD14 im Urin

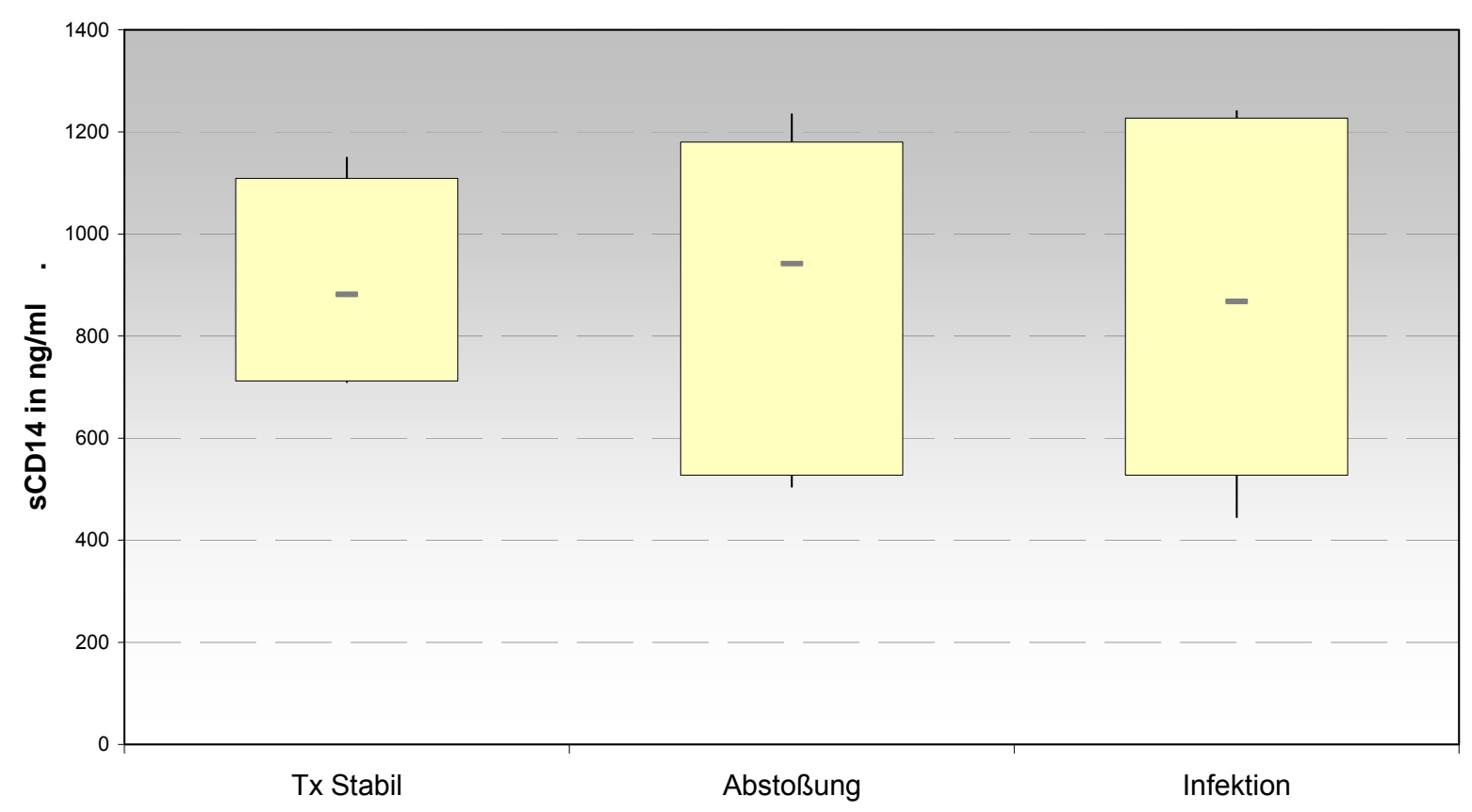

Abb. 3.27: Die Konzentrationen des löslichen CD14 im Urin sind in allen drei untersuchten Patientengruppen in einem nahezu identischen Bereich angesiedelt und lassen sich nicht signifikant voneinander unterscheiden.

Fazit: Die Konzentrationen des löslichen CD14-Rezeptors im Urin sind in den untersuchten Gruppen nahezu gleich. Eine Unterscheidung nicht möglich. 


\subsection{Quotientenbildung von SCD14 und Kreatinin}

Zur näheren Betrachtung des Einflusses der Nierenfunktion auf die Plasmakonzentration des löslichen CD14 wurde bei den untersuchten Patienten eine Quotientenbildung der Plasmawerte von sCD14 mit den Serumwerten des Kreatinin durchgeführt und in den jeweiligen Gruppen ausgewertet.

Tab. 3.9: Quotient von löslichem CD14 und Kreatinin im Gruppenvergleich:

\begin{tabular}{|l|c|c|c|}
\hline Werte in ng/ml & Gruppe Infekte & Gruppe Tx stabil & Gruppe Abstoßung \\
\hline n: & 13 & 10 & 19 \\
\hline Mittelwert: & 1733 & 1874 & 748 \\
\hline Median: & 1425 & 1832 & 730 \\
\hline Standard-Abweichung: & 903 & 538 & 478 \\
\hline Quantile: & & & 1650 \\
\hline \multicolumn{1}{|c|}{$95 \%$} & 3333 & 2777 & 248 \\
\hline & 499 & 2961 & 230 \\
\hline Minimum: & 396 & 1208 & 2024 \\
\hline Maximum: & 3747 & 2961 & \\
\hline
\end{tabular}

Anschließend wurden die verschiedenen Gruppen nach dem exakten, zweiseitigen Wilcoxon-Mann-Whitney-Test auf ihre Irrtumswahrscheinlichkeit (Signifikanz angenommen für $p<0,05)$ hin geprüft:

Tab 3.10: Irrtumswahrscheinlichkeit von sCD14/Kreatinin im Gruppenvergleich:

\begin{tabular}{|l|c|}
\hline Tx stabil vs. Abstoßung & $\mathbf{p}=\mathbf{0 , 0 0 0 3}$ \\
\hline Tx stabil vs. Infektion & $\mathbf{p}=\mathbf{0 , 6 5}$ \\
\hline Infekte vs. Abstoßung & $\mathbf{p}=\mathbf{0 , 0 0 6}$ \\
\hline
\end{tabular}


Abb. 3.28 : Quotienten von SCD14 und Kreatinin

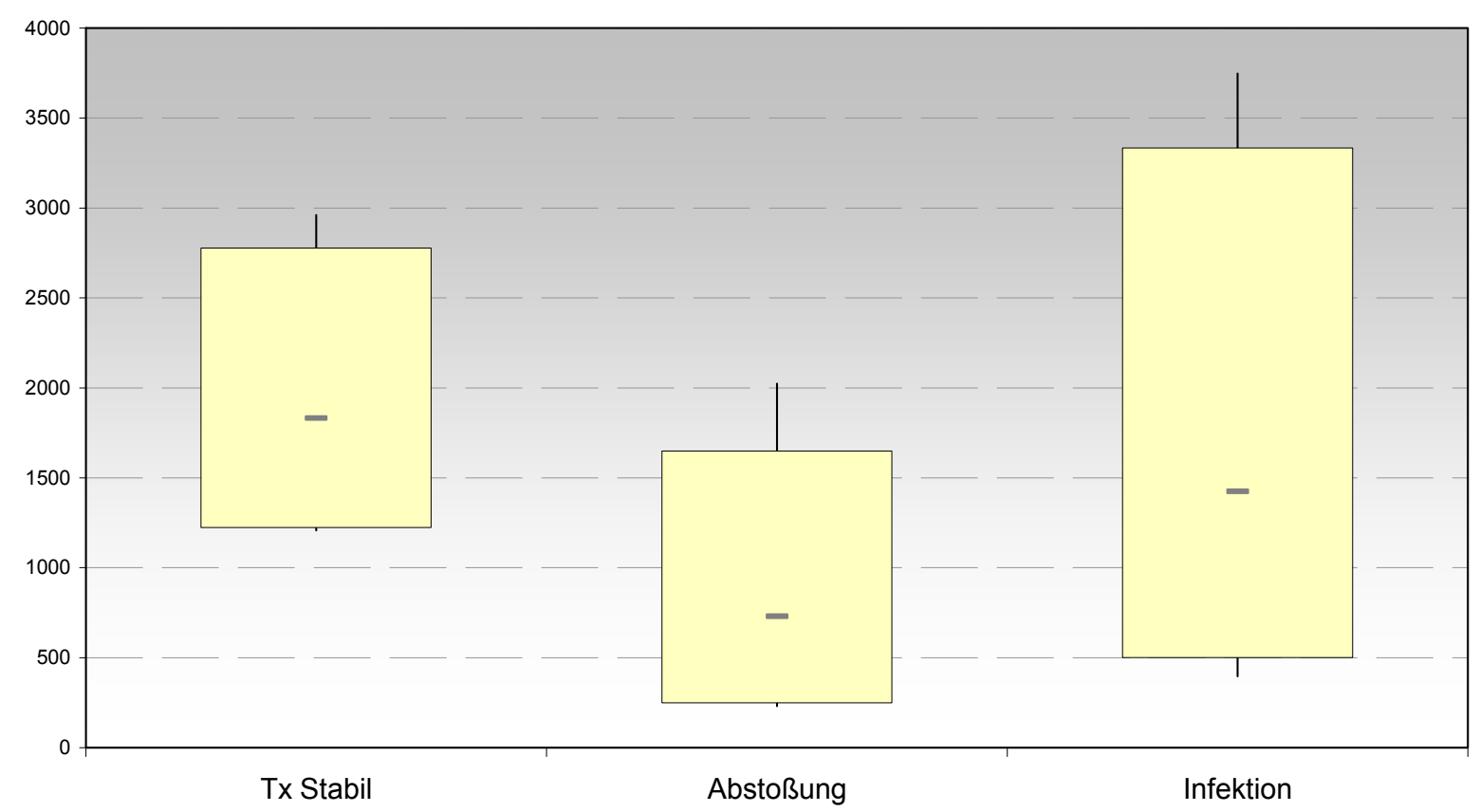

Abb. 3.28: Die Quotienten des löslichen CD14 (Plasma) und Kreatinin (Serum) sind bei der Abstoßungsreaktion im Mittel am niedrigsten. Eine vollständige Überlappung zeigt die stabile Transplantatfunktion mit den Infektionen bei dieser Quotientenbildung.

Es erfolgte die Berechnung von Spezifität und Sensitivität unter Angabe des Trennwertes sowie die Darstellung als ROC-Kurven (Anhang unter Abb. 7.1 bis 7.6).

Fazit: Trotz einer signifikanten Irrtumswahrscheinlichkeit der Abstoßungsgruppe gegenüber Infektionen und stabiler Transplantatfunktion zeigen die Berechnungen keine der Unterscheidung dienlichen Ergebnisse in der ROC-Analyse. 


\subsection{Korrelation von Kreatinin im Serum und sCD14 im Plasma}

Nachfolgend sind die Ergebnisse der erhobenen Werte des Kreatinin im Serum und des sCD14 im Plasma als Korrelation tabellarisch dargestellt (Anhang Abbildung 7.7 bis 7.9 ).

\begin{tabular}{|l|l|}
\hline Stabile Transplantatfunktion & $r=-0,22$ \\
\hline Abstoßung & $r=0,23$ \\
\hline Infektion & $r=0,59$ \\
\hline
\end{tabular}

Fazit: Es besteht in keiner Gruppe eine signifikante Korrelation.

\subsection{Korrelation von Kreatinin im Serum und sCD14 im Urin}

Nachfolgend sind die Ergebnisse der erhobenen Werte des Kreatinin im Serum und des SCD14 im Urin als Korrelation tabellarisch dargestellt. (Anhang Abbildung 7.10 bis 7.12).

\begin{tabular}{|l|l|}
\hline Stabile Transplantatfunktion & $r=-0,47$ \\
\hline Abstoßung & $r=-0,7$ \\
\hline Infektion & $r=0,59$ \\
\hline
\end{tabular}

Fazit: Es besteht lediglich in der Gruppe der Abstoßungen eine grenzwertige Korrelation beider Parameter.

\subsection{Korrelation der im Plasma und im Urin erhobenen Werte von sCD14}

Nachfolgend sind die Ergebnisse der erhobenen Werte des SCD14 im Plasma und im Urin als Korrelation tabellarisch dargestellt (Anhang Abbildung 7.13 bis 7.15).

\begin{tabular}{|l|l|}
\hline Stabile Transplantatfunktion & $r=-0,29$ \\
\hline Abstoßung & $r=-0,02$ \\
\hline Infektion & $r=0,1$ \\
\hline
\end{tabular}

Fazit: Es besteht in keiner Gruppe eine signifikante Korrelation.

Insgesamt kann kein Zusammenhang von Nierenfunktion und Konzentration von sCD14 in Plasma oder Urin dargestellt werden. 


\subsection{Das Verhältnis von sCD14 zu sIL2R}

\subsubsection{Plasmawerte des sIL2R}

In diesem Kapitel wird der lösliche IL2R-Rezeptor zunächst im Rahmen des jeweiligen Transplantatzustandes dargestellt und die Gruppen miteinander verglichen. Ebenso wird nach Quotientenbildung mit dem Serumkreatinin verfahren, um den möglichen Einfluss der Nierenfunktion darstellen zu können. In einem nächsten Schritt werden dann diese Ergebnisse mit denen des sCD14 verknüpft, um das Verhältnis beider Parameter zu analysieren.

Tab. 3.11: Lösliche IL2-Rezeptor-Plasmawerte im Gruppenvergleich:

\begin{tabular}{|l|c|c|c|}
\hline Werte in pM & Gruppe Infekte & Gruppe Tx stabil & Gruppe Abstoßung \\
\hline n: & 11 & 7 & 13 \\
\hline Mittelwert: & 218 & 102 & 265 \\
\hline Median: & 205 & 92 & 222,5 \\
\hline Standard-Abweichung: & 95,1 & 43,5 & 107,7 \\
\hline Quantile: & & & 443,3 \\
\hline \multicolumn{1}{|c|}{$5 \% \%$} & 355 & 171,5 & 142,5 \\
\hline Minimum: & 92,5 & 57,5 & 110 \\
\hline Maximum: & 75 & 50 & 505 \\
\hline
\end{tabular}

Anschließend wurden die verschiedenen Gruppen nach dem exakten, zweiseitigen Wilcoxon-Mann-Whitney-Test auf ihre Irrtumswahrscheinlichkeit (Signifikanz angenommen für $p<0,05)$ hin geprüft:

Tab. 3.12: Signifikanzniveau sIL2R Gruppenvergleich:

\begin{tabular}{|l|c|}
\hline Tx stabil gegen Abstoßung & $\mathbf{p}=\mathbf{0 , 0 0 4 9}$ \\
\hline Tx stabil gegen Infektion & $\mathbf{p}=\mathbf{0 , 0 0 5 4}$ \\
\hline Infekte gegen Abstoßung & $\mathbf{p}=\mathbf{0 , 2 3}$ \\
\hline
\end{tabular}


Es zeigt sich, dass die Situationen Abstoßung und Infektionen hochsignifikant gegenüber der stabilen Transplantatfunktion abgrenzbar sind $(p<0,01)$. Im Vergleich zwischen Infektionen und Abstoßung ist kein signifikanter Unterschied zu beobachten $(p=0,23)$.

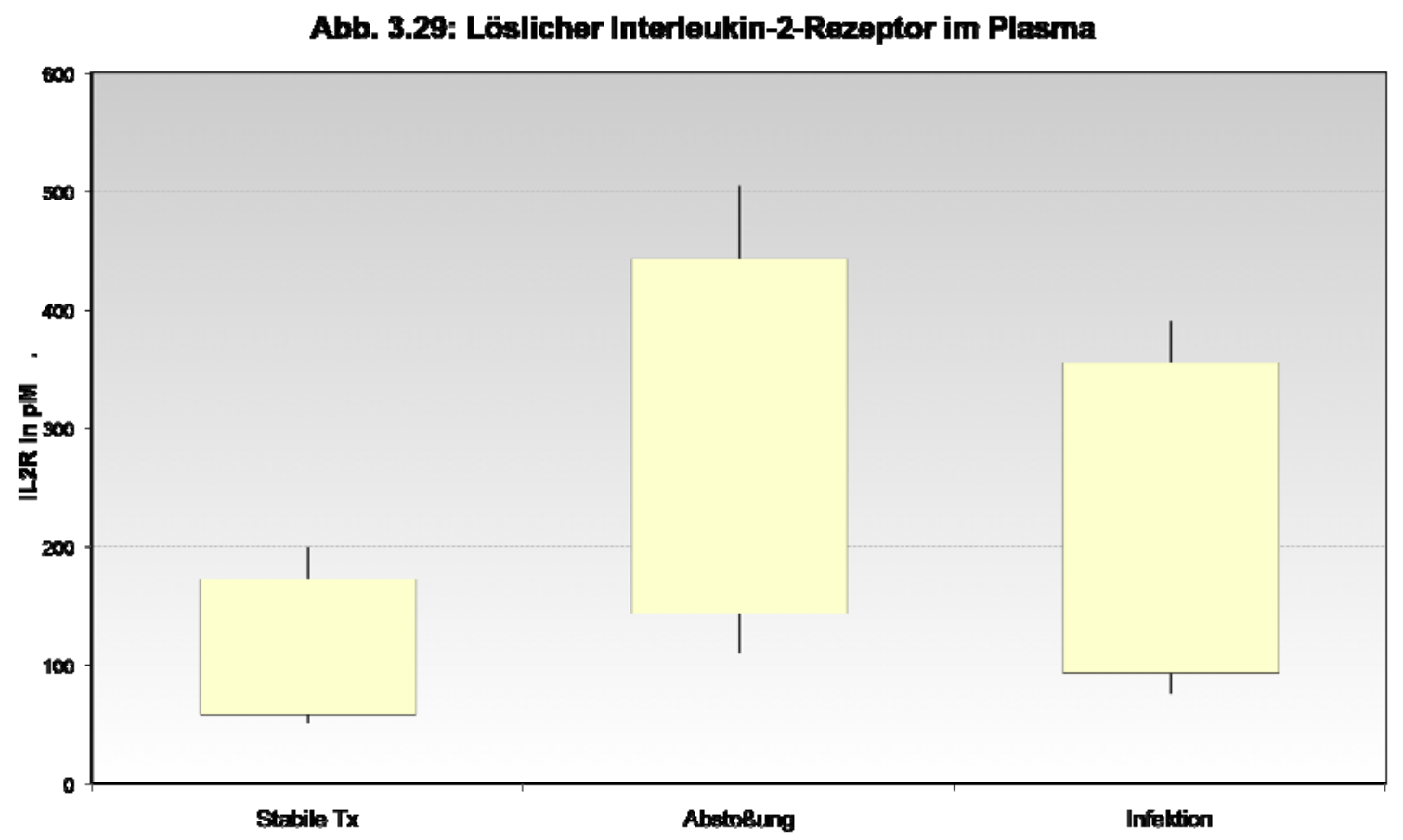

Abb. 3.29: Die Plasmawerte des löslichen IL2R sind bei einer stabilen Transplantatfunktion am niedrigsten. Bei den Komplikationsformen kommt es hingegen zu einer weitläufigen Überschneidung der ermittelten Werte. 
Es erfolgte die Berechnung von Spezifität und Sensitivität unter Angabe des Trennwertes sowie die Darstellung als ROC-Kurven:

Abb. 3.30: Löslicher IL2-Rezeptor im Plasma: Tx stabil vs. Abstoßung:

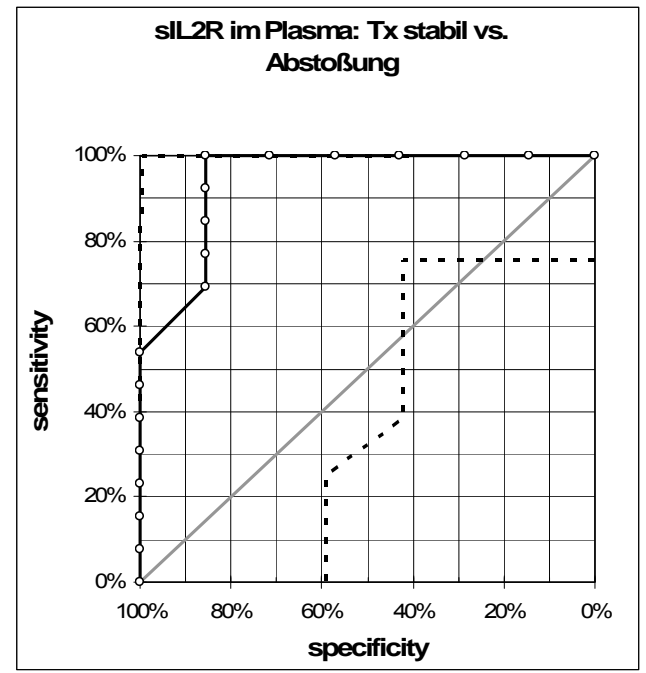

Abb. 3.30: In der ROC-Kurven-Analyse läßt sich die stabile Transplantatfunktion von der Abstoßungsreaktion bei einem angenommenen Cut-Off-Wert von 160 pM mit einer Sensitivität von $100 \%$ und einer Spezifität von $86 \%$ abgrenzen (AUC $=0,94$ ).

Abb. 3.31: Löslicher IL2-Rezeptor im Plasma: Tx stabil vs. Infektion:

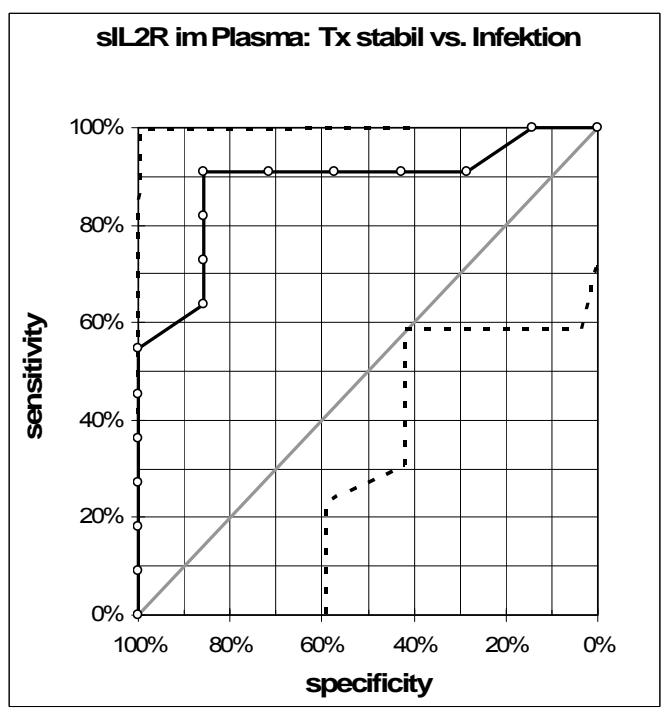

Abb. 3.31: In der ROC-Kurven-Analyse läßt sich die stabile Transplantatfunktion von der Infektion bei einem angenommenen Cut-Off-Wert von 110 pM mit einer Sensitivität von $91 \%$ und einer Spezifität von $86 \%$ abgrenzen $(A \cup C=0,88)$. 
Abb. 3.32: Löslicher IL2-Rezeptor im Plasma: Infektion vs. Abstoßung:

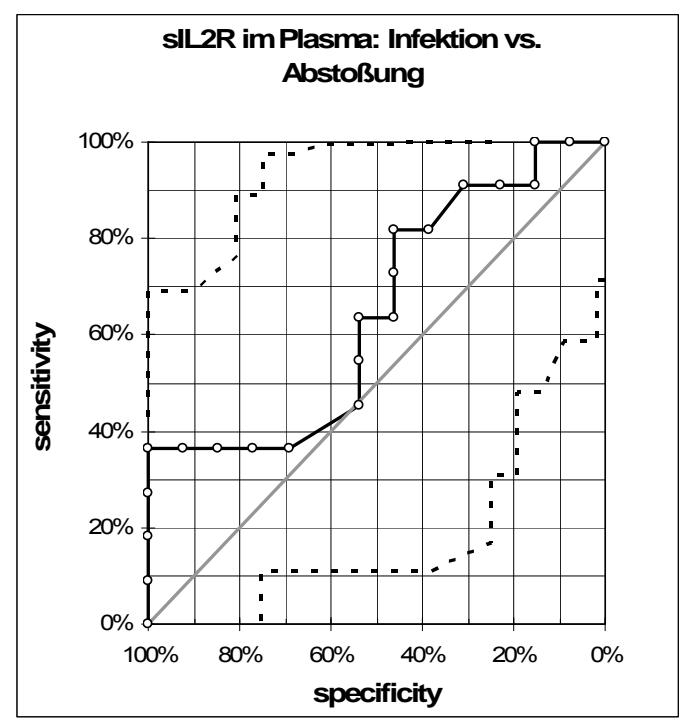

Abb. 3.32: In der ROC-Kurven-Analyse läßt sich die Abstoßung von der Infektion bei einem angenommenen Cut-Off-Wert von 150 pM mit einer Sensitivität von $37 \%$ und einer Spezifität von $100 \%$ abgrenzen $(A \cup C=0,65)$.

\section{Abb. 3.33: sIL2-Rezeptor im Plasma: Infektion vs. Abstoßung und Tx stabil:}

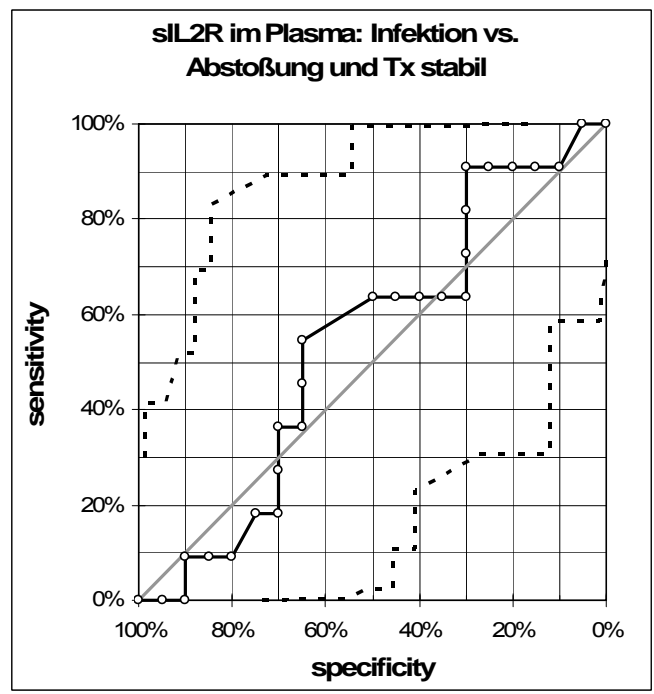

Abb. 3.33: In der ROC-Kurven-Analyse läßt sich die Infektion von der stabilen Transplantatfunktion sowie der Abstoßungsreaktion bei einem angenommenen Cut-Off-Wert von 110 pM mit einer Sensitivität von $91 \%$ und einer Spezifität von 30\% abgrenzen (AUC = 0,54). 
Abb. 3.34: sIL2-Rezeptor im Plasma: Abstoßung vs. Infektion und Tx stabil:

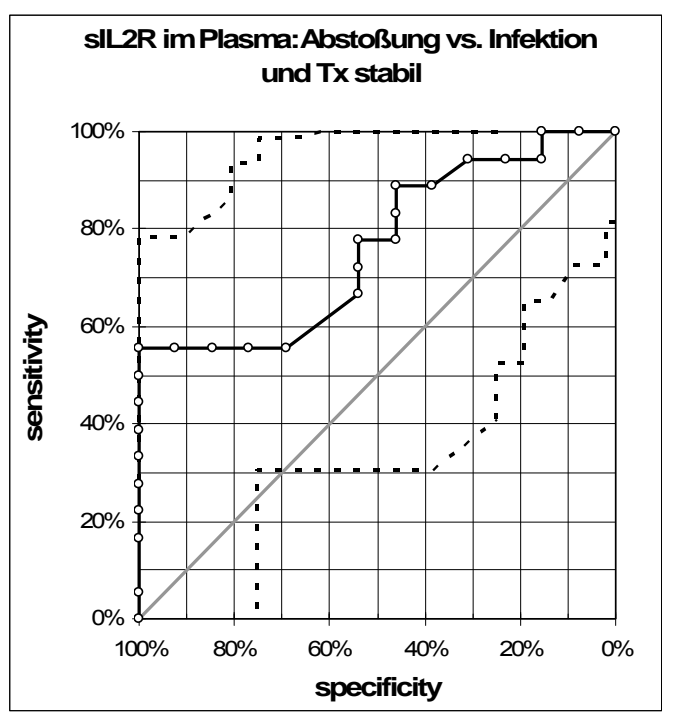

Abb. 3.34: In der ROC-Kurven-Analyse läßt sich die Abstoßungsreaktion von der stabilen Transplantatfunktion sowie der Infektion bei einem angenommenen Cut-Off-Wert von 150 pM mit einer Sensitivität von 56\% und einer Spezifität von 100\% abgrenzen (AUC = 0,76).

Abb. 3.35: sIL2-Rezeptor im Plasma: Tx stabil vs. Abstoßung und Infektion:

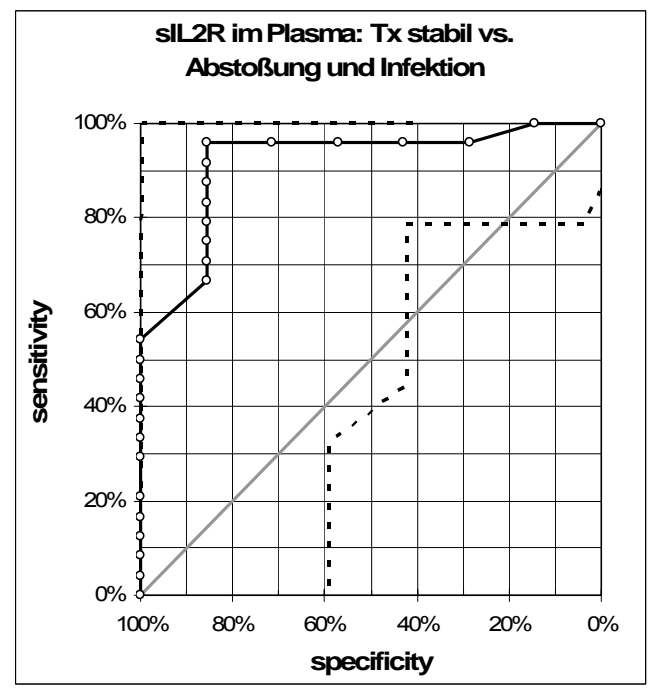

Abb. 3.35: In der ROC-Kurven-Analyse läßt sich die stabile Transplantatfunktion von der Abstoßungsreaktion sowie der Infektion bei einem angenommenen Cut-Off-Wert von $110 \mathrm{pM}$ mit einer Sensitivität von $96 \%$ und einer Spezifität von $86 \%$ abgrenzen (AUC = 0,92). 


\subsubsection{Quotient aus SCD14 und sIL2R}

Bei 29 Patienten wurden sowohl die Verlaufsparameter des löslichen CD-14Zellrezeptors sowie des löslichen IL2-Zellrezeptors aufgenommen und nach Quotientenbildung in den jeweiligen Gruppen miteinander verglichen.

Tab. 3.13: Gruppenvergleich SCD14/ sIL2R:

\begin{tabular}{|l|c|c|c|}
\hline Werte in ng/ml/[pM] & Gruppe Infekte & Gruppe Tx stabil & Gruppe Abstoßung \\
\hline $\mathrm{n}:$ & 9 & 7 & 13 \\
\hline Mittelwert: & 16,7 & 27,0 & 11,9 \\
\hline Median: & 14,6 & 25,8 & 11,4 \\
\hline Standard-Abweichung: & 6,6 & 9,7 & 4,2 \\
\hline Quantile: & & & \\
\hline \multicolumn{1}{|c|}{$95 \%$} & 27,9 & 40,6 & 18,0 \\
\hline \multicolumn{1}{|c|}{$5 \%$} & 10,3 & 13,3 & 6,1 \\
\hline Minimum: & 10,0 & 10,1 & 5,7 \\
\hline Maximum: & 30,0 & 42,2 & 19,9 \\
\hline
\end{tabular}

Anschließend wurden die verschiedenen Gruppen nach dem exakten, zweiseitigen Wilcoxon-Mann-Whitney-Test auf ihre Irrtumswahrscheinlichkeit (Signifikanz angenommen für $p<0,05)$ hin geprüft:

Tab 3.14: Irrtumswahrscheinlichkeit SCD14/sIL2R im Gruppenvergleich:

\begin{tabular}{|l|c|}
\hline Tx stabil vs. Abstoßung & $\mathbf{p}=\mathbf{0 , 0 0 2}$ \\
\hline Tx stabil vs. Infektion & $\mathbf{p}=\mathbf{0 , 0 7}$ \\
\hline Infekte vs. Abstoßung & $\mathbf{p}=\mathbf{0 , 1 9}$ \\
\hline
\end{tabular}

Lediglich die Gruppen stabile Transplantatfunktion und Abstoßung lassen sich bei diesem Quotientenvergleich in höchst signifikanter Weise voneinander differenzieren. Die beiden anderen Vergleiche erreichen nicht das notwendige Signifikanzniveau und sind zur Differenzierung nicht geeignet. 
Abb. 3.36: Quotient aus SCD14 und sIL2R:

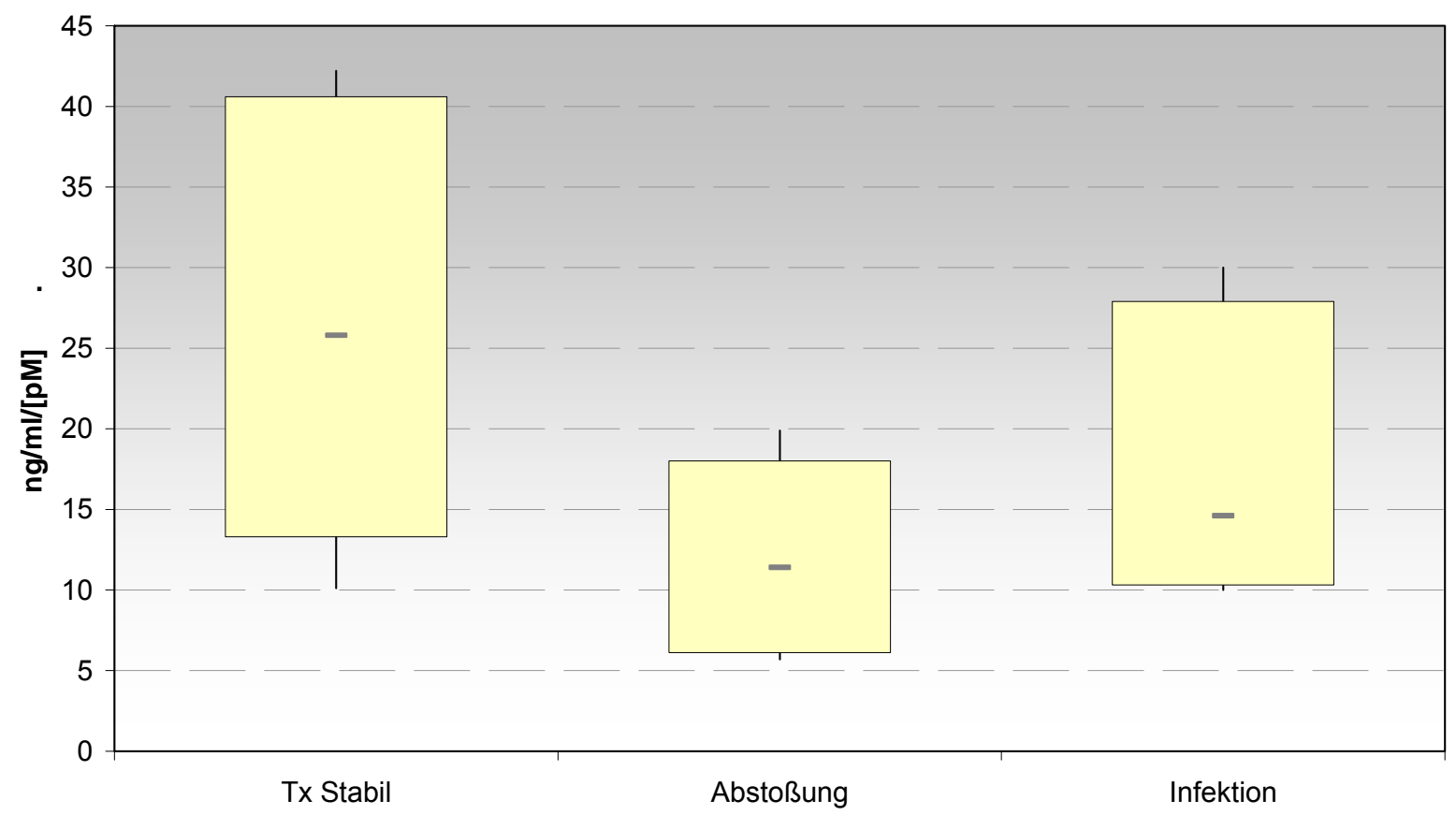

Abb. 3.36: Bei der Quotientenbildung von löslichem CD14 und löslichem IL2R im Plasma zeigen sich die niedrigsten Werte für die Abstoßungsreaktion, wobei es unter allen Gruppen zu deutlichen Werteüberschneidungen kommt. 
Es erfolgte die Berechnung von Spezifität und Sensitivität unter Angabe des Trennwertes sowie die Darstellung als ROC-Kurven:

Abb. 3.37: Quotient sCD14/sIL2R im Plasma: Tx stabil vs. Abstoßung:

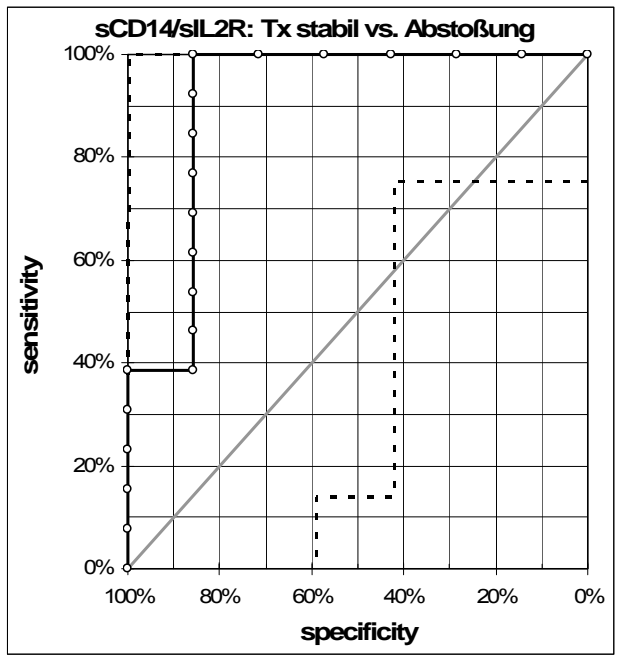

Abb. 3.37: In der ROC-Kurven-Analyse läßt sich die stabile Transplantatfunktion von der Abstoßungsreaktion bei einem angenommenen Cut-Off-Wert von 19,9 mit einer Sensitivität von 100\% und einer Spezifität von $86 \%$ abgrenzen $(A \cup C=0,91)$.

Abb. 3.38: Quotient sCD14/sIL2R im Plasma: Tx stabil vs. Infektion:

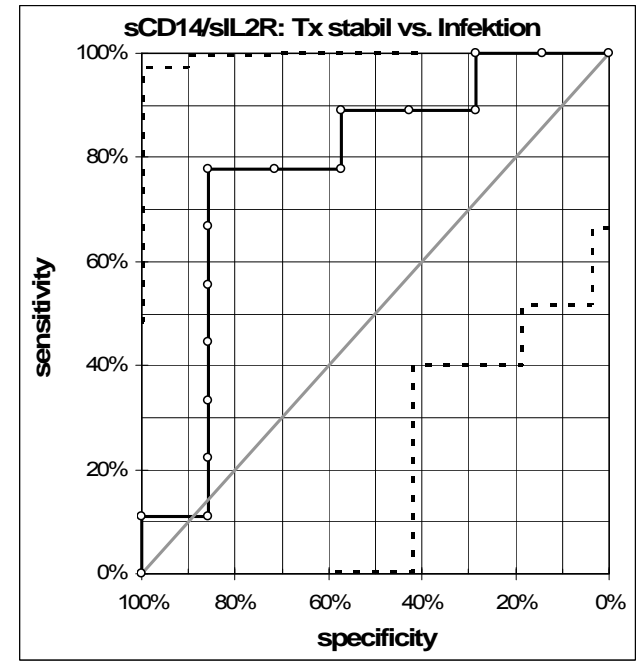

Abb. 3.38: In der ROC-Kurven-Analyse läßt sich die stabile Transplantatfunktion von der Infektion bei einem angenommenen Cut-Off-Wert von 20,7 mit einer Sensitivität von $78 \%$ und einer Spezifität von $86 \%$ abgrenzen $(A \cup C=0,78)$. 
Abb. 3.39: Quotient sCD14/sIL2R im Plasma: Infektion vs. Abstoßung:

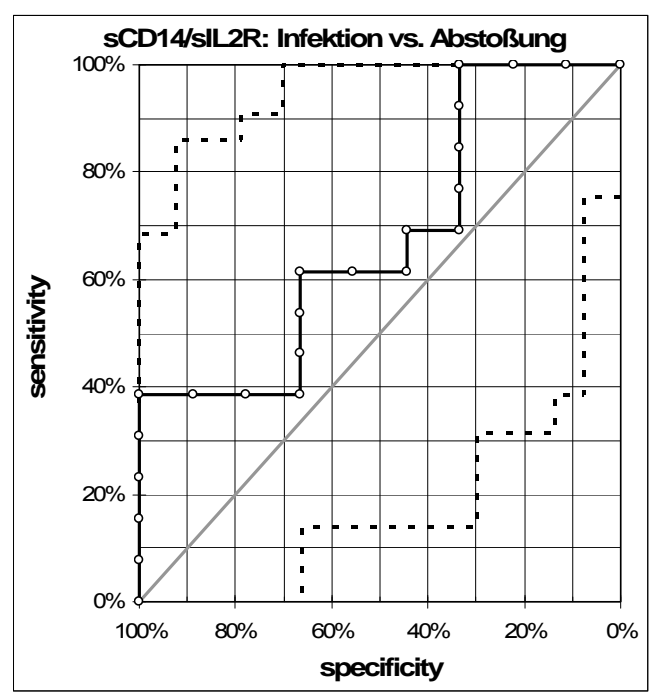

Abb. 3.39: In der ROC-Kurven-Analyse läßt sich die stabile Transplantatfunktion von der Abstoßungsreaktion sowie der Infektion bei einem angenommenen Cut-Off-Wert von 8,29 mit einer Sensitivität von $39 \%$ und einer Spezifität von $100 \%$ abgrenzen $(A \cup C=0,68)$.

Abb. 3.40: sCD14/sIL2R im Plasma: Infektion vs. Abstoßung und Tx stabil:

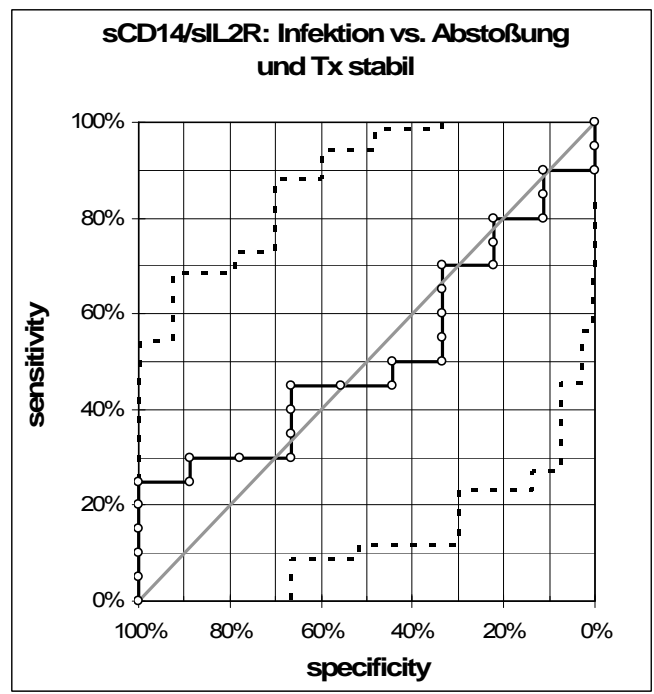

Abb. 3.40: In der ROC-Kurven-Analyse läßt sich die Infektion von der Abstoßungsreaktion sowie der stabilen Transplantatfunktion bei einem angenommenen Cut-Off-Wert von 8,29 mit einer Sensitivität von $25 \%$ und einer Spezifität von $100 \%$ abgrenzen (AUC $=0,51)$. 
Abb. 3.41: sCD14/sIL2R im Plasma: Abstoßung vs. Infektion und Tx stabil:

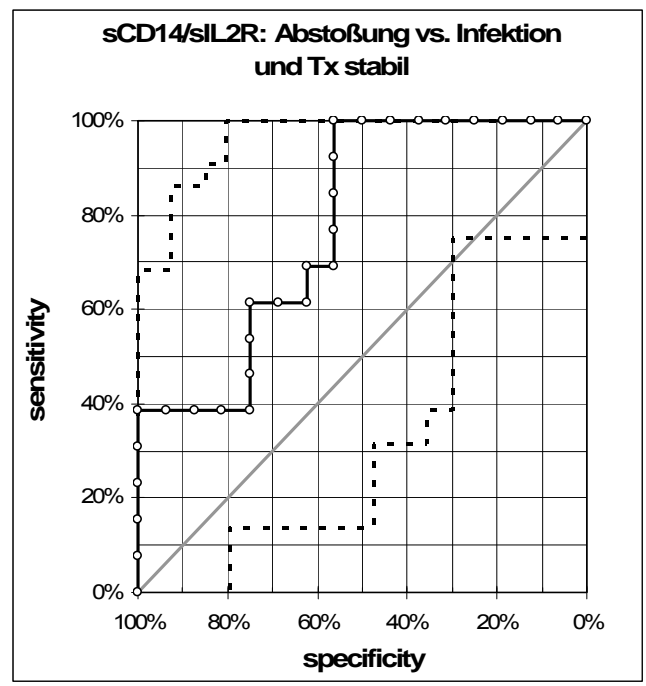

Abb. 3.41: In der ROC-Kurven-Analyse läßt sich die Abstoßungsreaktion von der Infektion sowie der stabilen Transplantatfunktion bei einem angenommenen Cut-Off-Wert von 19,9 mit einer Sensitivität von $100 \%$ und einer Spezifität von $56 \%$ abgrenzen (AUC $=0,78)$.

Abb. 3.42: sCD14/sIL2R im Plasma: Tx stabil vs. Abstoßung und Infektion:

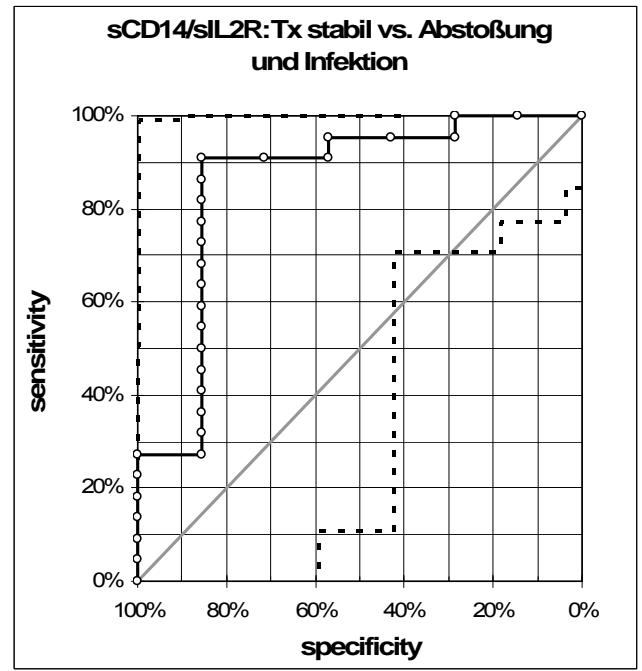

Abb. 3.42: In der ROC-Kurven-Analyse läßt sich die stabile Transplantatfunktion von der Infektion sowie der Abstoßungsreaktion bei einem angenommenen Cut-Off-Wert von 20,7 mit einer Sensitivität von $91 \%$ und einer Spezifität von $86 \%$ abgrenzen $(A \cup C=0,86)$. 


\subsubsection{Korrelation von SCD14 und sIL2R}

Nachfolgend sind die Ergebnisse der erhobenen Werte des SCD14 und des SIL2R im Plasma als Korrelation tabellarisch dargestellt. Die Diagrammform (Scatter-Plot) mit dem jeweiligen Korrelationskoeffizienten ist im Anhang unter Abbildung 7.16 bis 7.18 einzusehen.

\begin{tabular}{|l|ll|}
\hline Stabile Transplantatfunktion & $r=0,73$ \\
\hline Abstoßung & $r=0,23$ \\
\hline Infektion & $r=0,22$ \\
\hline
\end{tabular}

Fazit: Die Unterscheidung der stabilen Transplantatfunktion gegenüber den beiden Komplikationen einzeln wie auch zusammen gelingt signifikant, was sich auch in einer hohen Trennschärfe in der ROC-Analyse zeigt ( $A \cup C=0,94,0,92$ bzw. 0,88). Dies gilt nicht für die Komplikationsformen untereinander oder in Kombination mit der stabilen Transplantatfunktion.

Die Quotientenbildung mit SCD14 zeigt zum oben beschriebenen nahezu identische Ergebnisse. Unterscheidungsmerkmale über die der Einzelparameter hinaus lassen sich nicht ableiten.

Lediglich im Rahmen einer stabilen Transplantatfunktion korrelieren sIL2R und sCD14 signifikant. 


\subsection{Das Verhältnis von sCD14 zu sCD4}

\subsubsection{Plasmawerte des SCD4}

In diesem Kapitel wird der lösliche CD4-Rezeptor zunächst im Rahmen des jeweiligen Transplantatzustandes dargestellt und die Gruppen miteinander verglichen. Ebenso wird nach Quotientenbildung mit dem Serumkreatinin verfahren, um den möglichen Einfluss der Nierenfunktion darstellen zu können. Im nächsten Schritt werden dann diese Ergebnisse mit denen des sCD14 verknüpft, um genauere Informationen über das Verhältnis beider Parameter zu erhalten.

Tab. 3.15: Lösliche CD-4-Rezeptor Plasmawerte im Gruppenvergleich:

\begin{tabular}{|l|c|c|c|}
\hline Werte in ng/ml & Gruppe Infekte & Gruppe Tx stabil & Gruppe Abstoßung \\
\hline n: & 13 & 10 & 16 \\
\hline Mittelwert: & 1,72 & 0,78 & 1,28 \\
\hline Median: & 1,3 & 0,68 & 1,31 \\
\hline Standardabweichung: & 0,96 & 0,28 & 0,25 \\
\hline Quantile: & & & 1,6 \\
\hline \multicolumn{1}{|c|}{$95 \%$} & 3,35 & 1,28 & 0,91 \\
\hline Minimum: & 0,79 & 0,54 & 0,83 \\
\hline Maximum: & 0,67 & 0,53 & 1,79 \\
\hline
\end{tabular}

Anschließend wurden die verschiedenen Gruppen nach dem exakten, zweiseitigen Wilcoxon-Mann-Whitney-Test auf ihre Irrtumswahrscheinlichkeit (Signifikanz angenommen für $p<0,05)$ hin geprüft:

Tab.3.16: Signifikanzniveau des löslichen CD-4-Rezeptors:

\begin{tabular}{|l|c|}
\hline Tx stabil gegen Abstoßung & $\mathbf{p}=\mathbf{0 , 0 0 1 3}$ \\
\hline Tx stabil gegen Infektion & $\mathbf{p}=\mathbf{0 , 0 0 1 6}$ \\
\hline Infekte gegen Abstoßung & $\mathbf{p}=\mathbf{0 , 9 7 7}$ \\
\hline
\end{tabular}


Die Gruppen „Abstoßung“ und „Infektion“ können jeweils gegenüber der Gruppe „Tx stabil“ signifikant abgegrenzt werden. Zwischen den Gruppen „Abstoßung“ und „Infektion“ besteht kein signifikanter Unterschied.

Abb. 3.49: Loslicher CD4-Rezeptor im Plasma

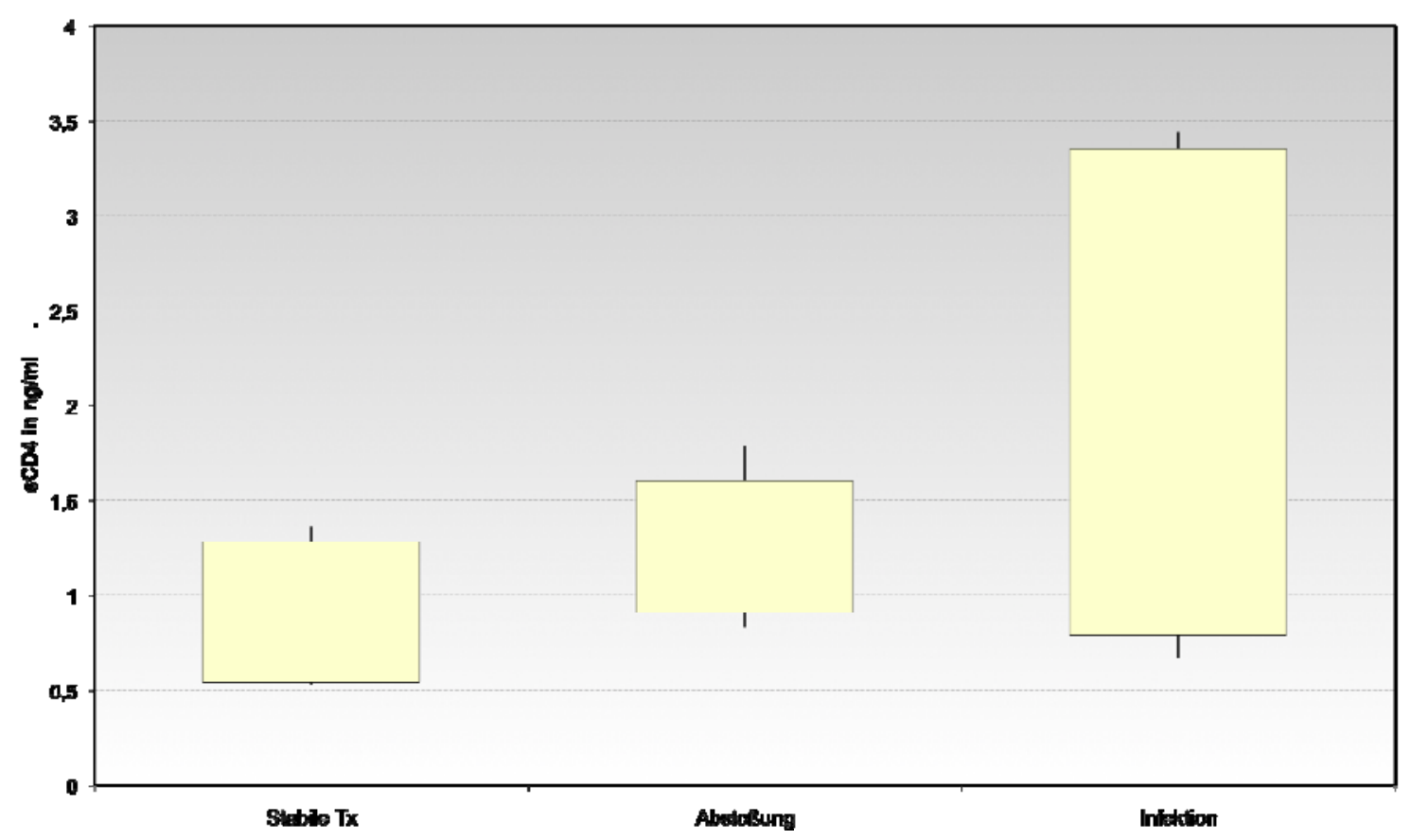

Abb. 3.43: Die Plasmawerte des löslichen CD4 sind in der Gruppe der stabilen Transplantatfunktion am niedrigsten. Abstoßung und Infektion überschneiden sich sehr deutlich, wobei die Gruppe der Infektionen eine weite Streuung der Werte aufweist. 
Es erfolgte die Berechnung von Spezifität und Sensitivität unter Angabe des Trennwertes sowie die Darstellung als ROC-Kurven:

Abb. 3.44: Löslicher CD4-Rezeptor: Tx stabil vs. Abstoßung:

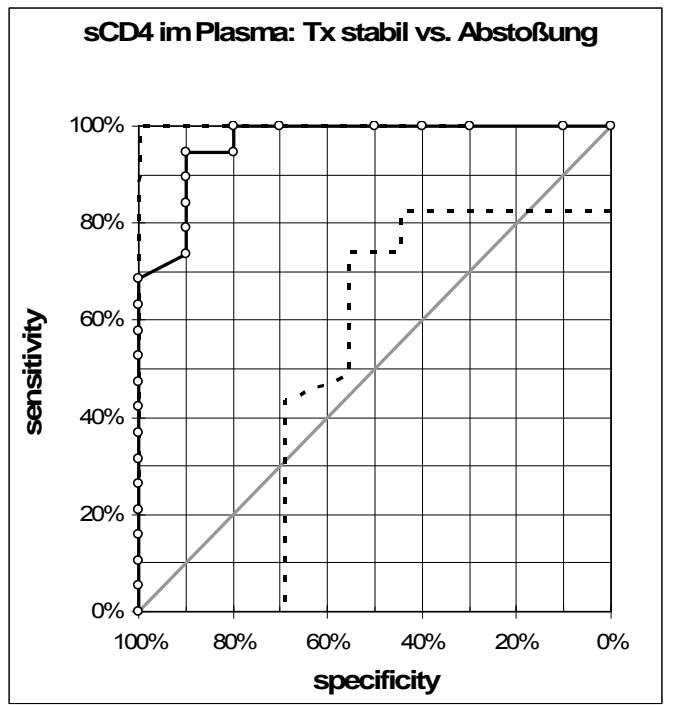

Abb. 3.44: In der ROC-Kurven-Analyse läßt sich die stabile Transplantatfunktion von der Abstoßungsreaktion bei einem angenommenen Cut-Off-Wert von 0,94 $\mathrm{ng} / \mathrm{ml}$ mit einer Sensitivität von $95 \%$ und einer Spezifität von 90\% abgrenzen (AUC = 0,97).

Abb. 3.45: Löslicher CD4-Rezeptor: Tx stabil vs. Infektion:

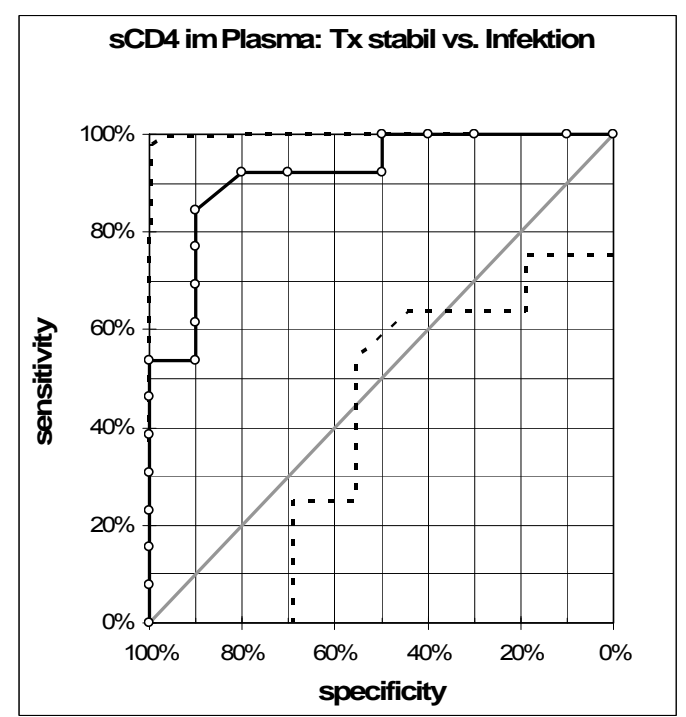

Abb. 3.45: In der ROC-Kurven-Analyse läßt sich die stabile Transplantatfunktion von der Infektion bei einem angenommenen Cut-Off-Wert von $0,97 \mathrm{ng} / \mathrm{ml}$ mit einer Sensitivität von $85 \%$ und einer Spezifität von $90 \%$ abgrenzen $(A \cup C=0,92)$. 
Abb. 3.46: Löslicher CD4-Rezeptor: Infektion vs. Abstoßung:

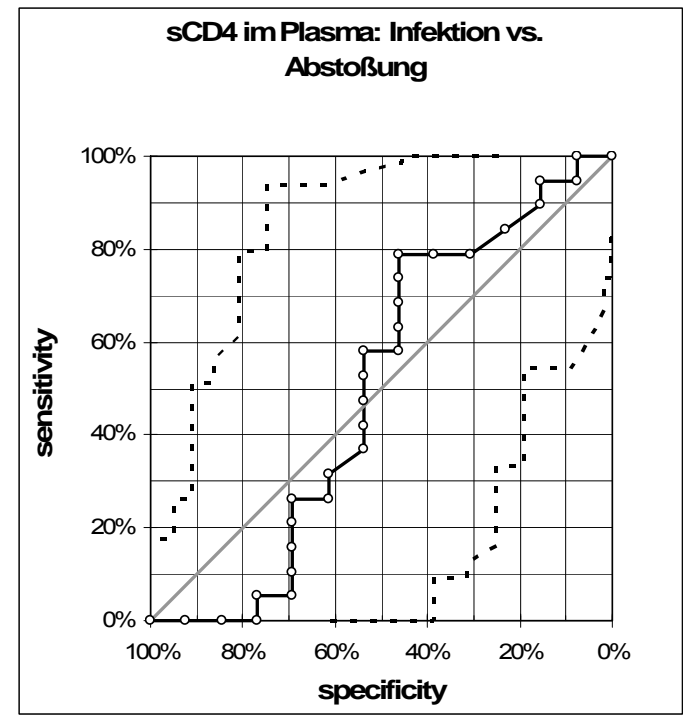

Abb. 3.46: In der ROC-Kurven-Analyse läßt sich die Infektion von der Abstoßungsreaktion bei einem angenommenen Cut-Off-Wert von $1,16 \mathrm{ng} / \mathrm{ml}$ mit einer Sensitivität von $78 \%$ und einer Spezifität von $46 \%$ abgrenzen (AUC $=0,5)$.

Abb. 3.47: sCD4-Rezeptor: Infektion vs. Abstoßung und Tx stabil:

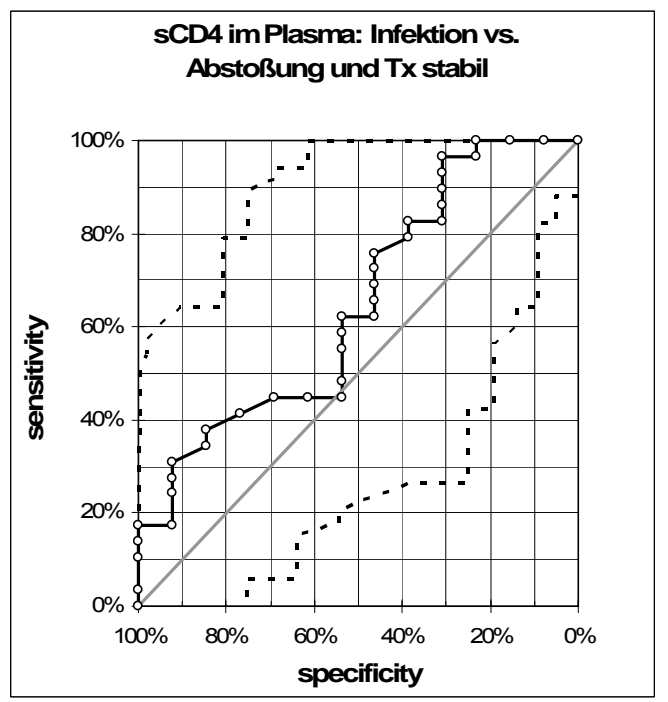

Abb. 3.47: In der ROC-Kurven-Analyse läßt sich die Abstoßungsreaktion von der stabilen Transplantatfunktion bei einem angenommenen Cut-Off-Wert von 2,67 ng/ml mit einer Sensitivität von $97 \%$ und einer Spezifität von 31\% abgrenzen $(A \cup C=0,65)$. 
Abb. 3.48: sCD4-Rezeptor: Abstoßung vs. Infektion und Tx stabil:

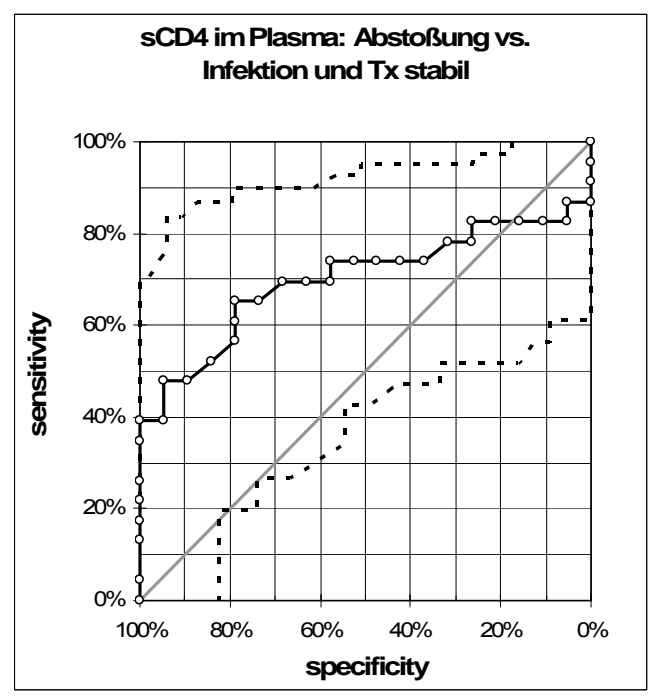

Abb. 3.48: In der ROC-Kurven-Analyse läßt sich die Abstoßungsreaktion von der stabilen Transplantatfunktion sowie der Infektion bei einem angenommenen Cut-Off-Wert von 1,13 ng/ml mit einer Sensitivität von $65 \%$ und einer Spezifität von $79 \%$ abgrenzen (AUC $=0,7)$.

Abb. 3.49: sCD4-Rezeptor: Tx stabil vs. Abstoßung und Infektion:

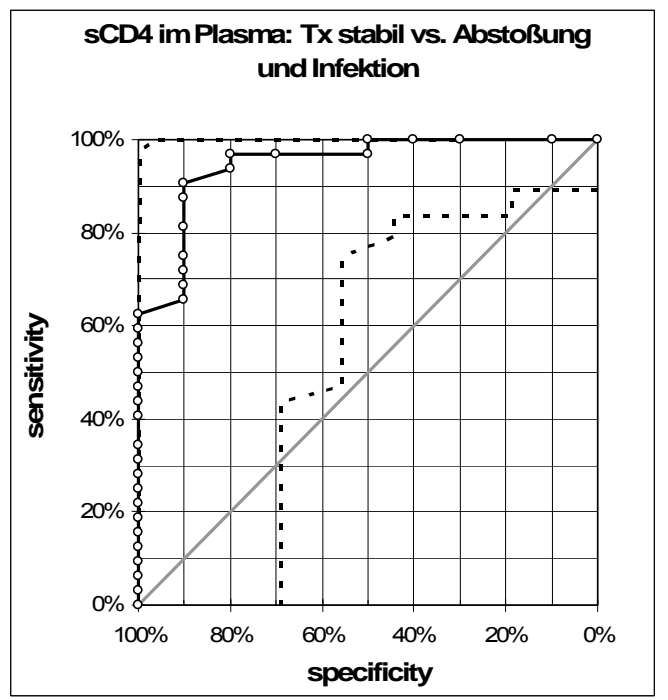

Abb. 3.49: In der ROC-Kurven-Analyse läßt sich die stabile Transplantatfunktion von der Abstoßungsreaktion sowie der Infektion bei einem angenommenen Cut-Off-Wert von 0,94 $\mathrm{ng} / \mathrm{ml} \mathrm{mit}$ einer Sensitivität von 91\% und einer Spezifität von 90\% abgrenzen (AUC = 0,95). 


\subsubsection{Quotient aus SCD14 und sCD4}

Bei 38 Patienten wurden nach der Nierentransplantation Plasmaverlaufswerte des löslichen CD14-Zellrezeptors sowie des löslichen CD4-Zellrezeptors aufgenommen und nach Quotientenbildung in den entsprechenden Gruppen miteinander verglichen.

Tab. 3.17: Gruppenvergleich sCD14/sCD4:

\begin{tabular}{|l|c|c|c|}
\hline Werte in ng/ml/ng/ml & Gruppe Infekte & Gruppe Tx stabil & Gruppe Abstoßung \\
\hline $\mathrm{n}:$ & 13 & 6 & 19 \\
\hline Mittelwert: & 2863 & 3259 & 2309 \\
\hline Median: & 3151 & 3367 & 2125 \\
\hline Standard-Abweichung: & 1315 & 825 & 861 \\
\hline Quantile: & & & 3809 \\
\hline \multicolumn{1}{|c|}{$95 \%$} & 4798 & 4224 & 1322 \\
\hline Minimum: & 1176 & 2014 & 974 \\
\hline Maximum: & 1122 & 1697 & 4551 \\
\hline
\end{tabular}

Anschließend wurden die verschiedenen Gruppen nach dem exakten, zweiseitigen Wilcoxon-Mann-Whitney-Test auf ihre Irrtumswahrscheinlichkeit (Signifikanz angenommen für $p<0,05)$ hin geprüft:

Tab 3.18: Irrtumswahrscheinlichkeit sCD14/sCD4 im Gruppenvergleich:

\begin{tabular}{|l|l|}
\hline Tx stabil vs. Abstoßung & $\mathbf{p}=\mathbf{0 , 0 2}$ \\
\hline Tx stabil vs. Infektion & $\mathbf{p}=\mathbf{0 , 6 9}$ \\
\hline Infekte vs. Abstoßung & $\mathbf{p}=\mathbf{0 , 4 9}$ \\
\hline
\end{tabular}

Lediglich eine Differenzierung zwischen einer stabilen Transplantatfunktion und einer Abstoßungsreaktion kann hier auf einem Niveau mit höchster Signifikanz vorgenommen werden. Die anderen Vergleiche haben ungenügende $p$-Werte und sind zur Unterscheidung nicht geeignet. 
Abb. 3.50: Quotient aus SCD14 und SCD4:

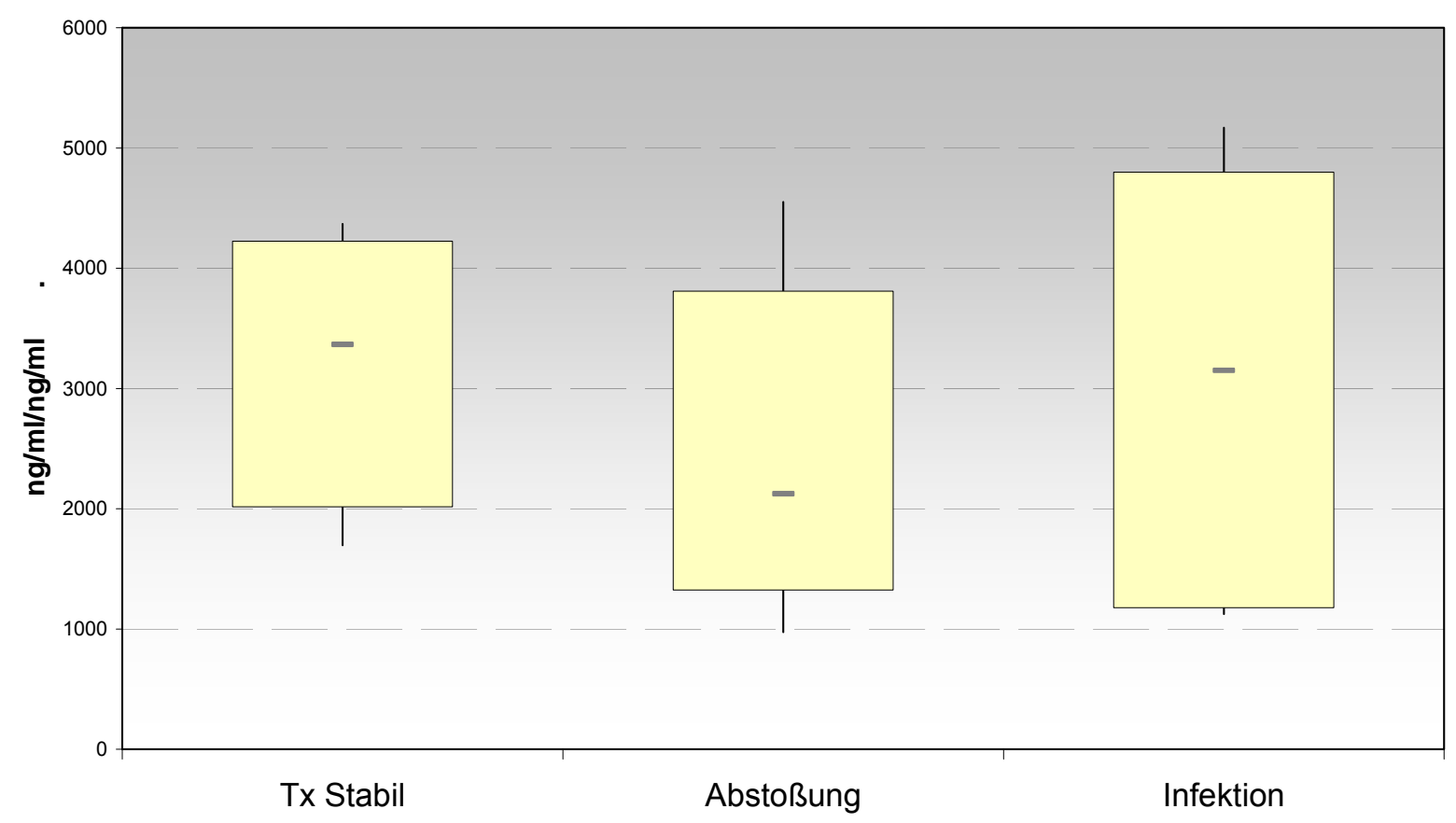

Abb. 3.50: Bei der Quotientenbildung von löslichem CD14 und CD4 im Plasma zeigen sich in allen drei untersuchten Gruppen fast vollständige Überlappungen der ermittelten Werte, was eine signifikante Unterscheidung nicht möglich macht.

Es erfolgte die Berechnung von Spezifität und Sensitivität unter Angabe des Trennwertes sowie die Darstellung als ROC-Kurven (Anhang Abb. 7.19 bis 7.21).

\subsubsection{Korrelation von SCD14 und SCD4}

Nachfolgend sind die Ergebnisse der erhobenen Werte des SCD14 und des SCD4 im Plasma als Korrelation tabellarisch dargestellt. Die Diagrammform (Scatter-Plot) mit dem jeweiligen Korrelationskoeffizienten ist im Anhang unter Abbildung 7.22 bis 7.24 einzusehen.

\begin{tabular}{|l|ll|}
\hline Stabile Transplantatfunktion & $r=0,47$ \\
\hline Abstoßung & $r=0,32$ \\
\hline Infektion & $r=0,36$ \\
\hline
\end{tabular}


Fazit: Mittels des löslichen CD4 läßt sich die stabile Transplantatfunktion signifikant von den Komplikationen abgrenzen und zeigt einzeln wie auch in Kombination in der ROC-Analyse hohe Trennschärfewerte (AUC = 0,97, 0,92 und 0,95). Dies gilt aber nicht für den Vergleich der Komplikationsformen untereinander.

Bei der Quotientenbildung findet sich ein signifikantes $p=0,02$ im Vergleich von stabiler Transplantatfunktion und Abstoßung, jedoch sind die ROC-Analysen im Bereich der Quotientenbildung ohne verwertbaren Unterscheidungsgewinn. Eine signifikante Korrelation beider Parameter gibt es nicht.

\subsection{Das Verhältnis von SCD14 zu SCD8}

\subsubsection{Plasmawerte des SCD8}

In diesem Kapitel wird der lösliche CD8-Rezeptor zunächst im Rahmen des jeweiligen Transplantatzustandes dargestellt und die Gruppen miteinander verglichen. Ebenso wird nach Quotientenbildung mit dem Serumkreatinin verfahren, um den möglichen Einfluss der Nierenfunktion darstellen zu können. Im nächsten Schritt werden dann diese Ergebnisse mit denen des SCD14 verknüpft, um genauere Informationen über das Verhältnis beider Parameter zu erhalten.

Tab. 3.19: Lösliche CD-8-Rezeptor Plasmawerte im Gruppenvergleich:

\begin{tabular}{|l|c|c|c|}
\hline Werte in U/mI & Gruppe Infekte & Gruppe Tx stabil & Gruppe Abstoßung \\
\hline n: & 11 & 6 & 14 \\
\hline Mittelwert: & 634 & 410 & 539 \\
\hline Median: & 650 & 370 & 530 \\
\hline Standardabweichung: & 202 & 118 & 189 \\
\hline Quantile: & & & 774 \\
\hline \multicolumn{1}{|c|}{$5 \% \%$} & 975 & 592 & 279 \\
\hline Minimum: & 378 & 303 & 240 \\
\hline Maximum: & 305 & 300 & 800 \\
\hline
\end{tabular}


Anschließend wurden die verschiedenen Gruppen nach dem exakten, zweiseitigen

Wilcoxon-Mann-Whitney-Test auf ihre Irrtumswahrscheinlichkeit (Signifikanz angenommen für $p<0,05)$ hin geprüft:

Tab. 3.20: Signifikanzniveau SCD8 Gruppenvergleich:

\begin{tabular}{|l|c|}
\hline Tx stabil gegen Abstoßung & $\mathbf{p}=\mathbf{0 , 1 9}$ \\
\hline Tx stabil gegen Infektion & $\mathbf{p}=\mathbf{0 , 0 2 6}$ \\
\hline Infekte gegen Abstoßung & $\mathbf{p}=\mathbf{0 , 3 6}$ \\
\hline
\end{tabular}

Die Gruppen Tx stabil und Infektionen können bei dieser Betrachtung auf einem signifikanten Niveau von $p=0,026$ voneinander unterschieden werden. Die weiteren Vergleiche zeigen mit $p=0,19$ sowie $p=0,36$ keinen signifikanten Unterschied.

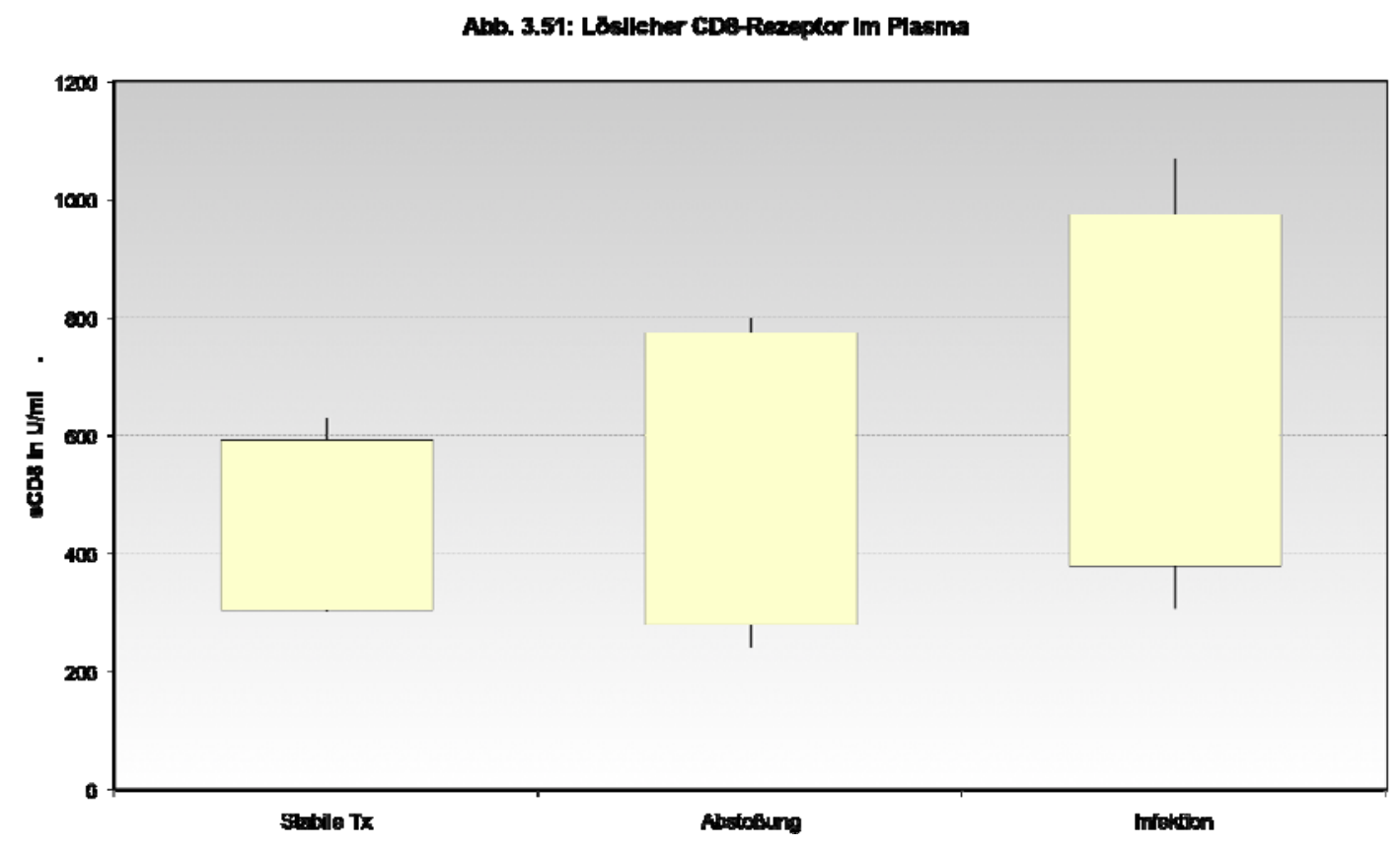

Abb. 3.51: Die Werte des löslichen CD8 im Plasma überlappen sich in großen Teilen. Dies macht eine signifikante Unterscheidung der Transplantatzustände anhand dieses Parameters nicht möglich.

Es erfolgte die Berechnung von Spezifität und Sensitivität unter Angabe des Trennwertes sowie die Darstellung als ROC-Kurven (Anhang unter Abb. 7.25 bis 7.27). 


\subsubsection{Quotient aus sCD14 und sCD8}

Bei 31 Patienten wurden im posttransplantären Verlauf die Plasmawerte des löslichen CD14-Zellrezeptors sowie des löslichen CD8-Zellrezeptors aufgenommen und nach Quotientenbildung miteinander verglichen.

Tab. 3.21: Gruppenvergleich sCD14/sCD8:

\begin{tabular}{|l|c|c|c|}
\hline Werte in mg/dl & Gruppe Infekte & Gruppe Tx stabil & Gruppe Abstoßung \\
\hline n: & 11 & 6 & 14 \\
\hline Mittelwert: & 6,3 & 5,5 & 6,3 \\
\hline Median: & 6,1 & 5,7 & 5,3 \\
\hline Standard-Abweichung: & 1,9 & 0,8 & 2,3 \\
\hline Quantile: & & & 9,6 \\
\hline \multicolumn{1}{|c|}{$95 \%$} & 10,0 & 6,4 & 3,6 \\
\hline & 4,3 & 4,3 & 3,4 \\
\hline Minimum: & 3,86 & 4,1 & 9,8 \\
\hline Maximum: & 10,2 & 6,5 & \\
\hline
\end{tabular}

Anschließend wurden die verschiedenen Gruppen nach dem exakten, zweiseitigen Wilcoxon-Mann-Whitney-Test auf ihre Irrtumswahrscheinlichkeit (Signifikanz angenommen für $p<0,05)$ hin geprüft:

Tab 3.22: Irrtumswahrscheinlichkeit sCD14/sCD8 im Gruppenvergleich:

\begin{tabular}{|l|l|}
\hline Tx stabil vs. Abstoßung & $\mathbf{p}=\mathbf{0 , 9 7}$ \\
\hline Tx stabil vs. Infektion & $\mathbf{p}=\mathbf{0 , 6 1}$ \\
\hline Infekte vs. Abstoßung & $\mathbf{p}=\mathbf{0 , 5 1}$ \\
\hline
\end{tabular}

Keine der Gruppen erreicht gegen eine der anderen ein Signifikanzniveau das eine Differenzierung der verschiedenen Transplantatsituationen erlaubt. 
Abb. 3.52: Quotient aus SCD14 und SCD8:

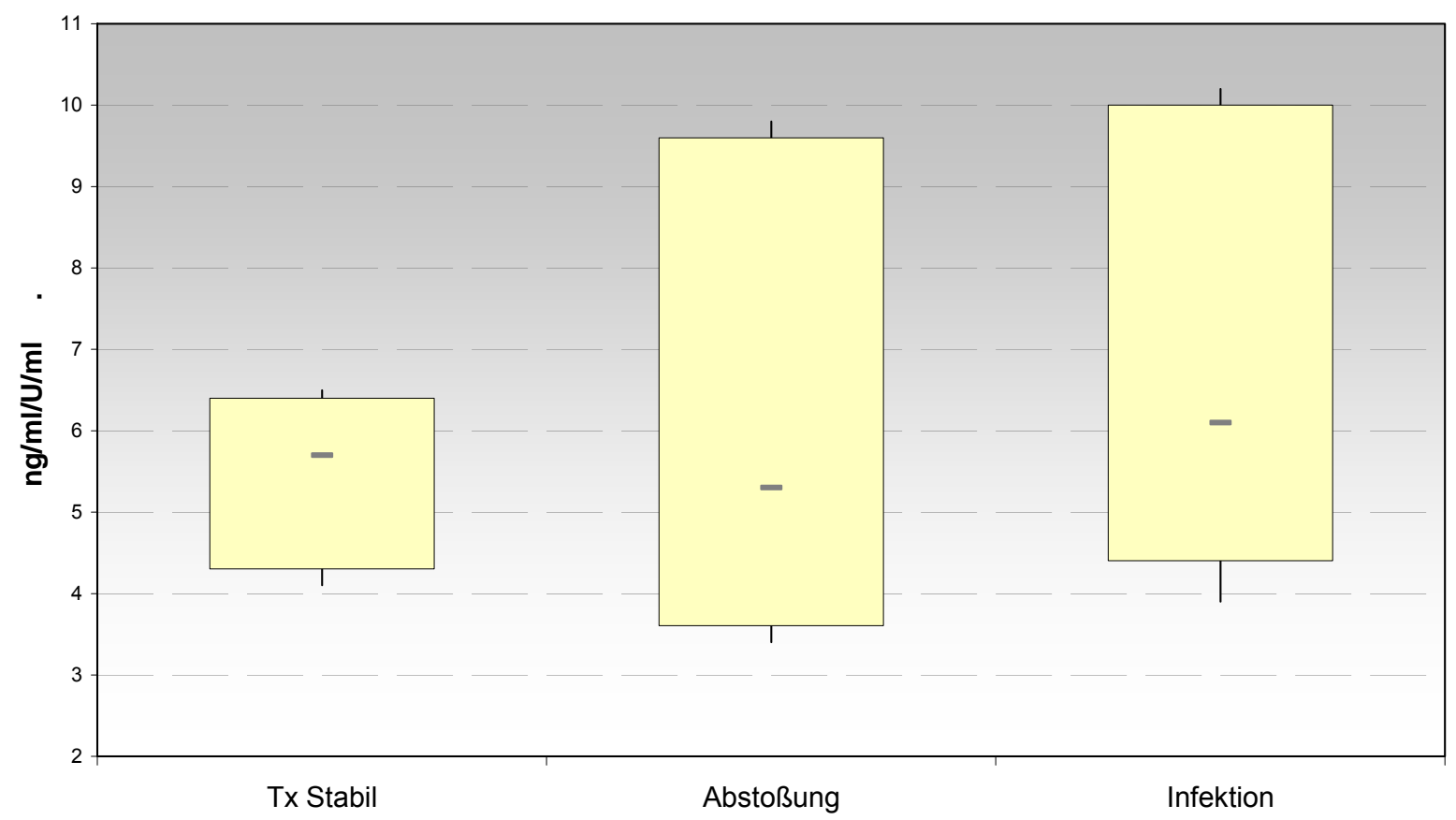

Abb. 3.52: Bei der Quotientenbildung von den löslichen Rezeptoren CD14 und CD8 kommt es innerhalb der untersuchten Gruppen zu großen Überschneidungen der ermittelten Werte. Eine signifikante Unterscheidung einzelner Transplantatzustände gelingt so nicht.

Es erfolgte die Berechnung von Spezifität und Sensitivität unter Angabe des Trennwertes sowie die Darstellung als ROC-Kurven, einsehbar im Anhang unter Abb. 7.28 bis 7.30 .

\subsubsection{Korrelation von SCD14 und SCD8}

Nachfolgend sind die Ergebnisse der erhobenen Werte des SCD14 und des SCD8 im Plasma als Korrelation tabellarisch dargestellt. Die Diagrammform (Scatter-Plot) mit dem jeweiligen Korrelationskoeffizienten ist im Anhang unter Abbildung 7.31 bis 7.33 einzusehen.

\begin{tabular}{|l|ll|}
\hline Stabile Transplantatfunktion & $r=0,85$ \\
\hline Abstoßung & $r=0,5$ \\
\hline Infektion & $r=0,51$ \\
\hline
\end{tabular}

Fazit: Zwischen der stabilen Transplantatfunktion und der Infektion lässt sich ein signifikantes $p=0,026$ herausarbeiten, jedoch zeigen die ROC-Analysen für den sCD8 allein wie auch nach Quotientenbildung mit sCD14 keine verwertbaren Unterscheidungsinformationen. Es besteht eine signifikante Korrelation beider Parameter bei stabiler Transplantatfunktion. 


\section{Diskussion}

Die Komplexität einer durch einen Auslöser -gleich welcher Ursache- generierten Immunantwort ist nach heutigem Wissensstand trotz weit reichendem Detailwissen in ihrem gesamten Ausmaß kaum darstellbar. Ungeachtet vieler detailliert beschriebener Einzelaspekte sind die Reaktionswege scheinbar derart vielschichtig angelegt, dass die Abbildung eines schlüssigen Gesamtkonzeptes noch nicht gelingt. Obwohl auch bereits vielfältiges Detailwissen über die hier untersuchten löslichen Rezeptoren vorliegt, ist das Herausarbeiten von monokausalen Zusammenhängen aufgrund der Komplexität im Rahmen dieser Arbeit sicher nicht zu gewährleisten, vielmehr geht es darum, dokumentierte Beobachtungen in mutmaßliche Zusammenhänge zu bringen und eine Beschreibung von unterschiedlichen Zuständen und Verhaltensweisen aufzuzeigen. Ziel ist es auch ohne detailfunktionell nachweisbare Kausalketten Reaktionsmuster aufzuzeigen, die möglicherweise eine Einbettung in den klinischen Alltag anstoßen können.

Konkret hinterfragt wird die Möglichkeit einer besseren Differenzierung der Transplantatzustände „akute Abstoßungsreaktion“, „Infektion“ und „stabile Transplantatfunktion“.

\subsection{Probengewinnung, Aufbewahrung und Verarbeitung}

Die abgeleiteten Daten dieser Arbeit rekrutieren sich aus unterschiedlichen Körperflüssigkeiten, namentlich aus Blut und Urin, und sind in verschiedenen Verfahren gewonnen und ausgewertet worden.

Bei der Bestimmung der Rezeptorkonzentrationen wurde Blut aus einem mit Heparin als Antikoagulanz versetzten herkömmlichen Blutentnahmeröhrchen gewonnen. Im Falle einer nicht unmittelbaren Weiterverarbeitung der Proben wurden diese zentrifugiert und bei $-20^{\circ}$ Celsius eingefroren, ansonsten erfolgte eine Probenbehandlung bzw. -aufbewahrung nach den Empfehlungen der Hersteller. Zum benötigten Zeitpunkt der weiteren Bearbeitung wurden die gefrorenen Proben schonend aufgetaut und darüber hinaus ein mehrmaliges Einfrieren vermieden. Dieses Vorgehen stellt ein etabliertes Verfahren in der Behandlung, Verwahrung und Verarbeitung von Blutproben dar. Schon Thavasu konnte zeigen, dass eine entsprechende Antikoagulation, 
verbunden mit einem raschen Zentrifugieren sowie nachfolgendem Einfrieren bei zu

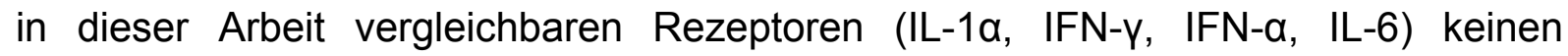
nennenswerten Einfluss auf das Ergebnis einer späteren Messung gegenüber einer unmittelbaren hat (Thavasu et al. 1992). Diese Angaben werden bestätigt durch eine analog durchgeführte Arbeit von Kvarnström et al. (2004). Das Einfrieren erscheint gegenüber einer Tiefkühlung ein besseres Ergebnis für die Stabilität von Rezeptoren zu erzielen (Panicker et al. 2007).

Genauso bedeutsam erscheint auch der Einfluss auf Messergebnisse durch die Benutzung von Messkits verschiedener Hersteller. Aziz konnte zeigen, dass ELISAKits unterschiedlicher Hersteller zu deutlich variablen und durchaus nicht miteinander zu vergleichenden Ergebnissen führten, so dass daraus eine entsprechende Empfehlung resultierte (Aziz et al. 1999).

In dieser Arbeit wurden pro löslichem Rezeptor jeweils Messkits eines Herstellers verwendet. Diese kommerziellen ELISA-Kits werden nach einem bereits beschriebenen standartisierten Verfahren durchgeführt und gewährleisten so laut Hersteller auch eine gute Reproduzierbarkeit mit nur geringen Variationskoeffizienten. Ein mehrfaches Auftauen und wieder Einfrieren von Proben fand in dieser Erhebung nicht statt. Bei den Urinproben wurde neben einer spontanen morgendlichen Mittelstrahlprobe für die Rezeptorbestimmung des Weiteren zur Ermittlung der Kreatinin-Clearance auch ein Sammelverfahren über 24 Stunden angewandt.

Beide Asservate wurden im Anschluss entweder zeitnah weiterbehandelt oder eingefroren. Auch die Gefriermethode stellt für den Urin ein gut etabliertes Verfahren dar, bei dem es nach dem Auftauen zu keinen wesentlichen Veränderungen in den Messkonzentrationen kommt (Parekh et al. 2007). Zusammenfassend kann festgestellt werden, dass die Gewinnung, Aufbewahrung und Bearbeitung der in dieser Arbeit verwendeten Blut- und Urinproben gängigen und gut etablierten Verfahren folgte. 


\section{2 Datengewinnung und Statistik}

\subsubsection{Erläuterungen zur Datengewinnung}

Die in dieser Arbeit erhobenen Blut- und Urinwerte, auf denen die Beschreibung der Ergebnisse, die statistische Auswertung und letztlich die Diskussion beruhen, basieren alle auf einer retrospektiven Einteilung verschiedener Zustände nach Nierentransplantation. Zunächst wurden die erhobenen Werte für jeden Patienten chronologisch aufgetragen, um so Verlaufsdatensätze jedes Patienten zu erhalten. Hier zeigten sich bereits deutlich individualspezifisch ausgeprägte Konzentrationsverhaltensweisen. Zur genauen Definition der einzelnen Zustände „stabile Transplantatfunktion“ (stabile Tx), „Abstoßungsreaktion“ und „Infektion“ sowie der nachfolgenden Zuordnung der ermittelten Werte in die jeweiligen Gruppen wurden wie bereits beschrieben eine Vielzahl klinischer, laborchemischer sowie apparativer Parameter herangezogen.

Für die Werte der löslichen Rezeptoren und des Kreatinin im Plasma bzw. Serum wurde je ein an dem Tag der retrospektiven Diagnosestellung erhobener Parameter in die Untersuchung eingeschlossen. Für das Heranziehen eines einzelnen Wertes als Beschreibung einer Situation gibt es verschiedene Ansichten und einige zusätzlich der Erläuterung dienlichen Bemerkungen. Einige Autoren sehen in der Berechung eines Mittelwertes aus beispielsweise drei Einzelwerten einer bestimmten klinischen Phase eine aussagekräftigere Möglichkeit, da so überdurchschnittlich hohe oder niedrige Momentanwerte an eine wahrscheinlichere Mitte angeglichen werden. Nun ist andererseits im Bereich der hier untersuchten löslichen Rezeptoren CD14, IL2R, CD4 und CD8 aber Folgendes festzustellen: Es fehlt hinlänglich das Wissen über die genaue immunologische Dynamik dieser Parameter. Fragen nach maximaler Aktivierung, Eliminationsprozessen, Einflussfaktoren durch beispielsweise eingeschränkte Nierenfunktion oder begleitende immunsuppressive Medikation sowie zeitlichem Verlauf von Plasmakonzentrationen bei Aktivierung des Immunsystems gleich welcher Ursache sind weitestgehend nicht geklärt. Ebenso erscheint eine Komplikation wie eine Abstoßungsreaktion oder eine Infektion nicht zu einem bestimmten Zeitpunkt „X“, sondern stellt ein hochkomplex dynamisches 
Geschehen dar, in dem exakt zeitbezogene Referenzpunkte für Beginn oder maximale Ausprägung nicht definierbar sind.

In Anbetracht dieser ungeklärten Faktoren bleibt nur der Rückzug auf die Definition von Zuständen durch anderweitig hinzuziehbare und bereits evaluierte Parameter. Auf diese Weise kann sich möglicherweise den erwähnten Wissenslücken angenähert werden.

Zudem wird unter anderem als Aufgabe dieser Arbeit die Frage nach der klinischen Verwertbarkeit der untersuchten Rezeptoren gestellt. Aus diesem Grund rechtfertigt eine Adaption an eben diese klinischen Verhältnisse durchaus auch das Heranziehen eines einzelnen Parameters und seine Überprüfung.

Die Bestimmung des löslichen CD14-Rezeptors im Urin erfolgte über eine gewöhnliche Spontanurinentnahme, wobei festzustellen ist, dass hier tatsächlich ein Mittelwert aus dem Zeitintervall von der letzten Blasenentleerung bis zur diagnostischen Urinprobe gemessen wurde. Eben dieses Zeitintervall ist jedoch erheblichen Variationen wie z.B. Trinkzeitpunkt, Miktionsdrang, Nierenfunktion oder intravenöser Volumensubstitution unterworfen und äußerst individuell ausgeprägt. Unklar ist dabei, ob und wenn in welcher Form die Konzentration des SCD14 im Endharn möglicherweise zusätzlich beeinflusst wurde. Hypothetisch wäre beispielsweise eine Abspaltung von monozytär-membranständigem CD14 (mCD14) denkbar, da diese CD14-positiven Zellen vermehrt im Endharn bei Abstoßungsreaktionen erscheinen (Grunewald et al. 2000a). Die dann lösliche Form (sCD14) würde fälschlicherweise mitdetektiert. Auch hier adaptiert sich die Datenerhebung an klinisch erprobten Vorgehensweisen.

Eine optimale und etablierte Vorgehensweise der Datengewinnung ohne interferierende Faktoren ist zusammenfassend nicht verfügbar. Viel bedeutender jedoch ist das Wissen um etwaige Fehlerquellen und die damit verbundene Wertigkeit und Aussagekraft der ermittelten Parameter für eine spätere Beurteilung, da so einer Überbewertung oder vorschnellen Festlegung auf absolute Messwerte vorgebeugt und einer Interpretation der Befunde mit der nötigen Sensibilität Vorschub geleistet werden kann (Boyd 1997). 


\subsubsection{Kritische Reflexion der angewandten biomathematischen Testverfahren}

Zur Beschreibung der erhobenen Ergebnisse und als Hilfe für eine nachfolgende Beurteilung wurden verschiedene statistische Kenngrößen erhoben bzw. Test- und Darstellungsverfahren angewandt.

Die klassischen Kenngrößen Minimum, Maximum, 95\%- und 5\%-Quartile sowie die Standardabweichung als Maß für die Streuung sind im einzelnen für jeden Datensatz aufgeführt und als Boxplot auch graphisch visualisiert worden. Das Ausmaß der teilweise weiten Streuung ist hier Ausdruck sehr interindividueller Ausprägung der gemessenen Werte auch bei gemeinsamer Zuordnung zu einem bestimmten Transplantatzustand.

Weiterhin wurde teilweise auch eine Quotientenbildung der ermittelten Werte vorgenommen, um so gegebenenfalls über eine verschiedenartige Gewichtung einzelner Parameter eine bessere Beschreibung der Verhältnisse der untersuchten löslichen Rezeptoren und des Kreatinin zueinander zu erreichen, was einem etablierten Verfahren in der klinisch chemischen Diagnostik entspricht.

Insgesamt handelt es sich bei den untersuchten Datensätzen nicht um eine klassisch-symmetrische und stetige Normalverteilung. Aus diesem Grund wird als statistischer Test der Wilcoxon-Mann-Whitney-Test gewählt und eine signifikante Irrtumswahrscheinlichkeit bei $p \leq 0,05$ angenommen.

In einem weiteren Schritt wurde über das Generieren von so genannten ROC-Kurven (Receiver-Operating-Characteristics) die Spezifität, die Sensitivität, die Area under the curve (AUC) als Hinweis auf die Trennschärfe der Untersuchung sowie auch die Cut-off-Werte ermittelt. Diese Schritte bedürfen einer äußerst kritischen Betrachtung. Es muss als erstes wiederholt werden, dass den erhobenen Daten allesamt eine retrospektive Betrachtung zugrunde liegt. Erst nach Festlegung einzelner, genau definierter Zustände wurden diese Werte in die weitere Bearbeitung eingebracht.

Die Berechnung der Spezifität und Sensitivität folgt der klassischen „Vierfeldertafel“, bei der ein Trennwert oder ein spezieller Zustand als Unterscheidungskriterium die Beobachtungen in die jeweiligen Kategorien „falsch positiv“, „richtig positiv“, „falsch negativ“ und „richtig negativ“ einteilen. Aufgrund der Überlappungsbereiche der Werte in den untersuchten Gruppen kann also für jeden Trennwert eine Kombination aus Spezifität und Sensitivität ermittelt werden. Möchte man beispielsweise bei der 
Festlegung eines Trennwertes (Cut-off-Wert) eine größere Sicherheit für richtig negative Beobachtungen (hier z.B. Nicht-Infektion/Abstoßungsreaktion als Abgrenzung zu einer stabilen Transplantatfunktion), so kann eine höhere Spezifität erreicht werden, indem man einen anderen Wert als Trennwert für die Beobachtungen definiert und erneut berechnet. Dies geht dann zu Lasten einer geringeren Sensitivität und umgekehrt.

Im Rahmen einer ROC-Kurven Berechnung wird für jeden in die Analyse eingebrachten Wert ein Trennwert angenommen und eine entsprechende Spezifität und Sensitivität ermittelt. Verschiedene Kombinationen für Spezifität und Sensitivität existieren also, eine Auswahl der geeigneten Kombination kann hier unter Gesichtspunkten der Gewichtung und Bedeutung der Treffsicherheit für die untersuchten Zustände vorgenommen werden (Linnet und Brandt 1986).

In dieser Arbeit wird als Vorgehensweise jenes Wertepaar repräsentativ herangezogen, bei dem die halbierte Summe aus Spezifität und Sensitivität den maximalen Wert aller möglichen Kombinationen ergibt [ Max = 0,5 x (Spez. + Sens.)]. Dies entspricht der Kombination, bei der die wenigsten Patienten falsch eingeordnet werden (Schäfer 1989). Abweichungen von diesem Prozedere zugunsten der ein oder anderen Optimierung bei Fragen der Unterscheidung zweier untersuchter Transplantatzustände werden explizit beschrieben.

Vergleicht man nun zwei Gruppen wie „Abstoßungsreaktion“ und „Infektion“ miteinander, so sind die gewonnenen Ergebnisse lediglich zur Unterscheidung dieser beiden ohne Einbeziehung möglicher anderer Zustände geeignet. Dieses Vorgehen eignet sich lediglich bei klinisch eindeutigem Verdacht auf eine Komplikation unter Zuhilfenahme anderer Parameter, nicht jedoch, wenn man beispielsweise gegen eine „stabile Transplantatfunktion“ abgrenzen will. Dazu müssen eben auch die dort erhobenen Werte in die Berechnung einfließen. Weiterhin ist eine Diskussion im Hinblick auf einen möglichen klinischen Einsatz nur mit prospektivem Ansatz möglich, da dann die Ergebnisse des Transplantatzustandes zum Zeitpunkt der Parameterrekrutierung nicht vorliegen. Somit müsste für die genaue Beschreibung dieser Situation jeder erhobene Wert $\mathrm{zu}$ jeder Zeit und bei jedem Transplantatzustand der statistischen Prüfung auf Spezifität und Sensitivität zugeführt werden können und diesem standhalten. Dies wiederum stellt aber nicht die Konzeption dieser Arbeit dar, entsprechend lassen sich die ermittelten Ergebnisse nicht direkt auf einen prospektiv klinisch orientierten Einsatz übertragen. 
Hier stößt die Aussagekraft der ermittelten Sensitivität und Spezifität im Rahmen dieser Arbeit an eine Grenze, die nicht dazu verleiten darf, gewonnene Ergebnisse als gemeinhin gültige Unterscheidungsmerkmale darzustellen (Linnet 1988). Gleiches gilt für den Bereich der Cut-off-Werte, die im Ergebnisteil in Klammern lediglich als orientierende Zusatzdaten mit aufgeführt sind und anzeigen, bei welchem Wert der Datengruppe die Kombination aus Spezifität und Sensitivität ausgewählt wurde. In einer retrospektiven Untersuchung kommen diese Grenzwertbestimmungen nicht zur Anwendung (Begg 1987).

Die ebenfalls dargestellte Area under the curve (AUC) folgt derselben Statistik über nichtparametrische, vergleichende Rang-Tests wie der bereits erwähnte WilcoxonMann-Whitney-Test und ist ein Maß für die Güte des Tests. Je weiter die Kurve sich von der Diagonalen abhebt (Werte zwischen 0,5 und 1 sind möglich), desto besser die Güte. Ein signifikantes Anheben der Kurve über der Diagonalen zeigt entsprechend die Trennschärfe des Tests an (Hanley und McNeil 1982).

Um weitere Informationen über das Verhalten der untersuchten Parameter zueinander zu erhalten, wurde durch eine Regressionsfunktion der Korrelationskoeffizient zwischen verschiedenen Datengruppen ermittelt. Dieser gilt hier mit Ausnahme der logarithmisch modifizierten Version bei Regression mit Exponentialfunktion im Rahmen des Vergleichs von Serumkreatinin und glomerulärer Filtrationsrate lediglich im Rahmen linear angenommener Zusammenhänge. Aufgrund der Wertespannen der untersuchten Gruppen scheint diese Annahme berechtigt. Durch das pathophysiologische Modell der Aktivierungskaskade der immunologischen Parameter kann zudem ein geforderter funktioneller Zusammenhang der Werte zur Vermeidung von Scheinkorrelationen vorausgesetzt werden. Ein Korrelationskoeffizient "r" von > oder $< \pm 0,7$ wurde als bedeutsame Korrelation gewertet (Hilgers 1995)

\subsection{GFR und Serumkreatinin, Varianzanalyse der Patientengruppen}

Bei der in dieser Arbeit neben der Serumkreatinin-Bestimmung verwandten KreatininClearance zur Abschätzung der GFR sind die Fehlerquellen bekannt, bei genauer Durchführung der Messung gilt diese Methode nach wie vor als akzeptables Instrument für die Beschreibung der Nierenfunktion. Bei einem herausgearbeiteten 
Korrellationkoeffizient von $r=-0,87$ zwischen GFR und Serumkreatinin bei Regression mit Exponentialfunktion für das untersuchte Patientenkollektiv wird gefolgert, dass eine Kreatininbestimmung im Serum vor den Hintergrund der kurzfristigen, unkomplizierten und schnellen Verfügbarkeit ein akzeptabler Laborparameter zur Beschreibung der Nierenfunktion im täglichen Gebrauch ist und dieser zu diesem Zweck auch benutzt wird.

\subsection{Löslicher CD14 im Plasma}

Die Gruppe mit der stabilen Transplantatfunktion zeigt im Plasma durchweg die niedrigsten sCD14-Konzentrationen, im Mittel $2260 \mathrm{ng} / \mathrm{ml}$ mit einer moderaten Standardabweichung von 328 ng/ml. Die Werte in den Gruppen mit Komplikationen liegen hingegen signifikant höher (stabile Tx vs. Infektion $p=0$, stabile Tx vs. Abstoßung $\mathrm{p}=0,0038$, wobei diese untereinander einen deutlichen Überlappungsbereich und eine weite Wertestreuung (Standardabweichung Abstoßung $=674 \mathrm{ng} / \mathrm{ml}$, Infektion $=685 \mathrm{ng} / \mathrm{ml}$ ) aufweisen, was auf eine sehr individualspezifische Ausprägung der immunologischen Antwort hindeutet. Diese scheint bei Infektionen mit einem Mittelwert von $3847 \mathrm{ng} / \mathrm{ml}$ insgesamt stärker ausgeprägt als bei einer akuten Abstoßungsreaktion mit einem Mittelwert von 3114 ng/ml. Betrachtet man zunächst die Gruppe mit den infektiösen Komplikationen, so finden sich hier vornehmlich Probleme im Bereich der ableitenden Harnwege, der Lunge (bakteriell) sowie die Zytomegalie-Virus-Infektion.

Innerhalb der Gruppe mit Infektionen fanden sich in dieser Untersuchung keine signifikanten Unterschiede bezüglich einer viralen oder bakteriellen Genese. Ein Mittelwert von 3975 ng/ml (Minimum = 3105 ng/ml, Maximum = $4497 \mathrm{ng} / \mathrm{ml}$ ) in der Untergruppe der bakteriellen Infektionen zeigte gegenüber viralen Infektionen mit einem Mittelwert von 3698 ng/ml (Minimum = 2987, Maximum = 5359 ng/ml) eben deutlich, dass sich die Werte beider Untergruppen auf dem gleichen PlasmaKonzentrationsniveau bewegen.

Die Klärung der Frage nach der im Mittel höheren Plasmakonzentration des löslichen CD14 bei Infektionen gegenüber Abstoßungsreaktionen erfährt substantielle Nährung durch den Umstand, dass dem löslichen CD14 unterschiedliche funktionelle Eigenschaften im Hinblick auf eine lokale oder systemische Reaktionslage zugeschrieben werden. 
So fanden Kitchens und Thompson, dass der sCD14 bei bakteriellen lokalentzündlichen Veränderungen einen lokal pro-inflammatorischen Effekt besitzt, gleichzeitig aber systemisch anti-inflammatorische Eigenschaften aufweist. Interpretiert wird dies mit der notwendigen Steigerung einer lokalen Immunantwort, ohne dabei nachteilige systemische Wirkungen zu generieren. Es handelt sich also um ein lokal bedarfsspezifisches Verhalten. Entsprechend erfährt das Immunsystem eine stärkere Aktivierung durch den sCD14 bei systemischen Infektionen. Dies wäre ein Erklärungsansatz dafür, warum die gemessenen Plasmakonzentrationen des sCD14 bei Infektionen (und hier handelt es sich in dieser Arbeit fast ausnahmslos um systemische Probleme, zumeist im Sinne septischer Verläufe), deutlich höher liegen als bei lokal entzündlichen Veränderungen. In diesem Fall allerdings vor allem durch eine Abstoßungsreaktion und nicht durch Bakterien hervorgerufene Inflammationen (Kitchens und Thompson 2005).

Bezüglich der stark variierenden Immunantwort des Iöslichen CD14-Rezeptors gibt es allerdings feste klinische Hinweise auf deren mögliche Ursache, die sich im Polymorphismus des löslichen wie auch membranständigen Rezeptors finden lassen. Bereits 1990 isolierte und charakterisierte Ferrero das Gen, welches den CD14Rezeptor codiert und vermutete bereits seinerzeit richtig, dass es sich dabei funktionell um einen Rezeptor handeln müsse (Ferrero et al. 1990). Weitere Untersuchungen spezifizierten den CD14 zunächst als myeloischen Zellrezeptor (Hubácek und Poledne 1999). Sie stellten seine Rolle als über den typischen LPSgesteuerten Weg einer Immunantwort auf verschiedene bakterielle Erreger (Pastor et al. 2007, Soler-Rodriguez et al. 2000, Cauwels et al. 1999, Steyaert et al. 2003, Ryan et al. 2002) ebenso dar wie sein erhöhtes Vorkommen bei nicht infektiösentzündlichen Prozessen (Nockher et al. 1994, Takeshita et al. 2000, Garty et al. 2000).

Das unterschiedliche Ausmaß der CD14-Expression auf Monozyten sowie die Sezernation als lösliche Form als Reaktion auf entzündliche Prozesse ist scheinbar durch unterschiedliche CD14-codierende Genotypen variabel ausgeprägt (Hubácek et al. 1999, Shimada et al. 2004, Giacconi et al. 2006, Inoue et al. 2007, Segala et al. 2007). Lin beschreibt für die T-Variante deutlich höhere sCD14-Plasmaspiegel sowie eine signifikante Akzeleration der mCD14-Expression bei Patienten mit schwergradigen Verbrennungen und Sepsis gegenüber Patienten ohne septische 
Komplikation. Dieser T-Genotyp ist in dieser Untersuchung allerdings als mit einem deutlich schwereren Krankheitsverlauf und einer erhöhten Mortalität vergesellschaftet beschrieben (Lin et al. 2006). Auch bei weiteren Erkrankungen (Verbrennungen / Sarkoidose) ist die Assoziation von signifikant erhöhten sCD14-Spiegeln mit der TGenotyp-Variante beschrieben (Dong et al. 2010, Fridlender et al. 2010).

Im Bereich der Transplantationsmedizin untersuchte Ward eine Gruppe lungentransplantierter Patienten und fand gegenüber einer stabilen Transplantatfunktion signifikant erhöhte Plasmaspiegel des sCD14 beim Bronchiolitis obliterans Syndrom (BOS) (Ward et al. 2002). Das Bronchiolitis obliterans Syndrom wird für eine chronische Form der Transplantatabstoßung gehalten (Jaramillo et al. 2005).

Gegenüber den zuvor eher prinzipiell in Erwägung gezogenen Zusammenhängen eines Genpolymorphismus des CD14-Rezeptors und der damit zusammenhängenden variablen Ausbildung einer Immunantwort in den Gruppen mit Infektionen und Abstoßungsreaktionen in dieser Arbeit präsentieren letztgenannte Untersuchungen Beobachtungen an Patienten, deren Situation mit den hier aufgeführten durchaus ähnlich bzw. vergleichbar ist. Es darf angenommen werden, dass auch für die hier untersuchten Patienten die genetische Variabilität des CD14Rezeptors mit entsprechender Ausprägung der jeweiligen Immunantwort vorhanden ist.

Auch ohne den direkten Beweis geführt zu haben wird dieses Phänomen sicherlich zumindest teilweise die interindividuell so unterschiedliche Spannbreite der löslichen CD14-Konzentrationen erklären. Vor diesem Hintergrund kann möglicherweise eine individuelle Verlaufkontrolle der Parameter vor und nach Transplantation sogar bessere Informationen zur Komplikationserkennung liefern.

Nicht außer acht gelassen werden darf dabei der sehr komplexe Mechanismus einer Immunantwort, der einen alleinigen Einfluss eines Parameters auf das Ausmaß der Immunaktivierung nicht in Anspruch nehmen bzw. entsprechend überbewerten darf. Wendet man sich nun der Bewertung dieser Ergebnisse vor dem Hintergrund einer klinischen Situation zu, so zeigt die isolierte Betrachtung in den Gruppen stabile Transplantatfunktion und Infektion für Spezifität und Sensitivität mit je $100 \%$ und einem $p=0$ die höchstmögliche Unterscheidbarkeitsstufe an. Beide Wertegruppen überschneiden sich nicht, die maximal gemessene sCD14-Plasmakonzentration in der Gruppe der stabilen Transplantatfunktion (2806 ng/ml) liegt noch unterhalb der 
minimal gemessenen Konzentration in der Gruppe der Infektionen (2987 ng/ml). Eine isolierte Betrachtung zwischen stabiler Transplantatfunktion und Abstoßungsreaktion zeigt einen Überlappungsbereich, der dazu führt, dass nur zu $70 \%$ die nicht von der Komplikation Betroffenen und zu 84\% die von einer Abstoßung betroffenen Patienten korrekt anzeigt werden. Schlechter wird die Abgrenzbarkeit zwischen den beiden Komplikationsformen aufgrund der Werteüberschneidung mit einer Spezifität von 63 $\%$ und einer Sensitivität von $92 \%$ bei isolierter Sicht auf beide Gruppen.

Insgesamt ist diese Vorgehensweise aus statistischer Sicht nicht ganz korrekt, da hier jeweils zwei von drei untersuchten Gruppen miteinander verglichen werden, Sensitivität und Spezifität sich aber auf das ganze Kollektiv der untersuchten Probanden beziehen müssen.

Klinisch interessiert vielmehr die Frage, wie sicher der Patientenanteil mit einer stabilen Transplantatfunktion von dem mit Komplikationen abgegrenzt werden kann. Legt man hier den Trennwert bei 2879 ng/ml fest, so können mit einer Spezifität von $100 \%$ nicht Betroffene erkannt werden. Eine Sensitivität von $78 \%$ zeigt, dass fast ein Viertel der Patienten nicht richtig der Gruppe der Komplikationen zugeordnet werden kann, also aus statistischer Sicht falsch negativ bewertet würde. Trotzdem weist eine Area under the curve (AUC) von 0,93 auf eine große Trennschärfe zwischen beiden Gruppen hin.

Zusammenfassend spiegeln diese Tatsachen einen Zustand wider, der sich auch in der Literatur finden lässt. Zahlreiche Arbeiten beschreiben für infektiöse Konstellationen deutlich erhöhte Plasmakonzentrationen des löslichen CD14Rezeptors gegenüber nicht infektbelasteten Patienten, ebenso finden sich Publikationen, die bei transplantierten Menschen einen signifikanten Unterschied zwischen einer Abstoßungsreaktion und einer normalen Transplantatfunktion darlegen. Nicht untersucht ist bislang die Fragestellung, ob es zwischen beiden Komplikationsformen eindeutige Unterschiede der Immunantwort bezüglich des Auftretens des löslichen CD14-Rezeptors im Plasma gibt.

Die Ergebnisse dieser Arbeit zeigen, dass eine Unterscheidung der Komplikationsformen mittels sCD14 im Plasma nicht gelingt. Ebenso ist keine Unterscheidung von bakteriellen und viralen Infektionen möglich. Die wahrscheinlich auf dem Boden eines Genpolymorphismus beruhende weite Streuung der Werte verhindert eine klare Zuordnung. Die stabile Transplantatfunktion kann gegenüber den Komplikationen mit 100\%iger Spezifität und 78\%iger Sensitivität abgegrenzt 
werden, immer zu betrachten vor dem Hintergrund der reduzierten Aussagekraft retrospektiv erhobener Daten.

Es bleibt allerdings fraglich, ob Höhe und Ausmaß der gemessenen Immunantwort, präsentiert durch den löslichen CD14-Rezeptor, wirklich die Summe aller Aktivierungsmechanismen des Immunsystems darstellen oder ob nicht auch die Elimination, hier besonders bei einer eingeschränkten Nierenfunktion, eine Rolle bei der gemessenen Plasmakonzentration des untersuchten löslichen Rezeptors spielt. Dies soll im Folgenden näher beleuchtet werden.

\subsection{Glomeruläre Teilfunktion und Konzentration des sCD14 im Plasma}

Da die Elimination der gemessenen löslichen Rezeptoren aufgrund ihres Molekulargewichts von weniger als 70 kD über die Niere erfolgt, stellt sich die Frage, ob die gemessenen Konzentrationen dieser Mediatoren wirklich nur den Grad der Aktivierung des Immunsystems widerspiegeln, oder ob nicht auch Veränderungen im Eliminationsweg einen Einfluss auf die gemessenen Werte haben. Beeinflusst also die Nierenfunktion die Rezeptorkonzentration im Plasma und im Urin ?

Um dieser Fragestellung nach zu gehen wurde die Konzentration des löslichen CD14 im Plasma mit der Kreatininkonzentration im Serum ins Verhältnis gesetzt, es erfolgte also eine Quotientenbildung beider Parameter. Das Gesamtergebnis zeigt zunächst, dass die Kreatininwerte der einzelnen Gruppen, und damit die glomeruläre Filtrationsrate als reziprokes Korrelat dieses Parameters, sich signifikant voneinander unterscheiden. Weist die Gruppe der stabilen Transplantatfunktion einen Mittelwert von 1,22 mg/dl auf, so ist dieser bei Infektionen bereits mit 3,37 mg/dl deutlich und bei Abstoßungsreaktionen mit 6,65 mg/dl noch bedeutend weiter erhöht. Zwischen der Gruppe des stabilen Transplantats und der Abstoßung besteht gar keine Werteüberschneidung ( $p=0$ ), die Gruppen „stabile Tx“ und Infektion unterscheiden sich darüber hinaus ebenso signifikant mit $p=0,002$ wie die Gruppen Abstoßung und Infektion mit $p=0,004$. Hierbei haben die Abstoßungsreaktionen erwartungsgemäß die höchsten Kreatininwerte, damit also die niedrigste glomeruläre Filtrationsrate. Kausal affektiert die Abstoßungsreaktion direkt das Organ Niere, was folglich zu einer erheblicheren Funktionseinschränkung führt als eine systemische Inflammationen mit begleitender und zumeist milderer Insuffizienz der Nierenfunktion. Würde nun erwartet werden, 
dass bei einer eingeschränkten glomerulären Filtrationsrate aufgrund des verminderten Ultrafiltrates entsprechend weniger lösliche Rezeptoren den Glomerulus passieren und deshalb entsprechend im Plasma verweilen, so müsste es zwischen dem Serumkreatinin und der Plasmakonzentration des löslichen CD14Rezeptors eine positive Korrelation geben. Diese besteht aber signifikant für keine der untersuchten Gruppen. Die Abstoßungsreaktionen und Infektionen zeigen mit einem $r=0,23$ bzw. $r=0,59$ zwar einen Trend der diese Annahme stützt, erreichen aber nicht den zuvor definierten Grad einer signifikanten Korrelation.

Im Bereich der stabilen Transplantatfunktion zeigt sich mit einem $r=-0,22$ ein diskret gegenläufiges Verhalten. Ein direkter Einfluss der glomerulären Filtrationsrate auf die Plasmakonzentration des löslichen CD14 mit der Idee einer höheren Plasmakonzentration durch eine verminderte GFR im Sinne einer verminderten Clearence lässt sich anhand dieser Daten also nicht ableiten.

Allerdings zeigt die Quotientenbildung beider Parameter, dass diese in der Gruppe der Abstoßungsreaktionen, also der Gruppe mit der weitaus niedrigsten glomerulären Filtrationsrate, sich signifikant von den beiden anderen Gruppen unterscheiden. Ein mittlerer Quotient von 730 gegenüber 1832 bei stabiler Transplantatfunktion und 1425 bei Infektionen verdeutlicht dies. Eine Varianzanalyse zeigt hier mit $p=0,0003$ gegenüber dem stabilen Transplantat und $p=0,006$ gegenüber den Infektionen ein ebenso signifikantes Unterscheidungsniveau. Der niedrige Quotient bei Abstoßungsreaktionen resultiert hier aus der verhältnismäßig hohen Kreatininkonzentration im Serum, gestärkt auch durch die Tatsache, dass die Konzentrationen des löslichen CD14 im Plasma in der Gruppe der Abstoßungsreaktionen im Mittel zwischen denen der stabilen Transplantatfunktion und den Infektionen liegen. Dies spricht für den überproportionalen Einfluss der Kreatininkonzentration und damit der Nierenfunktion auf das Quotientenniveau gegenüber den anderen Gruppen.

In einer unter retrospektiven Bedingungen erhobenen und mit den entsprechenden Einschränkungen für eine prospektive klinische Verwendung zu berücksichtigenden Analyse bezüglich der Spezifität und Sensitivität der untersuchten Gruppendaten kann bei der Quotientenbildung von löslichem CD14 und Serumkreatinin zwischen einer stabilen Transplantatfunktion und einer Abstoßung bei einem angenommenen Trennwert von 1208 mit einer Sensitivität von 100\% und einer Spezifität von 84\% unterschieden werden. 
Es könnte also jeder an einer Abstoßung erkrankte Patient richtig positiv erkannt werden und immerhin $84 \%$ der nicht von einer Abstoßungsreaktion betroffenen Patienten korrekt detektiert werden. Es verblieben also ca. 15\% der Patienten, denen zu Unrecht eine Abstoßungsreaktion diagnostiziert würde. Nun ist diese Konstellation für die klinische Betrachtungsweise allerdings weniger interessant als eine mögliche Unterscheidung zwischen den beiden Komplikationsformen. Hier findet sich bei einem angenommenen Trennwert von 914 eine Spezifität von 74\% bei einer Sensitivität von $85 \%$. Wie wenig unterscheidbar hingegen die Infektionen von den stabilen Transplantatfunktionen in dieser Analyse sind wird bei deren Vergleich mit einem angenommenen Trennwert von 1425 und einer Spezifität von 80\% sowie einer Sensitivität von lediglich $54 \%$ deutlich. Es muss hierbei aber eindringlich darauf hingewiesen werden, dass nur jeweils zwei von drei Gruppen miteinander verglichen wurden, also eine retrospektive Betrachtung mit vorheriger Gruppeneinteilung vorgenommen wurde.

Deshalb wurden die einzelnen Gruppen auch jeweils gegen die beiden verbliebenen Gruppen statistisch geprüft. Hier kann die akute Abstoßungsreaktion bei einem angenommenen Trennwert von 1208 immerhin mit einer Spezifität von 84\% und einer Sensitivität von $87 \%$ gegenüber den stabilen Transplantatfunktionen und den Infektionen abgegrenzt werden. Dabei werden jeweils ca. $15 \%$ der betrachteten Patienten allerdings einer nicht korrekten Diagnose zugeordnet.

Bei einer Area under the curve (AUC) von 0,88 zeigt diese Untersuchung jedoch eine deutliche Trennschärfe. Dies erklärt sich dadurch, dass durch den überproportional hohen Einfluss des Kreatinin in der Gruppe der Abstoßungsreaktionen die gebildeten Quotienten deutlich niedriger sind als in den beiden anderen untersuchten Patientensituationen. Entsprechend weniger scharf ist die Trennung der anderen Konstellationen. So können die Infektionen lediglich mit einer Spezifität von $66 \%$ und Sensitivität von 77\% (Trennwert angenommen für 1355, AUC = 0,7) und die stabilen Transplantatfunktionen mit einer Spezifität von $100 \%$ bei einer Sensitivität von lediglich 59\% (Trennwert angenommen für 1075, AUC = 0,78) von den entsprechend verbliebenen Gruppen abgegrenzt werden.

Die Hypothese, dass allein eine geringere glomeruläre Filtrationsrate eine erhöhte Plasmakonzentration des löslichen CD14 durch eine verminderte Clearance bedingt, lässt sich zunächst nicht bestätigen. 
Vergleichbare Daten aus dem Bereich von transplantierten Patienten liegen allerdings für das Cystatin C vor, einem 13-kD-großen (122 Aminosäuren) Protein aus der Familie der Cystein-Proteinase-Inhibitoren, welches mit einer konstanten Rate von allen kernhaltigen Zellen produziert wird. Es wird im Tubulus der Niere nicht sezerniert und unter physiologischen Bedingungen dort zu über 99\% resorbiert und abgebaut, also nicht in den Körper zurückgegeben (Baxmann et al. 2008, Mussap und Plebani 2004). Allerdings kann die Konzentration des Cystatin C im Plasma auch, aber möglicherweise nicht so stark wie das Kreatinin, durch extrarenale Faktoren wie eine Kortikoidtherapie, eine Herzinsuffizienz oder eine Schilddrüsenfehlfunktion beeinflusst werden (Herget-Rosenthal et al. 2007). Funktionell wird das Cystatin C wie auch die untersuchten löslichen Rezeptoren frei glomerulär filtriert.

Im Bereich von nierentransplantierten Patienten ist das Protein für eine stabile Transplantatfunktion wie auch für eine akute Abstoßungsreaktion untersucht. Es zeigt ein bezüglich der glomerulären Filtrationsrate ähnliches Verhalten wie das Kreatinin und wird je nach Autor und Untersuchung in seiner Aussagekraft dem Kreatinin als ebenbürtig bzw. leicht unterlegen dargestellt (Zahran et al. 2007b, Louvar et al. 2007, Zahran et al. 2007a, Koçak et al. 2005, Pöge et al. 2006). Wichtig ist in dem hier beleuchteten Kontext die Tatsache, dass für das Cystatin C ein klar erkennbarer Zusammenhang mit der GFR beschrieben ist bei einem auch in dieser Arbeit untersuchten Patientenkollektiv. Ferner ist es aufgrund seiner Molekülgröße den hier behandelten löslichen Rezeptoren sehr ähnlich.

Gegen eine direkte bzw. alleinige Abhängigkeit des löslichen CD14 von der glomerulären Filtrationsrate spricht jedoch eine Untersuchung von Ward und seiner Arbeitsgruppe, der diesen löslichen Rezeptor bei lungentransplantierten Patienten untersucht hat. Es zeigten sich hier signifikant erhöhte Plasmakonzentrationen in Assoziation mit dem Bronchiolitis obliterans Syndrom (BOS) (Ward et al. 2002), das als chronische Form der Transplantatabstoßung erachtet wird (Jaramillo et al. 2005). Es lag allerdings keine wie bei dieser Arbeit ermittelte Niereninsuffizienz vor, was eben gegen den unmittelbaren Einfluss der GFR auf die Plasmakonzentration des löslichen CD14 spricht.

Die Hypothese, dass die Konzentration des löslichen CD14 im Plasma direkt von der glomerulären Filtrationsrate abhängig ist, kann anhand dieser 
Daten zunächst nicht bestätigt werden. Dies wird gestützt durch die erwähnte Untersuchung von Ward. Allerdings gibt es andererseits in dieser Arbeit Beobachtungen, die einen eindeutigen Zusammenhang zwischen Nierenfunktion und sCD14-Spiegel nahelegen. Jeweils direkt nach Nierentransplantation lassen sich auch bei stabilem Transplantatverlauf zunächst hohe Kreatinin- wie auch SCD14Spiegel verfolgen, die im Verlauf gleichsinnig abnehmen (siehe bitte Abb. 3.1 und 3.2). Selbiges kann sogar zunächst für Verläufe aus den Gruppen Abstoßung (siehe bitte Abb. 3.6 und 3.7) und Infektion (siehe bitte 3.11 und 3.12) beobachtet werden. Gestützt wird dieser mögliche Zusammenhang durch Untersuchungen, in denen eine signifikant höhere CD14-Konzentration bei chronisch Nierenkranken gemessen wurde (Merino et al. 2008). Weiterhin gibt die Analogie zum Cystatin C der These einer Einflussnahme der Nierenfunktion auf sCD14-Plasmaspiegel recht.

Möglicherweise sind die Ergebnisse der Quotientenbildung von sCD14 und Kreatinin, bedingt durch überproportionale Erhöhung des Kreatinin bei Abstoßung, artifizieller Natur. Ein direkt-kausaler Zusammenhang erscheint sehr unwahrscheinlich.

Frei von beweisbarer Kausalität lassen aber trotz allem die Quotienten aus der CD14-Plasmakonzentration und dem Serumkreatinin eine in Teilen klare Unterscheidung der einzelnen Transplantatsituationen zu.

Möglicherweise spielt neben der glomerulären Funktion die tubuläre eine wichtige Rolle in diesem Geschehen, ein Punkt, der im Weiteren betrachtet werden soll.

\subsection{Proximaler Tubulus: Einfluss auf sCD14 in Plasma und Urin}

Da eine rein glomerulär gesteuerte Beziehung zwischen der Nierenfunktion und der Plasmakonzentration des löslichen CD14-Rezeptors nach Datenlage dieser Arbeit nicht zu bestehen scheint muss die Möglichkeit des tubulären Einflusses auf die Plasma- bzw. Urinkonzentration des untersuchten löslichen Rezeptors geprüft werden.

Zunächst wurde dazu eine Korrelation des Serumkreatinin mit der Urinkonzentration des löslichen CD14-Rezeptors vorgenommen. Dies geschah in der Annahme, dass eine Einschränkung der glomerulären Filtrationsrate eine verminderte Clearance des Iöslichen CD14 zur Folge haben müsste, dieses also bei einem hohen Kreatininwert mit einer negativen Korrelation im Urinbefund einhergehen müsste. 
Die abgeleiteten Ergebnisse zeigen in den untersuchten Transplantatzuständen zumindest einen Trend für eine solche Korrelation bei der stabilen Transplantatfunktion und der Abstoßungsreaktion mit Korrelationskoeffizienten von $r$ $=-0,47$ bzw. $r=-0,7$, wobei das zuvor festgelegte Signifikanzniveau lediglich in der Gruppe der Abstoßungsreaktionen gerade erreicht wird. Bei Patienten mit einer Infektion konnte indes eine entgegengesetzte, aber nicht signifikante Korrelation von $r=+0,59$ abgeleitet werden.

Weiterhin wurden die Konzentrationen des Iöslichen CD14 im Urin miteinander verglichen. Bei nahezu identischen Mittelwerten von 879 ng/ml, 855 ng/ml und 897 ng/ml für die Gruppen „stabile Transplantatfunktion“, „Abstoßungsreaktion“ und „Infektion“ fanden sich hier entsprechende Signifikanzniveaus von $p=0,78 / 0,86 / 0,97$, was als nahezu vollständige Überlappung aller Gruppenmesswerte interpretiert werden kann.

Eine weitere Korrelation des löslichen CD14, nämlich im Plasma und im Urin, erbrachte Koeffizienten von $r=-0,29,-0,02$ und $+0,1$ für die Gruppen „stabile Transplantatfunktion“, „Abstoßung“ und „Infektion“. Die Annahme, das eine hohe plasmatische Konzentration auch einen entsprechend akzelerierten Niederschlag im Urin nach sich ziehen würde konnte hiermit nicht bestätigt werden. Folglich wird die Urinkonzentration des SCD14 im Wesentlichen eben nicht durch die Konzentration im Plasma bestimmt.

Es muss an dieser Stelle noch einmal die physiologische Situation von frei glomerulär filtrierbaren Peptiden, Polypeptiden und Proteinen in Erinnerung gerufen werden. Diese unterliegen im proximalen Tubulus der Niere entweder einer Spaltung am luminalen Bürstensaum und werden als Aminosäuren resorbiert, oder als Dibzw. Tripeptide über spezifische Peptid- $\mathrm{H}^{+}-$Symportcarrier in die proximalen Tubuluszellen aufgenommen. Für Proteine von der Größe der untersuchten löslichen Rezeptoren steht eine ATP-abhängige endozytotische Resorption bereit. Alle diese Systeme arbeiten unter physiologischen Situationen bereits mit einer hohen Sättigungskinetik und einer Resorptionsquote von 98 bis 99,5\% (Silbernagl 2003). Unter pathologischen Bedingungen kommt es aufgrund von Überlastung durch vermehrtes Proteinaufkommen (glomerulärer Defekt) oder durch Funktionseinschränkungen am Tubulus (z.B. Ischämie) für das System zu nicht beherrschbaren Resorptionssituationen und einer nachfolgenden Proteinurie. Nimmt 
man nun an, dass nach Nierentransplantation das Transplantat stabil funktioniert und legt man zudem die ermittelte mittlere glomeruläre Flitrationsrate von $97 \mathrm{ml} / \mathrm{min}$ (im physiologischen Mittel werden pro Niere ca. 62,5 ml/min angegeben, eine Adaption an höhere Werte ist möglich) für diese Gruppe sowie eine Filtrationsfraktion von $20 \%$ zugrunde, müsste bei mittlerer Plasmakonzentration des löslichen CD14 von 2260 $\mathrm{ng} / \mathrm{ml}$ und angenommener, komplett fehlender Rückresorption im proximalen Tubulus eine mittlere Urinkonzentration von ca. $450 \mathrm{ng} / \mathrm{ml}$ folgen. Diese beträgt aber in dieser Untersuchung im Mittel 879 ng/ml, also weit mehr, als im „optimistischsten“ Fall hätte erwartet werden können.

Gleiches gilt für die pathologischen Zustände Abstoßung und Infektion. Auch hier wären unter maximal proteinurischen Verhältnissen im Mittel lediglich $623 \mathrm{ng} / \mathrm{ml}$ (Abstoßung) bzw. 769 ng/ml (Infektion) zu erwarten gewesen. Gemessen wurden aber im Mittel 855 ng/ml bzw. 897 ng/ml. Dies ausdrücklich unter der Annahme einer weiter bestehenden Filtrationsfraktion von 20\%, was angesichts der in diesen Gruppen bestehenden Niereninsuffizienz, ausgewiesen durch Serum Kreatininwerte von im Mittel 6,65 mg/dl (GFR-mittel $=27 \mathrm{ml} / \mathrm{min}$ ) bei Abstoßungen und 3,37 mg/dl $($ GFR-mittel $=59 \mathrm{ml} / \mathrm{min})$ bei Infektionen, nicht einer realen Situation zu entsprechen scheint. Die untersuchten Parameter scheinen ohne kausalen Zusammenhang nebeneinander zu existieren.

Gestützt wird die scheinbar unabhängig vom Plasmagehalt des löslichen CD14 bestehende Urinkonzentration durch die Tatsache, dass in den hier durchgeführten Untersuchungen keinerlei Korrelation zwischen der Plasma- und Urinkonzentration des löslichen CD14 besteht. Mit Korrelationskoeffizienten von $r=-0,29$ (stabile Transplantatfunktion), $r=-0,02$ (Abstoßung) und $r=+0,1$ (Infektion) wird die Annahme, dass eine hohe Plasmakonzentration aufgrund der bekannten Mechanismen an Glomerulus und proximalem Tubulus auch eine positive Korrelation in Bezug auf die Urinkonzentration nach sich ziehen müsse, deutlich widerlegt. Etwas widersprüchlich steht dieser Feststellung die Tatsache gegenüber, dass eine Korrelation von Serum Kreatinin mit der Konzentration des löslichen CD14 im Urin immerhin in der Gruppe der Abstoßungen mit $r=-0,7$ knapp ein signifikantes Niveau erreichte.

Wie lassen sich diese Daten nun in ein pathophysiologisches Konzept einbetten, das die Sachverhalte erklären kann? 
Da weder die Befunde von Plasma- und Urinkonzentration des löslichen CD14 noch die Serum-Kreatininwerte und die sCD14-Urinkonzentration hinreichend miteinander korrelieren und die maximal erwartete Urinkonzentration des löslichen CD14 vor dem Hintergrund bestehender Plasmakonzentrationen weit überschritten wird, muss es in allen Gruppen zwischen der Entstehung des Ultrafiltrates und der Rezeptorbestimmung im Endharn zu einer Konzentrationserhöhung des löslichen CD14 gekommen sein.

Als erste Hypothese wird eine mögliche Sezernation von sCD14 ins Tubuluslumen in Betracht gezogen.

Gut belegt ist hier die Tatsache, dass Proteine, die das Glomerulus passiert haben, an den tubulären Nierenzellen ein chemotaktisches Signal induzieren können, welches über MCP-1 (Monocyte chemoattractant protein-1 bzw. synonym CCL2 = Chemokine-ligand-2) eine Infiltration des Gewebes durch Makrophagen herbeiführt (Eardley et al. 2006). Insbesondere für das Albumin konnte dies jüngst in einer Untersuchung von Lai dargestellt werden, der diesen Mechanismus an einem in vitro Zelllkultur-System beobachtete (Lai et al. 2007). Das Ausmaß des Stimulus auf das MCP-1 korreliert wiederum mit der Konzentration der im Gewebe erscheinenden Monozyten/Makrophagen, wie Rice mit seiner Arbeitsgruppe an einem Rattenmodell im Rahmen einer induzierten renalen Ischämie zeigen konnte (Rice et al. 2002). Eine aktuelle Arbeit von Stasikowska vereint diese Befunde in sofern, als dass hier bei Patienten mit einer Glomerulopathie ganz unterschiedlicher Genese und Patienten mit einer Abstoßungsreaktion nach Nierentransplantation auf das MCP-1 und die Konzentration von Monozyten/Makrophagen in peritubulären Zellen hin untersucht wurden. Die Untersuchung bestätigt, dass in beiden Fällen eine erhöhte MCP-1Expression mit einer Erhöhung der im Gewebe nachweisbaren Monozyten/Makrophagen-Konzentration einhergeht (Stasikowska und WagrowskaDanilewicz 2007). Insgesamt wird hier aufgezeigt, dass eine Anreicherung der proximalen tubulären Epithelzellen mit CD14-positiven Monozyten/Makrophagen nach Nierentransplantation und insbesondere im Rahmen einer Abstoßungsreaktion auch für die in dieser Arbeit untersuchten Patienten gelten dürfte. Damit ist ein Umstand beschrieben, der günstige Verhältnisse für die aufgestellte These einer Sezernation von sCD14 oder CD14-positiven Zellen ins Tubuluslumen schafft. 
Es finden sich aber in der Literatur keinerlei Hinweise bzw. Beweise, die auch eine Sezernation dieser Zellen oder zumindest des löslichen CD14 ins Tubuluslumen beschreiben. Einzig eine Arbeit von Bussolati konnte in einem experimentellen Rahmen zeigen, dass die proximalen tubulären Epithelzellen im Rahmen einer Infektion bzw. Sepsis zwar vom bakteriellen Antigen in Form des LPS (Lipopolysaccharid) betroffen sind, aber nicht mit einer Expression von membranständigem CD14 oder löslichem CD14 reagieren oder dies sezernieren (Bussolati et al. 2002).

Bleibt also, der zweiten Hypothese zu folgen, die eine Veränderung der Konzentration im Endharn in den Blickpunkt weiterer Überlegungen rückt. Hier sei darauf verwiesen, dass die Messung des löslichen CD14 im Urin nicht einem Momentanwert entspricht, sondern gegenüber den Konzentrationsbestimmungen im Plasma aus einem Zeitintervall ermittelt wird. Dieses ist, wie bereits andernorts beschrieben, sehr variabel im Ausmaß und von vielerlei Faktoren beeinflusst. Denkbar wäre eine Abspaltung des membranständigen CD14-Rezeptors von entsprechenden Zellen im Endharn, welcher dann folglich als lösliche Variante gemessen wird. Das Vorkommen von CD14-positiven Monozyten/Makrophagen im Urin bei Nierentransplantierten wurde bereits von Grunewald und seiner Arbeitsgruppe untersucht. Hier fanden sich in der immunzytologischen Aufarbeitung wenige dieser Zellen bei stabiler Transplantatfunktion, aber signifikant höhere Vorkommen im Rahmen einer Abstoßungsreaktion (Grunewald et al. 2000a). Erhöhte Urinkonzentrationen des löslichen CD14 fanden sich darüber hinaus bei Patienten mit septischen Krankheitsbildern, in niedrigeren Konzentrationen sogar bei normal gesunden Probanden (Bussolati et al. 2002). Insgesamt scheinen die Vorraussetzungen für ein Modell der Ablösung des membranständigen CD14Rezeptors im Endharn bei der hier untersuchten Patientengruppe vor dem Hintergrund recherchierbarer Literatur gegeben, allein der direkte Beweis erschließt sich nicht aus den zeitgenössischen Publikationen.

Zusammenfassend bleibt festzustellen, dass die ermittelten Urinkonzentrationen des sCD14 in allen drei Patientensituationen das zu erwartende Maß deutlich überschreiten und sich untereinander nicht differenzieren lassen. Ein kausaler Zusammenhang mit der Nierenfunktion oder dem sCD14-Plasmagehalt ist nicht anzunehmen, die Phänomene sind unabhängig voneinander zu sehen. 
Welcher Mechanismus dieser Tatsache letztendlich zugrunde liegt, lässt sich auch nach eingehender Literaturrecherche nicht erhellen. Die Konzentrationsbestimmung des löslichen CD14 im Urin hat indes keinerlei diagnostischen Nutzen.

\subsection{Erhöhung von sCD14 bereits vor Diagnose von Infektion und Abstoßung}

Bei der Durchsicht der Plasmakonzentrationen des löslichen CD14 im chronologischen Verlauf einer Patientenbeobachtung zeigte sich, dass sich schon im Vorfeld der definierten Transplantatzustände „Abstoßungsreaktion“ und „Infektion“ die abgeleiteten Messergebnisse in den Gruppen mit Komplikationen deutlich vom Niveau einer stabilen Transplantatfunktion abhoben. Dieser Aspekt wurde jenseits der eigentlichen Fragestellung der Arbeit mit in diese Betrachtung aufgenommen, da dies augenscheinlich einen wichtigen Aspekt der Dynamik des löslichen Rezeptors widerspiegelt.

Lagen die gemessenen Plasmakonzentrationen des löslichen CD14 in den Gruppen der Komplikationen „Abstoßung“ und „Infektion“ vier Tage vor der retrospektiv analysierten Komplikationsform im Mittel mit 2696 ng/ml bzw. 2683 ng/ml zwar schon über dem Mittelwert von $2257 \mathrm{ng} / \mathrm{ml}$ bei stabiler Transplantatfunktion, aber immerhin noch im Bereich des Konzentrationspektrums bei stabilem Transplantat (Maximum bei stabiler Tx $=2806 \mathrm{ng} / \mathrm{ml}$ ), so fanden sich bereits 2 Tage vor den retrospektiv betrachteten Ereignissen erhebliche Unterschiede zum komplikationslosen Verlauf.

In der Gruppe der Abstoßung ließ sich eine 20\%ige Steigerung gegenüber der Konzentration bei stabilen Transplantatverhältnissen herausarbeiten $(2265 \mathrm{ng} / \mathrm{ml}$ vs. $2723 \mathrm{ng} / \mathrm{ml})$, bei Infektionen lag sogar eine Steigerung von 40\% (2265 ng/ml vs. 3170 $\mathrm{ng} / \mathrm{ml}$ ) vor. Die Differenzierung zwischen einer stabilen Transplantatfunktion und einer Abstoßung liegt hier bei einem $p=0,06$ knapp neben einem signifikanten Niveau. Gegenüber der Infektion läßt sich das stabile Transplantat mit $p=0,027$ jedoch signifikant angrenzen.

Dies legt die Vermutung nah, dass sich das immunologische Geschehen bereits vor klinischen, apparativen und laborchemischen Verfahrensweisen als bedeutsam signifikante Manifestation in der Konzentration des löslichen CD14 widerspiegelt. Vor allem in der Gruppe der Infektionen ist dieser Konzentrationssprung am deutlichsten ausgeprägt, möglicherweise als Antwort auf eine systemische Inflammation, 
da diese scheinbar mit einer generell erhöhten Rezeptorausschüttung einher zu gehen scheint als eine auf ein Organ bezogene Entzündungsreaktion. Zumindest weist die Gruppe mit Infektionen, und hier ausnahmslos septische Krankheitsbilder, die im Mittel höchsten Plasmakonzentrationen des löslichen CD14 auf.

Dies deckt sich mit einer Beobachtung von Grunewald, der bei der Untersuchung der löslichen Zellrezeptoren SCD4 und SCD8 bei einer akuten Abstoßungsreaktion sowie bei einer CMV Infektion bereits einen deutlichen Konzentrationsanstieg dieser beiden löslichen Rezeptoren im Plasma retrospektiv herausarbeiten konnte (Grunewald et al. 2000b).

Hier kann ein klinischer Ansatzpunkt für eine frühere Detektion von Komplikationen nach Nierentransplantation bestehen, da sich die beschriebenen immunologischen Parameter bereits vor konventionellen Methoden bedeutsam verändert zeigen. Diese Arbeit lässt eine weitere Vertiefung aufgrund der retrospektiven Datenaufarbeitung aber nicht zu. Weitere Bemühungen in diese Richtung sind wünschenswert.

\subsection{Verhältnis von löslichem CD14 und Iöslichem IL2R im Plasma}

Das Interleukin-2 und der analoge membranständige Rezeptor sind immunologische Marker, die bereits in einer sehr frühen Phase einer Aktivierung und an zentraler Position in die Reaktionskette einer Immunantwort eingreifen. Sie regeln dabei u.a. entscheidend die Stärke und die Dauer einer T-lymphozytären Immunantwort oder verstärken beispielsweise die Proliferation von B-Lymphozyten (Flad und Gemsa 1997).

Nach Abspaltung des Interleukin-2-Rezeptors wird dieser im Plasma als löslicher Interleukin-2-Rezeptor (sIL2R) in erhöhten Konzentrationen bei Aktivierung des Immunsystems gleich welcher Genese nachweisbar, wobei über eine eigene Funktion des löslichen Rezeptors wenig bekannt ist. Anhand der Konzentrationsmessungen beider aus der Überschrift ersichtlicher Parameter und deren Beurteilung ist es Ziel dieser Arbeit, gemeinsame oder gegenläufige Merkmale zu beschreiben und ggf. zu interpretieren, um so ein möglicherweise detailierteres Bild über definierte immunologische Situationen zu erhalten.

Zunächst zeigen die in dieser Arbeit gemessenen Konzentrationen des löslichen IL2Rezeptors deutlich höhere plasmatische Werte für die Komplikationsformen „Abstoßung“ und „Infektion“ als für eine stabile Transplantatfunktion. 
Liegen die mittleren Konzentrationen einer stabilen Transplantatfunktion bei 92 pM, so sind sie bei akuten Abstoßungsreaktionen und Infektionen mit mittleren Messungen von 205 pM bzw. 223 pM signifikant erhöht. Dies spiegelt sich auch in einem entsprechenden Signifikanzniveau von $p=0,0049$ für Abstoßungen und $p=$ 0,0054 für Infektionen gegenüber der komplikationslosen Verlaufsform wider. Untereinander lassen sich die Komplikationen bei einem großen Überlappungsgrad nicht differenzieren, was sich im resultierenden $p=0,23$ widerspiegelt.

Eine signifikante Konzentrationserhöhung des löslichen IL2-Rezeptors als Komplikationsindikator im Rahmen von Organtransplantationen ist neben der Niere auch bei Herztransplantierten bereits belegt. So konnten Zucchelli wie auch Gupta in diesem Bereich zeigen, dass sich sowohl bei akuten Abstoßungsreaktionen wie auch bei systemischen Infektionen im posttransplantären Verlauf signifikant höhere plasmatische Konzentrationen des löslichen IL2R nachweisen lassen als bei stabiler Transplantatsituation.

Ebenso wenig gelang es, eine Differenzierung zwischen Abstoßung und Infektion vorzunehmen, denn dazu wurde der Parameter als nicht spezifisch genug eingestuft (Gupta et al. 2004 / Zucchelli et al. 1990). Auch Mehta fand signifikant erhöhte sIL2R-Konzentrationen bei akuter Abstoßung einer Transplantatniere, kam nach einem Vergleich mit prä-transplantär ermittelten Daten aber zu dem Schluss, dass die individuelle post-transplantäre Ausprägung der sIL2R-Konzentration selbst ein schlechterer Indikator für die Detektion einer akuten Abstoßung sei als die Zuhilfenahme des prä-transplantären Wertes mit Bildung eines Quotienten. Dieses Vorgehen berücksichtige eine unabhängig von der Transplantation bestehende individuelle sIL2R-Ausprägung bzw. -Vorprägung, so der Autor (Mehta et al. 2004). Mit zwölf Individuen war die untersuchte Gruppe, kritisch betrachtet, relativ klein. Die Idee, der außerordentlich großen Spannweite der individuellen Immunantwort mit einem von der Transplantation unabhängigen, aber individuell bereits aussagekräftigen Parameter eine evidentere Position zu verschaffen, stellt einen viel versprechenden Ansatz dar.

Wendet man sich dem Vergleich der löslichen Rezeptoren zu, erscheinen beide positiv miteinander korreliert, wobei lediglich die Gruppe mit „stabiler Transplantatfunktion“ mit einem $r=0,73$ ein signifikantes Niveau erreicht, „Abstoßung“ und „Infektion“ mit $r=0,23$ bzw. $r=0,22$ allenfalls einen Trend zeigen. 
Warum diese Korrelation bei stärkerer Aktivierung des Immunsystems den signifikanten Korrelationsbereich verlässt, bleibt ein spekulatives Element. Möglicherweise kommen weitere beeinflussende Faktoren zum Tragen, die die Ausprägung der Konzentrationsanstiege doch unterschiedlich stark beeinflussen. Augenscheinlich handelt es sich allerdings um eine überproportionale Erhöhung des löslichen IL2-Rezeptors gegenüber dem löslichen CD14, da sich bei der Quotientenbildung beider Parameter in den Gruppen mit eindeutig aktiviertem Immunsystem sichtlich kleinere Quotienten als bei stabiler Nierenfunktion ergeben, was eben auf einen überproportionalen Anstieg des löslichen IL2-Rezeptors bei Infektionen und Abstoßungsreaktionen verweist. Des Weiteren zeichnet sich auch bei der Quotientenbildung der beiden Parameter eine deutliche Unterscheidbarkeit zwischen stabilem Transplantat und Komplikationsformen ab. Unter retrospektiven Bedingungen ergibt sich für die unauffällige Nierenfunktion gegenüber einer Abstoßung ein $p=0,002$, für Infektionen zumindest ein $p=0,07$.

Die verhältnismäßige plasmatische Konzentrationserhöhung bei Komplikationen bleibt also unbestritten deutlich, ebenso wie die Tatsache, dass zwischen Abstoßung und Infektion in keinem der Fälle eine Differenzierung gelingt $(p=0,19)$. Verdeutlicht wird dies durch eine Sensitivität von $100 \%$ bei einer Spezifität von $86 \%$ bei angenommenem Trennwert von 19,9 zwischen den Gruppen „Infektion“ und „stabile Transplantatfunktion“. Etwas schlechter (Sensitivität $=78 \%$, Spezifität $=86 \%$, Trennwert angenommen $=20,7$ ) stellt sich die Differenzierung zwischen stabilem Transplantat und Abstoßungsreaktion dar. Beide Verhältnisse wohlgemerkt unter retrospektiven Bedingungen und unter Ausblendung der dritten untersuchten Gruppe. Fügt man diese hinzu, so lässt sich der komplikationslose Verlauf von den übrigen beiden Zuständen zumindest mit einer Sensitivität von $91 \%$ und einer Spezifität von 86\% bei einem Trennwert von 20,7 abgrenzen. Unterscheidungsversuche zwischen den Komplikationsformen unter Einbeziehung der Gruppe mit komplikationslosem Verlauf zeigen hingegen eine weit geringere Trennschärfe und lassen eine suffiziente Differenzierung nicht zu.

Zusammenfassend zeigen beide löslichen Zellrezeptoren eine deutliche Akzeleration bei Aktivierung des Immunsystems gegenüber einem stabilen Transplantatzustand, lassen aber eine genauere Differenzierung der Komplikationen nicht zu. 
Augenscheinlich wird bei Aktivierung des Immunsystems der slL2-Rezeptor verhältnismäßig stärker sezerniert als der sCD14.

\subsection{Verhältnis von löslichem CD14 und löslichem CD4 im Plasma}

Die funktionelle Bedeutung des löslichen CD4 innerhalb eines immunologischen Geschehens und die Gründe und Mechanismen, die zu seinem Erscheinen im Plasma führen sind weitestgehend unbekannt. Eine deutliche Erhöhung der Plasmakonzentration bei verschiedenen aktivierten Zuständen des Immunsystems lässt sich jedoch nachweisen und als hilfreicher Parameter zur besseren Einschätzung immunologischer Situationen nutzen (Grunewald et al. 2000a). Gemeinhin wird eine Konzentrationserhöhung des löslichen CD4 gleichgesetzt mit einer vermehrten Expression des CD4 auf Lymphozyten und als allgemeine Tlymphozytäre Aktivierung interpretiert (Gilliland et al. 1991). Im Falle des CD4positiven Befundes ist dies unter dem Begriff der T-Helferzelle u.a. mit einer Sezernation von beispielsweise Interleukin-4 und Interleukin-10 verbunden (Di Julio et al. 1996).

Eine Quotientenbildung der beiden löslichen Rezeptoren weist in der Gruppe der Abstoßungsreaktionen den niedrigsten mittleren Quotienten auf. Dies zeigt an, dass der lösliche CD4 im Vergleich zum löslichen CD14 in dieser Gruppe verhältnismäßig stärker akzeleriert ist, da die Quotientenbildung einen mittleren Wert weit unterhalb der stabilen Transplantatfunktion ergibt. Es besteht aber darüber hinaus eine weite Streuung und Überlappung der Werte, so dass eine Differenzierung der Gruppen auf einem signifikanten Niveau in keiner Kombination möglich ist.

Insgesamt ist die Konzentration des löslichen CD4 bei immunologischer Aktivierung deutlich signifikant von der eines stabilen Transplantats zu unterscheiden. Es besteht in der Korrelation beider Parameter ein gleichläufig positives Verhalten ohne Erreichen des Signifikanzniveaus. Im Rahmen einer Abstoßungsreaktion ist der lösliche CD4 verhältnismäßig stärker akzeleriert als der lösliche CD14.

\subsection{Verhältnis von löslichem CD14 und Iöslichem CD8 im Plasma}

Die Rolle des löslichen CD8 innerhalb der komplex ausgestalteten Immunantwort bzw. Immunaktivierung ist bislang wenig beleuchtet worden. Neben der exakten 
funktionellen Bedeutung des löslichen Rezeptormoleküls ist darüber hinaus auch der Mechanismus der membranösen Abspaltung weitestgehend unklar. Assoziiert ist die lösliche Form mit den CD8-positiven T-Lymphozyten, die als Suppressorzellen oder zytotoxische Zellen bekannt sind (Lydyard und Grossi 1991). Verschiedene infektiösentzündliche (Zajkowska et al. 2004, Olszewski et al. 2003) und nicht infektiösentzündliche Erkrankungen (Vrbic et al. 2004, Uehara et al. 2004) zeigen eine deutliche plasmatische Konzentrationssteigerung des löslichen CD8 im Rahmen der Generation einer immunologischen Reaktion, ohne das hier weit reichende kausale Zusammenhänge bislang beschrieben werden konnten.

In den in der vorliegenden Untersuchung erhobenen Daten des Iöslichen CD8 zeigten die Infektionen mit $634 \mathrm{U} / \mathrm{ml}$ die höchsten mittleren Plasmakonzentrationen und konnten mit einem $\mathrm{p}=0,026$ signifikant gegenüber der stabilen Transplantatfunktion abgegrenzt werden. Akute Abstoßungsreaktionen generierten im Mittel mit $539 \mathrm{U} / \mathrm{ml}$ deutlich höhere plasmatische Konzentrationen als die stabilen Transplantate mit $410 \mathrm{U} / \mathrm{ml}$.

Eine signifikante Differenzierung gelang hier mit $p=0,19$ allerdings nicht. Ebenso wenig konnte zwischen einer akuten Abstoßung und einer Infektion hinreichend unterschieden werden $(p=0,36)$.

Aufgrund der deutlichen Überlappung aller drei Gruppen entpuppte sich die unter den zu bedenkenden und bereits diskutierten Gesichtspunkten der eingeschränkten Aussagekraft bei retrospektiver Betrachtung durchgeführte Ermittlung der Sensitivitäten und Spezifitäten als eine nicht zur weiteren Erhellung der Situation beitragende Methode. Alle Vergleiche zeigten eine unzureichende Trennschärfe der Datengruppen mit einer AUC, vornehmlich um 0,6 und maximal von 0,83, mit für eine mögliche praktische Anwendung unzureichenden Kombinationen aus Spezifität und Sensitivität.

Insgesamt lässt der SCD8 weder allein noch im Verhältnis oder in Korrelation mit dem sCD14 eine brauchbare Aussage zur Differenzierung von Transplantatzuständen zu. Einzig besteht ein gleichläufig korreliertes Verhalten mit Signifikanz bei stabiler Transplantatfunktion. 


\section{Zusammenfassung}

Diese retrospektiv durchgeführte Arbeit untersuchte das Konzentrationsverhalten des löslichen CD14 (sCD14) in Plasma und Urin nach Nierentransplantation.

Hinsichtlich dieser Fragestellung konnte eine 100\%ige Abgrenzung zwischen stabiler Transplantatfunktion und Infektion (unter Ausschluss der Abstoßungs-Gruppe) gezeigt werden. Mit der Gruppe der Abstoßung zusammen gelingt die Detektion einer stabilen Transplantatfunktion noch mit einer Spezifität von $100 \%$ und einer Sensitivität von $78 \%$.

Eine Unterscheidung zwischen Infektion und Abstoßung gelingt indes nicht. Als Grund muss ein interindividuell sehr verschieden ausgeprägter Genpolymorphismus angenommen werden, der eine äußerst variable Rezeptorkonzentration generiert. Eventuell ist ein intraindividueller Verlauf des SCD14 die bessere Möglichkeit zur Komplikationsdetektion.

Hinzu kommt, dass die Nierenfunktion selbst Einfluss auf die sCD14-Konzentration haben muss. Dass die ermittelten Daten aus SCD14 in Plasma und Urin keine Korrelation ergeben, lässt nicht den Rückschluss auf Kausalität zu, vielmehr sind die Phänomene unabhängig von einander zu betrachten. Insgesamt werden die SCD14Spiegel augenscheinlich sowohl durch den Genpolymorphismus wie auch durch die Nierenfunktion entscheidend beeinflusst.

Die Messung der sCD14-Urinkonzentration ist nicht aussagekräftig und als Parameter zur Unterscheidung einzelner Transplantatzustände nicht geeignet.

Auffallend ist, dass die sCD14-Plasmakonzentrationen bereits 2 Tage vor der klinischen Diagnose einer Komplikation deutlich für die "Abstoßung“ und sogar signifikant für die „Infektion“ erhöht sind. Diese Dynamik kann bei der Erkennung von Komplikationen Vorteile gegenüber anderen Parametern haben.

Die kombinierte Betrachtung mit den anderen löslichen Rezeptoren IL2R, CD4 und CD8 erlaubt keine weitere Aussage bezüglich einer Differenzierung verschiedener Transplantatzustände.

Begünstigt durch die für Patienten gefahrlose Probengewinnung und vor dem Hintergrund der retrospektiven Interpretation sollte weiterführend die Eignung der Parameter für den klinischen Einsatz durch eine prospektive Analyse überprüft werden. 


\section{Literaturverzeichnis}

Abbas AK, Lichtman AH, Pober JS: B-Zell-Aktivierung und Antikörperproduktion; in: Immunologie, Verlag Hans Huber Bern 1996, 229-250.

Al-Safi SA, Maddocks JL (1983): Effects of azathioprin on the human mixed lymphozyte reaction. Br J Clin Pharmac; 15: 203-209.

Andersson M, Nilsson U, Hjalmarsson C, Haraldsson B, Nyström JS (2007): Mild renal ischemia-reperfusion reduces charge and size selectivity of the glomerulär barrier. Am J Physiol Renal Physiol; 292(6): 1802-1809.

Arias MA, Rey-Nores JE, Vita N, Stelter F, Borysiewicz LK, Ferrara P, Labeta MO (2000). Cutting edge: human $B$ cell function is regulated by interaction with soluble CD14: opposite effects on IgG1 and IgE production. J Immunol; 164(7): 3480-6.

Aziz N, Nishanian P, Mitsuyasu R, Detels R, Fahey JL (1999): Variables that affect assays for plasma cytokines and soluble activation markers. Clin Diagn Lab Immunol; $\underline{6(1)}$ : 89-95.

Ball ED, Guyre PM, Shen L, Glynn JM, Maliszewski CR, Baker PE, Fanger MW (1984): Gamma interferon induces monocytoid differentiation in the HL-60 cell line. J Clin Invest; $\underline{73}$ (4): 1072-1077.

Ballermann BJ (2007): Contribution of the endothelium to the glomerulär permselectivity barrier in health and diseases. Nephron Physiol; 106(2): 19-25.

Barrera P, Boerbooms AM, van de Putte LB, van der Meer JW (1996): Effects of antirheumatic agents on cytokines. Semin Arthritis Rheum; 25(4): 234-253. 
Baxmann AC, Ahmed MS, Marques NC, Menon VB, Pereira AB, Kirsztajn GM, Heilberg IP (2008): Influence of muscle mass and physical activity on serum and urinary creatinine and serum cystatin C. Clin J Am Soc Nephrol; 3(2): 348-54.

Bazil V und Strominger JL (1991): Shedding as a mechanism of down-modulation of CD-14 on stimulated human monocytes. J Immunol; 147: 1567-1574.

Begg CB (1987): Biases in the assessement of diagnostic tests. Stat Med; $\underline{6(4):}$ 411-423.

Birn H, Christensen El (2006): Renal albumin absorption in physiology and pathology. Kidney Int; 69(3): 440-9.

Bogman MJJT, Dooper PhMM, Hoitsma AJ, de Jong MCJW, Tax WJM, Assmann KJM, Koene RAP (1991): Diagnostic value of monocyte/macrophage (WT14) staining in renal allograft biopsies. Transplant Proc ; 23(1):1293-1294.

Boyd JC (1997): Mathematical tools for demonstrating the clinical usefulness of biochemical markers. Scand J Clin Invest Suppl; 227: 46-63.

Burgmann H, Winkler S, Locker J, Presterl E, Laczika K, Staudinger T, Knapp S, Thalhammer F, Wenisch C, Zedwitz-Liebenstein K, Frass M, Graninger W (1996): Increased serum concentrations of soluble CD14 is a prognostic marker in gram-positive sepsis. Clin Immunol Immunopathol; 80(3): 307-310.

Bussolati B, David S, Cambi V, Tobias PS, Camussi G (2002): Urinary soluble CD14 mediates human proximal tubular epithelial cell injury induced by LPS. Int J Mol Med; 10(4): 441-449. 
Can M, Yüksel B, Demirtas S, Tomac N (2006): The effect of montelukast on soluble interleukin-2 receptor and tumor necrosis factor alpha in pediatric asthma. Allergy Asthma Proc; 27(4): 383-386.

Caruso-Neves C, Pinheiro AA, Cai H, Souza-Menezes J, Guggino WB (2006): PKB and megalin determine the survival or death of renal proximal tubule cells. Proc Natl Acad Sci USA; 103(49): 18810-18815.

Catalfamo M, Karpova T, McNally J, Costes SV, Lockett SJ, Bos E, Peters PJ, Henkart PA (2004): Human CD8 ${ }^{+}$T cells store RANTES in a unique secretory compartment and release it rapidly after TcR stimulation. Immunity; 20(2): 219-230.

Cauwels A, Frei K, Sansano S, Fearns C, Ulevitch R, Zimmerli W, Landmann R (1999): The origin and function of soluble CD14 in experimental bacterial meningitis. J Immunol; 162(8): 4762-4772.

Cecka JM, Terasaki PI (1989): Early rejection episodes. Clin Transpl; $\underline{6}$ : 425-434.

Clarkson MR, Sayegh MH (2005): T-cell costimulatory pathways in allograft rejection and

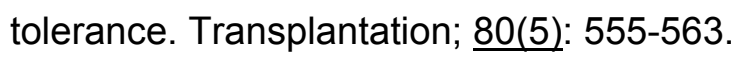

Corsini E, La Mantia L, Gelati M, Dufour A, Milanese C, Massa G, Nespolo A, Salmaggi A (2000): Long-term immunological changes in azathioprine-treated MS patients. Neurol Sci ; 21(2): 87-91.

Cravens PD, Hayashida K, Davis LS, Nanki T, Lipsky PE (2007): Human peripheral blood dendritic cells and monocytes subsets display similar chemokine receptor expression profiles with differential migratory responses. Scand J Immunol; 65 (6): 514-524. 
Cunningham MD, Seachord C, Ratcliffe K, Bainbridge B, Aruffo A, Darveau RP (1996): Helicobacter pylori and Porphyromonas gingivalis lipopolysaccarides are poorly transferred to recombinant soluble CD14. Infect Immun; 64(9): 3601-3608.

Daniel V, Pasker S, Wiesel M, Carl S, Pomer S, Staehler G, Schnobel R, Weimer R, Opelz G (1995): Cytokine Monitoring of infection and rejection in renal transplant recipients. Transplant Proc; 27: 884-886.

Dayyani F, Belge KU, Frankenberger M, Mack M, Berki T, Ziegler-Heitbrock L (2003): Mechanism of glucocorticoid-induced depletion of human CD14+CD16+ monocytes. J Leukoc Biol; 74(1): 33-9.

Degiannis D, Czarnecki M, Hornung N, Raskova J, Raska K Jr. (1991): Mixed lymphocyte reaction-induced release of soluble IL-2 receptor. Transplantation; $\underline{51(2): ~ 518-523 .}$

Dejica D (2001): Serum soluble IL-2 receptor as a marker of lymphocyte activation in some autoimmune diseases. Effect of immunsuppresssive therapy. Roum Arch Microbiol Immunol; 60(3): 183-201.

Deng MC: Transplantatdysfunktion und immunologische Veränderungen in der Frühphase nach Herztransplantation. Symposium: Klinische und immunologische Aspekte nach Organtransplantation, Westfälische Wilhelms-Universität Münster, 29.-30.11.1996.

Dickenmann MJ, Nickeleit V, Tsinalis D, Gürke L, Mihatsch MJ, Thiel G (2002): Why do kidney grafts fail ? A long-term single-center experience. Transpl Int; (9-10): 508-514.

Di Julio NA, Xu H, Fairchild RL (1996): Diversion of CD4+ T cell development from regulatory $\mathrm{T}$ helper to effector $\mathrm{T}$ helper cells alters the contact hypersensivity response. Eur $\mathrm{J}$ Immunol; 26(11): 2606-2612. 
Dong N, yao YM, Yu Y, cao YJ, Sheng (2010): Distribution and clinical significance of CD14 promoter-159C/T polymorphism in patients with extensive burn. Zhonghua Shao Shang Za Zhi; 25(2):115-118.

Dooley MA, Cush JJ, Lipsky PE, Dawson DV, Pisetsky DS (1993): The effects of nonsteroidal antiinflammatory drug therapy in early rheumatoid arthritis on serum levels of soluble interleukin 2 receptor, CD4, and CD8. J Rheumatol; 20(11): 1857-1862.

Dooper IM, Hoitsma AJ, Maass CN, Assmann KJ, Tax WJ, Koene RA, Bogmann M (1994): The extent of peritubular CD14 staining in renal allograft as an independent immunohistological marker for acute rejection. Transplantation; 58(7): 820-827.

Dozil V, Horejes V, Bandys M, Kristofova H, Strominger JL, Losta W, Hilgert I (1986): Biochemical Characterization of a soluble form of the $53 \mathrm{kDa}$ monocyte surface antigen. Eur J Immunol; 16: 1583-1589.

Duperrier K, Velten FW, Bohlender J, Demory A, Metharom P, Goerdt S (2005): Immunsuppressive agents mediate reduced allostimulatory properties of myeloid-derived dendritic cells dispite induction of divergent molecular phenotypes. Mol Immunol; $\underline{42(12)}$ : 1531-1540.

Durieux JJ, Vita N, Popescu O (1994): The two soluble forms of the liposaccaride receptor, CD14: characterization and release by normal human monocytes. Eur J Immunol; 24: 20062012.

Eardley KS, Zehnder D, Quinkler M, Lepenies J, Bates RL, Savage CO, Howie AJ, Adu D, Cockwell P (2006): The relationship between albuminuria, MCP-1/CCL2, and interstitial macrophages in chronic kidney disease. Kidney Int; 69(7): 1189-1197.

Erkan E, Devarajan P, Schwartz GJ (2007): Mitochondria are the main targets in albumininduced apoptosis in proximal tubule cells. J Am Soc Nephrol; 18(4): 1199-1208. 
Feldmann M und Male D: Zellkooperation bei der Antikörperantwort; in: Kurzes Lehrbuch der Immunologie 2. Auflage Hrsg.: Roitt IM, Brostoff J, Male DK. Georg Thieme Verlag Stuttgart 1991, 90-101.

Ferrero E, Hsieh CL, Francke U, Goyert SM (1990): CD14 is a member of the family of leucine-rich proteins and is encoded by a gene syntenic with multiple receptor genes. $J$ Immunol; 145(1): 331-336.

Flad HD, Gemsa D: Zytokine; in: Immunologie, Grundlagen, Klinik, Praxis. Georg Thieme Verlag Stuttgart 1997: 45-69.

Foxwell BMJ, Ruffel B (1989): The mechanism of action of cyclosporin. Immunol Allerg Clin North Americ; $\underline{9}$ : 79-93.

Frei U, Schober-Halstenberg HJ: Nierenersatztherapie in Deutschland. QuaSi-Niere Jahresbericht 2006/2007, Berlin, Deutschland 2008.

Fretier S, Besse A, Delwail A, Garcia M, Morel F, Leprivey-Lorgeot V, Wijdenes J, Praloran V, Lecron JC (2002): Cyclosporin A inhibition of macrophage colony-stimulating factor (M-CSF) production by activated human T Iymphocytes. J Leukoc Biol; 71(2): 289-94.

Fridlender ZG, Schwartz A, Kohan M, Amir G, Glazer M, Berkman N (2010): Association between CD14 gene polymorphisms and disease phenotype in sarcoidosis. Respir Med; 104 (9): 1336-1343.

Garty BZ, Monselise Y, Nitzan M (2000): Soluble CD14 in children with status asthmaticus. Isr Med Assoc J; 2(2):104-7.

Gay D, Maddon P, Sekaly R, Talle MA, Godfrey M, Long E, Goldstein G, Chess L, Axel R, Kappler J, Marrack P (1987): Functional interaction between human CD4 and the major histocompatibility complex HLA-DR-antigen. Nature; 328: 626-629. 
Giacconi R, Caruso C, Lio D, Muti E, Cipriano C, Costarelli L, Saba V, Gasparini N, Malavolta M, Mocchegiani E (2006): CD14 C(-260)T polymorphism, artherosclerotis, elderly: Role of cytokines and metallothioneins. Int J Cardiol; 120(1):45-51.

Gilliland LK, Teh SH, Uckun FM, Norris NA, Teh S, Schieven GL, Ledbetter JA (1991): CD4 and CD8 are positive regulators of $\mathrm{T}$ cell receptor signal transduction in early $\mathrm{T}$ cell differentiation. J Immunol; 146: 1759-1765.

Grandaliano G, Gesualdo L, Ranieri E, Monno R, Stallone G, Schena FP (1997): Monocyte Chemotactic peptide-1 expression and monozyte infiltration in acute renal transplant rejection. Transplantation; $\underline{63(3)}$ : 414-420.

Grunewald RW, Fiedler GM, Stock B, Grunewald JM, Müller GA (2000a): Immunocytological determinations of lymphocytes and monocytes/macrophages in urinary sediments of renal allograft recipients. Nephrol Dial Transplant, 15: 888-892.

Grunewald RW, Fiedler GM, Stock B, Grunewald JM, Müller GA (2000b): Soluble CD-4 and CD-8 as markers of immunological activation in renal transplant recipients. Nephrol Dial Transplant; 15: 71-77.

Gupta RK, Jain M, Sharma RK (2004): Serum \& urinary interleukin-2 levels as predictors in acute renal allograft rejection. Indian J Med Res; 119(1): 24-27.

Halloran PF, Cockfield SM, Madrenas J (1989): The mediators of inflammation (interleukin-1, interferon gamma and tumor necrosis factor) and their relevance to rejection. Transplant Proc; 21: 26-30. 
Hamza A, Fischer K, Loertzer H, Fornara P (2006): Is the determination of the soluble interleukin-2 receptor after application of interleukin-2 receptor antibodies still appropriate for immunological monitoring after renal transplantation ? Urol Int; $\underline{77(3)}$ : 232-239.

Hanley JA, McNeil BJ (1982): The meaning and use of the area under a receiver operating characteristic (ROC) curve. Radiology; 143(1): 29-36.

Hariharan S, Johnson CP, Bresnahan BA, Taranto SE, Macintosh MJ, Stablein D (2000): Improved graft survival after renal transplantation in the united states, 1988 to 1996. N Engl J Med; 342 (9): 605-612.

Haziot A, Chen S, Ferrero E, Low MG, Silber R, Goyert SM (1988): The monozyte differentiation antigen, CD14, is anchoraged to the cell membrane by a phosphatidylinositol linkage. J Immunol; 141(2): 547-552.

Hemmi H, Akira S (2005): TLR signalling and the function of dentritic cells. Chem Immunol Allergy; $\underline{86}$ : 120-135.

Herget-Rosenthal S, Bökenkamp A, Hofmann W (2007): How to estimate GFR-serum creatinine, serum cystatin C or equations ? Clin Biochem; 40(3-4): 153-161.

Hernandez C, Ortega F, Garcia-Ramirez M, Villarroel M, Casado J, Garcia-Pascual L, Fernandez-Real JM, Simo R (2010): Lipopolysaccharide-binding protein and soluble CD14 in the vitreous fluid of patients with proliferative diabetic retinopathy. Retina; 30 (2): 345-352.

Hilgers R: Lineare Regression; in: Biomathematik für Mediziner, 4. Auflage, Göttingen 1995, 42-51.

Hjelm F, Carlsson F, Getahun A, Heyman B (2006): Antibody-mediated regulation of the immune response. Scand J Immunol; 64(3): 177-184. 
Hodge S, Hodge G, Flower R, Han P (2000): Surface and intracellular interleukin-2-receptor expression on various resting and activated populations involved in cell-mediated immunity in

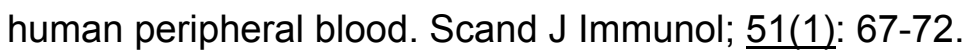

Hubácek JA, Poledne R (1999): The common cDNA and amino acid sequences of the CD14 (myeloid cell-specific leucine-rich glycoprotein) receptor. Physiol Res; 48(4): 323-326.

Hubácek JA, Rothe G, Pit'ha J, Skodova Z, Stanek V, Poledne R, Schmitz G (1999): C(-260)$\mathrm{T}$ polymorphism in the promoter of the CD14 monocyte receptor gene as a risk factor for myocardial infarction. Circulation; 99(25): 3218-3220.

Inoue Y, Shimojo N, Suzuki Y, Campos Alberto EJ, Yamaide A, Suzuki S, Arima T, Matsuura T, Tomiita M, Aoyagi M, Hoshioka A, Honda A, Hata A, Kohno Y (2007) : CD14-550 C/T, with is related to the serum level of soluble CD14, is associated with the development of respiratory syncytial virus bronchiolitis in the Japanese population. J Infect Dis; 195(11): 1618-1624.

Jaramillo A, Fernandez FG, Kuo EY, Trulock EP, Patterson GA, Mohanakumar T (2005): Immune mechanism in the pathogenesis of bronchiolitis obliterans syndrome after lung transplantation. Pediatr Transplant; $\underline{9(1): 84-93 .}$

Julius P, Grosse-thie C, Kuepper M, Bratke K, Virchow JC (2010): sCD14 in bronchoalveolar lavage 18, 42, and 162 hours after segmental allergen provocation. Scand J Immunol; 71(4): 304-311.

Kaever $\mathrm{V}$ und Resch K: Antiallergika, Immunsuppressiva, Immunmodulatoren; in: Pharmakologie und Toxikologie, 4. Auflage, Hrsg. Estler CJ, Schattauer Verlag, Stuttgart 1995, 101-126. 
Kamath S, Dean D, Peddi VR, Schroeder TJ, Alexander JW, Cavallo T, First MR (1997): Efficacy of OKT3 as primary therapy for histologically confirmed acute renal allograft rejection. Transplantation; $\underline{64(10)}$ : 1428-1432.

Kappes DJ und Tonewaga S (1991): Surface expression of alternative forms of the TCR/CD3 complex. Proc Natl Acad Sci; 88: 10619- 10623.

Kavai M, Szegedi G (2007): Immune complex clearance by monocytes and macrophages in

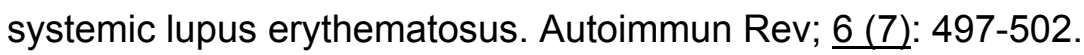

Kitchens RL, Thompson PA (2003): Impact of sepsis-induced changes in plasma on LPS interactions with monocytes and plasma lipoproteins: role of soluble CD14, LPS, and acute phase lipoproteins. J Endotoxin Res; 9(2): 113-8.

Kitchens RL, Thompson PA (2005): Modulatory effects of sCD14 and LBP on LPS-host cell interactions. J Endotoxin Res; 11: 225-229.

Koçak H, Oner-lyidoğan Y, Gürdöl F, Koçak T, Nane I, Genç S (2005): Cystatin-C and creatinine as indices of glomerular filtration rate in the immediate follow-up of renal transplant patients. Clin Exp Med; 5(1): 14-19.

Köhler H, Zanker B, Strom TB (1991): Immunbiologie der Transplantatabstoßung und deren pharmakologische Beeinflussung. Dtsch Med Wochenschr; 116: 264-269.

Kono N, Kanda Y, Yamamoto R, Chizuka A, Suguro M, Hamaki T, Arai C, Matsuyama T, Takezako N, Miwa A, Togawa A (2000): Prognostic significance of serum soluble interleukin2 receptor level in non-Hodgkin`s lymphoma: a single center study in Japan. Leuk Lymphoma; 37(1-2): 151-156.

Krensky AM, Weiss A, Crabtree G (1990): T-Lymphocyte-antigen interactions in transplant rejection. N Engl J Med; 322: 510-517. 
Krüger C, Schütt C, Obertake O (1991): Serum CD14 levels in polytraumatized and severly burned patients. Clin Exp Immunol; 85: 297-301.

Kuhns MS, Davis MM (2007): Disruption of extracellular interactions impairs T cell receptorCD3 complex stability and signalling. Immunity; 26 (3): 357-369.

Kurane I, Innis BL, Nimmannitya S, Nisalak A, Meager A, Janua J, Ennis FA (1991): Activation of the T lymphocytes in dengue virus infections. High levels of soluble interleukin 2 receptor, soluble CD4, soluble CD8, interleukin 2, and interferon-gamma in sera of children with dengue. J Clin Invest; 88(5): 1473-1480.

Kuypers DR (2005): Immunosuppressive drug monitoring - what to use in clinical practice today to improve renal graft outcome. Transpl Int; 18(2): 140-50.

Kvarnström M, Jenmalm MC, Ekerfelt C (2004): Effect of cryopreservation on expression of Th1 and Th2 cytokines in blood mononuclear cells from patients with different cytokine profiles, analysed with three common assays: an overall decrease of interleukin-4. Cryobiology ;49(2): 157-68.

Lai KN, Leung JC, Lai FM (1991): Soluble interleukin 2 receptor release, interleukin 2 production, and interleukin 2 receptor expression in activated T-lymphocytes in vitro. Pathology; 23(3): 224-228.

Lai KN, Leung JC, Chan LY, Guo H, Tang SC (2007): Interaction between proximal tubular epithelial cells and infiltrating monocytes/T cells in the proteinuric state. Kidney Int; $\underline{7(6)}$ : 526 538.

Landmann R, Reber AM, Sansano S, Zimmerli W (1996): Function of soluble CD14 in serum from patients with septic shock. J Infect Dis; 173(3): 661-668. 
Langenberg C, Wan L, Egi M, May CN, Bellomo R (2007): Renal blood flow and function during recovery from experimental septic acute kidney injury. Intensive Care Med; $\underline{33(9)}$ : 1614-8.

Le Bricon T, Thervet E, Benlakehal M, Bousquet B, Legendre C, Erlich D (1999): Changes in plasma cystatin $C$ after renal transplantation and acute rejection in adults. Clin Chem; $\underline{45(12)}$ : 2243-9.

Lehtonen A, Ahlfors H, Veckman V, Miettinen M, Lahesmaa R, Julkunen I (2007): Gene expression profiling during differentiation of human monocytes to macrophages or dendritic cells. J Leukoc Biol; 82(3): 710-20.

Lin J, Yao YM, Huang ZH, Yu Y, Zhu JM, Chai JK, Sheng ZY (2006): The influence of CD14 genomic polymorphism on CD14 gene expression as well as protein release and its clinical significance in patients with extensive burns. Zhonghua Wai Ke Za Zhi; 44(13): 907-910.

Linnet K (1988): On the sensitivity of linear discriminant analysis to sampling variation and analytical errors. Comput Biomed Res; 21 (2): 158-168.

Linnet K, Brandt E (1986): Assessing diagnostic tests once an optimal cutoff point has been selected. Clin Chem; 32(7): 1341-1346.

Liu J, Wu DS, Zhang S, Yan CH, Zhou Y, Zhang YD, Qi ZH (2005): Relation between the expression of SIL-2R and the relapse in patients with acute lymphoblastic leukemia. Beijing Da Xue Xue bao; 37(3): 249-251.

Louvar DW, Rogers TB, Bailey RF, Matas AJ, Ibrahim HN (2007): Cystatin C is not superior to creatinine-based models in estimating glomerular filtration rate in former kidney donors. Transplantation; $84(9)$ : 1112-7. 
Lydyard P, Grossi C: Zellen der Immunantwort; in: Kurzes Lehrbuch der Immunologie, 2. Auflage, Hrsg.: Roitt IM, Brostoff J, Male DK Georg Thieme Verlag Stuttgart 1991, 11-29.

Ma JS, Monu N, Shen DT, Mecklenbräuker I, Radoja N, Haydar TF, Leitges M, Frey AB, Vukmanovic, Radoja S (2007): Protein kinase Cdelta regulates antigen receptor-induced lytic granule polarization in mouse CD8+ CTL. J Immunol; 178(12): 7814-7821.

Martin TR, Rubenfeld GD, Ruzinski JT, Goodman RB, Steinberg KP, Leturcq DJ, Moriarty AM, Raghu G, Baughman RP, Hudson LD (1997): Relationship between soluble CD14, Lipopolysaccharide binding protein, and the alveolar inflammatory response in patients with acute respiratory distress syndrom. Am J Respir Crit Care Med; 155: 937-944.

Mehta R, Shah G, Adler W, Kittur D (2004): Soluble interleukin 2 receptor (sIL-2R) levels in renal transplant recipients. Clin Transplant; $\underline{18}$ : 67-71.

Merino A, Nogueras S, Buendia P, Ojeda R, Carracedo J, Ramirez-Chamond R, Martin-Malo A, Aljama P (2008): Microinflammation and endothelial damage in hemodialysis. Contrib Nephrol; 161: 83-88.

Moon Y, Kim Y, Kim M, Lim J, Kang CS, Kim WI, Shim SI, Chung NG, Park YH, Min WS, Han K (2004): Plasma soluble interleukin-2 receptor (sIL-2R) levels in patients with acute leukaemia. Ann Clin Lab Sci; 34(4): 410-415.

Moreillon P, Majcherczyk PA (2003): Proinflammatory activity of cell-wall constituents from gram-positive bacteria. Scand J Infect Dis; 35(9): 632-41.

Mosmann TR und Moore KW (1991): The role of IL-10 in crossregulation of TH1 and TH2 responses. Immunol Today; 12(3) : A49-53. 
Mussap M, Plebani M (2004): Biochemistry and clinical role of human cystatin C. Crit Rev Clin Lab Sci; 41(5-6): 467-550.

Nelson BH (2002): Interleukin-2 signaling and the maintance of self-tolerance. Curr Dir Autoimmune; $\underline{5}:$ 92-112.

Nicu EA, Laine ML, Morre SA, Van der Velden U, Loos BG (2009): Soluble CD14 in periodontitis. Innate Immun; 15(2): 121-128.

Niitsu N, lijima K, Chizuka A (2001): A high serum-soluble interleukin-2 receptor level is associated with poor outcome of aggressive non-Hodgkin`s lymphoma. Eur J Haematol; 66(1): 24-30.

Nockher WA, Scherberich JE (1995): Monocyte cell-surface CD14 expression and soluble CD14 antigen in haemodialysis: Evidence for chronic exposure to LPS. Kid Int; $\underline{48}$ : 14691476.

Nockher WA, Wigand R, Schoeppe W, Scherberich JE (1994): Elevated levels of soluble CD14 in serum of patients with sytematic lupus erythematosus. Clin Exp Immunol; 96: 15-19.

Ohnishi T, Muroi M, Tanamoto K (2010): Inhibitory effects of soluble MD-2 and soluble CD14 on bacterial growth. Microbiol Immunol; 54(2): 74-80.

Olszewski J, Chudzik W, Wisniewski K, Milonski J, Matyja R (2003): An assessment of concentrations of soluble CD4 and CD8 receptors in serum before and after surgical treatment in patients with chronic maxillary sinusitis. Am J Rhinol; 17(3): 123-126.

Orditura M, De Vita F, Roscigno A, Auriemma A, Infusino S, Catalano G (1998). Soluble interleukin-2 receptor and soluble CD8 antigen levels in serum from patients with solid tumors. Int J Mol Med; 2(1): 75-79. 
Panicker G, Meadows KS, Lee DR, Nisenbaum R, Unger ER (2007): Effect of storage temperatures on the stability of cytokines in cervical mucous. Cytokine; $\underline{37(2): 176-9 .}$

Parekh RS, Kao WH, Meoni LA, Ipp E, Kimmel PL, La Page J, Fondran C, Knowler WC, Klag MJ; Family Investigation of Nephropathy and Diabetes Research Group (2007): Reliability of urinary albumin, total protein, and creatinine assays after prolonged storage: the Family Investigation of Nephropathy and Diabetes. Clin J Am Soc Nephrol; 2(6): 1156-62.

Pascual M, Theruvath T, Kawai T, Tolkoff-Rubin N, Cosimi AB (2002): Strategies to improve long-term outcomes after renal transplantation. N Engl J Med; 346 (8): 580-590.

Pastor Rojo O, Lopez San Roman A, Albeniz Arbizu E, de la Hera Martinez A, Ripoll Sevillano E, Albillos Martinez A (2007): Serum lipopolysaccharide-binding protein in endotoxemic patients with inflammatory bowel disease. Inflamm Bowel Dis; 13(3): 269-277.

Paul LC, Grothman GT, Benediktsson H, Davidoff A, Rozing J (1992): Macrophage subpopulations in normal and transplantated heart and kidney tissues in the rat.

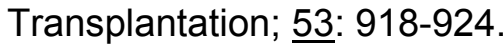

Peng Q, Wu Q, Chen CH, Hong H, Zhang LY (2006): Value of serum soluble interleukin-2R, interleukin-6 and C-reaktive protein in the early diagnosis of Kawasaki disease. Zhongguo

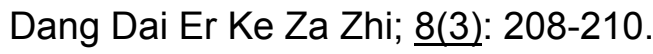

Pezzilli R, Billi P, Gullo L, Beltrandi E, Maldini M, Mancini R, Incorvaia L, Miglioli M (1994): Behaviour of serum soluble interleukin-2 receptor, soluble CD8 and soluble CD4 in the early phases of acute pancreatitis. Digestion; 55(4): 268.273. 
Pöge U, Gerhardt T, Stoffel-Wagner B, Palmedo H, Klehr HU, Sauerbruch T, Woitas RP (2006): Cystatin C-based calculation of glomerular filtration rate in kidney transplant recipients. Kidney Int; 70(1): 204-210.

Pollok CA, Poronnik P (2007): Albumin transport and processing by the proximale tubule: physiology and pathophysiology. Curr Opin Nephrol Hypertens; 16: 359-364.

Ponticelli C (2004): Renal transplantation 2004: Where do we stand today? Nephrol Dial Transplant; 19: 2937-2947.

Port FK, Dykstra DM, Merion RM, Wolfe RA (2005): Trends and results for organ donation and transplantation in the United States 2004. Am J Transplant; $\underline{5}$ : 843-9.

Prodjosudjadi W, Daha MR, Gerritsma JS, Florijn KW, Barendregt JN, Bruijn JA, van der Woude FJ, van Es LA (1996): Increased urinary excretion of monocyte chemoattractant protein-1 during acute renal allograft rejection. Nephrol Dial Transplant; 11(6): 1096-1103.

Raj DS, Shah VO, Rambod M, Kovesdy CP, Kalantar-Zadeh K (2009): Association of soluble endotoxin receptor CD14 and mortality among patients undergoing hemodialysis. Am J Kidney Dis; 54(6): 1062-1071.

Rauchhaus M, Koloczek V, Volk H, Kemp M, Niebauer J, Francis DP, Coats AJ, Anker SD (2000): Inflammatory cytokines and the possible immunological role for lipoproteins in chronic heart failure. Int J Cardiol; $\underline{76(2-3)}$ : 125-133.

Regueiro V, Campos MA, Morey P, Sauleda J, Agusti AG, Garmendia J, Bengoechea JA (2009): Lipopolysaccharide-binding protein and CD14 are increased in the bronchoalveolar lavage fluid of smokers. Eur Respir J; 33(2): 273-281. 
Rey-Nores JE, Bensussan A, Vita N, Stelter F, Arias MA, Jones M, Lefort S, Borysiewicz LK, Ferrara P, Labeta MO (1999): Soluble CD14 acts as a negative regulator of human $\mathrm{T}$ cell activation and function. Eur J Immunol; 29(1): 265-276.

Rice JC, Spence JS, Yetman DL, safirstein RL (2002): Monocyte chemoattractent protein-1 expression correlates with monocyte infiltration in the post-ischemic kidney. Ren Fail; 24 (6): 703-723.

Roberti I, Reisman L (2001): Serial evaluation of cell surface markers for immune activation after acute renal allograft rejection by urine flow cytometry- correlation with clinical outcome. Transplantation; 71(9): 1317-1320.

Röllinghoff M, Wagner $\mathrm{H}$ : Zelluläre Immunantwort; in: Immunologie, Grundlagen, Klinik, Praxis. Georg Thieme Verlag Stuttgart 1997, 29-44.

Rothstein DM, Sayegh MH (2003): T-cell costimulatory pathways in allograft rejection and tolerance. Immunol Rev; 196: 85-108.

Rubin B, Riond J, Leghait J, Gairin JE (2006): Interactions between CD8alphabeta and the TCRalphabeta/CD3-receptor complex. Scand J Immunol; 64(3): 260-270.

Rubin B, Knibiehler M, Gairin JE (2007): Allosteric changes in the TCR/CD3 structure upon interaction with extra- or intra-cellular ligands. Scand J Immunol; $\underline{66(2-3)}$ : 228-237.

Rubin LA, Kurman CC, Fritz ME, Biddison WE, Boutin B, Yarchoan R, Nelson DL (1985): Soluble interleukin 2 receptors are released from activated human lymphoid cells in vitro. J Immunol; 135(5): 3172-3177.

Rubin LA, Jay G, Nelson DL (1986): The released interleukin 2 receptor binds interleukin 2 efficiently. J Immunol; 137(12): 3841-3844. 
Rudnicki M, Eder S, Perco P, Enrich J, Scheiber K, Koppelstätter C, Schratzberger G, Mayer B, Oberbauer R, Meyer TW, Mayer G (2007): Gene expression profiles of human proximal tubular epithelial cells in proteinuric nephropathies. Kidney Int; 71(4): 325-335.

Ryan LA, Zheng J, Brester M, Bohac D, Hahn F, Anderson J, Ratanasuwan W, Gendelman HE, Swindells S (2002): Plasma levels of soluble CD14 and tumor necrosis factor-alpha type II receptor correlate with cognitive dysfunction during human immunodeficiency virus type 1 infection. J Infect Dis; 184(6): 699-706.

Schäfer H (1989): Constructing a cut-off point for a quantitative diagnostic test. Stat Med; 8(11): 1381-1391.

Schreiber SL, Crabtree GR (1992): The mechanism of action of cyclosporin A and FK506. Immunol Today; 13: 136-141.

Segala C, Poizeau D, Mesbah M, Willems S, Maidenberg M (2007): Winter air pollution and infant bronchiolitis in Paris. Environ Res; 106(1): 96-100.

Shen DT, Ma JS, Mather J, Vukmanovic S, Radoja S (2006): Activation of primary T lymphcytes results in lysosome development and polarized granule exocytosis in CD4+ and CD8+ subsets, whereas expression of lytic molecules confers cytotoxity to CD8+ T cells. J Leukoc Biol; $\underline{80(4): ~ 827-837 . ~}$

Shimada K, Miyauchi K, Mokuno H, Watanabe Y, Iwama Y, Shigekiyo M, Matsun M, Okazaki S, Tanimoto K, Kurata T, Sato H, Daida H (2004): Promotor polymorphism in the CD14 gene and concentration of soluble CD14 in patients with in-stent restenosis after elektive coronary stent. Int J Cardiol; 94(1): 87-92.

Shimizu Y, Newmann W, Tanaka Y, Shaw S (1992): Lymphozyte interaction with endothelial cells. Immunol Today; 13: 106-112. 
Shimomura Y, Tsurumi H, Sawada M, Yamada T, Hara T, Fukuno TK, Goto H, Moriwaki H (1999): Clinical significance of serum soluble interleukin-2 receptor level in patients with nonHodgkin`s lymphoma. Rinsho Ketsueki; 40(8): 639-645.

Shinn C, Malhotra D, Chan L, Cosby RL, Shapiro JI (1999): Time course of response to pulse methylprednisolone therapy in renal transplant recipients with acute allograft rejection. Am $\mathrm{J}$ Kidney Dis; 34(2): 304-307.

Shitrit D, Izbicki G, Bar-Gil Shitrit A, Raz M, Sulkes J, Kramer MR (2006): Role of soluble interleukin-2 receptor levels in patients with latent tuberculosis. Lung; 184(1): 21-24.

Sijpkens YW, Doxiadis II, Mallat MJ, de Fijter JW, Bruijn JA, Claas FH, Paul LC (2003): Early versus late acute rejection episodes in renal transplantation. Transplantation; 75(2): 204-208.

Silbernagl S: Die Funktion der Niere; in: Physiologie. Georg Thieme Verlag Stuttgart 2003, 326-373.

Sindhi R, Allaert J, Gladding D, Koppelmann B, Dunne JF (2001): Cytokines and cell surface receptors as target end points of immunosuppression with cyclosporine $\mathrm{A}$. J Interferon Cytokine Res; 21(7): 507-514.

Soler-Rodriguez AM, Zhang H, Lichenstein HS, Qureshi N, Niesel DW, crowe SE, Peterson JW, Klimpel GR (2000): Neutrophil activation by bacterial lipoprotein versus lipopolysaccaride: differential requirements for serum and CD14. Eur J Immunol; 164(5): 2674-2683.

Spetz A, Kourilsky P, Larrson-Sciard M (1991): Induction of CD8 molecules on thymic gd T cells in vitro is dependent upon ab cells. Eur J Immunol; 21: 2755-2759. 
Stasikowska O, Wagrowska-Danilewicz M (2007): Chemokines and chemokine receptors in glomerulonephritis and renal allograft rejection. Med Sci Monit; 13(2): 31-36.

Stewart M: Antigenerkennung; in: Kurzes Lehrbuch der Immunologie, 2. Auflage, Hrsg.: Roitt IM, Brostoff J, Male DK, Georg Thieme Verlag Stuttgart 1991, 79-88.

Steyaert S, Vanlandschoot P, Van Vlierberghe H, Diepolder H, Leroux-Roels G (2003): Soluble CD14 levels are increased and inversely correlated with the level of hepatitis B surface antigen in chronic hepatitis B patients. J Med Virol; 71(2): 188-94.

Taga T, Kishimoto T (1992): Cytokine receptors and signal transduction. FASEB J; $\underline{6(15)}$ : 3387-3396.

Takeshita S, Nakatani K, Tsujimoto H, Kawamura Y, Kawase H, Sekine I (2000): Increased levels of circulating soluble CD14 in Kawasaki disease. Clin Exp J Immunol; 119(2): 376-381.

Thavasu PW, Longhurst S, Joel SP, Slevin ML, Balkwill FR (1992): Measuring cytokine levels in blood. Importance of anticoagulants, processing, and storage conditions. J Immunol Methods; 153(1-2): 115-24.

Thomas L: Creatinin; in: Labor und Diagnose, 7. Auflage, TH Books Verlagsgesellschaft $\mathrm{mbH}$, Frankfurt/Main 2008, 535-541

Trivedi HL (2007): Immunobiology of rejection and adaption. Transplant Proc; 39(3): 647-752.

Uehara S, Gothoh K, Handa H, Tomita H, Tomita Y (2004): Immune function in patients with acute pancreatitis. J Gastroenterol Hepatol; 18(4): 363-370. 
von Geldern M, Simm B, Braun M, Weiss EH, Schendel DJ, Falk CS (2006): TCRindependent cytokine stimulation induces nom-MHC-restricted T cell activity and is negatively regulated by HLA class I. Eur J Immunol; 36(9): 2347-2358.

Vrbic M, Vrbic S, Skoric S, Mihailovic V, Rankovic Z, Konstantinovic L, Kostic V, Krstic M, Jovanovic M (2004): Soluble CD4 antigens in the cerebrospinal fluid as a marker of lymphocytic infiltration of the central nervous system. Vojnosanit Pregl; 61(3): 247-253.

Wada T, Furuichi K, Sakai N, Iwata Y, Kitagawa K, Ishida Y, Kondo T, Hashimoto H, Ishiwata Y, Mukaida N, Tomosugi N, Matsushima K, Egashira K, Yokoyama H (2004): Gene therapy via blockade of monocyte chemoattractant protein-1 for renal fibrosis. J Am Soc Nephrol; 15 (4): 940-948.

Ward C, Walters EH, Zheng L, Whitford H, Williams TJ, Snell GI (2002): Increased soluble CD14 in bronchoalveolar lavage fluid of stable lung transplant recipients. Eur Respir J; 19(3): 472-478.

Wenisch C, Wenisch H, Parschalk B, Vanijanonta S, Burgmann H., Exner M, ZedwitzLiebenstein K, Thalhammer F, Georgopoulus A, Graninger W, Looareesuwan S (1996): Elevated Levels of soluble CD14 in serum of patients with acute plasmodium falciparum malaria. Clin Exp Immunol; 105: 74-78.

Wohlfahrth V, Drumm K, Mildenberger S, Freudinger R, Gekle M (2003): Protein uptake disturbs collagen homeostasis in proximal tubule-derived cells. Kidney Int; $\underline{84}$ : 103-109.

Wonigeit K, Pichlmayr R: Organtransplantation; in: Immunologie, Grundlagen, Klinik, Praxis, Georg Thieme Verlag Stuttgart 1997, 636-660.

Wright SD, Ramos RA, Tobias PS, Ulevitch RJ und Mathison JC (1990): CD14, a receptor for complexes of liposaccaride (LPS) and LPS binding protein. Science; 249(4975): 1431-1433. 
Yoneyama A, Nakahara K, Higashihara M, Kurokawa K (1995): Increased levels of soluble CD8 and CD4 in patients with infectious mononucleosis. Br J Haematol; 89(1): 47-54.

Zahran A, El-Husseini A, Shoker A (2007a): Can cystatin C replace creatinine to estimate glomerular filtration rate? A literature review. Am J Nephrol; 27(2): 197-205.

Zahran A, Qureshi M, Shoker A (2007b): Comparison between creatinine and Cystatin Cbased GFR equations in renal transplantation. Nephrol Dial Transplant; 22(9): 2659-68.

Zajkowska JM, Swierzbinska R, Pancewicz SA, Kondrusik M, Hermanowska-Szpakowicz T (2004): Concentration of soluble CD4, CD8, CD25 receptors as well IFN-gamma and IL-4 released by lymphocyte of chronic Lyme patients cultured with 3 genotypes of borrelia burgdorferi. Pol Merkur Lekarsk; 16(95): 447-450.

Zanker B, Walz G, Wieder KJ, Strom TB (1990): Evidence that glucocorticosteroids block expression of the human interleukin-6 gene by accessory cells. Transplantation; $\underline{49}$ : 183-185.

Ziegler-Heitbrock L, Passlick B, Flieger D (1988): The monoclonal anti-monocyte antibody My4 stains B Lyphocytes and two distinct monocyte subsets in human peripheral blood. Hybridoma; 7(6): 521-527.

Zorn U, Dallmann I, Grosse J, Kirchner H, Poliwoda H, Atzpodien J (1994): Soluble interleukin 2 receptors abrogate IL-2 induced activation of peripheral mononuclear cells. Cytokine; $\underline{6(4)}$ : 358-364.

Zucchelli GC, Clerico A, De Maria R, Carmellini M, Di Stefano R, Masini S, Pilo A, Donato L (1990): Increased circulating concentrations of interleukin 2 receptor during rejection episodes in heart- or kidney-transplant recipients. Clin Chem; 36(12): 2106-2109. 


\section{Anhang: Abbildungen 7.1 bis 7.42}

\section{Abb. 7.1: Quotienten sCD14 und Kreatinin: Tx stabil vs. Abstoßung}

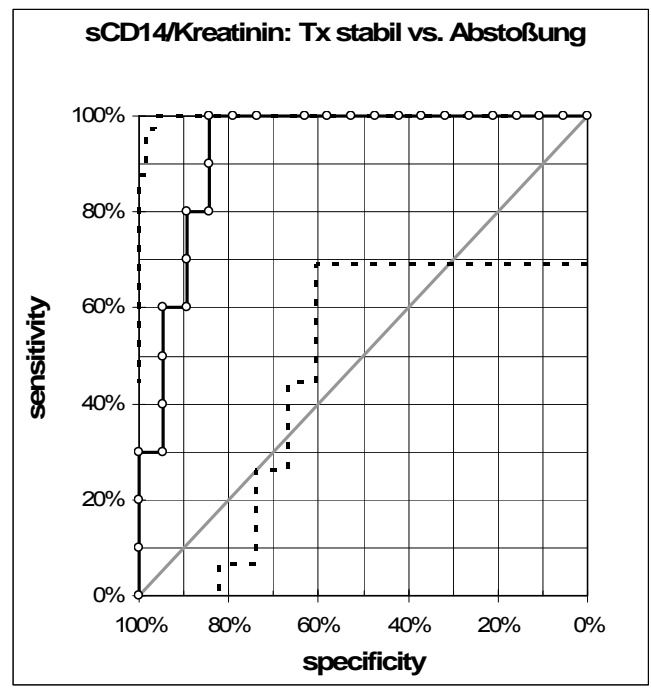

Abb. 7.1: In der ROC-Kurven-Analyse läßt sich die stabile Transplantatfunktion von der Abstoßungsreaktion bei einem angenommenen Cut-Off-Wert von 1208 mit einer Sensitivität von $100 \%$ und einer Spezifität von $84 \%$ abgrenzen (AUC $=0,93$ ).

\section{Abb. 7.2: Quotienten sCD14 und Kreatinin: Infektion vs. Tx stabil}

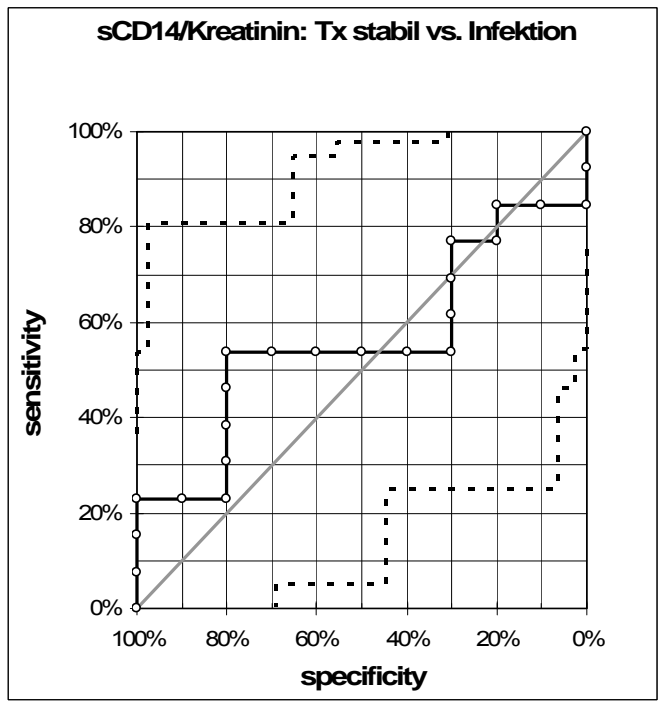

Abb. 7.2: In der ROC-Kurven-Analyse läßt sich die stabile Transplantatfunktion von der Infektion bei einem angenommenen Cut-Off-Wert von 1425 mit einer Sensitivität von 54\% und einer Spezifität von $80 \%$ abgrenzen $(A \cup C=0,56)$. 
Abb. 7.3: Quotienten sCD14 und Kreatinin: Abstoßung vs. Infektion

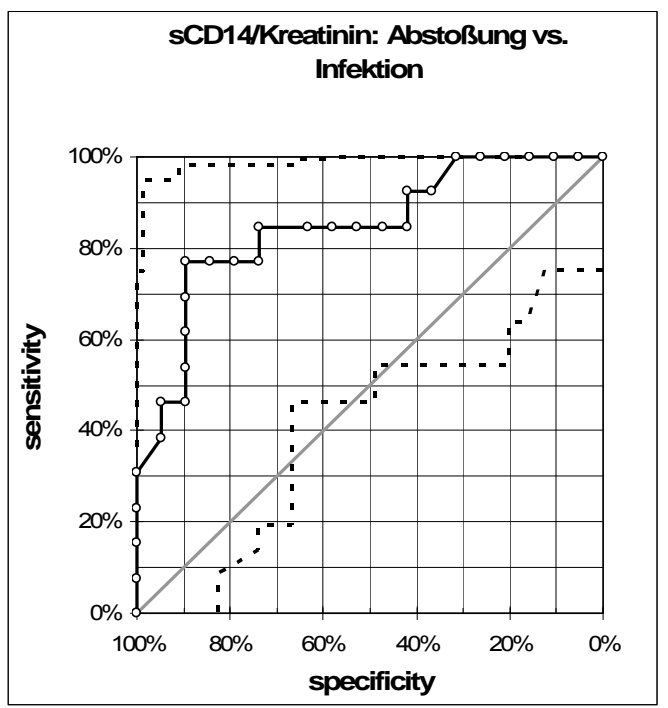

Abb. 7.3: In der ROC-Kurven-Analyse läßt sich die Infektion von der Abstoßungsreaktion bei einem angenommenen Cut-Off-Wert von 914 mit einer Sensitivität von $85 \%$ und einer Spezifität von $74 \%$ abgrenzen $(A \cup C=0,84)$.

Abb.7.4: Quotient sCD14 / Kreatinin: Abstoßung vs. Infektion und Tx stabil:

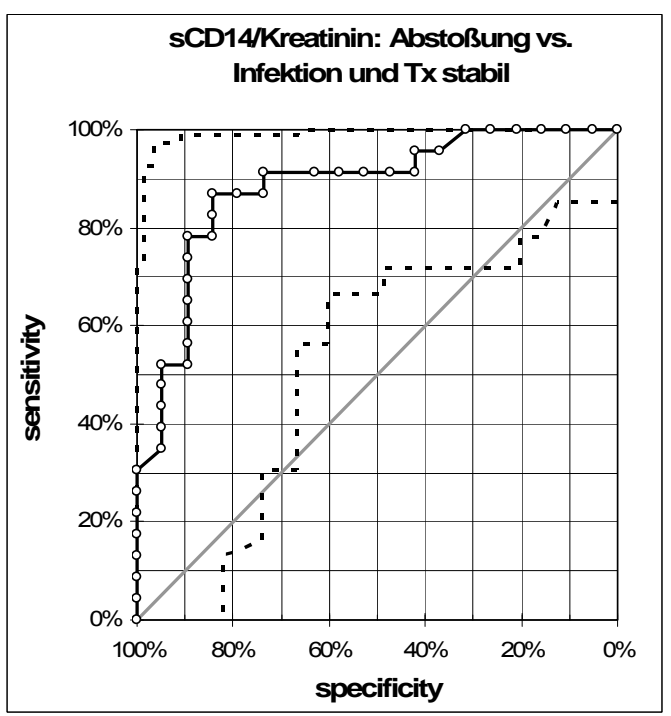

Abb. 7.4: In der ROC-Kurven-Analyse läßt sich die Abstoßungsreaktion von der Infektion sowie der stabilen Transplantatfunktion bei einem angenommenen Cut-Off-Wert von 1208 mit einer Sensitivität von $87 \%$ und einer Spezifität von $84 \%$ abgrenzen (AUC $=0,88$ ). 
Abb.7.5: Quotient sCD14 / Kreatinin: Infektion vs. Abstoßung und Tx stabil:

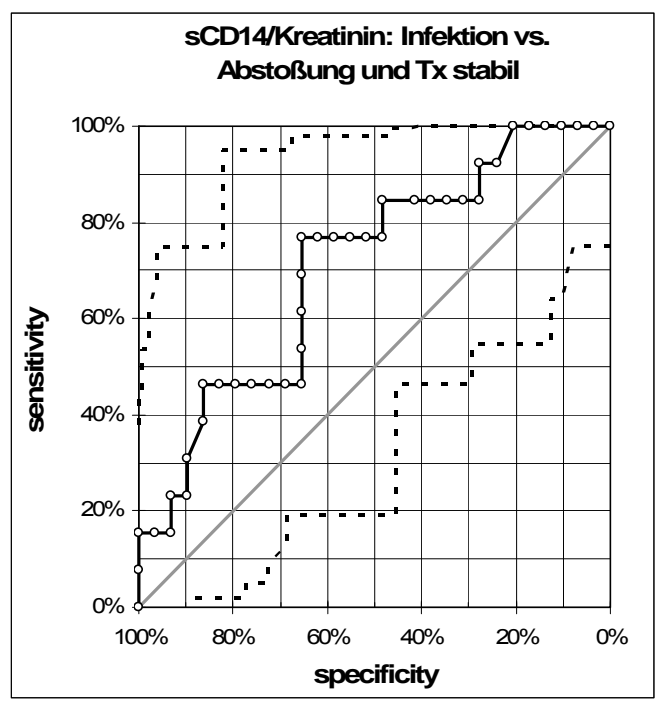

Abb. 7.5: In der ROC-Kurven-Analyse läßt sich die Infektion von der Abstoßungsreaktion sowie der stabilen Transplantatfunktion bei einem angenommenen Cut-Off-Wert von 1355 mit einer Sensitivität von $77 \%$ und einer Spezifität von $66 \%$ abgrenzen (AUC $=0,7)$.

\section{Abb.7.6: Quotient sCD14 / Kreatinin: Tx stabil vs. Infektion und Abstoßung:}

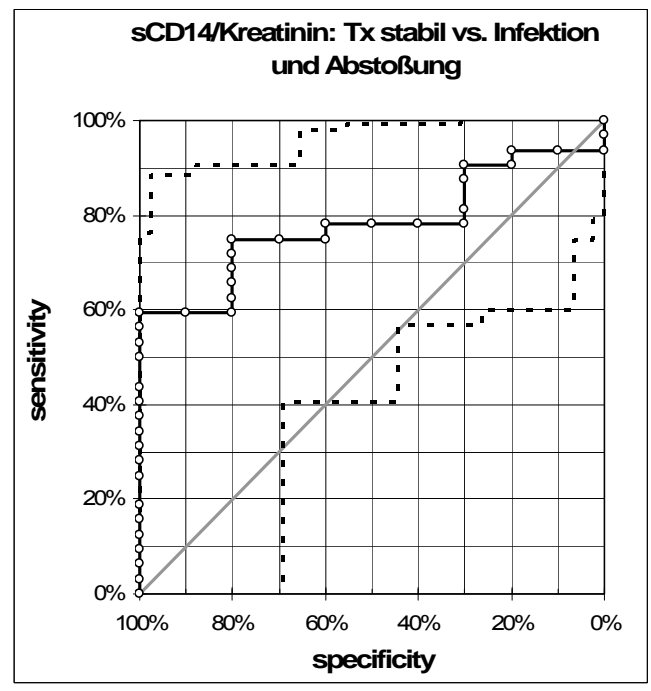

Abb. 7.6: In der ROC-Kurven-Analyse läßt sich die stabile Transplantatfunktion von der Abstoßungsreaktion sowie der Infektion bei einem angenommenen Cut-Off-Wert von 1075 mit einer Sensitivität von 59\% und einer Spezifität von 100\% abgrenzen (AUC = 0,78). 
Abb. 7.7: Korrelation der im Rahmen einer stabilen Transplantatfunktion erhobenen Werte von SCD14 und Kreatinin:

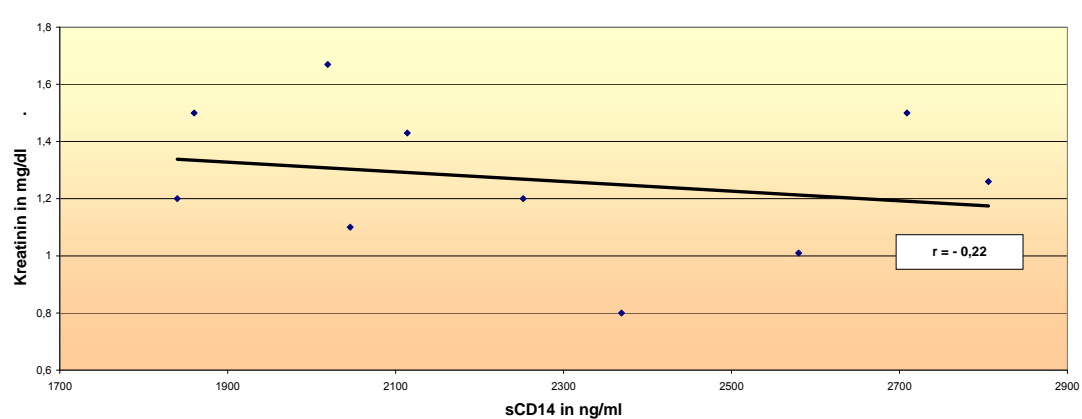

Abb. 7.8: Korrelation der im Rahmen einer Abstoßungsreaktion erhobenen Werte von sCD14 und Kreatinin:

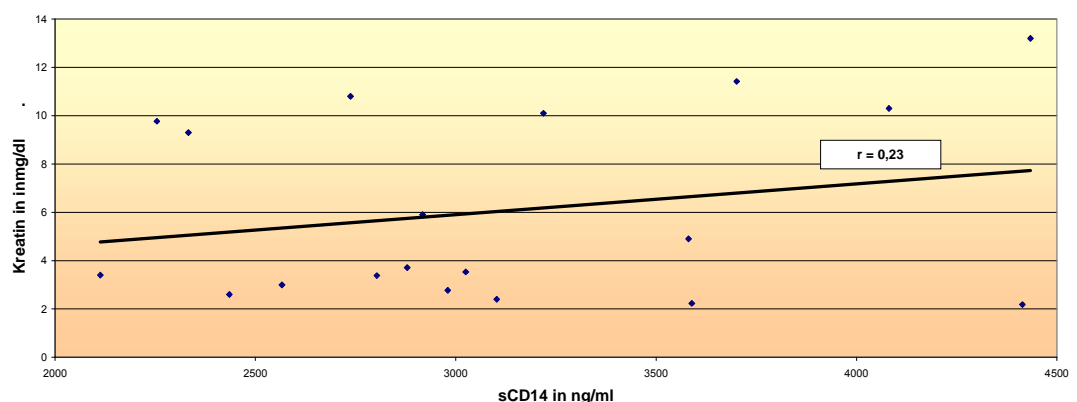

Abb. 7.9: Korrelation der im Rahmen einer Infektion erhobenen Werte von sCD14 und Kreatinin:

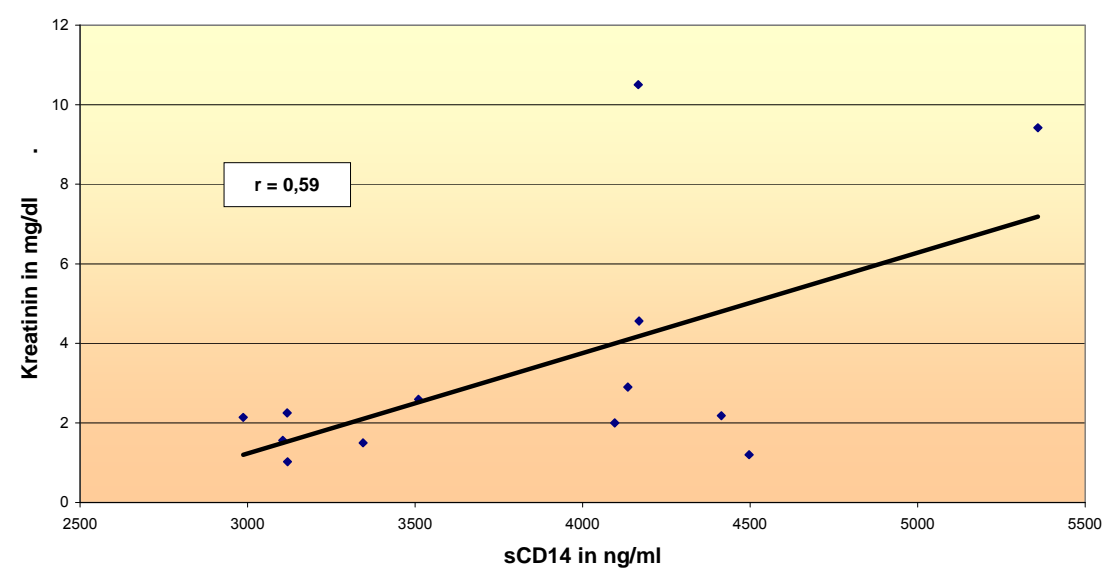

Abb. 7.7 bis 7.9: Die Korrelation des löslichen CD14 im Plasma mit dem Kreatinin im Serum ergibt in keiner der Gruppen ein signifikantes Ergebnis. 
Abb. 7.10: Korrelation der im Rahmen einer stabilen Transplantatfunktion erhobenen Werte von Kreatinin im Serum und SCD14 im Urin:

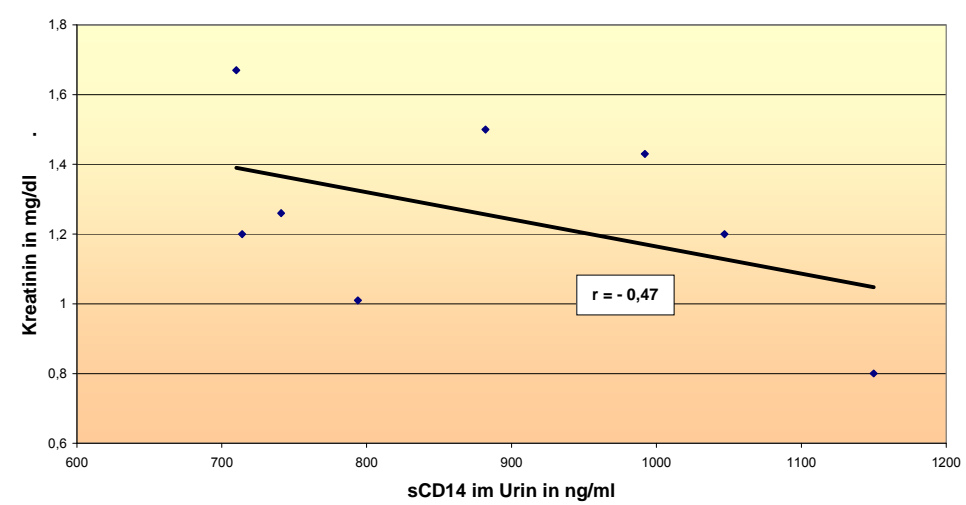

Abb. 7.11: Korrelation der im Rahmen einer Abstoßung erhobenen Werte von Kreatinin im Serum und SCD14 im Urin:

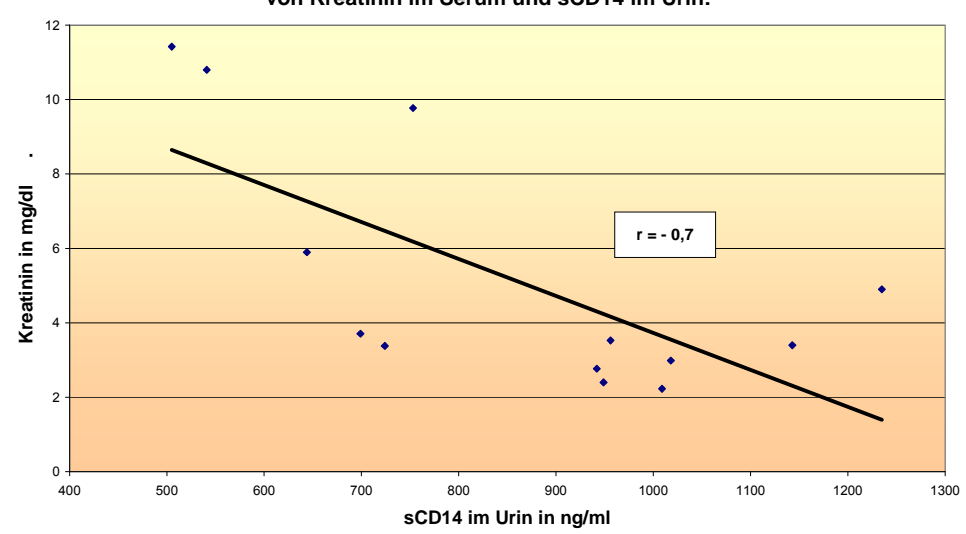

Abb. 7.12: Korrelation der im Rahmen einer Infektion erhobenen Werte von Kreatinin im Serum und SCD14 im Urin:

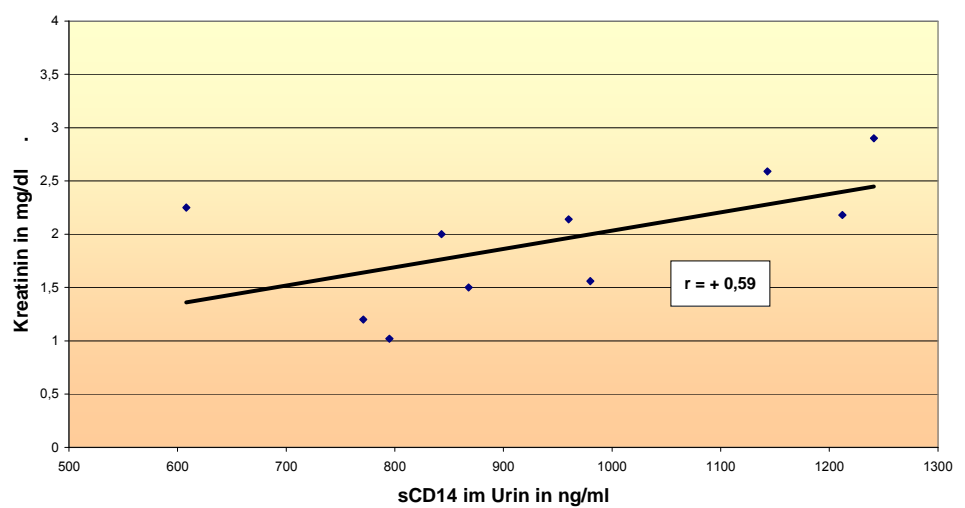

Abb. 7.10 bis 7.12: Die Korrelation des löslichen CD14 im Urin mit dem Kreatinin im Serum ergibt in der Gruppe der Abstoßungsreaktionen ein signifikantes Ergebnis mit $r=-0,7$. In den anderen beiden untersuchten Gruppen ergibt sich keine signifikante Korrelation. 
Abb. 7.13: Korrelation der im Plasma und im Urin im Rahmen einer stabilen Transplantatfunktion erhobenen Werte von SCD14:

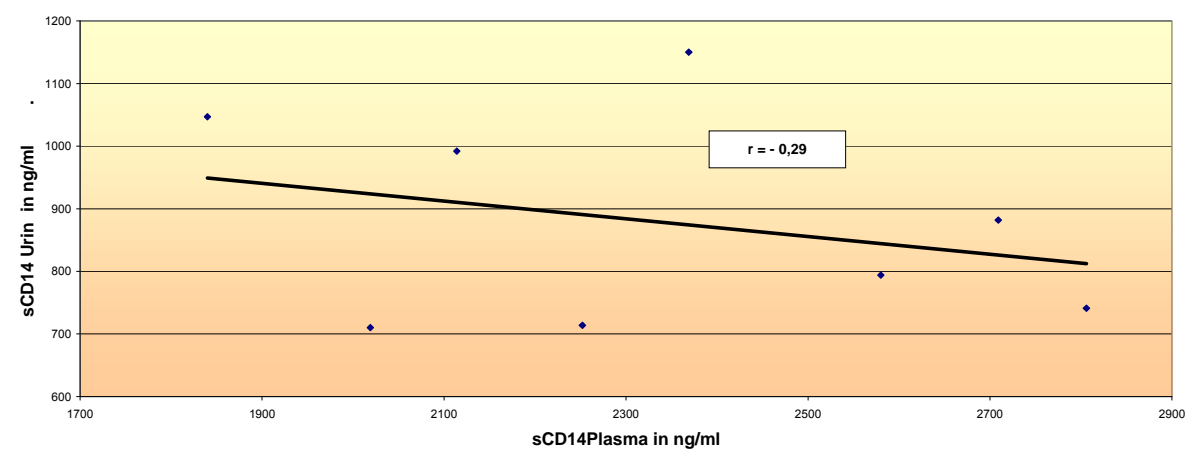

Abb. 7.14: Korrelation der im Plasma und im Urin im Rahmen einer Abstoßungsreaktion erhobenen Werte von SCD14:

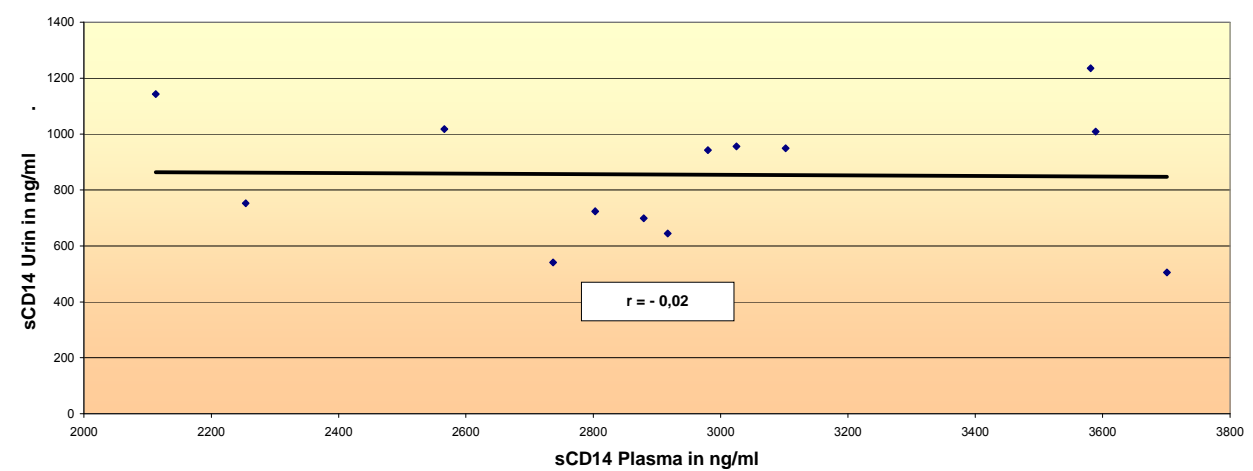

Abb. 7.15: Korrelation der im Plasma und im Urin im Rahmen einer Infektion erhobenen sCD14 Werte:

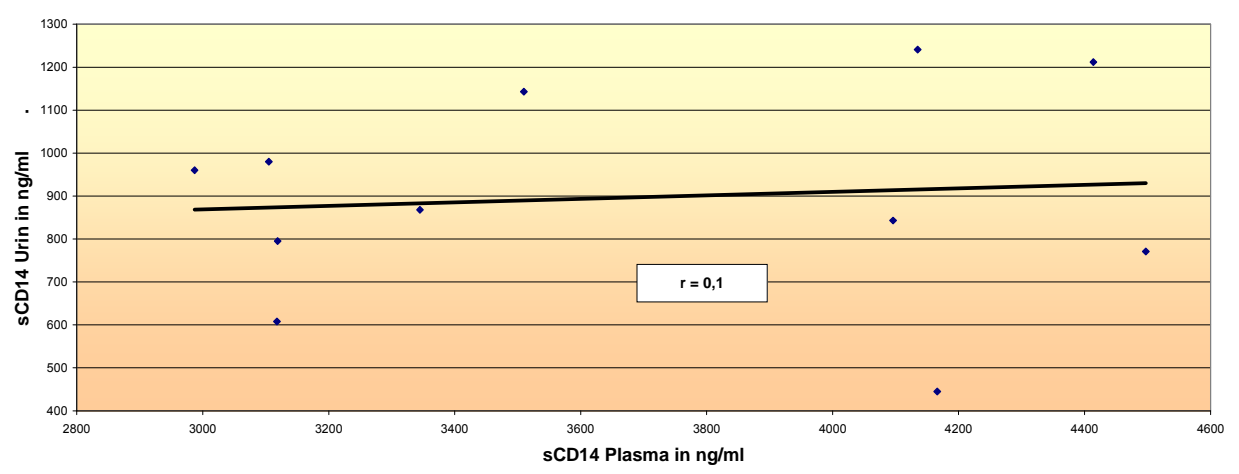

Abb. 7.13 bis 7.15: Die Korrelation des löslichen CD14 im Urin mit der Konzentration im Plasma ergibt in keiner der untersuchten Gruppen ein signifikantes Ergebnis. 
Abb. 7.16: Korrelation der im Rahmen einer stabilen Transplantatfunktion erhobenen Plasmawerte von SCD14 und SIL2R:

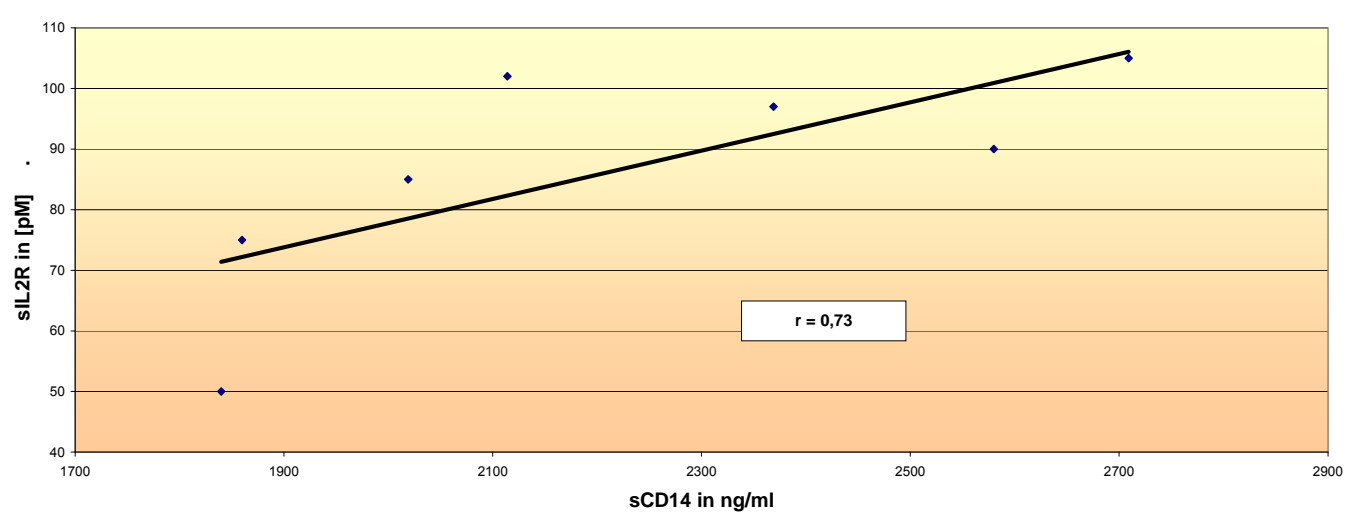

Abb. 7.17: Korrelation der im Rahmen einer Abstoßungsreaktion erhobenen Plasmawerte von sCD14 und SIL2R:

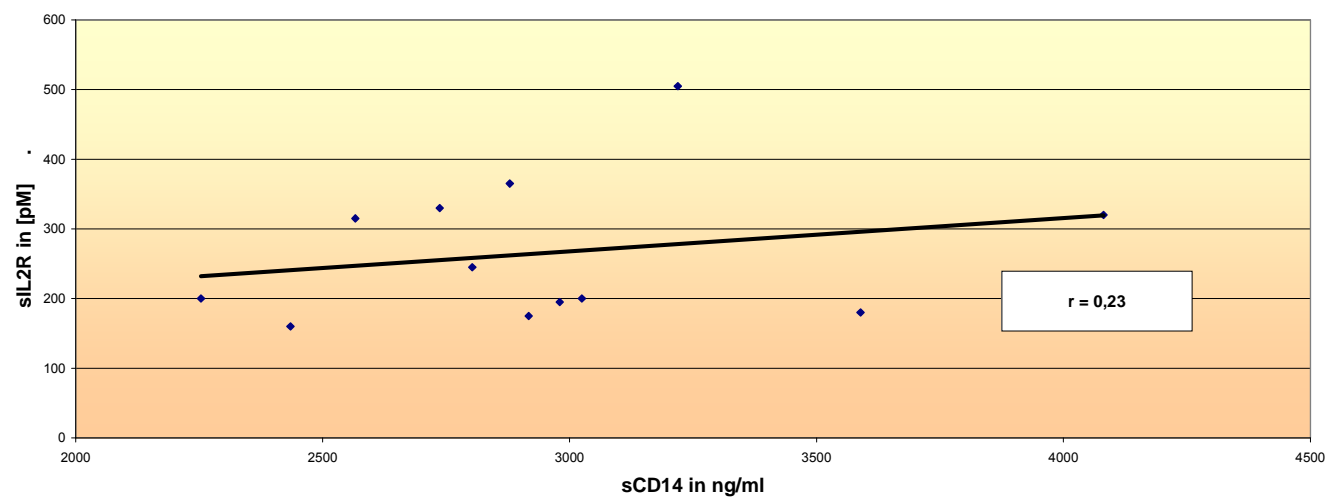

Abb. 7.18: Korrelation der im Rahmen einer Infektion erhobenen Plasmawerte von SCD14 und SIL2R:

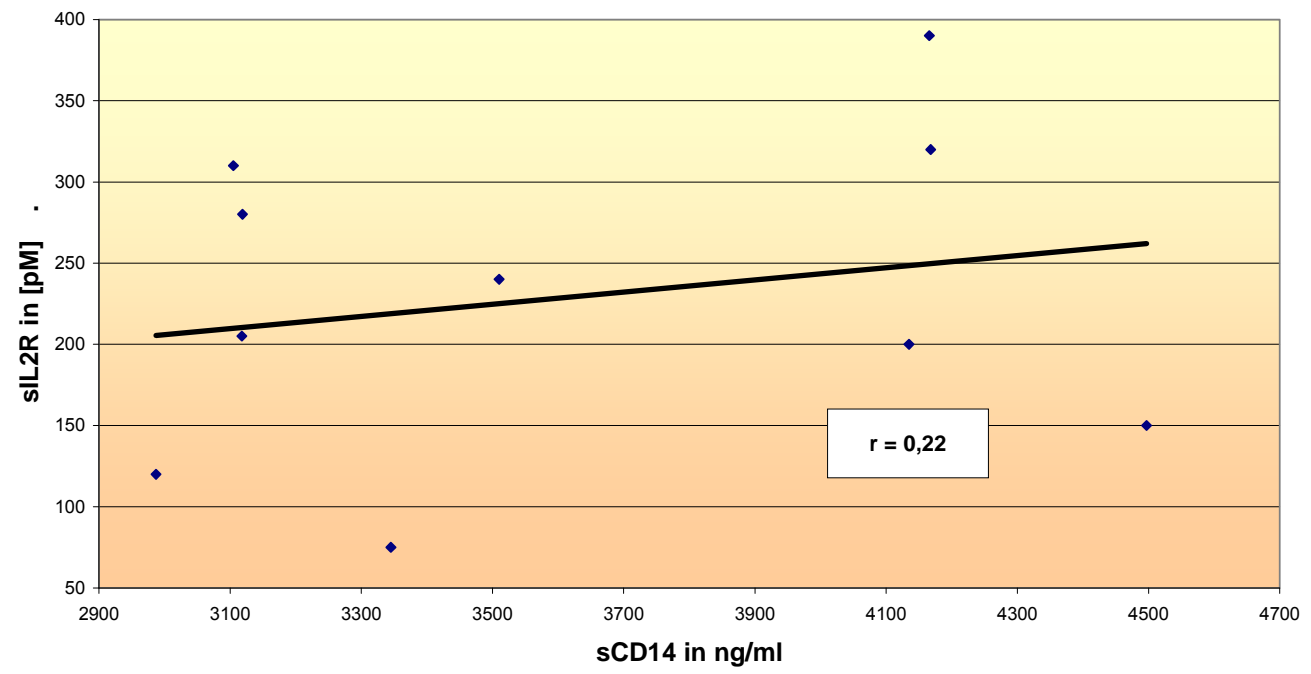

Abb. 7.16 bis 7.18: Die Korrelation des löslichen CD14 im Plasma mit dem löslichen IL2R im Plasma ergibt nur in der Gruppe mit der stabilen Transplantatfunktion ein signifikantes Ergebnis von $r=+$ 0,73 . 
Abb. 7.19: Quotient aus sCD14 und sCD4 im Plasma: Tx stabil vs. Abstoßung:

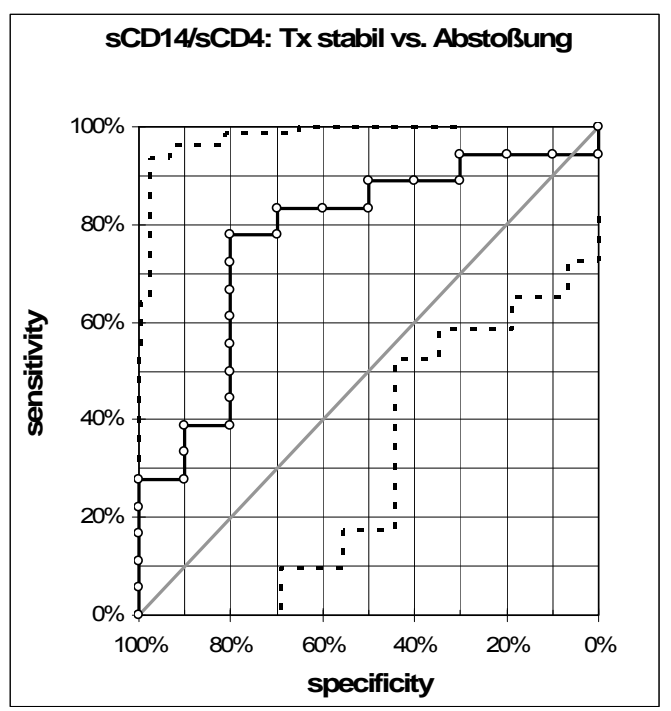

Abb. 7.19: In der ROC-Kurven-Analyse läßt sich die stabile Transplantatfunktion von der Abstoßungsreaktion bei einem angenommenen Cut-Off-Wert von 2811 mit einer Sensitivität von $78 \%$ und einer Spezifität von $80 \%$ abgrenzen (AUC $=0,77$ ).

Abb. 7.20: Quotient aus SCD14 und sCD4 im Plasma: Tx stabil vs. Infektion:

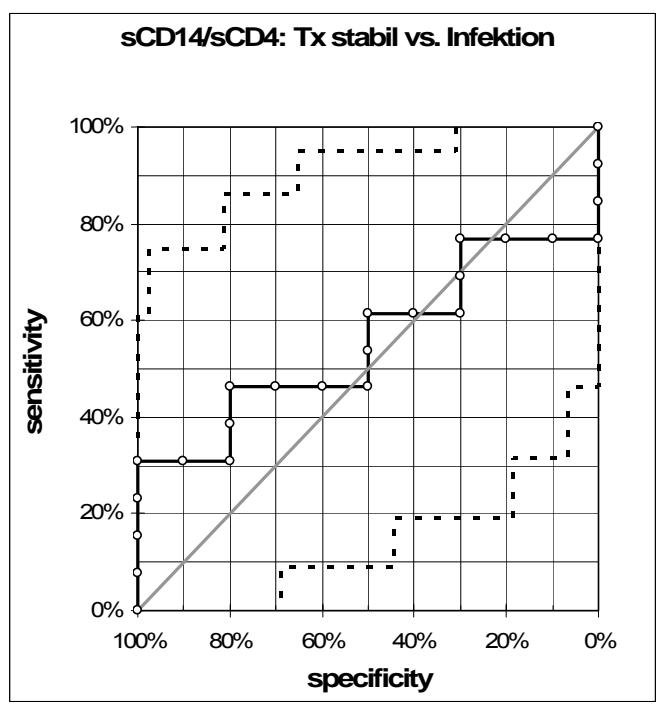

Abb. 7.20: In der ROC-Kurven-Analyse läßt sich die stabile Transplantatfunktion von der Infektion bei einem angenommenen Cut-Off-Wert von 3156 mit einer Sensitivität von 62\% und einer Spezifität von $50 \%$ abgrenzen $(\mathrm{AUC}=0,55)$. 
Abb. 7.21: Quotient aus sCD14 und sCD4 im Plasma: Infektion vs. Abstoßung:

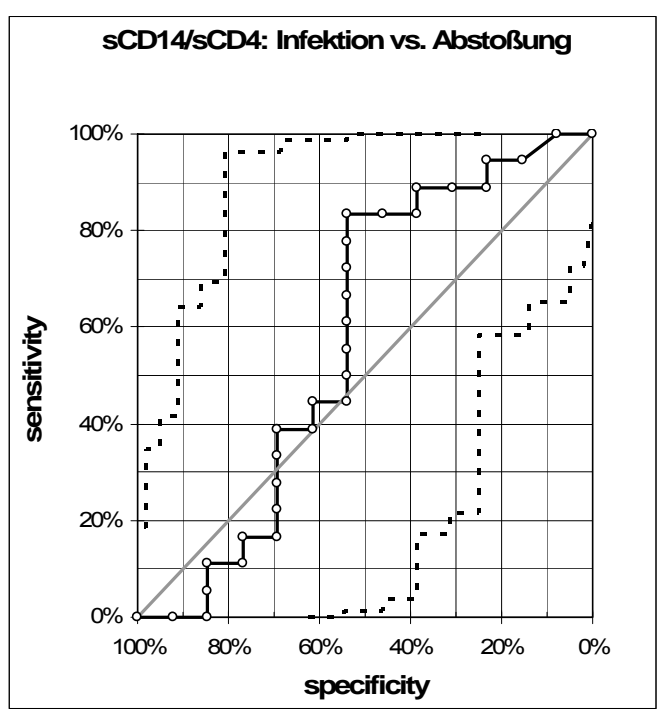

Abb. 7.21: In der ROC-Kurven-Analyse läßt sich die Abstoßungsreaktion von der Infektion bei einem angenommenen Cut-Off-Wert von 2879 mit einer Sensitivität von 83\% und einer Spezifität von 54\% abgrenzen $(A \cup C=0,58)$.

Abb. 7.22: Quotient sCD14 / sCD4: Infektion vs. Abstoßung und Tx stabil:

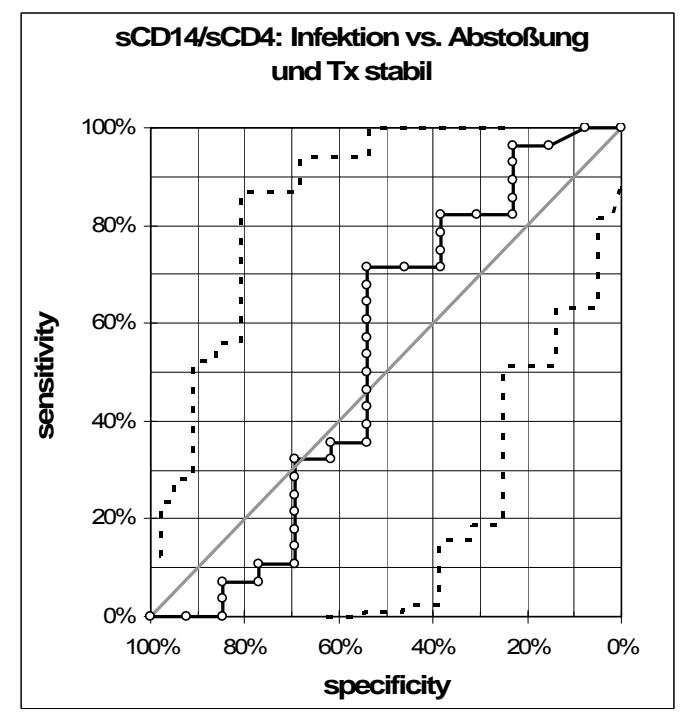

Abb. 7.22: In der ROC-Kurven-Analyse läßt sich die Infektion von der stabilen Transplantatfunktion sowie der Abstoßung bei einem angenommenen Cut-Off-Wert von 2999 mit einer Sensitivität von 71\% und einer Spezifität von $54 \%$ abgrenzen $(A \cup C=0,52)$. 
Abb. 7.23: Quotient SCD14 / sCD4: Abstoßung vs. Infektion und Tx stabil:

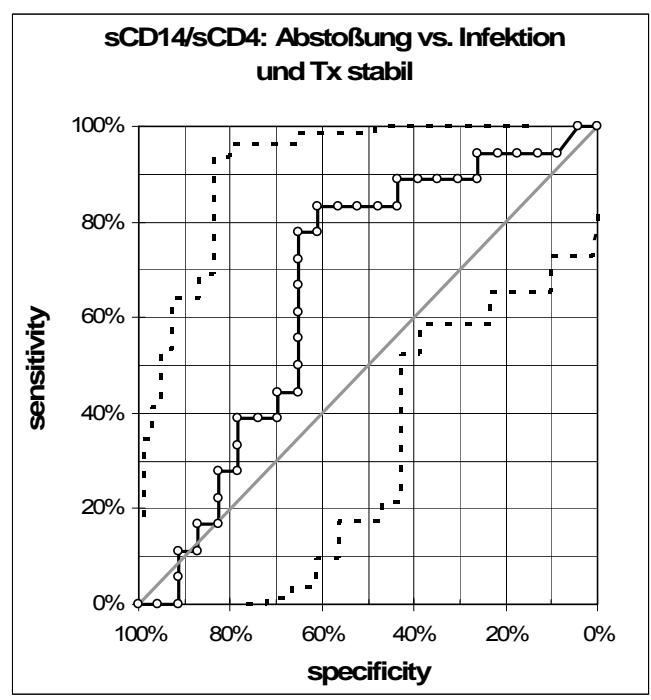

Abb. 7.23: In der ROC-Kurven Analyse läßt sich die Abstoßung von der stabilen Transplantatfunktion sowie der Infektion bei einem angenommenen Cut-Off-Wert von 2879 mit einer Sensitivität von $83 \%$ und einer Spezifität von $61 \%$ abgrenzen $(A \cup C=0,66)$.

Abb. 7.24: Quotient SCD14 / sCD4: Tx stabil vs. Abstoßung und Infektion:

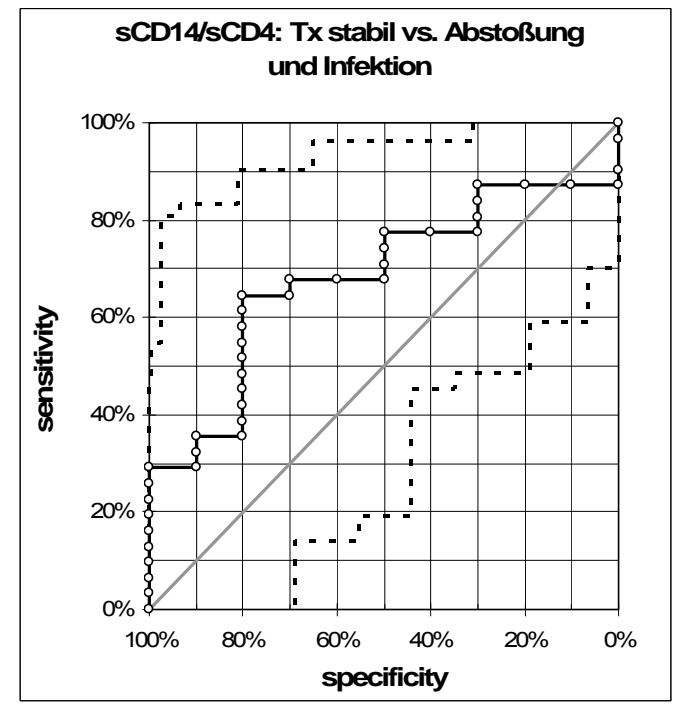

Abb. 7.24: In der ROC-Kurven Analyse läßt sich die stabile Transplantatfunktion von der Infektion sowie der Abstoßungsreaktion bei einem angenommenen Cut-Off-Wert von 2811 mit einer Sensitivität von $65 \%$ und einer Spezifität von $80 \%$ abgrenzen $(A \cup C=0,68)$. 
Abb.7.25: Korrelation der im Rahmen einer stabilen Transplantatfunktion erhobenen Plasmawerte für SCD14 und SCD4:

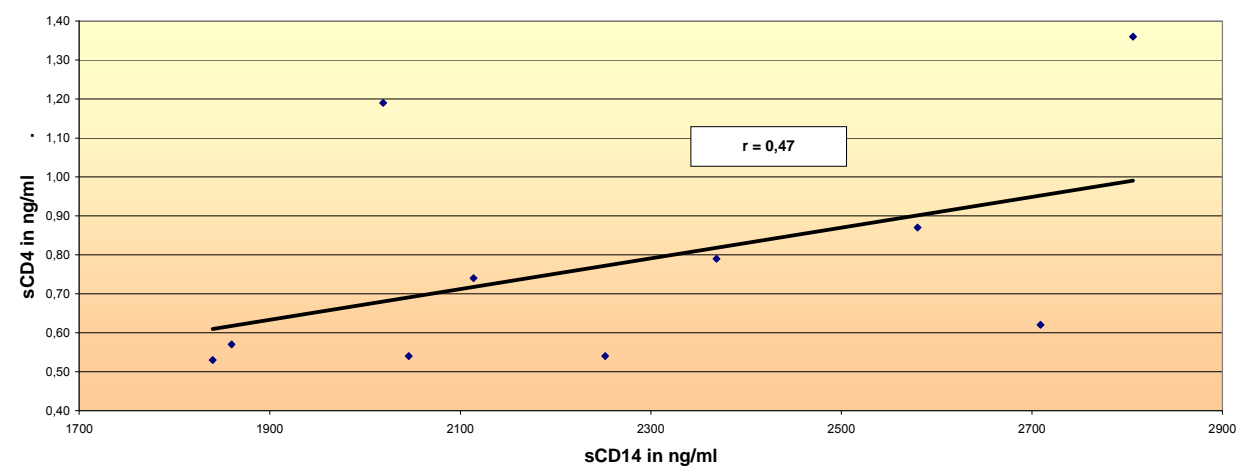

Abb. 7.26: Korrelation der im Rahmen einer Abstoßungsreaktion erhobenen Plasmawerte von SCD14 und SCD4:

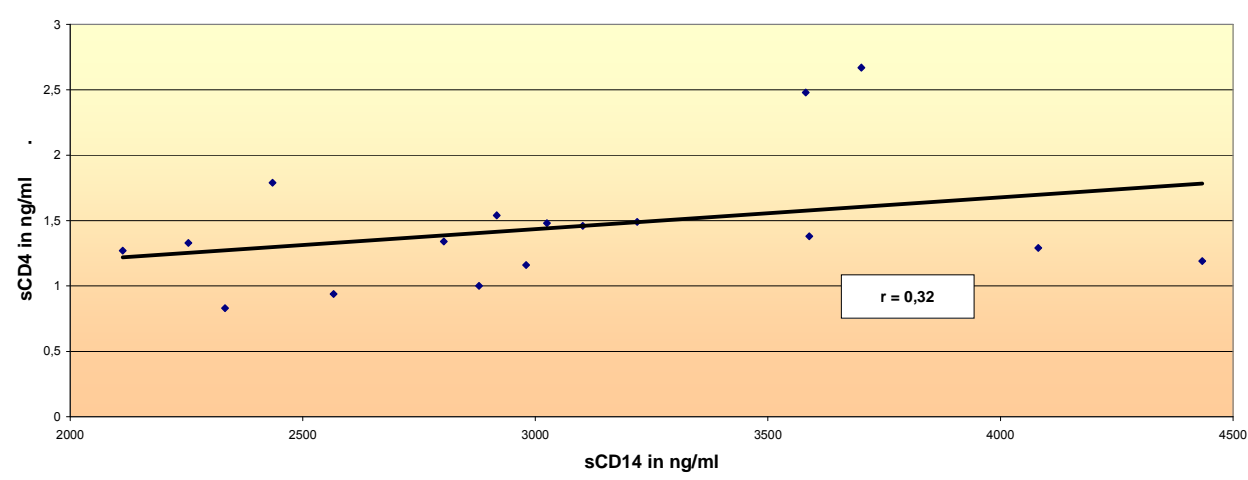

Abb. 7.27: Korrelation der im Rahmen einer Infektion erhobenen Plasmawerte von sCD14 und sCD4

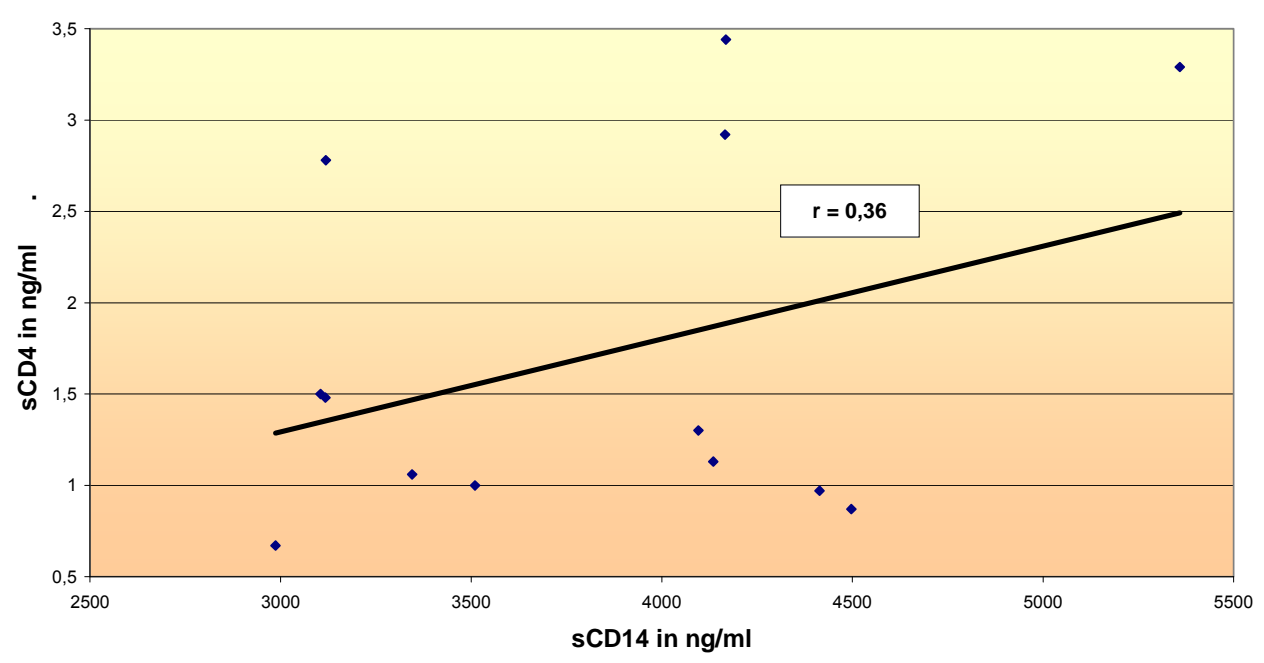

Abb. 7.25 bis 7.27: Die Korrelation des löslichen CD14 im Plasma mit dem löslichen CD4 im Plasma ergibt für keine der untersuchten Gruppen ein signifikantes Ergebnis. 
Abb. 7.28: Löslicher CD8 im Plasma: Tx stabil vs. Abstoßung:

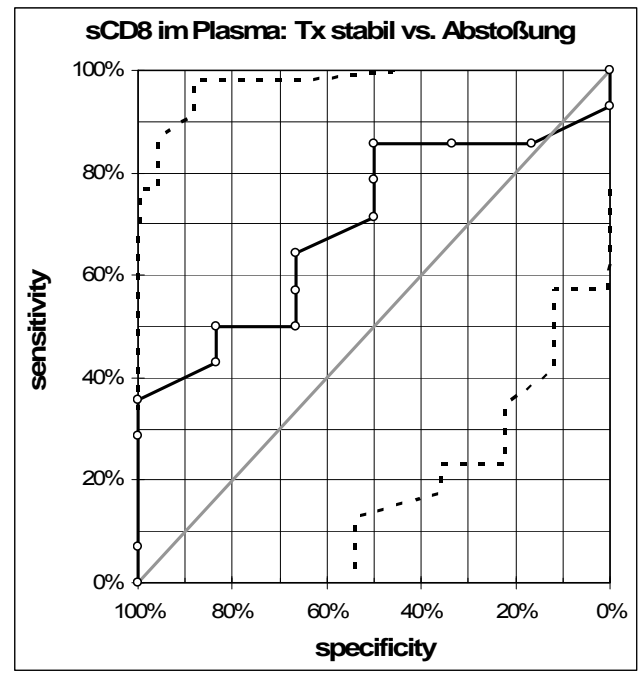

Abb. 7.28: In der ROC-Kurven Analyse läßt sich die stabile Transplantatfunktion von der Abstoßungsreaktion bei einem angenommenen Cut-Off-Wert von $340 \mathrm{U} / \mathrm{ml}$ mit einer Sensitivität von $86 \%$ und einer Spezifität von $50 \%$ abgrenzen $(A \cup C=0,7)$.

Abb. 7.29: Löslicher CD8 im Plasma: Tx stabil vs. Infektion:

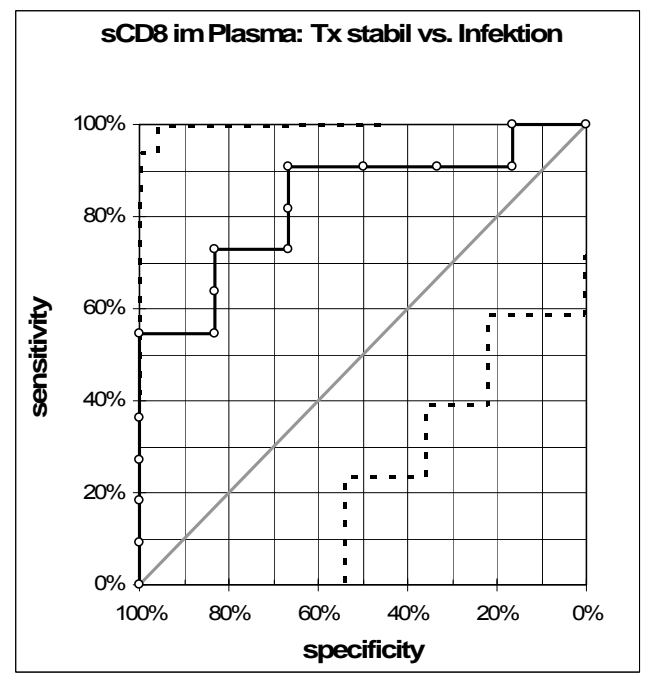

Abb. 7.29: In der ROC-Kurven Analyse läßt sich die stabile Transplantatfunktion von der Infektion bei einem angenommenen Cut-Off-Wert von $450 \mathrm{u} / \mathrm{ml}$ mit einer Sensitivität von $91 \%$ und einer Spezifität von $67 \%$ abgrenzen $(A \cup C=0,83)$. 
Abb. 7.30: Löslicher CD8 im Plasma: Infektion vs. Abstoßung:

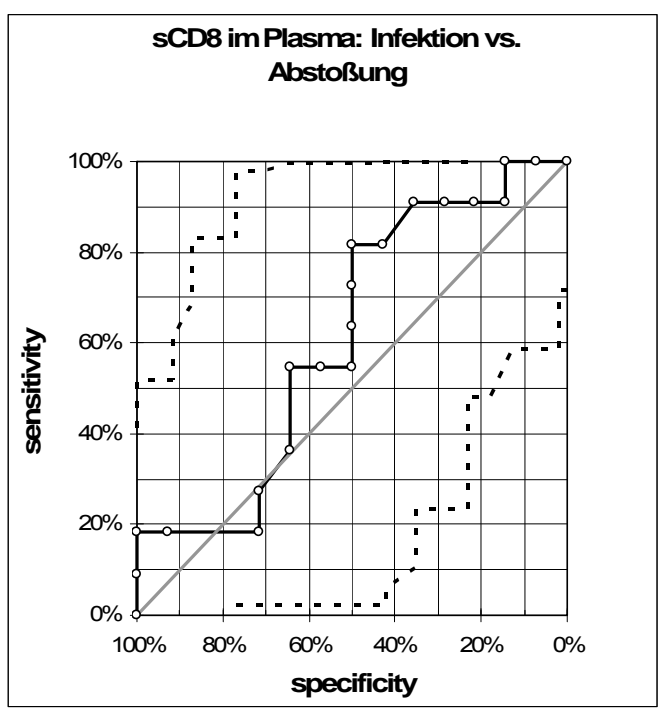

Abb. 7.30: In der ROC-Kurven Analyse läßt sich die Infektion von der Abstoßungsreaktion bei einem angenommenen Cut-Off-Wert von $470 \mathrm{U} / \mathrm{ml}$ mit einer Sensitivität von $82 \%$ und einer Spezifität von $50 \%$ abgrenzen $(A \cup C=0,61)$.

Abb. 7.31: Löslicher CD8 im Plasma: Infektion vs. Abstoßung und Tx stabil:

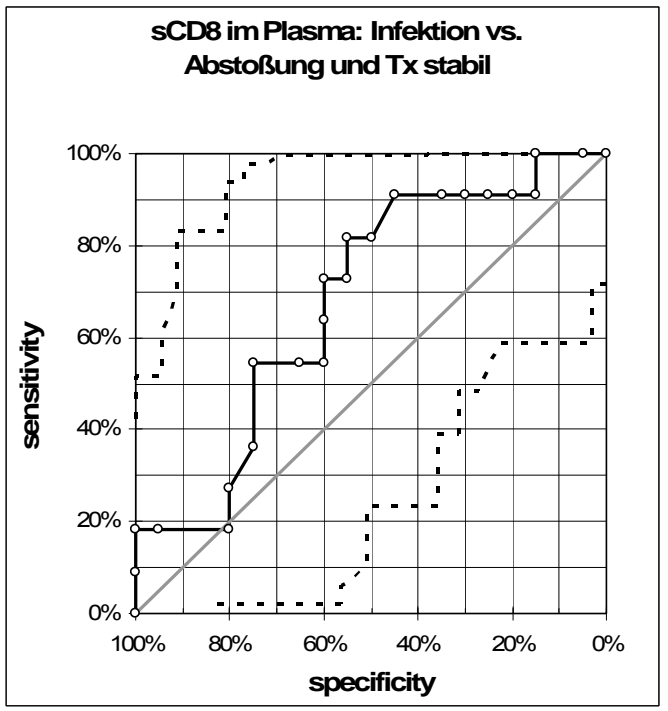

Abb. 7.31: In der ROC-Kurven Analyse läßt sich die stabile Infektion von der stabilen Transplantatfunktion sowie der Abstoßungsreaktion bei einem angenommenen Cut-Off-Wert von 460 $\mathrm{U} / \mathrm{ml}$ mit einer Sensitivität von $82 \%$ und einer Spezifität von $43 \%$ abgrenzen $(A \cup C=0,6)$. 
Abb. 7.32: Löslicher CD8 im Plasma: Abstoßung vs. Infektion und Tx stabil:

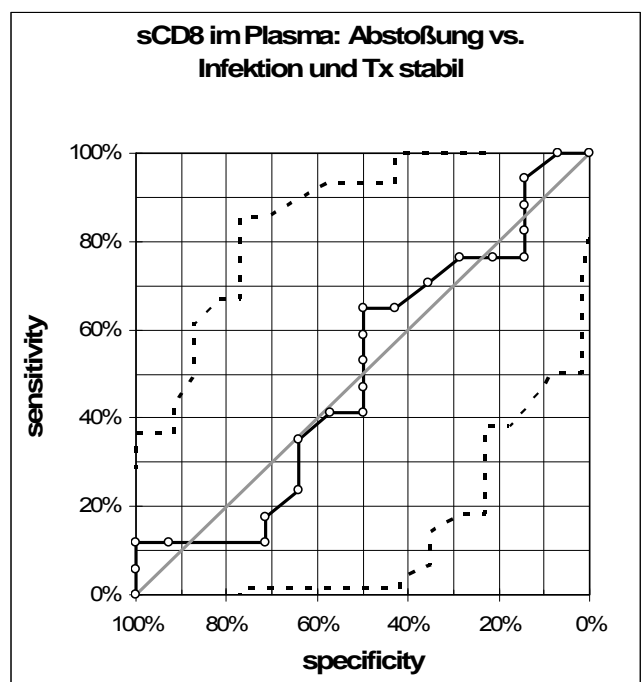

Abb. 7.32: In der ROC-Kurven Analyse läßt sich die Abstoßungsreaktion von der stabilen Transplantatfunktion sowie der Infektion bei einem angenommenen Cut-Off-Wert von $460 \mathrm{U} / \mathrm{ml}$ mit einer Sensitivität von 82\% und einer Spezifität von 43\% abgrenzen (AUC = 0,6).

Abb. 7.33: Löslicher CD8 im Plasma: Tx stabil vs. Abstoßung vs. Infektion:

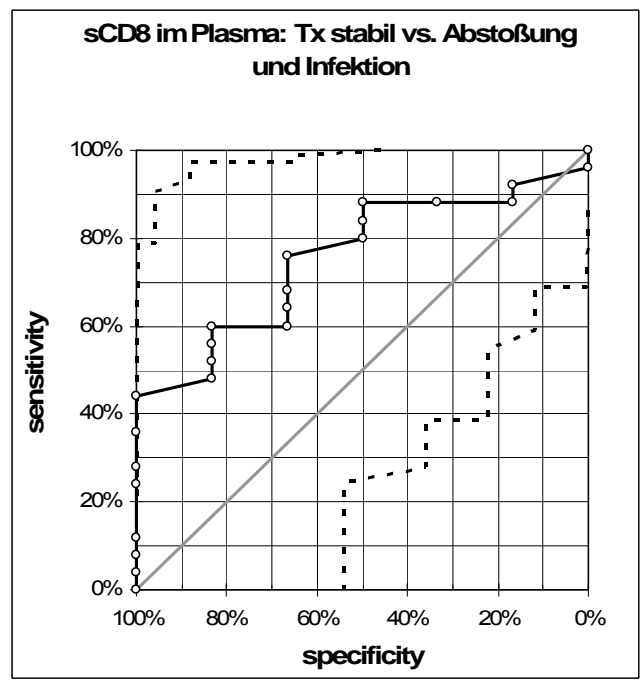

Abb. 7.33: In der ROC-Kurven Analyse läßt sich die stabile Transplantatfunktion von der Infektion sowie der Abstoßungsreaktion bei einem angenommenen Cut-Off-Wert von $650 \mathrm{U} / \mathrm{ml}$ mit einer Sensitivität von $44 \%$ und einer Spezifität von $100 \%$ abgrenzen (AUC = 0,76). 
Abb. 7.34: Quotient aus sCD14 und sCD8 im Plasma: Tx stabil vs. Abstoßung:

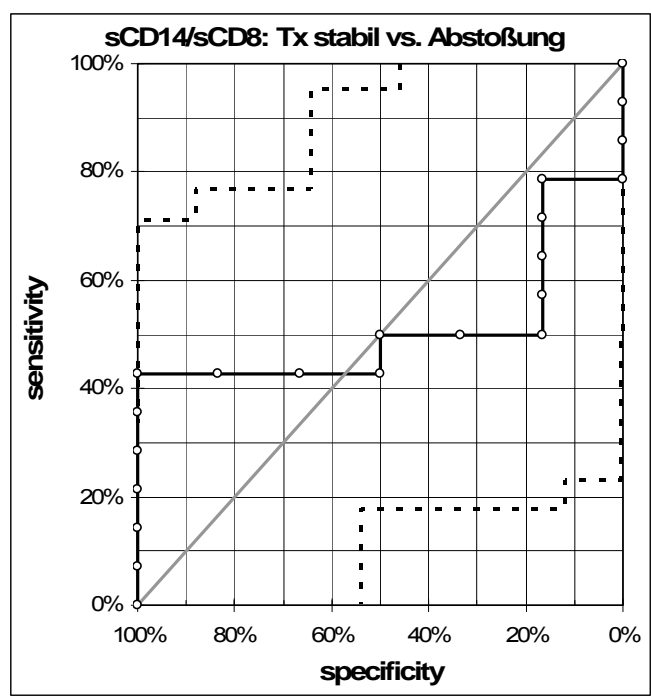

Abb. 7.34: In der ROC-Kurven Analyse läßt sich die stabile Transplantatfunktion von der Abstoßungsreaktion bei einem angenommenen Cut-Off-Wert von 6,76 mit einer Sensitivität von $43 \%$ und einer Spezifität von $100 \%$ abgrenzen (AUC $=0,51)$.

Abb. 7.35: Quotient aus sCD14 und sCD8 im Plasma: Tx stabil vs. Infektion:

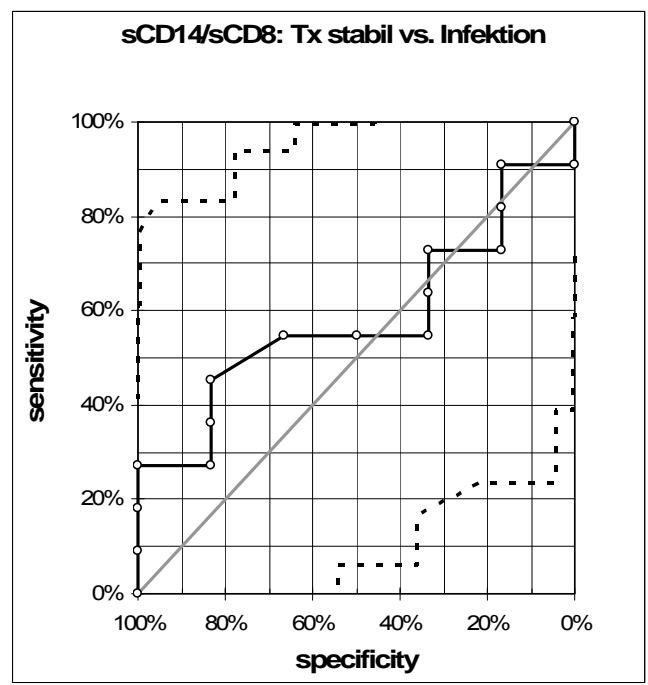

Abb. 7.35: In der ROC-Kurven Analyse läßt sich die stabile Transplantatfunktion von der Infektion bei einem angenommenen Cut-Off-Wert von 6,36 mit einer Sensitivität von $46 \%$ und einer Spezifität von $83 \%$ abgrenzen $(A \cup C=0,58)$. 
Abb. 7.36: Quotient aus sCD14 und sCD8 im Plasma: Infektion vs. Abstoßung:

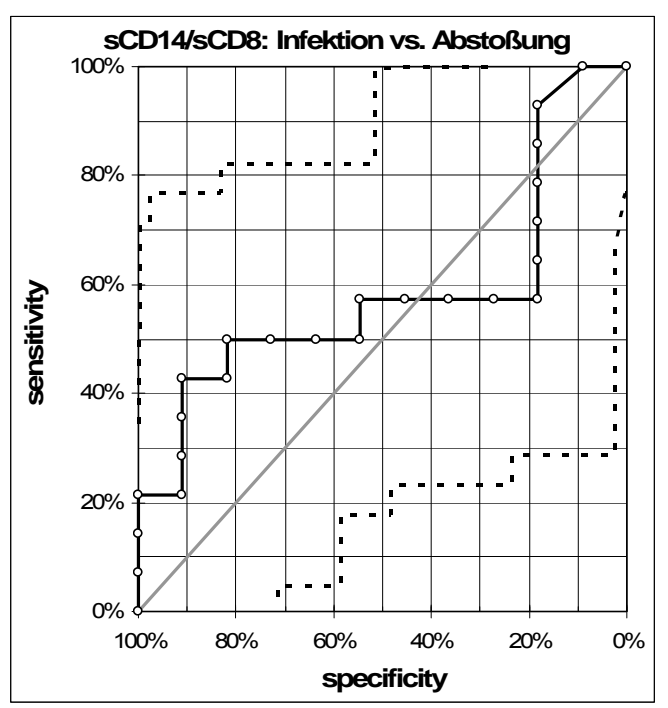

Abb. 7.36: In der ROC-Kurven Analyse läßt sich die Infektion von der Abstoßungsreaktion bei einem angenommenen Cut-Off-Wert von 4,73 mit einer Sensitivität von $43 \%$ und einer Spezifität von $91 \%$ abgrenzen $(A \cup C=0,58)$.

Abb. 7.37: sCD14 / sCD8 im Plasma: Infektion vs. Abstoßung und Tx stabil:

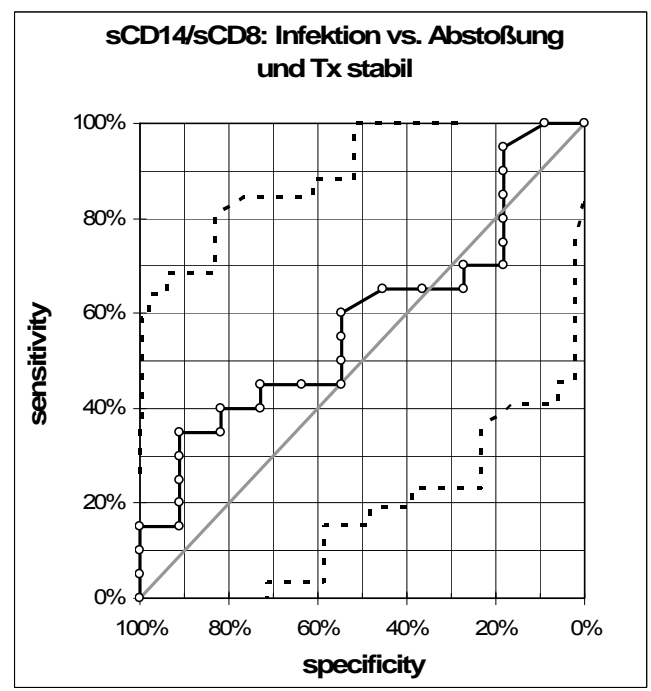

Abb. 7.37: In der ROC-Kurven Analyse läßt sich die Infektion von der stabilen Transplantatfunktion sowie der Abstoßungsreaktion bei einem angenommenen Cut-Off-Wert von 4,73 mit einer Sensitivität von $35 \%$ und einer Spezifität von $91 \%$ abgrenzen $(A \cup C=0,58)$. 
Abb. 7.38: sCD14 / sCD8 im Plasma: Abstoßung vs. Infektion und Tx stabil:

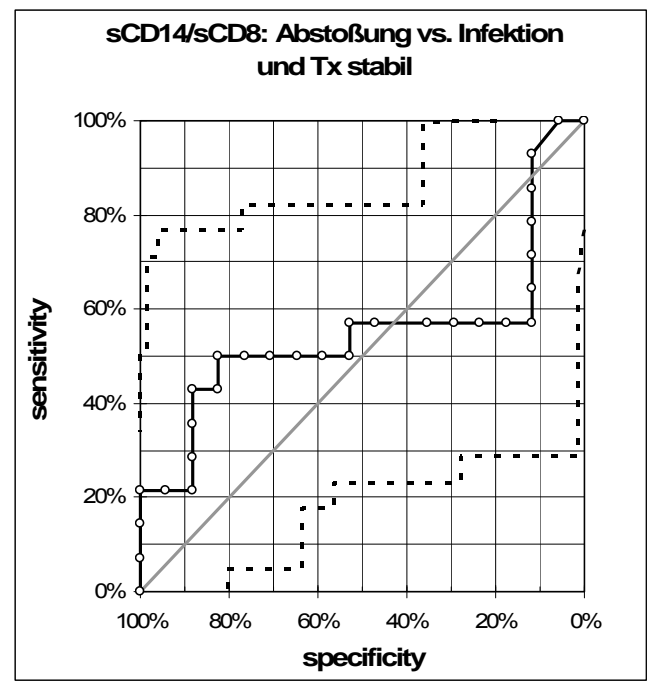

Abb. 7.38: In der ROC-Kurven Analyse läßt sich die Abstoßungsreaktion von der stabilen Transplantatfunktion sowie der Infektion bei einem angenommenen Cut-Off-Wert von 4,8 mit einer Sensitivität von $50 \%$ und einer Spezifität von $82 \%$ abgrenzen (AUC = 0,54).

Abb. 7.39: sCD14 / sCD8 im Plasma: Tx stabil vs. Abstoßung und Infektion:

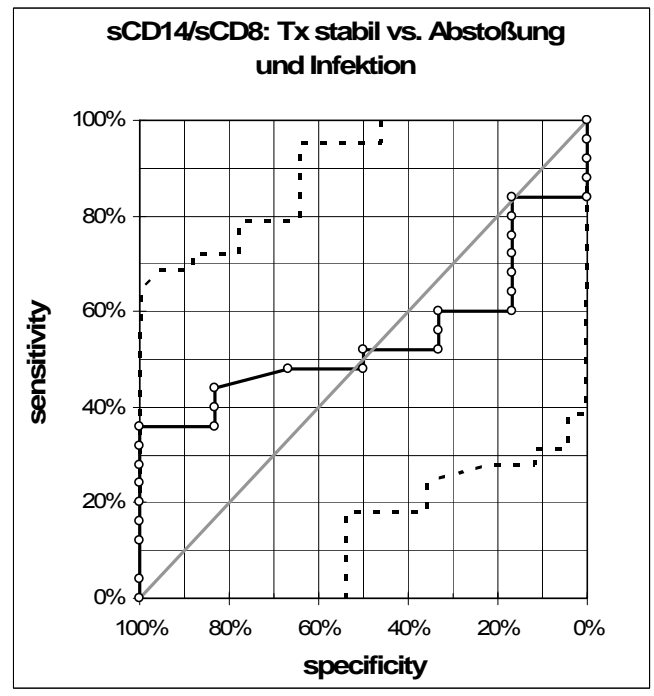

Abb. 7.39: In der ROC-Kurven Analyse läßt sich die stabile Transplantatfunktion von der Abstoßungsreaktion sowie der Infektion bei einem angenommenen Cut-Off-Wert von 6,56 mit einer Sensitivität von $36 \%$ und einer Spezifität von $100 \%$ abgrenzen (AUC = 0,54). 
Abb. 7.40: Korrelation der im Rahmen einer stabilen Transplantatfunktion erhobenen Werte von sCD14 und SCD8:

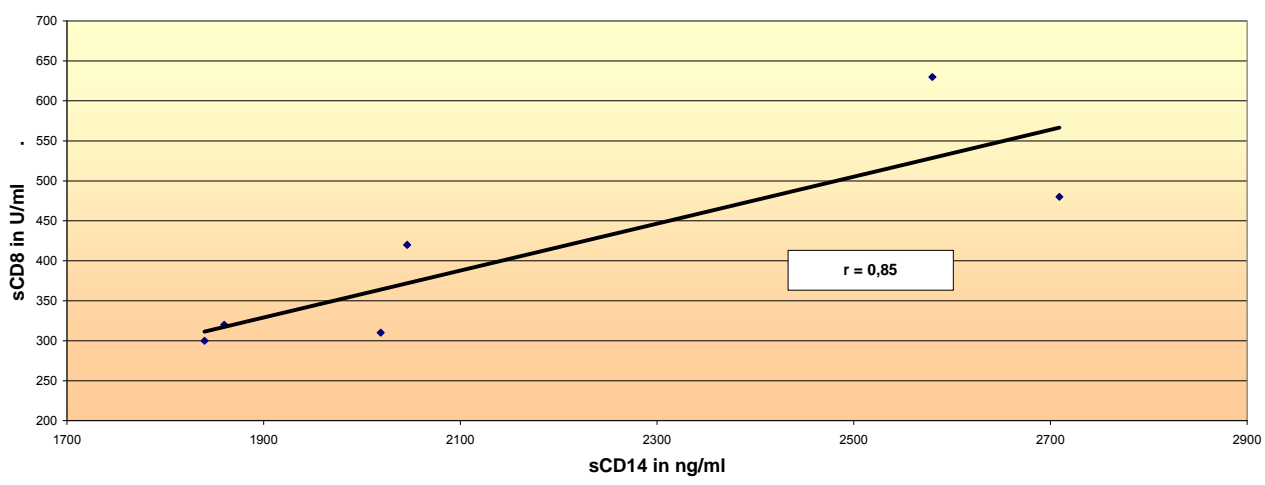

Abb. 7.41: Korrelation der im Rahmen einer Abstoßung erhobenen Werte von SCD14 und sCD8:

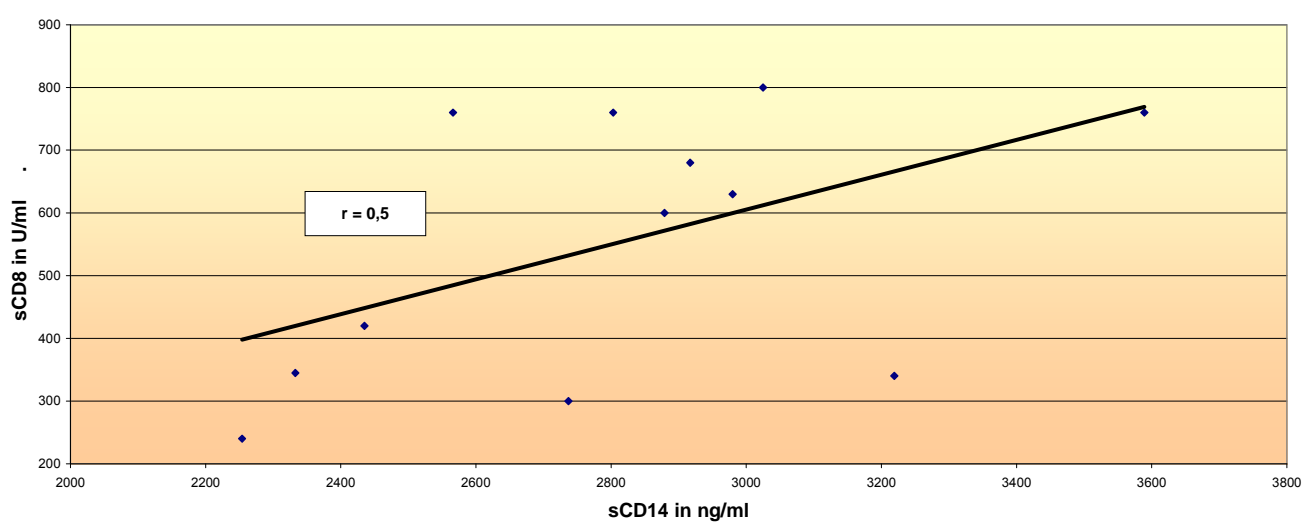

Abb. 7.42: Korrelation der im Rahmen einer Infektion erhobenen Werte von SCD14 und SCD8:

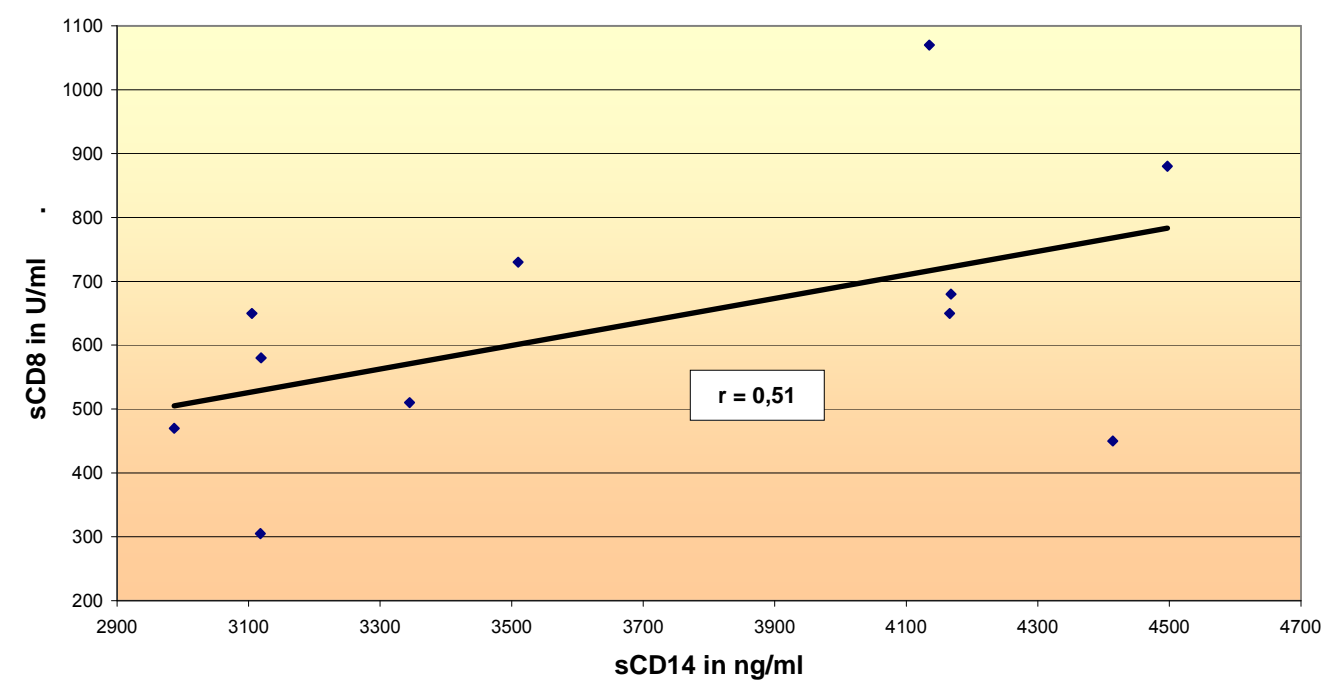

Abb. 7.40 bis 7.42: Die Korrelation des löslichen CD14 im Plasma mit dem löslichen CD8 im Plasma ergibt nur für die Gruppe mit der stabilen Transplantatfunktion ein signifikantes Ergebnis. 
Danksagung

Hiermit bedanke ich mich bei allen, die zum Gelingen der vorliegenden Arbeit beigetragen haben.

Insbesondere bedanke ich mich bei Herrn Prof. Dr. med. R.W. Grunewald, Bremerhaven, für die Inspiration zur Umsetzung des behandelten Themas sowie die Betreuung und die Begutachtung.

Ebenso bedanke ich mich bei Herrn Dr. med. Martin Fiedler, Universität Leipzig, für sein Engagement zum Beginn der Promotion und der Durchsicht der Dissertation im weiteren Verlauf. 